\title{
THE MARINE AND FRESH-WATER SPONGES OF CALIFORNIA
}

\author{
By M. W. de Laubenfels \\ Pasadena, Calif.
}

\section{INTRODUCTION}

The sponges of the western coast of the United States have been very little studied, although they exist in profusion and comprise a large variety of interesting forms. One hundred and one species are discussed in the following pages, and six of these (Polymastia pachymastia, Hymeniacidon ungodon, Zygherpe hyaloderma, Plocamia igzo, Halichoclona gellindra, and Spongia idia) are described for the first time. In addition, three genera and five varieties are described as new. In order to render this paper of use to those who are not specialists as well as to specialists, all species that I have been able to find in California are described, whether they be new or old. Briefer reference is made to those forms that are to be found only in the literature on the subject.

California's length of more than 1,400 kilometers exceeds the distance from New York to Florida and that from Denmark to the Mediterranean, and depths of more than 1,500 meters are reached within 20 to 60 kilometers offshore. A great variety of species of sponges is to be expected within such limits. In addition to those treated herein, many species are to be looked for in the deeper waters offshore, as well as other shallow-water forms from the northern part of the State. Most of the present marine biological investigation, however, is being carried on off the central and southern coasts, and it is believed that the species of those waters are herein rather thoroughly covered.

I have personally searched the intertidal areas rather carefully, have had much dredged material representing the central-California region presented to me by E. F. Ricketts, and have studied the extensive collection dredged off southern California during the years 1909 to 1927 by the University of Southern California. (See Figure 1 for map of localities mentioned in this report.) 
Much of the preparation of this paper was carried on at the British Museum (Natural History) in London, and special gratitude is expressed to Maurice Burton, of that institution, for cooperation kindly extended. To the officials of the United States National Museum, grateful acknowledgment also is made for the loan of specimens for study and for literature otherwise inaccessible.

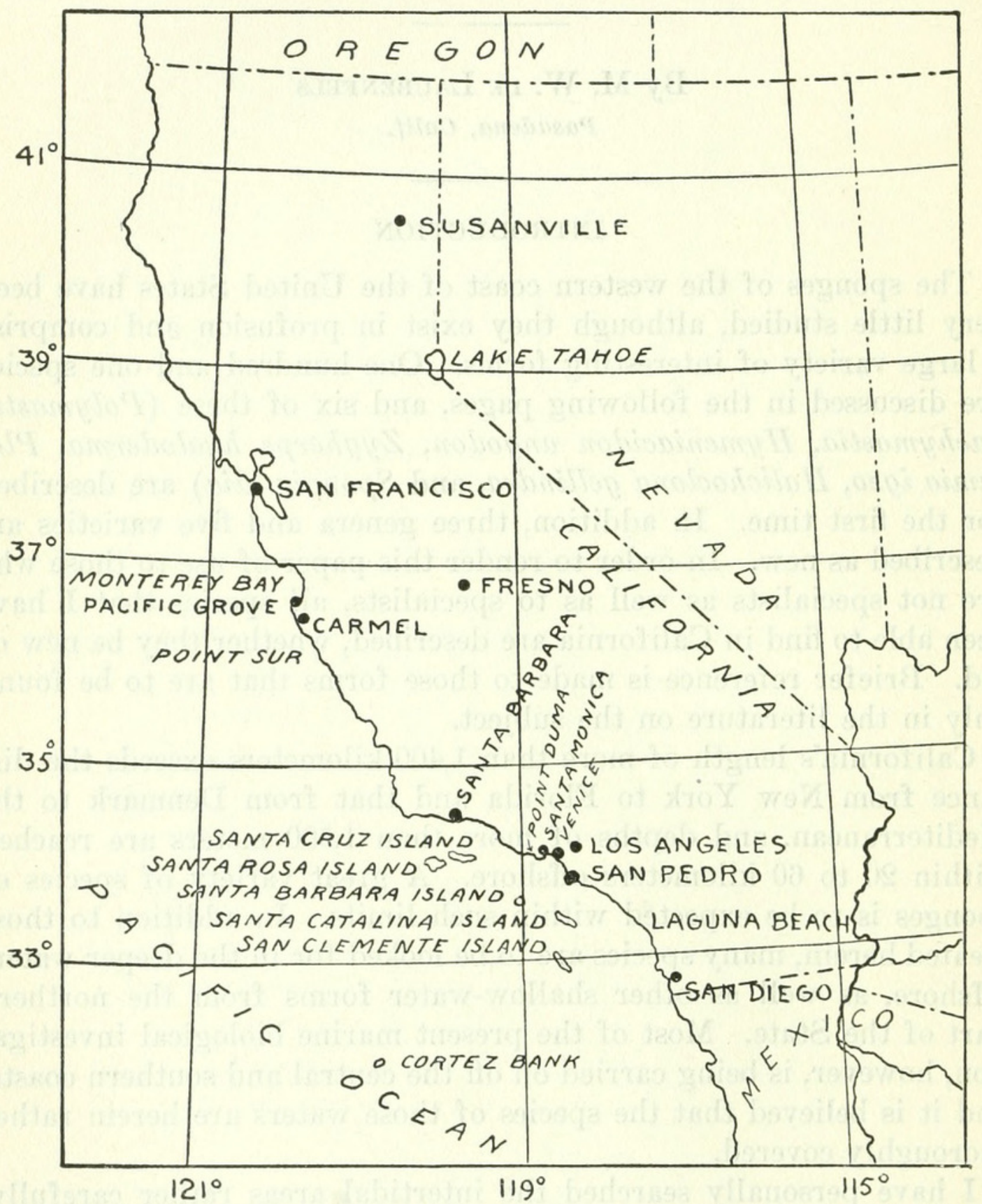

Figure 1.- Sketch map showing California localities mentioned in text of this report

So far as possible, representative and type specimens or a portion of these have been deposited in the United States National Museum in Washington (U.S.N.M.) and in the British Museum (Natural History) in London (B. M.), and, unless otherwise indicated, the descriptions given are based on the material so referred to. Under the headings "Type locality" and "Material examined" will be found notes upon the occurrence and habit of the species. 
All drawings were made with the aid of a camera lucida unless otherwise indicated.

\section{HISTORICAL SUMMARY}

Very little has been published on sponges in or from California. Search of the literature yields 10 references, as follows:

The first is by E. Haeckel, 1872, Die Kalkschwämme. In volume 2 of this monograph of the calcareous sponges of the world, as taken up more fully in the descriptive portion of this paper, he described Ascilla (now Leucosolenia) convallaria (p. 45), Sycandra (now Sycon) coronata (p. 305), and Leucetta (now Leuconia) sagittata (p. 125) merely as from California, "Brown." These species can not now be located in this State.

Fifteen years later E. Potts, 1887, in his monograph on Freshwater Sponges, described Meyenia (now Ephydatia) robusta (p. 225) from Honey Lake Valley, near Susanville in northeastern California. This species has been found again only once, this time by Annandale (1907, p. 24), who recorded it from Bhim Tal, in the mountains of northern India, at 1,350 meters, almost the same altitude as that of the California specimen.

Lendenfeld (1889, p. 258) named Euspongia hospes from Africa and California (which may be Lower California, Mexico). The species is not recognizably described, being characterized merely as growing inside of mollusk shells, taxonomically a relatively insignificant description.

The fourth reference is by L. Lambe, 1894, Sponges from the Western Coast of North America. He reported (p. 124) finding a sponge, which he called Plocamia manaarensis (Carter), from California. He did not know the locality within the State, and his identification was incorrect, as explained later in this paper.

The next reference to California sponges is by F. E. Schulze, who in 1899 published his Amerikanische Hexactinelliden nach dem Materiale der Albatross-Expedition, in which he described 14 species from California, as discussed hereafter. He cited as from California, however, four additional species from other localities, as shown by the data, including the latitude and longitude, of the Albatross stations involved. Two are from the State of Washington: Acanthosaccus tenuis (p. 66) and Farrea aculeata (p. 69); and two are from Lower California, Mexico: Farrea ocea (p. 68) and Bathyxiphus subtilis (p. 82).

Then there were published two articles by F. Urban. In 1902 in the Zeitschrift für Wissenschaftliche Zoologie, he described Rhabdodermella nuttingi, which had been sent him by the late Prof. C. C. Nutting, of the University of Iowa; and in 1905 in the Archiv für Naturgeschichte, he described Leucosolenia eleanor (p. 36), 
Sycandra (now Sycon) coacta (p. 55), Leucandra (now Leuconia) heathi (p. 59), Leucandra (now Leuconia) apicalis (p. 67). These were sent him from Monterey Bay by Prof. Harold Heath, of Stanford University.

Lendenfeld, in his large monograph on The Geodidae, described in 1910 the following from California: Sidonops angulata (p. 24), S. bicolor (p. 46), Geodia mesotriaena (p. 96), G. agassizii (p. 113), G. mesotriaenella (p. 151), G. breviana (p. 155), G. ovis (p. 161), and Geodinella robusta (p. 205). Many of these, because of the unjustifiably fine distinctions drawn, have proved to be identical and must hence be regarded as synonyms.

Finally, in 1926, I described three species: Gellius textapatina, Esperella fisheri, and Suberites gadus; and in 1927 three more: Acarnus erithacus, Plocamia karykina, and Plocamia (better Isociona) lithophoenix; with a redescription of Desmacella (better Ophlitaspongia) pennata Lambe, 1894. So far as I am able to ascertain, this is a complete list of references to sponges from California. Reference is made to the Bibliography, page 128, for complete citations to the papers mentioned.

\section{PREPARATION OF ALCOHOLIC MATERIAL FOR STUDY}

Identification of sponges depends upon miscroscopic characteristics, for it is utterly impossible to rely upon macroscopic features alone. This need not unduly discourage attempts to identify species, as it is possible to prepare a sponge for examination in about 10 minutes, especially if the material has already been hardened in alcohol.

Take a small portion (less than 1 cubic centimeter) that includes some of the outer surface of the sponge, and place it on a clean slide. With a sharp razor (a safety-razor blade will do), section the material, if possible, both perpendicularly to the surface and tangentially. In a surprisingly large number of cases, this will be found to be possible; however, if only fragments can be obtained, they can still serve. The sections or fragments should be less than $0.5 \mathrm{~mm}$, but may be nearly that thick to good advantage. Flood the material with a few drops of absolute alcohol, dry with paper towel or blotting paper, and repeat from one to three times as necessary to dehydrate. Add a few drops of carbol xylene and again blot dry to complete the dehydration thoroughly. Add a few drops of xylene to complete the clearing and, without drying more than slightly, add some very stiff balsam and cover slip. A little stain, such as basic fuchsin, may be added to the alcohol to advantage. Comparison of slides thus made with illustrations as given herein should make identification possible in most instances. 


\section{GENERAL CLASSIFICATION}

Students of sponges do not agree as to methods for classifying them. One of the most recent and best of myriad systems is that of Topsent (1928), which roughly is the source of the arrangement herein employed. For the phylum Porifera Topsent employs 11 orders without diagnosing them. The following represents an attempt to describe these orders (except one that has been dropped) in a manner convenient for students who have not specialized at all in the systematics of sponges, although for proper taxonomy such descriptions are unsuitable:

1. Calcarea: Sponges with calcareous skeletons; this may be tested with acid, as calcium carbonate dissolves in most of the common acids, but silica only in hydrofluoric acid. The normal inorganic skeletal material in the other orders is siliceous.

2. Hexactinellida: Sponges whose principal spicules have five or six rays diverging from a central point. Such spicules may occur as small or auxiliary spicules in the other orders, but not as chief spicules.

3. Myxospongida: Sponges with no skeleton whatever, neither fiber nor spicule; sometimes called "slime sponges." It is not known whether they are primitive or degenerate, but probably they are the latter. They may possibly be derived from more than one of the other orders.

4. Choristida: Sponges typically with tetraxons among their principal spicules, often having a conspicuously radiate structure and a cartilaginous rind, or ectosome.

5. Hadromerina: Sponges often with pin-shaped spicules (tylostyles), asters as microscleres, corticate ectosome, and radiate structure. Almost any sponge lacking tetraxon spicules and having any two of these features should be put in this order.

6. Halichondrina: This order is very difficult to describe to the nonspecialist. In general, there is very confused arrangement of spicules, together with simplicity of spiculation. Very few members of this group have any microscleres, and, if any, they are few and simple.

7. Poecilosclerina: Almost all the sponges that have any one of the following characteristics belong here: (a) Larger spicules spiny; $(b)$ chelas as microscleres; $(c)$ fibers containing monactinal spicules. If there is any possibility that the sponge for which identification is sought belongs in this order, try that assumption hopefully, as many more sponge species are assigned to this order than to any other.

8. Haplosclerina: Sponges with only diactinal chief spicules and with only very simple microscleres, if any; they are usually markedly 
reticulate in plan. It will be observed that this order, by definition, approaches close to some members, at least, of both the two preceding orders. The fresh-water sponges might be placed here or in the preceding group as a unit. Topsent does not discuss them in his 1928 article proposing the classification here considered.

9. Dictyoceratina: Sponges with no proper spicules (some from other sponges may become included as the sponge grows) but with a decided reticulation of spongin fibers.

10. Dendroceratina: Sponges with no proper spicules (see note above) but with spongin fibers that branch and do not reunite, resembling little trees in form.

Topsent regards the first of these orders as also a class, the second order as a second class, and the rest as a third class.

SYSTEMATIC DISCUSSION

\section{Order CALCAREA Gray}

\section{Family LEUCOSOLENIIDAE Minchin}

\section{Genus LEUCOSOLENIA Bowerbank}

\section{LEUCOSOLENIA CONVALI ARIA (Haeckel)}

Ascilla convallaria HAECKEL, 1872, vol. 2, p. 45.

Leucosolenia convallaria DENDY and Row, 1913, p. 725.

Holotype.-Location unknown.

Type locality.-Described from the Pacific coast of North America (California, Brown). The species has not since been found in the State.

Description.-Hollow cylinders $0.05-0.1 \mathrm{~mm}$ thick, $2-4 \mathrm{~mm}$ long. Fragile, white, surface minutely hispid. The wall of the tube is of simple ascon type, strengthened by usually two layers of quadriradiates only, of which the apical ray is from two-thirds to as long as each of the facial rays.

Remarks.-Ascon type sponges with only quadriradiates are very rare. Hozawa $(1929$, p. 285$)$ described a very similar one, Leucosolenia kagoshimensis, from Kagoshima Bay, Japan, and Haeckel (1872, vol. 2, p. 47) described another, Leucosolenia (Ascilla) japonica, also from Japan.

LEUCOSOLENIA MACLEAYI Lendenfeld

Leucosolenia macleayi LENDENFELD, 1885, p. 1086.

Leucosolenia stipitata DENDY, 1891, p. 51.

Holotype.-Location unknown.

Type locality.-First described from Australia. 
Material examined.-About a dozen specimens were studied, all collected near Laguna Beach, intertidal, March 14, 1926, by myself. They were found principally pendant on the underside of sandstone bowlders.

Description (U.S.N.M. No. 21464; B.M. No. 29.8.22.49).-Shape, clathrous, vasiform, pedunculate. Size, up to $4 \mathrm{~mm}$ in diameter, $8 \mathrm{~mm}$ in height. Consistency, fragile. Color in life and when pre-

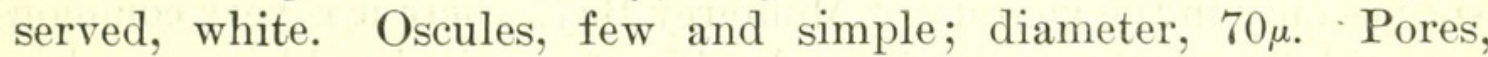
minute; diameter, about $5 \mu$. Surface, superficially smooth, microscopically hispid.

Ectosomal specialization, none. Endosomal structure, ascon tubes $80 \mu$ to $130 \mu$ in diameter, branching and anastomosing to make a reticulation with meshes $70 \mu$ to $270 \mu$ in diameter. The skeleton consists of about two layers of simple triaxons. Histological details: I have

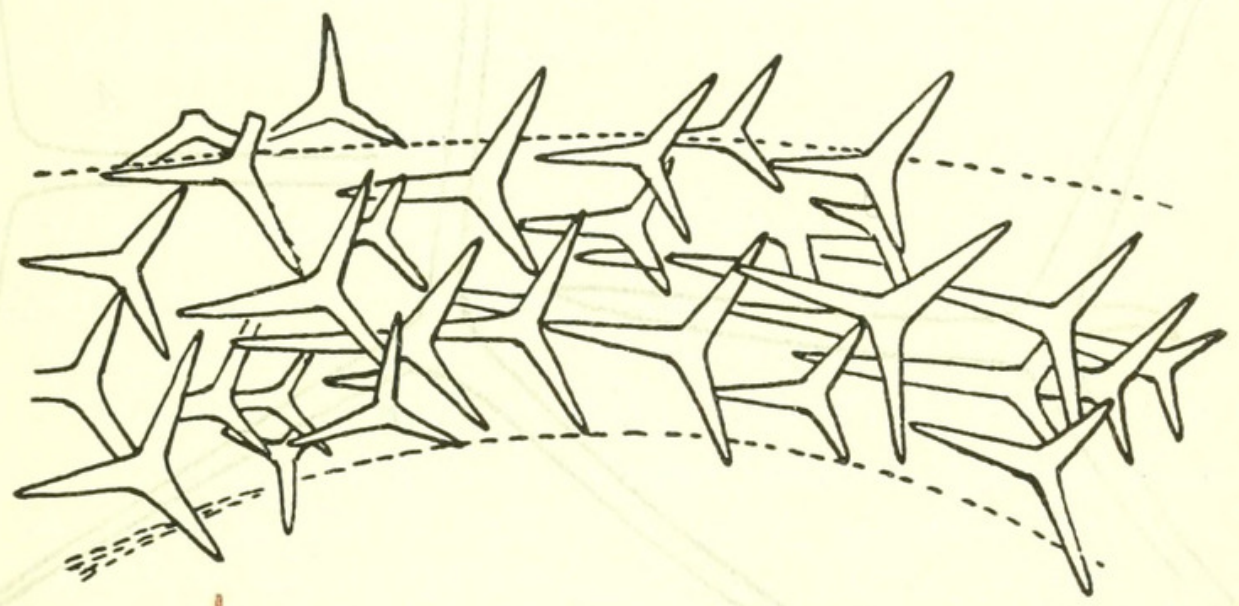

Figure 2.-Leucosolenia macleayi Dendy: One of the ascon tubes, $\times 300$; illustrating the spicules and their placement

a preparation of this species in which the axial canals of the spicules are clearly evident. This is rather uncommon in calcareous spicules. Statements have even been made that calcareous spicules lack such an axial canal, although Minchin $(1900$, p. 40) calls attention to the fact that there really is one.

Principal spicules, triaxons (fig. 2). Size of each ray, $3 \mu$ by $40 \mu$ to $6 \mu$ by $60 \mu$; the usual size is $6 \mu$ by $40 \mu$.

Remarks.-There are rather few Leucosolenias having only triradiates, but some of these, including the present species, are common and nearly cosmopolitan. L. macleayi is characterized by delicate lacy form, regularity, and simplicity of spiculation, and by the stipitate habitus. I wish to thank Maurice Burton, of the British Museum of Natural History, for help in allocating this species, as by a mistake I had identified it with the rather similar Leucosolenia coriacea Montagu. L. coriacea differs in that it always has more repent form than macleayi. 


\section{LEUCOSOLENIA ELEANOR Url , n}

Leucosolenia eleanor UrBan, 1905, p. 36.

Holotype.-In the possession of Prof. F. Urban, Marienbad, Czechoslovakia.

Type locality.-Monterey Bay.

Material examined.-Abundant California specimens. I find this species only in the vicinity of Monterey Bay, where it is very common intertidally. It occurs on the underside of granite bowlders or underneath protrusions of rock, often where the surf breaks on it.

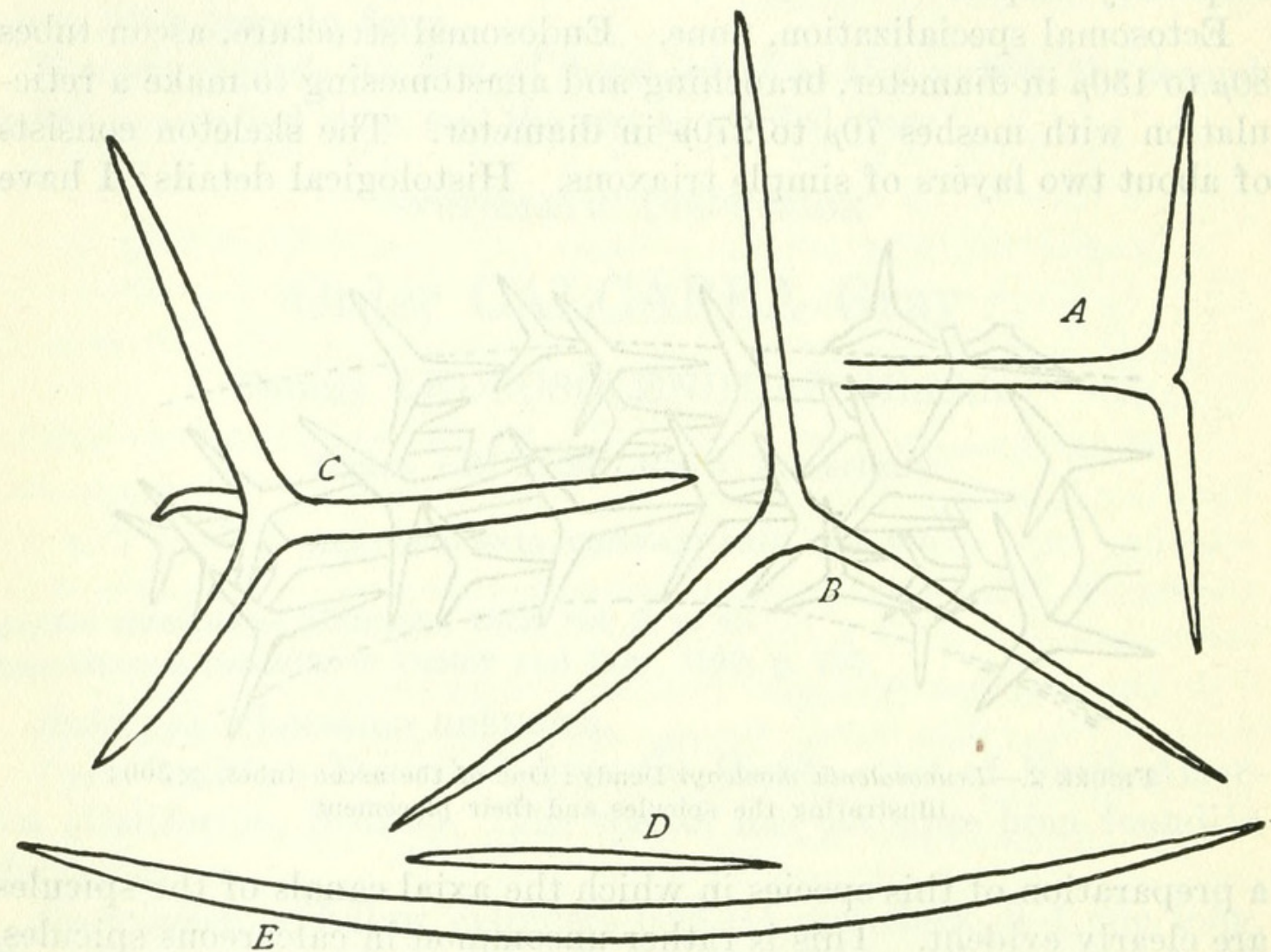

Figurn 3.-Leucosolenia eleanor Urban: Triradiates $(A, B)$ and quadriradiates $(C)$ of average size, and extremes of the oxeas $(D, E), \times 300$

Description (U.S.N.M. No. 21465; B.M. No. 29.8.22.46).-Shape, clathrate masses of branching and anastomosing tubes. Size, up to $10 \mathrm{~cm}$ in diameter; the tubes are $0.3-1.7 \mathrm{~mm}$ in diameter. Consistency, fragile, slightly spongy. Color in life and when preserved, white. Oscules, simple, few, approximately $1 \mathrm{~mm}$ in diameter. Pores, minute, abundant. Surface, superficially smooth.

Ectosomal specialization, none. Endosomal structure, typically ascon. It is remarkable that although clathrate there are no blind diverticulations, the number of oscules increasing as the size of the colony increases. That which is now regarded as the genus Leucosolenia was formerly divided into two genera, the second called Clathrina, the basis of separation being the absence or presence of 
clathrate form, and the fact that in the latter there were not only many blind diverticulations, but the number of oscules did not increase with enlargement of the colony; eleanor is precisely intermediate between the two. Histological details: The nuclei of the collar cells are sometimes placed basically, sometimes apically, according to Urban.

First type of spicules, oxeas (fig. $3, D$ and $E$ ) ; size, $4 \mu$ by $105 \mu$ to $9 \mu$ by $434 \mu$. Second type of spicules, quadriradiates (fig. $3, C$ ); size of rays, about $9 \mu$ by $140 \mu$. Third type of spicules, sagittal alate triradiates (fig. $3, A$ ) ; size of rays, about $7 \mu$ by $80 \mu$. Fourth type of spicules, regular triradiates (fig. $3, B$ ) ; size of rays, about $7 \mu$ by $140 \mu$.

Remarks.-There does not seem to be any other Leucosolenia very close to eleanor, although, of course, many species of this genus have much in common with it. Most characteristic is the extent to which it is intermediate between the characteristics formerly assigned to Clathrina and those always assigned to Leucosolenia.

\section{LEUCOSO ENIA NAUTILIA de Laubenfels}

Leucosolenia nautilia de LAUBENFELs, 1930, p. 25.

Holotype.-U.S.N.M. No. 21466; B.M. No. 29.8.22.11.

Type locality.-A small group of California specimens was studied, all collected by myself, July 20, 1926, from the bottom of a motor-driven fishing vessel that had been in active use near Monterey Bay since its previous cleaning, about six months earlier. This sponge was here associated with the introduced mussel, Mytilus edulis, a remarkable circumstance. The only mussel at all common locally is $M$. californianus.

Description.-Shape, there is a stoloniferous basal reticulation from which rise separate tubes. Size of largest colony, $20 \mathrm{~mm}$ high, $35 \mathrm{~mm}$ in diameter. Tubes, $0.2-2 \mathrm{~mm}$ in diameter and about $20 \mathrm{~mm}$ long; walls, about $50 \mu$ thick. Consistency, fragile. Color in life and when preserved, white. Oscules, apical; diameters, as for the tubes. Pores, about $50 \mu$ in diameter; they cause the walls of the tubes to appear fenestrated. Surface, superficially hispid.

Ectosomal specialization, none. Endosomal structure, typical ascon sort. Histological details: The nuclei of the collar cells are so located in the main body of the cell as to be dubiously basal.

First type of spicules, large oxeas (fig. $4, A$ ), size, $10 \mu$ by $400 \mu$ to $20 \mu$ by $1,000 \mu$. Second type of spicules, small oxeas (fig. $4, D$ and $E$ ); size, about $4 \mu$ by $140 \mu$. Third type of spicules, triradiates (fig. $4, B)$; size of rays, about $9 \mu$ by $140 \mu$. Fourth type of spicules, quadriradiates (fig. $4, C$ ); size of projecting rays, about $8 \mu$ by $30 \mu$, tangential rays as for the triradiates. 
Remarks.-The most abundant spicules seem to be the oxeas, which are commonly about $600 \mu$ to $800 \mu$ long but sometimes more than $1 \mathrm{~mm}$. They are typically nearly tangential, but not quite, the distal fourth or third hispidating the surface. Smaller ones occur among them. The triradiates are between them and the gastral layer. The gastral (or cloacal) layer is packed with autogastral quadriradiates, the projecting ray comparatively short. The choanocytes are arranged on this inner surface only, as typical of ascons, and their nuclei are centrally located within the mass of the cell.

This species comes very close to the genus Ascute, which has the large oxea entirely embedded within the flesh. Its genotype, A. uteoides Dendy (1893, p. 178), from Australia, has besides this difference the further ones of lacking triradiates and having oxeas

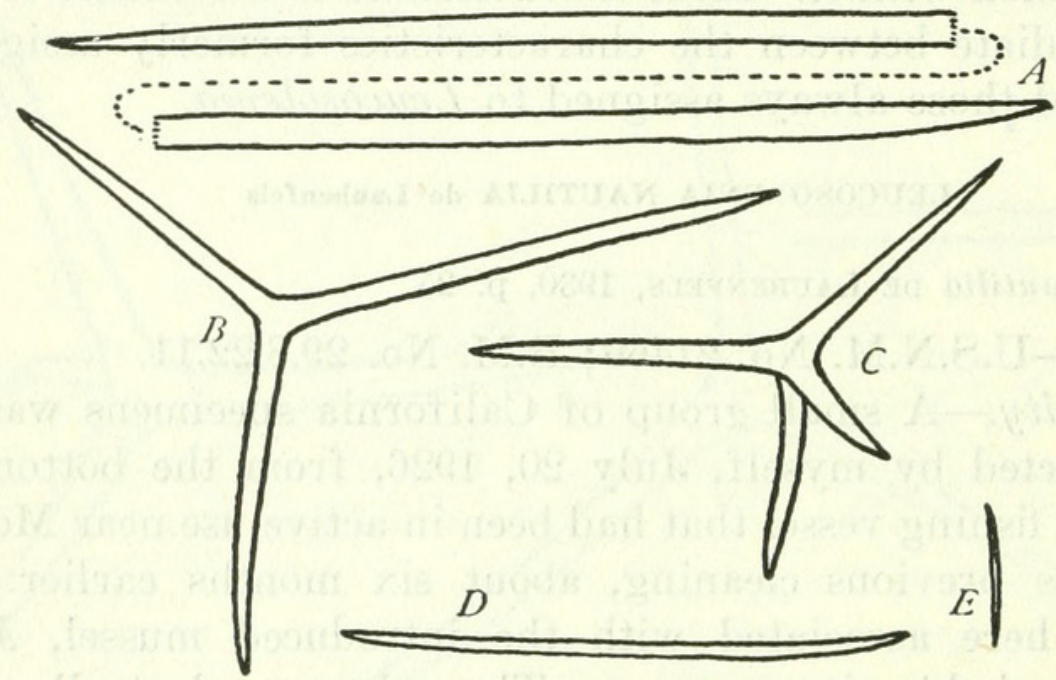

Figure 4.-Leucosolenia nautilia de Laubenfels: Extremes of size for the small oxeas $(D, E)$ and average sizes for the other spicule sorts $(A, B, C), \times 300$

twice as thick though not much longer; nevertheless, I regard it as fairly closely related to nautilia, as other items are very similar. There is some possibility that the numerous differences from Leucosolenia eleanor, the common local intertidal member of this genus (p. 8), may be accounted for by the peculiar ecological placement of nautilia. There seems to be no other record of calcareous sponges fouling boat bottoms. Neither mussels nor sponges occur at all commonly on the bottoms of the fishing boats around Monterey Bay.

\section{Family SYCETTIDAE Dendy \\ Genus SYCON Risso \\ SYCON COACTUM (Urban)}

Sycandra coacta Urban, 1905, p. 55.

Sycon coactum DENDY and Row, 1913, p. 745.

Holotype.-In the possession of Prof. F. Urban, Marienbad, Czechoslovakia. 
Type locality.-Monterey Bay, Calif. I have not succeeded in finding this species in the field, in spite of very careful search in the type locality.

Description.-This is a noncolonial, flask or vase-shaped sponge, about $5 \mathrm{~mm}$ in diameter and $6 \mathrm{~mm}$ high. The color is white. There is an erect oscular crown. The chamber system is of the second type (sycon). There are oxea of the oscular fringe, size $3 \mu$ by $500 \mu$ to $10 \mu$ by $500 \mu$, and of the choanosome, size $35 \mu$ by $1,000 \mu$ and less, and microxeas about $2 \mu$ by $40 \mu$ in the walls of the radial tubes and pseudogastral layer. The latter two locations are also supplied with triradiates and quadriradiates, rays about $10 \mu$ by $90 \mu$. The triradiates are usually sagittal.

Remarks.-Urban fails to explain how this differs from the numerous other Sycons or Sycandras. It seems to differ from Sycon coronatum in its microxea and in the lack of dermal tufts over the distal ends of the radial tubes.

\section{SYCON CORONATUM (Ellis and Solander)}

Spongia coronata Ellis and SolAnder, 1786.

Grantia ciliata BowerBank, 1864, according to HAEckel, 1872.

Sycandra coronata HAECKEL, 1872.

Sycon coronatum DENDY, 1892.

Holotype.-Location unknown.

Type locality.-Europe. Haeckel (1872, vol. 2, p. 305) lists this species as from California, Brown. The species is cosmopolitan, but I have not found it in California.

Description.-This is a single cylindrical individual (noncolonial), usually $3 \mathrm{~mm}$ by $10 \mathrm{~mm}$ to $7 \mathrm{~mm}$ by $30 \mathrm{~mm}$ in diameter and height. Unless soiled it is white. The canal system is of the second, or sycon, type. There are many triradiates and quadriradiates, both regular and sagittal or alate; the single rays are often $0.007 \mathrm{~mm}$ by $0.14 \mathrm{~mm}$ in size. There are large oxea (about $0.02 \mathrm{~mm}$ by 1 to 2 $\mathrm{mm}$ ) in tufts on the surface, particularly over the outer ends of the lateral diverticula of the pseudogastral cavity. The oscule is crowned with an erect spicular fringe.

\section{Family GRANTIIDAE Dendy}

\section{Genus LEUCONIA Grant}

LEUCONIA SAGITTATA (Haeckel)

Leucetta sagittata HAECKEL, 1872, p. 125.

Leucandra sagittata DENDY and Row, 1913, p. 774.

Holotype-Location unknown.

Type locality.-Pacific coast of North America (California, Brown).

Description.-A mass of branching and anastomosing tubes 35 
by $70 \mathrm{~mm}$ in size, with oscula much fewer than the total number of tubes. The color in alcohol is given as brown. The tubes are mostly $3 \mathrm{~mm}$ thick but vary from about 2 to $5 \mathrm{~mm}$, with walls 0.4 to $0.8 \mathrm{~mm}$ thick. The surface is smooth both inside and out. Canal system leuconoid. The skeleton is of triradiates only, the largest having rays up to 0.06 by $0.8 \mathrm{~mm}$, others are as small as 0.01 by $0.1 \mathrm{~mm}$. All or nearly all are decidedly alate.

Remarks.-No one seems to have found another specimen of this sponge since Haeckel described it.

This genus has been quite generally known as Leucandra; but, as Burton (1929, p. 403) points out, the name Leuconia Grant, 1833, has clear priority and should never have been dropped for Leucandra Haeckel, 1872.

\section{LEUCONIA HEATHI (Urban)}

Leucandra heathi URBAN, 1905, p. 59.

Leucandra apicalis URBAN, 1905, p. 67.

Holotype.-In the possession of Prof. F. Urban, Marienbad, Czechoslovakia.

Type locality.-Monterey Bay, Calif.

Material examined.-Numerous California specimens were studied. The species is abundant near Monterey Bay, occurring on and under granite bowlders near low-tide mark. In southern California, one finds what I take to be the same species, but so far only small and misshapen specimens. I found one intertidal at Laguna Beach in October, 1925. Other specimens were dredged by the University of Southern California on July 19, 1924, in 78 meters off Catalina Island, and on September 26, 1925, in 29 meters near Long Beach (U.S.N.M. No. 21422).

Description (material from type locality, U.S.N.M. No. 21462; B.M. No. 29.8.22.39).-Shape, pyriform, if not crowded, otherwise distorted. Size, up to at least $9 \mathrm{~cm}$ high, $11 \mathrm{~cm}$ in diameter. Consistency, mediocre. Color in life and when preserved, basically white but usually dirty. Oscules, apical and usually but one to a sponge. Diameter, up to $10 \mathrm{~mm}$. Pores, about $20 \mu$ in diameter. Surface, superficially hispid.

Ectosomal specialization, none, aside from the spicule plush. Endosomal structure, leucon type. Histological details: Flagellate chambers $45 \mu$ to $85 \mu$ diameter.

First type of spicules, coronal oxeas (fig. $5, E$ ) ; size, $4 \mu$ by $8,000 \mu$ to $12 \mu$ by more than $10,000 \mu$. Second type of spicules, large oxeas (fig. $5, G$ ); size, $30 \mu$ by $3,400 \mu$ to $150 \mu$ by more than $5,000 \mu$. Third type of spicules, sagittal triradiates (fig. $5, A$ ); size of rays, about $10 \mu$ by $140 \mu$. Fourth type of spicules, endosomal triradiates (fig. 5, $B, C$, and $D$ ) ; size, up to $10 \mu$ by $225 \mu$. Microscleres, microxeas (fig. $5, F)$; size, about $4 \mu$ by $140 \mu$. 
The large oxeas are radially placed in the sponge mass and echinate the most of the exterior surface. The sagittal triradiates line the upper cloacal surface. The endosomal triradiates occur frequently in all sizes from the maximum down. The microxeas are located sparsely throughout the sponge.

Remarks.-A noteworthy feature is the sphincter (glistening white) around the upper end of the cloaca, which latter is often quite a third of the diameter of the entire sponge and reaches nearly to the base. Professor Heath tells of finding specimens exposed at

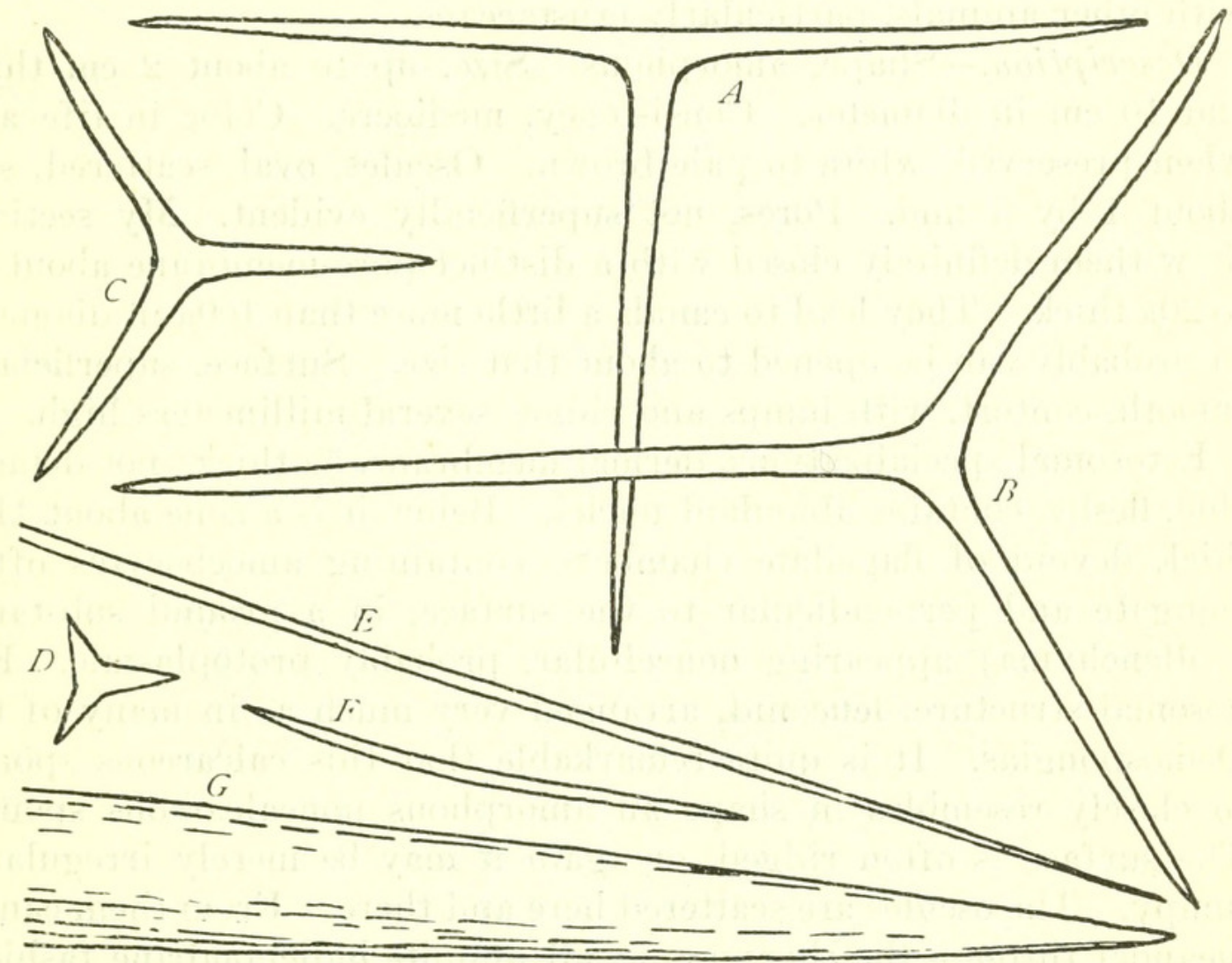

Figure 5.-Leuconia heathi (Urban): Spicule varieties, $\times 300$; only the terminations of the longer oxeas are shown

low tide, of blowing tobacco smoke at their open oscules, and watching the moderately quick closing by the sphincter. Urban writes of a pore membrane for closing the afferent openings.

In describing $L$. apicalis, Urban fails to cite means whereby it may be distinguished from $L$. heathi of the same locality; therefore I consider it a synonym of $L$. heathi.

\section{Family LEUCASCIDAE Dendy}

\section{Genus LEUCETTA Haeckel}

\section{LEUCETTA LOSANGELENSIS (de Laubenfels)}

Leuconia losangelensis de LAUBENFELs, 1930, p. 25.

Holotype.-U.S.N.M. No. 21463; B.M. No. 29.8.22.40.

Type locality.-Laguna Beach, Calif., October, 1925, intertidal, collected by the author. Numerous California specimens were 
studied, all from southern California. The species is abundant at this locality. In September, 1925, I found it on pilings of a wharf at Venice, Calif. The University of Southern California collected it twice in July, 1914, without locality record, at Whites Point (near San Pedro) without date record (U.S.N.M. No. 21407), and on July 13, 1923, at Point Vincente (near San Pedro) (U.S.N.M. No. 21402). The species occurs in a variety of situations throughout the lower half of the intertidal zone, seeming to favor situations in the bottom of crevices and where the wave action is strong. It is much infested with other animals, particularly crustaceans.

Description.-Shape, amorphous. Size, up to about $2 \mathrm{~cm}$ thick and $10 \mathrm{~cm}$ in diameter. Consistency, mediocre. Color in life and when preserved, white to pale brown. Oscules, oval, scattered, size about 1 by $3 \mathrm{~mm}$. Pores, not superficially evident. My sections show them definitely closed with a distinct pore-membrane about $5 \mu$ to $20 \mu$ thick. They lead to canals a little more than $100 \mu$ in diameter so probably can be opened to about that size. Surface, superficially smooth, contort, with lumps and ridges several millimeters high.

Ectosomal specializations, dermal membrane, $5 \mu$ thick; not detachable, fleshy, contains abundant nuclei. Below it is a zone about $115 \mu$ thick devoid of flagellate chambers, containing amoebocytes often elongate and perpendicular to the surface, in a ground substance (collenchyma) appearing noncellular, probably protoplasmic. Endosomal structure, leuconid, arranged very much as in many of the Demospongias. It is quite remarkable that this calcareous sponge so closely resembles in shape an amorphous noncalcareous sponge. The surface is often ridged, or again it may be merely irregularly lumpy. The oscules are scattered here and there. From them canals meander through the choanosome, all in quite halichondrine fashion. I have found small specimens scarcely more than a centimeter in diameter, and even they had two or three small oscules and none of the characteristic symmetry of the Calcarea. It would be most interesting to find still younger forms and trace the early stages. Histological details (besides those mentioned above) : The flagellate chambers are usually oval, extreme measurements about $30 \mu$ to $80 \mu$.

First type of spicules regular triaxons (fig. $6, C, D$, and $H$ ); second type of spicules, sagittal triaxons (fig. $6, F$ ).

The characteristic spiculation of this species is a confused tangle of two sizes of triaxons, the larger (fig. $6, C$ ) with rays about $40 \mu$ by $400 \mu$, the smaller (fig. $6, E$ ) with rays about $13 \mu$ by $130 \mu$. Some specimens, including the type specimen, contain numerous intermediates, but in many specimens the distinction into two different sized ranges is conspicuous. Careful study of many specimens yields the following as supplementary remarks: In two instances I have found a small fourth ray on a spicule (fig. $6, G$ ); this item is so rare that 
I doubt if quadriradiates should be cited as of normal occurrence. In a few cases I have found small oxeas near the surface (fig. $6, A$ ). These are not certainly proper. Rather more often I find microtylostyles about $5 \mu$ by $40 \mu$ (fig. $6, B$ ). I interpret these as essentially triradiates, with two rays almost entirely suppressed. In some parts of some specimens I find curious microspined cylinders, about $3 \mu$ in diameter, of variable lengths, with abrupt ends (fig. $6, H)$. It seems doubtful that they are proper spicules, or even

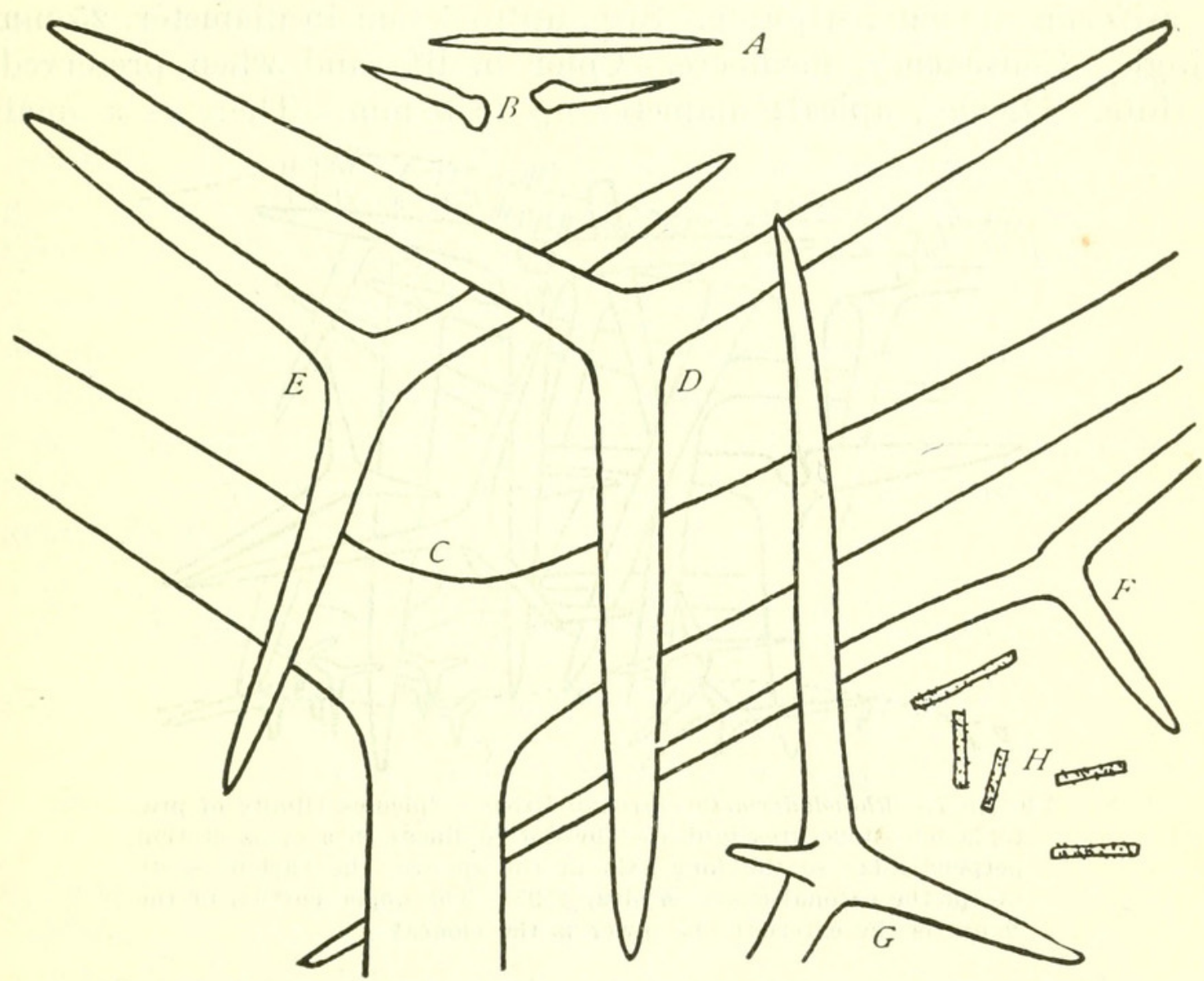

Figure 6.-Leucetta losangelensis (de Laubenfels), spicules, $\times 300$

spicules at all; but they should be mentioned. Some of the triradiates are both alate and sagittal, these being, as usual, around the oscules.

Remarks.-The species closest here would seem to be that described by Hozawa, 1929, as Leucandra solida.

\section{Family AMPHORISCIDAE Dendy}

\section{Genus RHABDODERMELLA Urban}

\section{RHABDODERMELLA NUTTINGI Urban}

Rhabdodermella nuttingi URBAN, 1902, p. 268.

Leucilla nuttingi DENDY and Row, 1913, p. 784.

- Holotype.-In the possession of Prof. F. Urban, Marienbad. Czechoslovakia.

Type locality.-Monterey Bay, Calif. 
Material examined.-Numerous California specimens were studied. The species is very common in the intertidal zone both in southern California and the Monterey region; and E. F. Ricketts reports seeing sponges resembling this at various intermediate points. The University of Southern California dredged it in 27 meters off Long Beach. It often hangs from the underside of bowlders, and as exposed at low tide makes beautiful pearllike pendants.

Description (U.S.N.M. No. 21486; B.M. No. 29.8.22.43).-Shape, vasiform, elongate, stipitate. Size, up to $5 \mathrm{~mm}$ in diameter, $25 \mathrm{~mm}$ high. Consistency, mediocre. Color in life and when preserved, white. Oscules, apical; diameter up to $3 \mathrm{~mm}$. There is a small

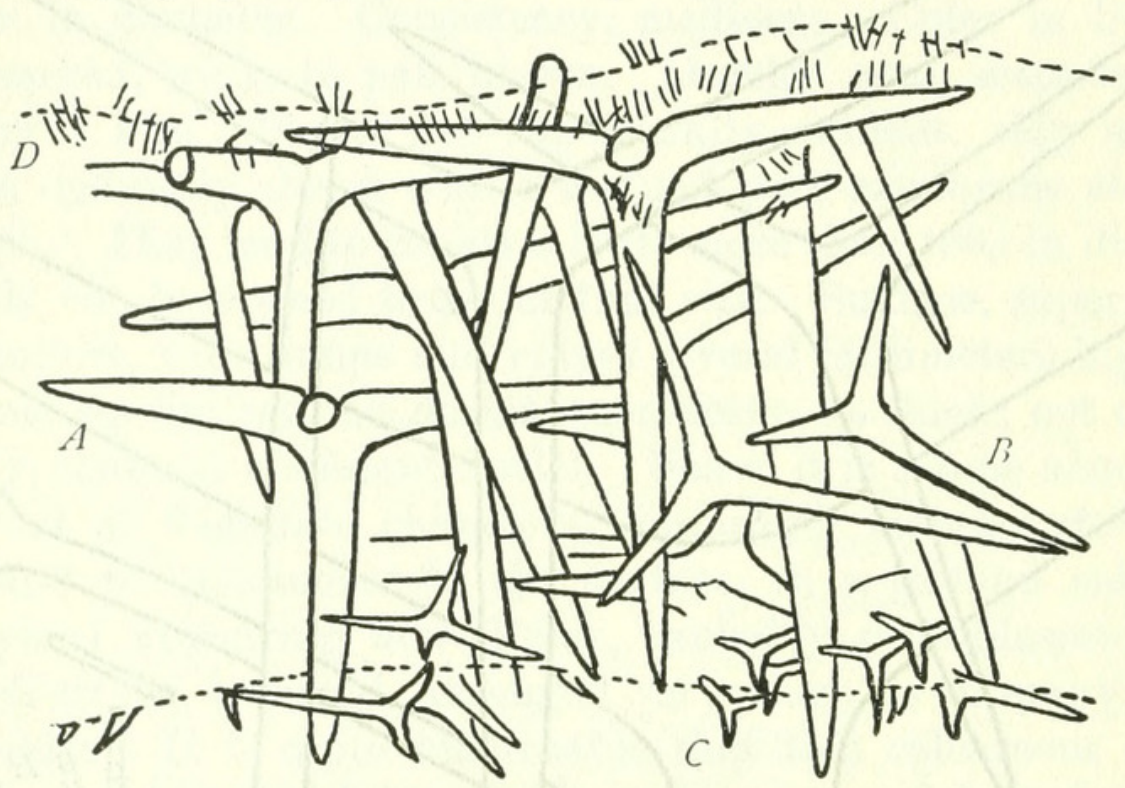

FIGURB 7.-Rhabdodermella nuttingi Urban: Spicules (limits of protoplasmic structures indicated by dotted lines) in a cross section perpendicular to the long axis of the sponge, the various sorts except the coronal oxeas in situ, $\times 95$. The upper portion of the figure is the external, the lower is the cloacal

coronal palisade of erect spicules. Pores, up to $200 \mu$ in diameter. Surface, superficially smooth.

Ectosomal specialization, the dermis $(20 \mu$ thick) contains distinctive microrhabds, placed vertically, in great abundance. Endosomal structure, leuconid of the sort termed sylleibid, that is, with the fiagellate chambers in grape-cluster arrangement. Histological details: The flagellate chambers are oval, about $70 \mu$ by $126 \mu$ in size.

First type of spicules, coronal oxeas (not figured) ; size about $25 \mu$ by $1,250 \mu$. Second type of spicules, large hypodermal quadriradiates or triradiates (fig. 7, A); size of rays, about $40 \mu$ by $875 \mu$. Third type of spicules, smaller triradiates (fig. $7, B$ ); size of rays, about $10 \mu$ by $230 \mu$. Fourth type of spicules, very small quadriradiates or triradiates (fig. $7, C$ ) ; size of rays, about $4 \mu$ by $20 \mu$ to $5 \mu$ by $100 \mu$. Microscleres, microxeas (fig. $7, D$ ); size, abont $2 \mu$ by $45 \mu$. 
The coronal oxeas are arranged in a palisade about the oscule, as usual. The large quadriradiates or triradiates are hypodermal. Their rhabds reach clear to the gastral layer, the cladome being near the outer surface. The smaller triradiates are scattered in the choanosome. The still smaller quadriradiates or triradiates line the gastral surface. The fourth ray, or in the case of the triradiates, one of the three, is autodermal.

Remarks.-Dendy and Row in monographing the Calcarea (1913, p. 793) put this in the large genus Leucilla. The type species of that genus, $L$. amphora, is somewhat like the species under discussion in shape, and to a lesser extent in canal system and arrangement of the larger spicules. Lendenfeld regarded the difference in canal system great enough, however, to create a separate family for those of the type of Polynia and Vosmaeria (family Sylleibidae). $R$. nuttingi would be in this family if it were regarded as valid, but it is usually not so regarded. Furthermore, nuttingi differs so widely from amphora in other respects, especially in having the peculiar dermis with its special microscleres, that I believe the two can not fairly be classed as congeneric. I therefore hold with Urban, recognizing his genus, Rhabdodermella.

\section{Order HEXACTINELLIDA Schmidt}

\section{Family HYALONEMATIDAE Gray}

\section{Genus HYALONEMA J. E. Gray}

\section{HYALONEMA POPULIFERUM Schulze}

Hyalonema populiferum F. E. Schulze, 1899, p. 10.

\section{Holotype.-U.S.N.M. No. 7557.}

Type locality.-Albatross Station 2928, near San Clemente Island, Calif., depth 764 meters, sand bottom.

Other specimens recorded by Schulze from the vicinity of San Clemente Island are from:

Albatross Station 2936, depth 656 meters, mud bottom.

Albatross Station 2937, depth 847 meters, mud bottom.

Albatross Station 2980, depth 1,192 meters, mud bottom.

\section{Family ROSSELLIDAE Schulze}

\section{Genus APHORME Schulze}

\section{APHORME HORRIDA Schulze}

Aphorme horrida F. E. Schulze, 1899, p. 40.

Holotype.-U.S.N.M. No. 7504.

Type locality.-Albatross Station 2937, near San Clemente Island, Calif., depth 847 meters, mud bottom. 


\section{Genus ACANTHASCUS Schulze}

\section{ACANTHASCUS PLATEI Schulze}

Acanthascus platei F. E. Schulze, 1899, p. 45.

Holotype.-U.S.N.M. No. 7502.

Type locality.-Albatross Station 2927, west from San Diego, Calif., depth 572 meters, mud bottom.

\section{Genus STAUROCALYPTUS Ijima \\ STAUROCALYPTUS DOWLINGI (Lambe)}

Rhabdocalyptus dowlingi LAMBE, 1893, p. 37.

Staurocalyptus dowlingi IJIMA, 1897, vol. 1, p. 53.

Holotype.-In the Museum of the Geological Survey, Ottawa, Canada; described from the west coast of Canada.

Other records.-Schulze (1899, p. 47) described Californian specimens from Albatross Station 2955, depth 221 meters. This station is just south of Santa Rosa Island. The specimen he figures is U.S.N.M. No. 7578. He also had a specimen from Alaska.

\section{STAUROCALYPTUS SOLIDUS Schulze}

Staurocalyptus solidus F. E. SchUlze, 1899, p. 51.

Holotype.-U.S.N.M. No. 7581.

Type locality.-Albatross Station 2948, near Santa Cruz Island, depth 486 meters.

Other specimens recorded by Schulze are from:

Albatross Station 3071, Washington, depth 1,253 meters.

Albatross Station 3202, Monterey Bay, depth 699 meters.

Three other specimens from Monterey Bay are in the collection of Stanford University. The species is also represented in the British Museum (No. 29.8.22.26).

Description (based on the Stanford University specimens).Shape, vasiform; a hollow cylinder. Size, up to $15 \mathrm{~cm}$ in diameter, $24 \mathrm{~cm}$ high. Consistency, fragile. Color in life and when preserved, drab. Oscules, on cloacal surface only; round, 1 to $4 \mathrm{~mm}$ in diameter. Pores, on outer surface only; round, 0.2 to $0.4 \mathrm{~mm}$ in diameter. Surface covered with a forest of projecting spicules.

Parenchyma, about $23 \mathrm{~mm}$ thick. Prostalia marginalia, none as distinct from pleuralia. Prostalia pleuralia, abundant diacts 40 to $60 \mathrm{~mm}$ long. Prostalia basalia, none. Dermalia autodermal, diacts up to $20 \mathrm{~mm}$ long. Dermalia hypodermal, conspicuous pentacts, rhabds about $20 \mathrm{~mm}$ long, clads about $4 \mathrm{~mm}$ above the surface and each arm about 3 to $5 \mathrm{~mm}$ long. There are here also small pentacts, each arm spined and about $12 \mu$ by $150 \mu$. Gastralia autodermal, 
diacts 20 to $30 \mathrm{~mm}$ long. Gastralia hypodermal, abundant pentacts, each arm $200 \mu$ long. There are further a few diacts about $2 \mathrm{~mm}$ long, perpendicular to the surface and in, but not protruding from, the cloacal layer. Parenchymalia principalia, oxeas about $30 \mathrm{~mm}$ long. Parenchymalia comitalia, strongyles almost tylotes, with spined heads and four hemispherical protrusions so placed centrally as to indicate that this is a reduced hexact. Size, about 0.016 by 3 $\mathrm{mm}$. Parenchymalia intermedia, oxyhexasters, all or most of the six primary rays being dichotomously branched. Each ray totals about $45 \mu$ long. There are also discohexasters of about $180 \mu$ total diameter.

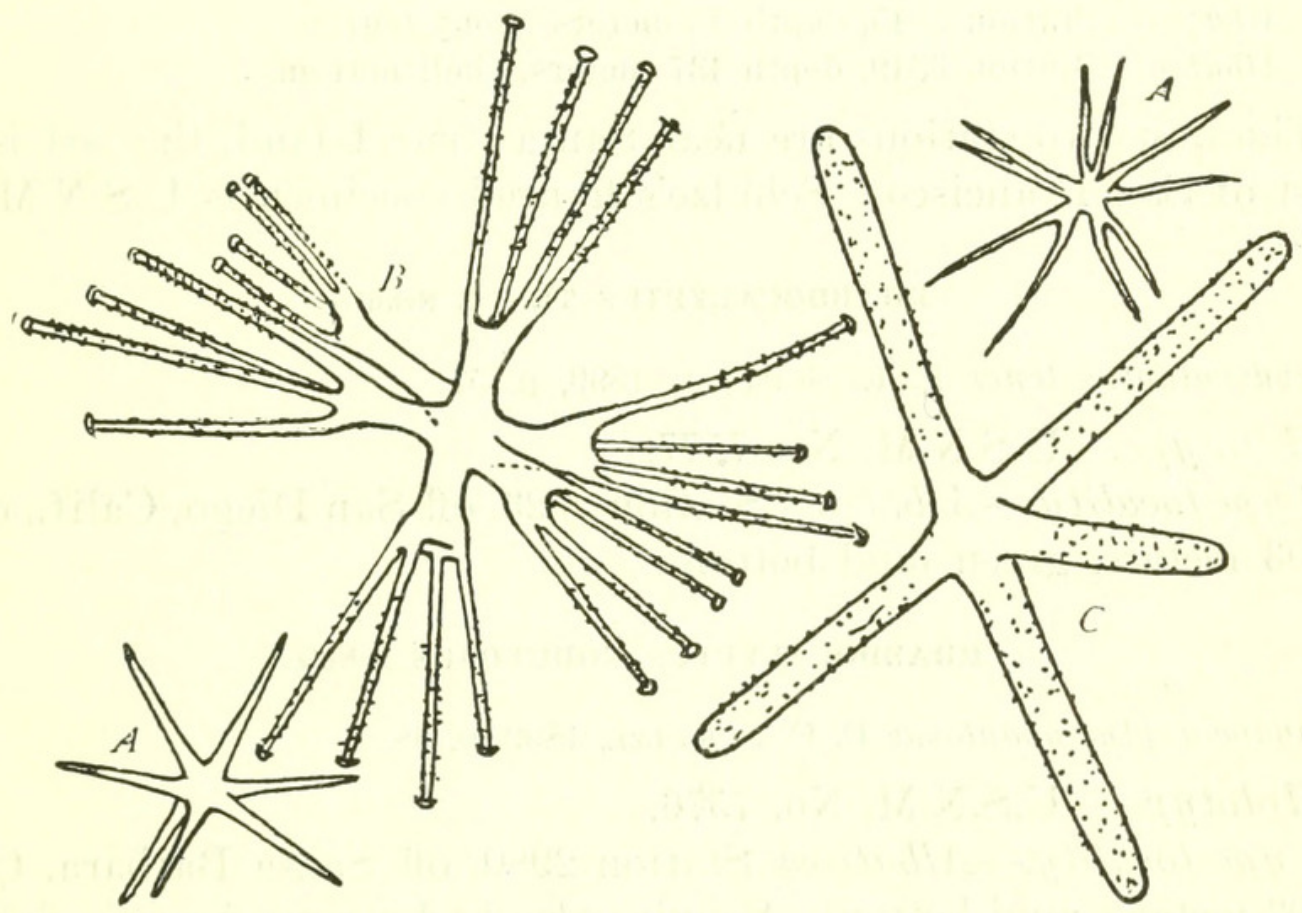

Figure 8.-Staurocalyptus solidus Schulze: $A$, Oxyhexasters; $B$, discohexaster; $C$, one of the smaller pentacts. $\times 300$

Remarks.-Schulze's description is rather brief and is based in a large measure on a comparison to Staurocalyptus dowtingi (Lambe) Ijima. This latter form is described as having discohexasters $250 \mu$ to $320 \mu$ in diameter, as compared to S. solidus, which has discohexasters $150 \mu$ to $180 \mu$ in diameter; moreover, the former is semistipitate, but in other respects the two forms are practically identical. I follow Schulze in retaining these as separate species for the time being but with serious doubts. It is very possible that future work may show that $S$. solidus should fall as a synonym to $S$. dowlingi.

\section{STAUROCALYPTUS FASCICULATUS Schulze}

Staurocalyptus fasciculatus F. E. SchUlze, 1899, p. 53.

Holotype.-U.S.N.M. No. 7580.

Type locality.-Albatross Station 2979, north of Santa Cruz Island, Calif., depth 690 meters, mud bottom. 


\section{Genus RHABDOCALYPTUS Schaize RHABDOCALYPTUS DAWSONI (Lambe)}

Bathydorus dawsoni LAMBE, 1892, p. 73.

Rhabdocalyptus daisoni F. E. Schulze, 1899, p. 54.

Holotype.-In the Museum of the Geological Survey, Ottawa, Canada.

Type locality. - The west coast of Canada.

Other records.-Schulze (1899) has specimens from the same vicin. ity and from three California localities, as follows:

Albatross Station 2975, depth 66 meters, stony bottom.

Albatross Station 2945, depth 55 meters, stony bottom.

Albatross Station 3349, depth 437 meters, shell bottom.

The first two stations are near Santa Cruz Island, the last is just west of San Francisco. Schulze's figured specimen is U.S.N.M. No. 7570 .

\section{RHABDOCALYPTUS TENER Schulze}

Rhabdocalyptus tener F. E. Schulze, 1899, p. 57.

Holotype.-U.S.N.M. No. 7577.

Type locality.-Albatross Station 2923, off San Diego, Calif., depth 1,503 meters, green mud bottom.

\section{RHABDOCALYPTUS NODULOSUS Schulze}

Rhabdocalyptus nodulosus F. E. Schulze, 1899, p. 58.

\section{Holotype.-U.S.N.M. No. 7576.}

Type locality.-Albatross Station 2980, off Santa Barbara, Calif., 1,103 meters, mud bottom. Schulze also had a second specimen from Albatross Station 2936, off San Diego, depth 657 meters, mud bottom.

\section{RHABDOCALYPTUS ASPER Schulze}

Rhabdocalyptus asper F. E. Schulze, 1899, p. 60.

\section{Holotype.-U.S.N.M. No. 7568.}

Type locality.-Albatross Station 2936, off San Diego, Calif., depth 657 meters, mud bottom.

\section{Family EURETIDAE Zittel}

\section{Genus FARREA Bowerbank \\ FARREA CONVOLVULUS Schulze}

Farrea convolvulus F. E. Schulze, 1899, p. 71.

Holotype.-U.S.N.M. No. 7553.

Type locality.-Albatross Station 2936, off San Diego, Calif., depth 656 meters, mud bottom. 


\title{
Family COSCINOPORIDAE Zittel
}

\author{
Genus CHONELASMA Schuize \\ CHONELASMA CALYX Schuize
}

Chonelasma calyx F. E. Schulze, 1887 , p. 326.

Holotype.-Location unknown.

Type locality.-Japan.

Other records.-The Albatross dredged this species from nine stations, as reported by F. E. Schulze (1899, p. 78), as follows:

Station 3326, Aleutian Islands, Alaska, depth 1,053 meters.

Stations 2877 and 2875, near Washington State, depths 108 and 73 meters.

Stations 2862 and 2864, near Vancouver, Canada, depths 435 and 88 meters.

Station 3051, near Oregon, depth 108 meters.

Station 3202, Monterey Bay, Calif., depth 699 meters, mud bottom.

Station 2952, near Santa Barbara, Calif., depth 104 meters, rocky bottom.

Station 2980, west of Santa Rosa Island, Calif., depth 1,103 meters, mud bottom.

The specimen that Schulze figures is U.S.N.M. No. 8585.

\section{CHONELASMA TENERUM Schulze}

Chonelasma tenerum F. E. Schulze, 1899, p. 81.

Cotypes.-U.S.N.M. Nos. 7540 and 7541.

Type locality.-Albatross Station 2916, depth 170 meters, stony bottom (1 specimen), and Albatross Station 2919, depth 1,800 meters, mud bottom ( 5 specimens). Both stations are in the vicinity of the Cortez Bank, Calif., which, strictly speaking, lies in Mexican waters. Four paratypes (U.S.N.M. No. 7542) were taken at Albatross Station 2923, depth 1,503 meters, mud bottom, off San Diego, Calif.

\section{Family APHROCALLISTIDAE Schulze \\ Genus APHrocallistes J. E. Gray \\ APHROCALLISTES VASTUS Schulze}

Aphrocallistes vastus $\mathrm{F}$. E. Schulze, 1887, p. 317.

Aphrocallistes whiteavesianus LAMBE, 1892, p. 74.

Holotype.-Location unknown.

Type locality.-Japan.

Other records.-Lambe's specimen was from Canadian waters. According to Schulze, the Albatross dredged this from 13 stations, as follows:

Stations $3316,3330,3331$, and 3337 , in Alaskan waters, depths 565, 642, 640, and 512 meters, respectively.

Stations 2860, 2862, 2864, and 2877, off the coast of Canada, depths 1,602, 435,88 , and 108 meters, respectively.

Stations 2882 and 3054, off the coast of Oregon, depths 124 and 97 meters, respectively.

Station 3008, off the coast of Merico, depth 560 meters. 
Station 2925, near San Diego, Calif., latitude $32^{\circ} 32^{\prime}$ N., longitude $117^{\circ}$ $24^{\prime}$ W., depth 620 meters, mud bottom.

Station 2935, near San Diego, Calif., latitude $33^{\circ} 04^{\prime} \mathrm{N}$., longitude $117^{\circ}$ $42^{\prime}$ W., depth 839 meters, mud bottom.

In the dredging operations of E. F. Ricketts, of the Pacific Biological Laboratories, Pacific Grove, Calif., there have been brought up and presented to me by him, macerated skeletons evidently belonging to the genus Aphrocallistes and very probably to the species vastus; but they lack the soft parts and loose spicules.

\title{
Order MYXOSPONGIDA Sollas
}

\section{Family HALISARCIDAE Schmidt}

\author{
Genus HALISARCA Johnston
}

HALISARCA SACRA de Laubenfels

Halisarca sacra de LAUbenfels, 1930, p. 25.

Holotype.-U.S.N.M. No. 21454; B.M. No. 29.8.22.53.

Type locality.-Elkhorn Slough, at the east side of Monterey Bay, Calif. Collected by E. F. Ricketts, July 4, 1929. I also have collected the species at the same locality. It is found associated with Mycale macginitiei on rocks introduced by man in the midst of an environment of sheltered tidal mud flats.

Description.-Shape, encrusting. Size, up to $0.7 \mathrm{~mm}$ thick, in patches up to $14 \mathrm{~mm}$ in diameter. Consistency, very soft. Color in life and when preserved, very pale drab. Oscules, about $100 \mu$ to $200 \mu$ in diameter. Pores, very minute, well under $50 \mu$; exact sizes obscured by contractility, but none observed more than $10 \mu$. Surface, superficially shiny smooth.

Ectosomal specialization, $20 \mu$ to $40 \mu$ thick, characterized by rounded cells in a more darkly staining ground mass than that of the endosome. There are subdermal cavities about $20 \mu$ in diameter. Endosomal structure, collenchymatous. The abundant mesogloea takes nuclear stains very definitely. Histological details: The exceedingly long flagellate chambers are often radiately clustered around excurrent canals, which are often near the substrate. Many prosopyles are very short, and often there is almost direct contact with the subdermal cavities. The chambers are always about $40 \mu$ in diameter, and average well over $200 \mu$ long, lengths up to $280 \mu$ being common.

Remarks.-Some authors regard all Halisarcas as conspecific with H. dujardini, the genotype. The genus is so simplified that it is very difficult to find adequate grounds for separating any species from dujardini, but I hesitate to believe that all the members found over the entire world really are conspecific. This, our California 
representative, is, of course, close to the genotype, but may be separated, I believe, on the basis of the extreme length of the flagellate chambers. In the literature one finds few or no references to chambers longer than $125 \mu$, though I have seen in the British $\mathrm{Mu}$ seum prepared slides showing chambers-presumably of the genotype-longer than $200 \mu$; these are, however, out of the ordinary for European or Australian material. In sacra they are usually well

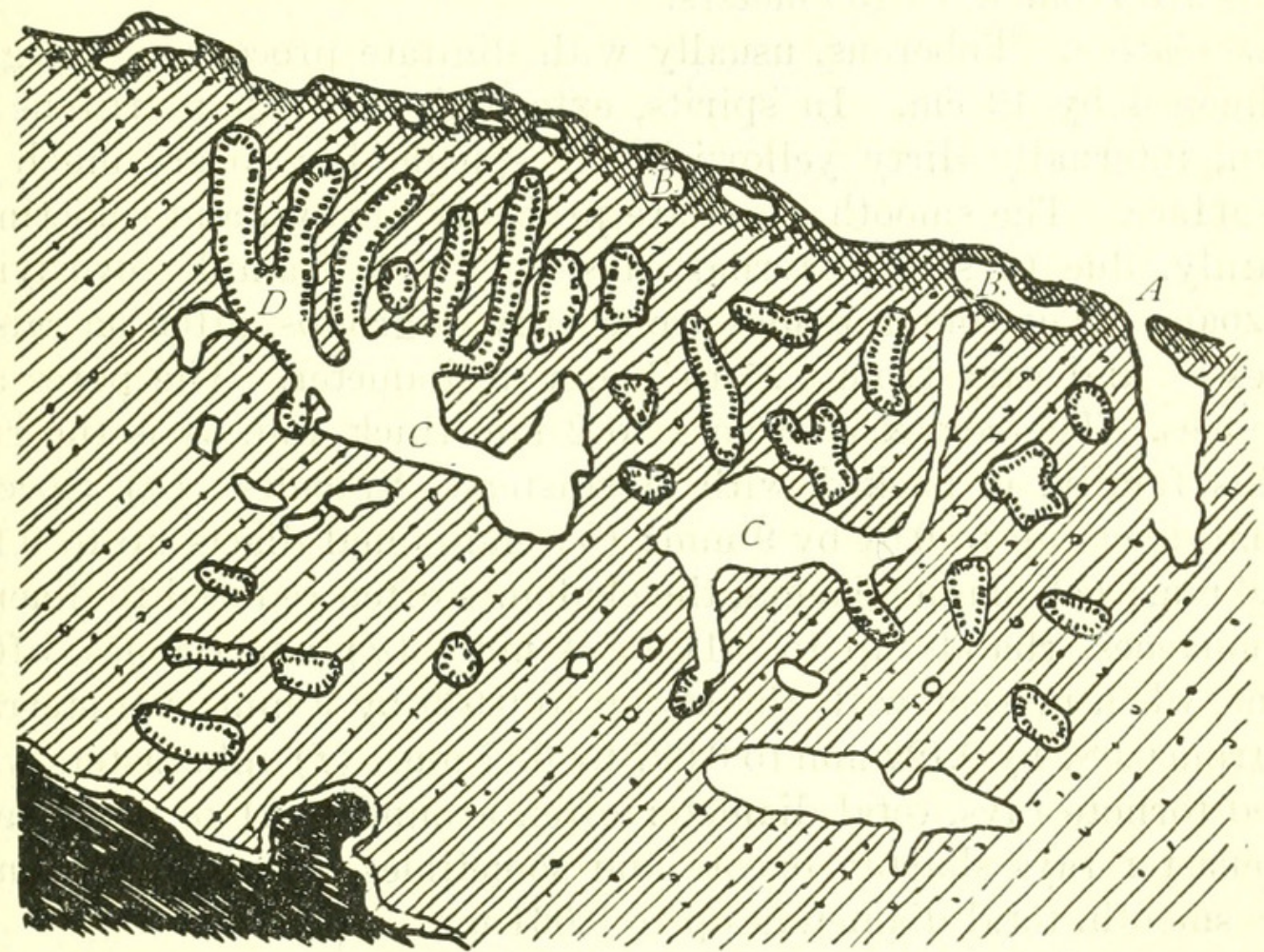

Figure 9.-Halisarca sacra de Laubenfels: Typical section perpendicular to the surface. It was found impractical to draw in fine items of detail. $A$, An oscule; $B$, subdermal cavities; $C$, excurrent canals, $D$, flagellate chamber, $\times 120$

over $200 \mu$ and rather often reach lengths of $280 \mu$. The general picture as made by slides of sacra is so different from that made by other slides of this genus that I have seen that I had a certain degree of confidence in naming this as a new species.

\section{Order CHORISTIDA Sollas}

Family GEODIIDAE Gray

\section{Genus SIDONOPS Sollas}

\section{SIDONOPS ANGULATA Lendenfeld}

Sidonops angulata LENDENFELD, 1910, p. 18 (based on three described varieties: megana, microana, and orthotriaena).

Sidonops bicolor Lendenfexd 1910, p. 46.

Holotype--Here established as U.S.N.M. No. 8380, S. angulata var. microana. 
Type locality.-Albatross Station 4417, 53 meters, off Santa Barbara Island, Calif.

Occurrence.-Lendenfeld identifies as $S$. angulata 4 specimens dredged by the Albatross near Santa Barbara Island, southern California, Stations 2945, 2975, and 4417, and as bicolor 15 specimens in the same collection dredged at Stations 2958, 2981, 3168, 4420, 4531, and 4551. These range from southern to central California. The depths are from 42 to 100 meters.

Description.-Tuberous, usually with digitate processes. Largest specimen 4 by $10 \mathrm{~cm}$. In spirits, externally whitish to rufous to brown, internally dirty yellowish. A spicule fur covers much of the surface. The smooth areas are probably always, and sometimes certainly, due to such external causes as, for example, overlying bryozoans. The round oscules are usually in groups, often on raised processes, and vary from 0.25 to $1 \mathrm{~mm}$ in diameter. The pores are in chones. The cortex is from 1 to $2 \mathrm{~mm}$ thick and, as is the rule in this family, is packed with sterrasters. Spicules: (a) Special dermal diacts up to 0.04 by $9 \mathrm{~mm}$; $(b)$ endosomal diacts up to 0.105 by $5.6 \mathrm{~mm}$; $(c)$ plagiotriaenes, the cladomes often reduced to diaenes or monaenes, rhabds up to 0.11 by $4 \mathrm{~mm}$; $(d)$ anatriaenes, often absent, when present with rhabds up to 0.039 by $9 \mathrm{~mm}$; $(e)$ sterrasters from 0.087 by $0.122 \mathrm{~mm}$ to 0.097 by $0.17 \mathrm{~mm} ;(f)$ spherasters with spined tornote rays, total diameter often around 0.021 to $0.028 \mathrm{~mm}$; $(g)$ euaster rays sharply oxeote and sometimes microspined, sometimes smooth, total diameters up to $0.064 \mathrm{~mm}$.

Remarks.-I have not examined Lendenfeld's specimens personally, so use his published data, with this warning: E. F. Hallmann, 1914, examined the material from which Lendenfeld described very numerous Australian sponges and reports serious inaccuracies in many of Lendenfeld's descriptions. Although Lendenfeld produced two large volumes on the Geodidae of the Albatross dredgings, I feel we can only surmise the true status of his species pending a re-examination of the material by some competent investigator.

In establishing angulata and bicolor Lendenfeld (1910) mentions for the former that some of the spicules were sharply bent. This is a very common malformation in many sorts of sponges. In the same article Lendenfeld figures such deformities for various of the Geodias. He does not say this feature was conspicuously absent from his bicolor. He established this latter name because of darker color on one side than the other. As is well known, sponges receiving more light from one side than the other tend to be darker on the exposed side. Lendenfeld notes (p. 47) that the darker was the upper side of these specimens. S. bicolor and $S$. angilata are not to be separated on such differences alone. 


\section{Genus GEODIA Lamarck}

\section{GEODIA MESOTRIAENA Lendenfeld}

Cydonium mülleri Lambe (not Fleming), 1892, p. $72 ; 1893$, p. 36.

Geodia mesotriaena Lendenfeld, 1910, p. 96.

Geodia agassizii Lendenfeld, 1910, p. 113.

Geodia mesotriaenella Lendenfeld, 1910, p. 151.

Geodia breviana Lendenfeld, 1910, p. 155.

Geodia ovis Lendenfeld, 1910, p. 161.

\section{Holotype.-Here designated as U.S.N.M. No. 8410.}

Type locality.-Albatross Station 2942, off southern California, 41 meters.

Occurrence.-Lendenfeld had 10 specimens from California, from Albatross Stations 2894, 1909, 2942, 2958, 2975, 2978, 4417, 4551, and 3168 ; and 24 specimens from north of California, Stations 2886, 2887, 3098, 4193, 4199, and 4228, ranging from Oregon to southeastern Alaska. I have four specimens from southern California, all dredged by the University of Southern California at depths from 41 to 47 meters. The Albatross specimens were from 32 to 180 meters, except one from 369 meters. This species is also represented in the British Museum (No. 29.9.30.11).

Description.-Shape, massive; younger specimens subglobular, older ones spread laterally to form cakes. Size, up to at least $6 \mathrm{~cm}$ thick, spreading laterally to at least $20 \mathrm{~cm}$. Consistency, mediocre. Color in life and when preserved, whitish externally, dirty yellow internally, the exterior often discolored on account of outside influences. Oscules, chones. Pores, chones. Surface, superficially covered by a dense spicular plush, which may be broken off, but in that case it is represented by broken ends of spicules.

Ectosomal specialization, cortical; it is largely sterraster armor and ranges from $200 \mu$ to $1 \mathrm{~mm}$ thick. Endosomal structure, radiate, Histological details: I have a slide showing spherical flagellate chambers that are $16 \mu$ to $20 \mu$ in diameter.

Spicules: (a) Large endosomal diacts, rarely styles or strongyles, usually oxeas (fig. $10, H$ ) ; size, $20 \mu$ to $112 \mu$ thick. Lengths are hard to state as the longer ones are usually broken, but they reach at least $9 \mathrm{~mm}$. The common size is about 0.05 by $2.5 \mathrm{~mm}$. (b) Plagiotriaenes or diaenes (fig. 10, $J, K$ ) of the same size range as the oxeas mentioned above. These are placed with their cladomes just below or actually within the cortex, the rhabds continuing on down, directed toward the base or center of the sponge. (c) Anatriaenes of very great variation in size and abundance (fig. 10, D, E, F, G). In the same specimen their rhabd diameter may range from $2 \mu$ to $45 \mu$. They are commonly 5 to $10 \mathrm{~mm}$ in length, in extreme cases as much as $22 \mathrm{~mm}$ long. They may be placed like the plagiotriaenes, or their 
cladomes may be actually projecting beyond the surface of the sponge. $(d)$ A type of spicule (fig. 10, $A, B, C$ ) that is typically a mesoprotriaene but may have a very small epirhabd or none; may be protriaene or orthotriaene; or may be triaene, diaene, or monotriaene. This occurs usually or always in the spicule fur, and therefore tends to be lost when that is rubbed off. Its frequency and shape seem to be the most characteristic items distinguishing California Geodias. I find rhabd diameter $11 \mu$ to $48 \mu$. Lendenfeld reports $7 \mu$ to $12 \mu$. Dermal small oxea or styles (fig. $10, L$ ), diameters $2 \mu$ to $13 \mu$, lengths

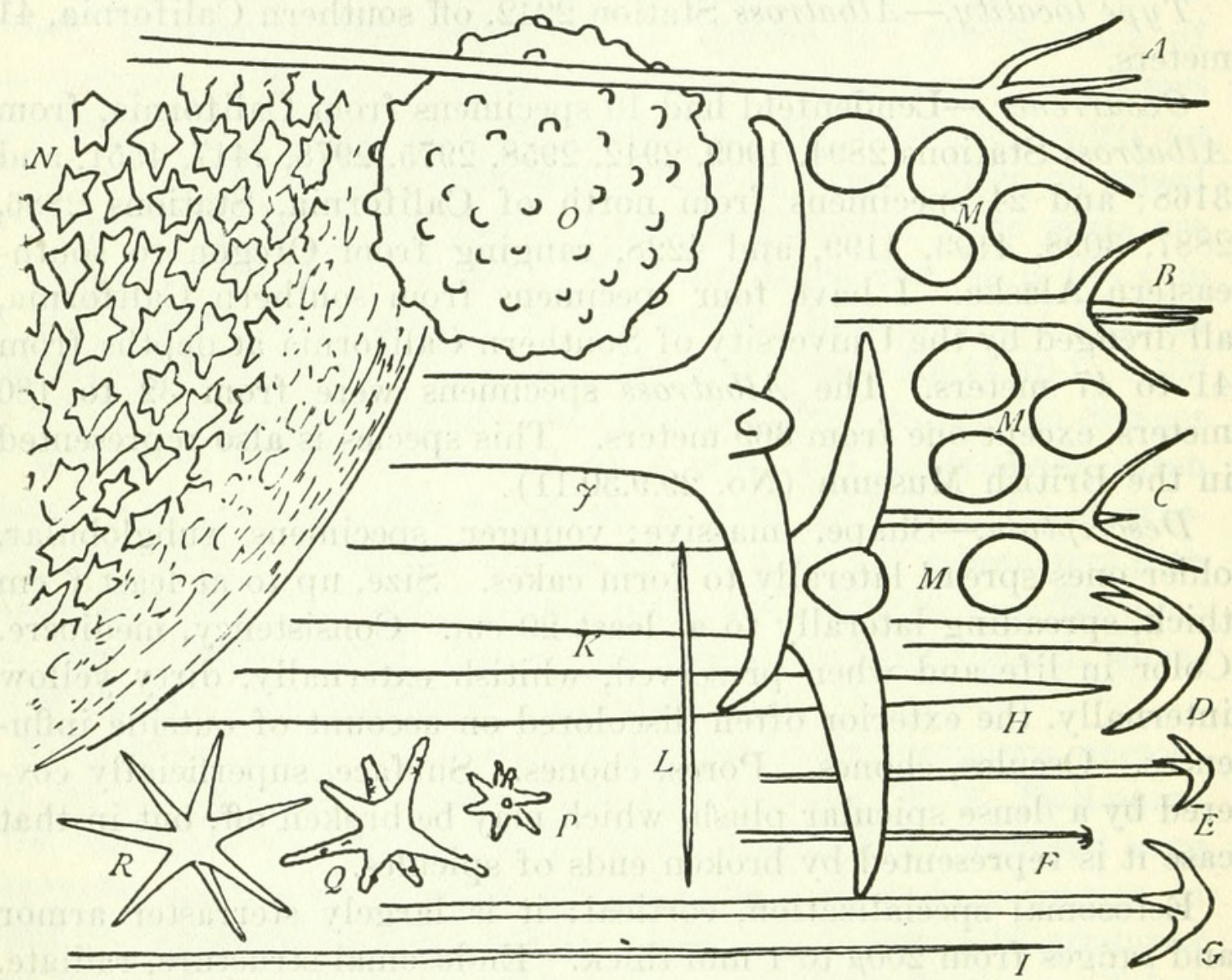

Figure 10.-Geodia mesotriaena Lendenfeld: Spicules $A$ to $M, \times 80$; others, $\times 1,333$. $O$, a developmental form of the sterraster, of which $N$-to the same scale-can only show a small bit of the surface. $H$, pointed end, which is the same for the oxeas and the esactines of the plagio spicules. I, esactine of the other polyactinal megascleres

usually about $200 \mu . \quad(f)$ Sterrasters (fig. 10, $M, N, O$ ), greatest lengths ranging from $65 \mu$ to $118 \mu$, least diameters from $42 \mu$ to $83 \mu$, usually $50 \mu$ by $70 \mu$ by $60 \mu$. (g) Strongylospherasters (fig. $10, P, Q$ ), $4 \mu$ to $15 \mu$ in diameter. (h) Oxyspherasters $6 \mu$ to $24 \mu$ in diameter. (i) Oxyeuasters $9 \mu$ to $35 \mu$ in diameter (fig. $10, R$ ). It might be much more accurate to say there are small asters of great variability, the ends of the spines varying from strongylote (rounded) to oxeote (sharp) but usually more rounded in the smaller and sharper in the larger. A centrum may be present varying from comparatively very large to absent, but most conspicuous in the smaller asters. The rays seem always to be spined, but the spines vary from almost invisible to very 
conspicuous. The whole range can be found within a single specimen, though not in every specimen.

Remarks.-In his work on the Geodidae, Lendenfeld (1910) described as new 11 species from the west coast of North America. The 10 specimens from California he placed in 5 new species. According to these standards, I would have needed two new species for my four specimens, continuing the average of a new species for each two specimens. This probably does not represent the true state of affairs. It is possible that we have here but one Geodia, exhibiting a considerable range of variability. Table 1 (p. 28) gives the spicule measurements of my four specimens and Lendenfeld's five species, based on his figures. Since each spicule goes through all intermediate sizes before attaining its maximum and since it may require a very long time in accomplishing this growth, many specimens might lack maximum sizes. I believe this table gives good grounds for merging all these into one species. Are there any grounds for splitting them into more than one?

In discussing mesotriaena, Lendenfeld emphasized the mesotriaenes. They are specified in his other four species. It seems that the frequence and development of this type of spicule do distinguish the California Geodias from those of, say, Asia or Europe. It is practically the only difference from some East Indian Geodias, but can not be used to separate our local forms into species.

Lendenfeld does not set forth differences between mesotriaena and agassizii, though his tables show the latter to have somewhat smaller mesotriaenes. The mesotriaenes typically protrude from the surface and may be broken off by animals crawling over the sponge, or by jostling in the dredge as it comes up. Furthermore, the longest ones are the most likely to be lost. The differences Lendenfeld shows are probably due to the fact that some specimens receive somewhat rougher treatment in collecting than the others.

G. mesotriaenella is based upon one specimen that had none of the larger sizes of spicules. In view of the probability that this is but a younger specimen (it was only 1.5 by $2 \mathrm{~cm}$ ), no species should be made for it.

G. breviana is established for a specimen that Lendenfeld says had anatriaenes with much shorter clads than the other specimens. His illustration shows no conspicuous difference in this respect, and the agreement of other characteristics leads one to beliere this was but a very slightly aberrant individual.

For ovis Lendenfeld emphasizes its very thick spicule fur and mentions its very small as well as very large anatriaenes. These smaller ones may be merely a new crop beginning to form. Practically all its other spicules, including many of the anatriaenes, are somewhat larger than in the others, and it has expanded laterally 
farther than any. It seems likely that this is but a more mature specimen than any of the others. There is one most interesting item in its description, however. Lendenfeld states the spicule fur was about $20 \mathrm{~mm}$ high. The very longest spicule he records is $23 \mathrm{~mm}$ long. Not only do his tabulated measurements show that most of the spicules involved were less than $20 \mathrm{~mm}$, but he specifically says (p. 163) that there are spicules lying in it freely. It is hardly conceivable that the nonattached spicules came from another sponge. We have here, then, proof of the shedding of spicules, and the great thickness of the fur in this specimen is due, in all probability, to good fortune in not having had the loose extra layers washed or shaken off.

Lambe in 1892 (p. 72) records a sponge from Vancouver Island as Cydonium mülleri Fleming. Lendenfeld says it is his breviana. Lambe in 1893 (p. 36) records another from Queen Charlotte Islands, about $3^{\circ}$ of latitude away, also as Cydonium mülleri. Lendenfeld says it is his agassizii. Lendenfeld is probably correct in separating Lambe's from Fleming's species, but Lambe was probably quite right as to the identity of the two with each other. In fact, Lendenfeld quotes the 1893 article in both respects and, but for a clew given by his page references, gives every indication that he is talking about the same sponge in both cases. (See Lendenfeld, 1910, pp. $113,155$.

TABLE 1.-Measurements of the spicules of California Geodias

\begin{tabular}{|c|c|c|c|c|c|c|c|c|c|}
\hline Spicule 1 & $\begin{array}{c}\text { meso- } \\
\text { triaena }\end{array}$ & $\begin{array}{l}\text { agas- } \\
\text { sizii }\end{array}$ & $\begin{array}{l}\text { meso- } \\
\text { triae- } \\
\text { nella }\end{array}$ & $\begin{array}{c}\text { brevi- } \\
\text { ana }\end{array}$ & ovis & $\begin{array}{l}\text { Speci- } \\
\text { men A }\end{array}$ & $\begin{array}{l}\text { Speci- } \\
\text { men B }\end{array}$ & $\begin{array}{l}\text { Speci- } \\
\text { men C }\end{array}$ & $\begin{array}{l}\text { Speci- } \\
\text { men D }\end{array}$ \\
\hline Endosomal diacts & $\stackrel{\mu}{\mu} \underset{50-105}{ }$ & $\stackrel{\mu}{60-112}$ & $\stackrel{\mu}{20-50}$ & $\stackrel{\mu}{30-88}$ & $\stackrel{\mu}{30-40}$ & $\stackrel{\mu}{\mu} \underset{27-148}{ }$ & $\stackrel{\mu}{26-65}$ & $\stackrel{\mu}{55-59}$ & $\stackrel{\mu}{\mu}-67$ \\
\hline Rhabds of plagiotriaenes.... & $85-120$ & $65-150$ & $75-120$ & $60-130$ & $74-100$ & $27-90$ & $52-70$ & $65-85$ & $40-104$ \\
\hline Rhabds of anatriaenes.... & $8-40$ & $10-50$ & $18-30$ & $25-40$ & $2-45$ & $13-16$ & $17-30$ & $16-30$ & $13-25$ \\
\hline Rhabds of mesotriaenes.. & $38-70$ & $7-40$ & $9-19$ & $15-32$ & $20-120$ & $25-33$ & $11-27$ & $13-48$ & $14-30$ \\
\hline Dermal diacts............... & $9-19$ & $5-12$ & 4-5 & $2-9$ & $8-13$ & $7-13$ & $4-12$ & $3-12$ & $7-9$ \\
\hline Length of sterraster... & $92-125$ & $82-118$ & $87-107$ & $84-105$ & $82-92$ & $72-87$ & $70-73$ & $65-85$ & $65-95$ \\
\hline Sterraster................ & $67-82$ & $58-89$ & $58-68$ & $55-77$ & $54-61$ & $48-78$ & $42-57$ & $45-52$ & $55-76$ \\
\hline Strongylospheraster..... & $6-14$ & 4-11 & $6-11$ & $6-12$ & $?$ & $8-15$ & $9-14$ & $14-15$ & $6-9$ \\
\hline Oxyspheraster & $19-32$ & $10-21$ & $20-21$ & $12-21$ & $11-24$ & $6-15$ & $12-15$ & $12-21$ & $6-20$ \\
\hline Oxyeuaster ............ & $19-54$ & $9-31$ & $17-26$ & $16-27$ & $20-35$ & $20-28$ & $?$ & $28-30$ & $20-30$ \\
\hline
\end{tabular}

1 Diameters, except where stated as "length."

\section{Genus GEODINELLA Lendenfeld}

GEODINELLa ROBUSTA Lendenfeld

Geodinella robusta var. megasterra LENDENFELD, 1910, p. 205.

Holotype.-U.S.N.M. No. 8389.

Type locality.-Albatross Station 2946, off southern California, 270 weters. 
Other records.-Lendenfeld describes as varieties of this species other specimens from Vancouver Island to southeastern Alaska.

Description (after Lendenfeld).-Massive, 10 by 16 by $43 \mathrm{~mm}$, dirty white. The surface was covered by a monaxonid sponge, but it shows indications of a spicule plush broken off. The efferent and afferent openings are chones. The cortex, largely sterraster armor, is about $1 \mathrm{~mm}$ thick. Spicules: $(a)$ Endosomal oxeas up to 0.04 to 0.08 by $2.5 \mathrm{~mm}$; (b) plagiomonaenes, rhabds 0.026 to 0.042 by 2.1 $\mathrm{mm}$; $(c)$ sterrasters, 0.88 by 0.18 to 0.13 by $0.237 \mathrm{~mm} ;(d)$ strongylospherasters 0.007 to $0.013 \mathrm{~mm}$; $(e)$ oxyspherasters to oxy (eu)asters, 0.009 to $0.038 \mathrm{~mm}$.

Remarks.-This form differs from the common California Geodias by lacking the mesotriaenes, which might well be due to accident in collection or misadventure to the growing sponge. It is significant that the specimen had been overgrown by another sponge. It also lacks anatriaenes. My observation is that their occurrence is very patchy; I found them in all my local specimens of Geodia, but while in one they were abundant, in another it required careful search to locate any. Its plagioclad spicules are never triaene, acrording to Lendenfeld, but usually monaene or at most diaene. These modifications are common in Geodias along with regular triaenes. Its sterrasters are, according to Lendenfeld's statistics, definitely of a larger size range than for Geodia mesotriaena. This, with the other more dubious differences, leads me to treat this provisionally as a separate species.

\section{Family STELLETTIDAE Sollas}

\section{Genus STELLETTA 0 . Schmidt}

STElletta Clarella de Laubenfels

Stelletta clarella DE LaUbenfels, 1930, p. 25.

Holotype-U.S.N.M. No. 21488; B. M. No. 29.8.22.27.

Type locality.-Pescadero Point, near Carmel, Calif., intertidal, July, 1925, my collecting. Many specimens were examined, as the species is abundant in the Monterey Bay Region. It is frequently found under overhanging ledges near low-tide mark and seems always confined to well-shaded locations.

Description.-Shape, massive to encrusting. Size, up to $7 \mathrm{~cm}$; thick, spreading laterally indefinitely; I have seen encrustations of this species over $40 \mathrm{~cm}$ in diameter. Consistency, spongy to cartilaginous. Color in life and when preserved, white; usually more or less dirty. Thin sections cut tangent to the surface show it to be packed with the cladomes of the dichotriaenes with the areas between uniformly closed over by flesh. The pores are abundant, $50 \mu$ to 
$100 \mu$ in diameter when open, and about $200 \mu$ from center to center over almost the entire surface. The oscules are chones, diameter about $500 \mu$ to $600 \mu$, with the sieve openings $100 \mu$ to $150 \mu$. Surface superficially very hispid. There is a dense spicule fur $3 \mathrm{~mm}$ high, composed of erect spicules. As is often true of tetraxon sponges, this spicule plush renders the sponge more dangerous to touch than a cactus plant; numerous spicules penetrate the skin and are removed only with much pain and difficulty.

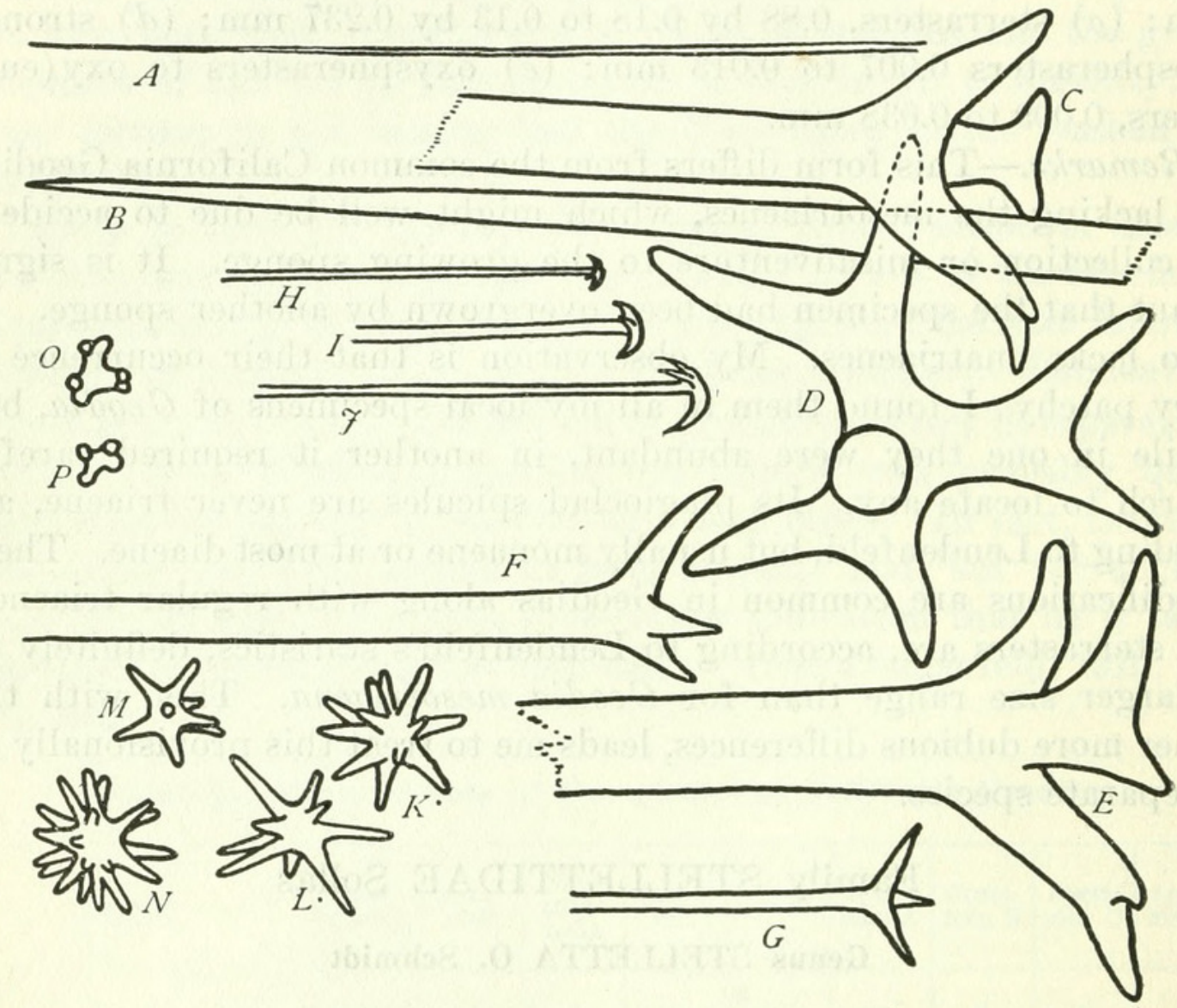

Figure 11. - Stelletta clarella de Laubenfels: $A$ to $G, \times 80$; others, $\times 1,333$. $A$, either end of the ectosomal oxea, or the esactinal termination of the anatriaene; $B$, either end of the endosomal oxea, or the esactinal termination of the plagio spicule; $C-G$, variations of the principal radiate spicule. Any of this spicule sort may be diaene instead of triaene in this species. The range from orthotriaenes through plagiotriaenes to dichotriaenes is a matter of age ; $H-J$, anatriaenes ; $K-N$, euasters ; $O, P$, siliceous structures

Ectosomal specialization, corticate, cartilaginous, about 1 to $2 \mathrm{~mm}$ thick. Endosomal structure, the smaller masses are strongly radiate in structure and even in the larger encrustations the structures within about $1 \mathrm{~cm}$ of the surface are strongly marked by fascicular columns of spicules perpendicular to the surface.

Principal spicules, oxeas (fig. $11, B$ ); size about $50 \mu$ by $3,500 \mu$. Ectosomal spicules, oxeas (fig. $11, A$ ) ; size about $15 \mu$ by $1,400 \mu$. Interstitial spicules, anatriaenes (fig. $11, H, I, J$ ) ; size of rhabds $9 \mu$ by $1,100 \mu$ to $15 \mu$ by $2,000 \mu$, chords $45 \mu$ to $90 \mu$. Chief radiate spicules 
orthotriaenes to plagietriaenes to dichotriaenes (fig. 11, $C$ ) ; size of rhabds, $20 \mu$ by $2,000 \mu$ to $100 \mu$ by $3,000 \mu$, chords $120 \mu$ to $180 \mu$. (See below for further details.) Microscleres, euasters (fig. 11, $K, L, M$, $N$ ) ; diameter, $9 \mu$ to $15 \mu$. Their rays vary from oxeote to strongylote, and from spiny to smooth; they are located throughout the sponge.

I find also small siliceous structures (fig. 11, $O, P$ ) in some parts of some specimens; these may be malformed microscleres, a second sort of microsclere, or (more probably) foreign inclusions.

Remarks.-The nearest relative of this form seems to be $S$. lendenfeldi Sollas, 1888, from Australia, which differs in having tylasters; these two and $S$. estrella are unique in the small size of the aquiferous apertures.

Related species of this genus are reported from all parts of the world.

\section{STELLETTA ESTRELLA de Laubenfels}

Stelletta estrella DE LAUbenfei.s, 1930, p. 26.

Holotype.-U.S.N.M. No. 21399; B.M. No. 29.9.30.10.

Type locality.-Southern California, collected by the University of Southern California, July 10, 1926. Exact locality not known.

Additional material examined.-I collected two specimens at Laguna Beach, intertidal. Two others were dredged by the University of Southern California-one September 26, 1925, near Long Beach, depth 28 meters, the other October 10, 1925, near San Pedro, depth 41 meters.

Description.-Shape, subspherical to massive. Size, up to $5 \mathrm{~cm}$ thick and at least $7 \mathrm{~cm}$ in diameter. Consistency, spongy to cartilaginous. Color in life and when preserved, white, often dirty. Oscules, inconspicuous, diameter about $1 \mathrm{~mm}$; they are merely scattered, simple holes. Pores, at least $130 \mu$ diameter, abundant, scattered. Surface, superficially very hirsute, often much covered by foreign material.

Ectosomal specialization, cortical, about $1 \mathrm{~mm}$ thick; it is cartilaginous, hyaline, dense, and contains a few asters and is traversed by megascleres. There is a spicule fur, 1 to $3 \mathrm{~mm}$ high, of erect spicules, mostly plagiotriaenes with their cladomes far out from the sponge surface. Endosomal structure, fundamentally radiate in plan, though this is obscured in the central portions of older specimens.

Principal spicules, oxeas (fig. $12, F, G, H$ ) ; size $45 \mu$ by $2,600 \mu$. to $100 \mu$ by $4,000 \mu$. Ectosomal spicules, plagiomonaenes, diaenes, or triaenes (fig. $12, A, B, C, D, E$ ); size of rhabds $9 \mu$ to $78 \mu$ by $4,000 \mu$, chords $35 \mu$ to $200 \mu$. The latter two sorts now and then have the dicho-modification; some of the larger ones are plagiomesotriaenes. 
First microscleres, oxyspheraster (fig. $12, K, L, M$ ); diameter $2 \frac{1}{2} \mu$ to $12 \mu$. Second microsclere, tylospheraster (fig. $12, I, J$ ); diameter, $10 \mu$ to $11 \mu$. These are rather uncommon.

Remarks.-This species is peculiar for the very large average size of its megascleres; not many other Stellettas have quite such enormous ones. S. clarella from central California has a few as large and, like S. estrella, has very inconspicuous vents, but the two are separated in many ways. The northern form has chiefly strongylote rayed asters; the southern form has few or none of that sort, but

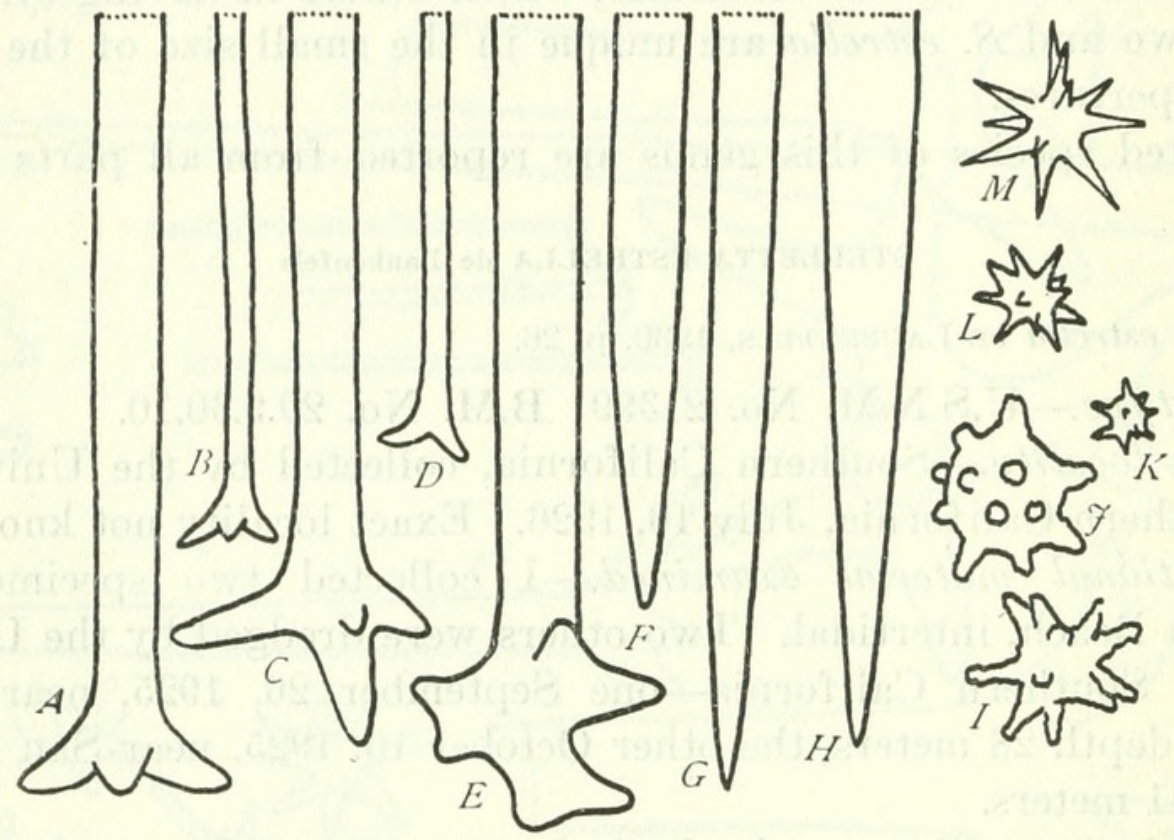

Figure 12.-Stelletta estrella de Laubenfels: Spicules $A$ to $H, \times 80$; others, $\times 1,333$. $A-E$, endosomal spicules; $F, G$, and $H$, variation in ends of the axeas and esactinal ends of the tetractinal megascleres; $I, J$, tylospherasters; $K-M$, oxyspherasters

instead has two distinct sorts, one with decidedly oxeote and the other with tylote rays. Two other features separate estrella not only from clarella but indeed from most other Stellettas; first, the peculiarly short clads typical of this species, and second, the lack of anatriaenes. That the clads of the plagiotriaenes project beyond the surface is also noteworthy.

\section{Family THENEIDAE Sollas \\ Genus POECILLASTRA Sollas}

POECILLASTRA RICKETTSI ${ }^{1}$ de Laubenfels

Poecillastra rickettsi de Laubenfels, 1930, p. 26.

Holotype.-U.S.N.M. No. 21482; B.M. No. 29.8.22.7.

Type locality.-Monterey Bay, Calif., 800 meters; collected by E. F. Ricketts, July, 1925. Notes on other specimens that he col-

${ }^{1}$ Named for E. F. Ricketts, of the Pacific Biological Laboratories, Pacific Grove, Calif. 
lected from the same general locality and depth, in May, 1929, are given under Remarks below.

Description.-Shape, various (see discussion below). Size, up to $2 \mathrm{~cm}$ thick, $20 \mathrm{~cm}$ in diameter. Consistency, fragile, friable. Color in life and when preserved, pale drab. Oscules, skeletal openings, 1 to $2 \mathrm{~mm}$ in diameter, and about 2 to 10 to the square centimeter. They are covered with a fenestrated membrane packed with asters, having roundish apertures about $0.4 \mathrm{~mm}$ in diameter. They open from subdermal spaces upwards of $1.2 \mathrm{~mm}$ in depth into which open numerous afferent pores usually 0.2 to $0.7 \mathrm{~mm}$ in diameter. Pores, skeletal openings, about $1 \mathrm{~mm}$ in diameter, covered with a fenestrated membrane having apertures 0.1 to $0.2 \mathrm{~mm}$ in diameter. The skeletal pores and oscules are roughly outlined (surrounded) by the cladomes of the ectosomal tetraxons. Surface, superficially smooth, with scattered projecting spicules a few millimeters high.

Ectosomal specialization: A dermal membrane about $40 \mu$ thick, very fragile and delicate; it contains abundant asters. Endosomal structure "crumb-of-bread," with fascicular tracts of oxeas, others scattered, and abundant scattered calthrops. Many calthrops have three of their rays directly beneath the dermis and parallel to it. Principal tracts (found only running lengthwise of lamellate forms), $100 \mu$ to $200 \mu$ in diameter.

Principal spicules, calthrops (fig. $13, A, B, C$ ) ; size of rays, $50 \mu$ by $450 \mu$ to $70 \mu$ by $650 \mu$. Interstitial spicules, oxeas, sometimes styles (fig. $13, D, E, F$ ) ; size, about $65 \mu$ by $3,700 \mu$. Coronal spicules, oxeas (not figured) ; size, $15 \mu$ to $30 \mu$ by $17,000 \mu$. First microscleres, abundant plesiasters (fig. $13, J, K$ ); size of rays, about $6 \mu$ to $8 \mu$ long, greatest diameter $14 \mu$ to $18 \mu$. Some have so few rays that they are microcalthrops. Second microscleres, rare spirasters or metasters (fig. $13, L, M, N$ ) ; length, $10 \mu$ to $13 \mu$; rays about $3 \mu$ long. Third microscleres, toxas (fig. 13, I) ; length, about $80 \mu$; located throughout the sponge. These toxas are, of course, quite probably foreign, yet they are found in every part of the holotype that I have examined. One can hardly believe them proper, yet their occurrence deserves mention. Fourth microscleres, microxeas, $4 \mu$ by $170 \mu$ to $5 \mu$ by $270 \mu$ (fig. 13, $G, H$ ). As many Poecillastras have spined microxea, I made an especial examination of these. With very high magnification (more than 1,000 diameters), the surface of these spicules was seen to very minutely roughened. As such roughening might be detected on almost any spicule by sufficient magnification, it is questionable how much taxonomic value it has. These spicules are rather evenly distributed throughout the sponge.

Remarks.-The holotype is of the usual form of Poecillastra, with spiculation not greatly differing from $P$. compressa, $P$. schultzei, and $107704-32-3$ 
P. Zaminaris. This shape is found, however, mainly in the largest fragments, some $10 \mathrm{~cm}$ in diameter, which seem to have been part of a large platelike growth about $20 \mathrm{~cm}$ high; its oscular surface covers most of the concave side. On the small fragments such oscular fields as the following are observed: Oval, 1 by $2 \mathrm{~cm}$ and depressed $1 \mathrm{~cm}$; hourglass shaped, each oval 1 by $2.5 \mathrm{~cm}$ and depressed $1 \mathrm{~cm}$; oval, 1 by $3.5 \mathrm{~cm}$ and depressed $1 \mathrm{~cm}$; triangular, 1 by $1.5 \mathrm{~cm}$ and depressed only about $3 \mathrm{~mm}$. It must be stressed that each oscular area was surrounded by a dense coronal palisade of very long spicules, usually very close to $17 \mathrm{~mm}$ in length except in the smaller specimens. The function of these seems to be separation of exhalent current from inhalent.

On May 1, 1929, Mr. Ricketts brought up a macerated hexactinellid dictyonine skeleton from very much the same depth and locality as of the type. On it were about a dozen sponges that I iden-
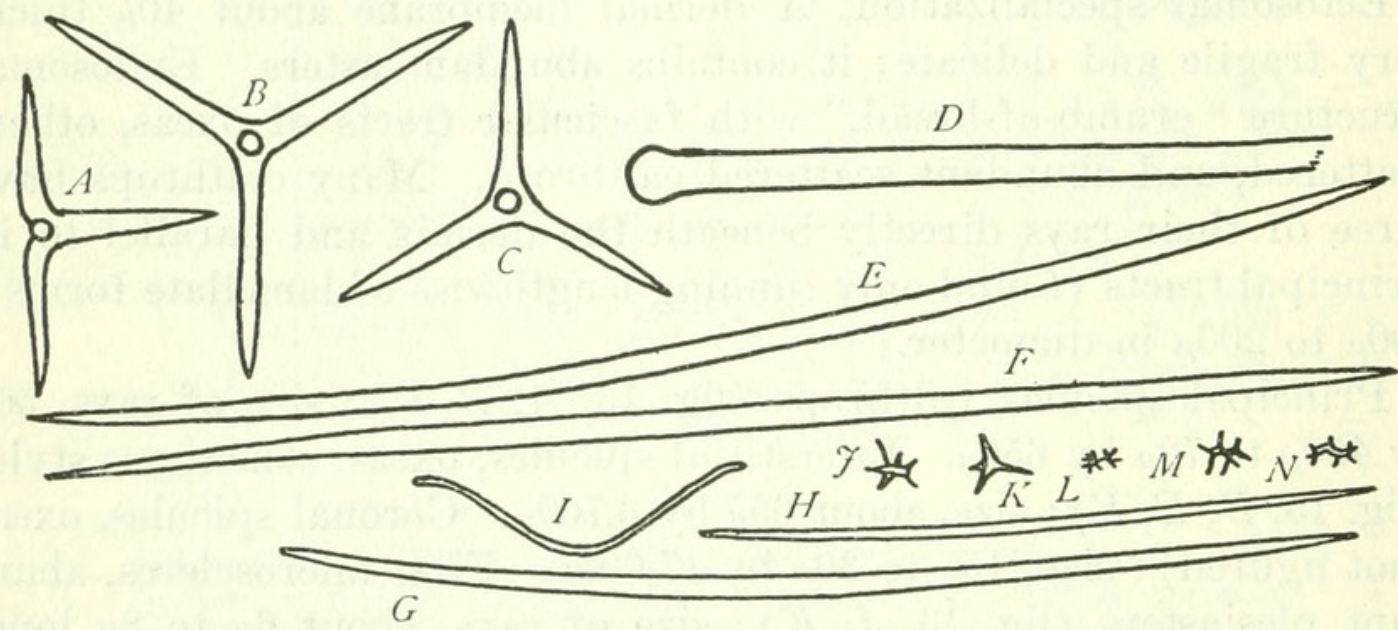

Figure 13.-Poecillastra rickettsi de Laubenfels: A to $F, \times 14$; others $\times 300$

tify as conspecific here. These are rough cylinders, the largest about $1.5 \mathrm{~cm}$ high and $2 \mathrm{~cm}$ in diameter, the smallest $1 \mathrm{~cm}$ high and $3 \mathrm{~mm}$ in diameter. The spiculation is the same, except that I do not find the toxas in them. The oscular areas with covering fenestrated membrane, the convex pore surfaces, and the dense coronal palisades are all the same. The inference is that this species grows to a height of about $1 \mathrm{~cm}$ before expanding laterally very much, but that afterwards its growth is almost exclusively horizontal.

Do all Poecillastras have such a change of form during their life history? It is to be noted that many of the specimens might fairly be classed as Sphinctrella, except that they lack the annulation so characteristic of the spicules of those certainly Sphinctrella.

Were the toxas proper, they would be a most striking feature. As it is, the enormous oscular crowns distinguish this species from all others of the genus. P. laminaris Sollas (1886, p. 186) from the East Indies is probably the closest, as it had a low $(4.5 \mathrm{~mm})$ fringe around its oscular areas. 
Normania tenuilaminaris Sollas, 1886, p. 186.

Poecillastra tenuilaminaris Sollas, 1888, p. 85.

Holotype.-B.M. No. 89.1.1.31.

Type locality.-Japan.

Material examined.-The specimen described below (U.S.N.M. No. 21400 ; B.M. No. 29.9.30.9) was trawled by the University of Southern California, June 23, 1916, west of Santa Catalina Island, Calif., depth not given.

Description.-Shape, lamellate. Size, 9 to $13 \mathrm{~mm}$ thick and about $10 \mathrm{~cm}$ high. Consistency, stiflly fragile. Color in alcohol, drab. Oscules, scattered, on one face only; diameter about $0.9 \mathrm{~mm}$; distance apart, less than $1 \mathrm{~cm}$. Pores, small and scattered, principally or only on the nonoscular face. Surface, superficially smooth.

Ectosomal specialization, not evident. Endosomal structure, a confused mass of calthrops and oxeas.

Principal spicules, calthrops (fig. 14, $C, D$,

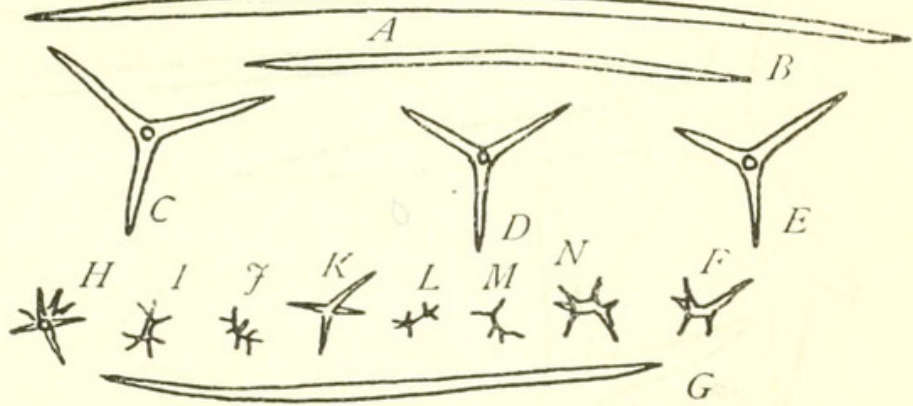

Figure 14.-Poecillastra tenuilaminaris (Sollas) : $A-E$, megascleres, $\times 14$; lower spicules are the microscleres, $\times 300$. A row of typical asters is shown to iliustrate the range of variation from plesiasters almost to spirasters

$E$ ) ; size of rays, about $40 \mu$ by $350 \mu$. Interstitial spicules, exeas (fig. $14, A, B)$; size $35 \mu$ by $1,350 \mu$ to $45 \mu$ by $2,500 \mu$. First microscleres, plesiasters (fig. 14, $F$ ) ; length, $20 \mu$ to $28 \mu$. Second microscleres, metasters (fig. 14, L); length, $14 \mu$ to $16 \mu$. Third microscleres, microxeas (fig. $14, G$ ) ; size, about $3 \mu$ by $135 \mu$.

Remarks.- This genus is regarded by various authors, for instance, Dendy, as synonymous with Pachastrella, but I hold with Wilson (1925) in retaining Poecillastra. Many of the species referred to the latter are probably conspecific with tenuilaminaris, but, pending a revision of the genus, I make no decisions in this regard but would comment that following such revision it may devolve that some other specific name has priority.

\section{Genus PENARES J. E. Gray \\ PENARES CORTIUS de Laubenfels}

Penares cortius de Ladbenfels, 1930, p. 26.

Holotype.-U.S.N.M. No. 21479; B.M. No. 29.8.22.47.

Type locality.-Collected by me at Pescadero Point near Carmel, Calif., intertidal, July, 1925. 
Additional material examined.-On April 15, 1929, E. F. Ricketts dredged this species in shallow water in Monterey Bay. I collected a third specimen on Monterey Peninsula, intertidal, in the summer of 1930 ; all three are very similar to one another.

Description.-Shape, massive. Size, $4 \mathrm{~cm}$ thick, $10 \mathrm{~cm}$ in diameter. Consistency, mediocre; the ectosome is tough and leathery. Color in life and when preserved, drab, except that in life the ectosome in places is very dark brown, paling after death. Oscules, oval, size about 1 by $2.5 \mathrm{~mm}$; there is one for about every 5 square centimeters.

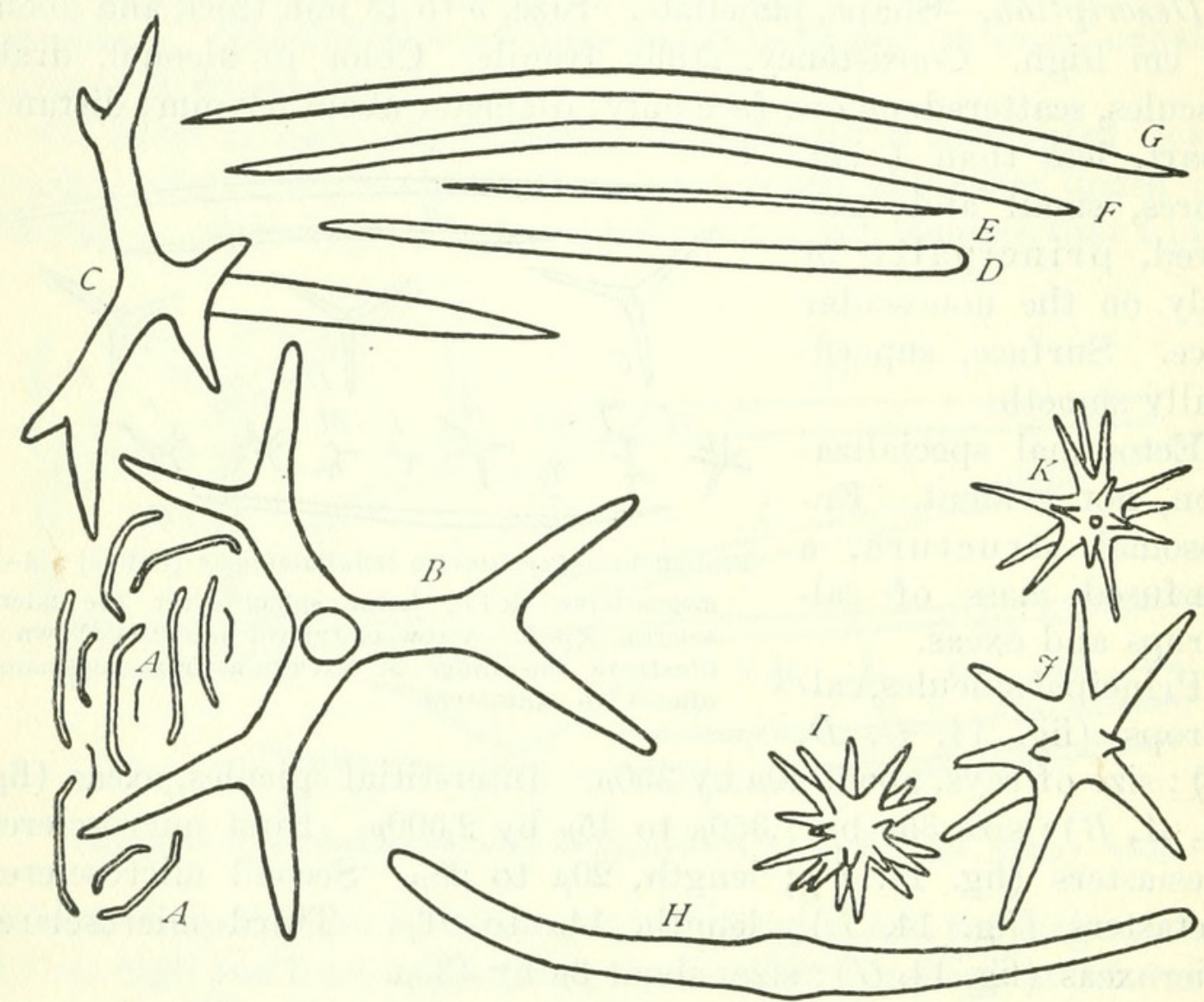

Figure 15.-Penares cortius de Laubenfels: $A-G, \times 80$; others, $\times 1,333$. $A-A$, range in size of the peculiar microsclere, to the same scale as the megascleres; $H$, unusual shape of the same spicules, with the centrotylote modification; $B, C$, dichotriaenes; $D, E$, unusual shape and size for the principal spicules; $F, G$, oxeas ; $I-K$, oxyspherasters

They are often on low prominences about $3 \mathrm{~mm}$ high and $10 \mathrm{~mm}$ in diameter. Pores, at least $65 \mu$ in diameter; spaced about $250 \mu$ from center to center. Surface, superficially smooth to minutely punctiform.

Ectosomal structure, a densely felted mass of the bicurvates, containing also the cladomes of the dichotriaenes; thickness about $200 \mu$. This is very easily detachable. Endosomal structure "crumb-ofbread," with evident spicules (diactines) mostly in confusion, but with traces of tracts. Principal, or ascending, tracts, $170 \mu$ to $230 \mu$ in diameter, fascicular, few and scattered. 
Principle spicules, oxeas (fig. $15, F, G$ ) ; size, ranging up to $22 \mu$ by $950 \mu$. Ectosomal spicules, dichotriaenes (fig. 15, $B, C$ ); size of rhabds, about $50 \mu$ by $400 \mu$; size of clads, including the deuteroclads, up to $50 \mu$ by $310 \mu$. First microscleres, bicurvate microstrongyles (fig. $15, A)$; size $3 \mu$ by $50 \mu$ to $8 \mu$ by $160 \mu$; a very few of the smallest ones are faintly centrotylote. Second microscleres, oxyspherasters (fig. $15, I, J, K)$; total diameter, $9 \mu$ to $25 \mu$, the smaller ones having the more numerous rays.

Remarks.-This species is very sharply set off by the peculiar bicurvates. $P$. tyloaster Dendy, 1924, from New Zealand occasionally has its dermal microscleres twice bent but they are oxea, not strongyles, and the bicurvate form is rare; moreover the asters are tylasters in that species. For further notes see the remarks under Papymula saccharis.

\section{Genus PAPYRULA O. Schmidt}

\section{PAPYRULA SACCHARIS de Laubenfels}

Papyrula saccharis de LAUbenfels, 1930, p. 26.

Holotype--U.S.N.M. No. 21476; B.M. No. 29.8.22.5.

Type locality.-Collected by me, at Point Pinos, Pacific Grove, Calif., June 29, 1926. Found together with two smaller specimens, lying loose under stones near low-tide mark.

Description.-Shape, massive, rounded. Size, up to 1.5 by 1.5 by $3.5 \mathrm{~cm}$. Consistency, cartilaginous. Color in life and when preserved, white. Oscules, round, with depressed, rounded edges, diameter about $200 \mu$. Pores, of various sizes; some are $65 \mu$ to $150 \mu$ and perhaps larger. Many openings can not be identified as to whether they are pores or oscules. Surface, superficially smooth.

Ectosomal specialization, a densely felted mass of microxeas, containing also the cladomes of the dichotriaenes; thickness about $100 \mu$. This is not easily detachable. Endosomal structure, "crumb-ofbread," with spicules not very evident; there is much solid matter as compared to cavity. Histological details: The flagellate chambers are spherical, about $30 \mu$ in diameter. There are very definite radiating fascicular tracts of diactines; total tract diameter, about $100 \mu$.

Principal spicules, oxeas (fig. 16, E, $F, G$ ) ; size ranging up to $22 \mu$ by $780 \mu$; some are modified as styles. Ectosomal spicules, dichotriaenes (fig. $16, B, C, D$ ) ; size of clads, $10 \mu$ by $120 \mu$ to $30 \mu$ by $210 \mu$, size of rhabds, $20 \mu$ by $320 \mu$ to $30 \mu$ by $435 \mu$. Microscleres, microxeas (fig. $16, A$ ) ; size, $1 \mu$ by $35 \mu$ to $3 \mu$ by $145 \mu$; a very few are microstrongyles and some are bent once or twice; very rarely they are centrotylote. 
Remarks.-This species clearly fits Papyrula, which differs from Penares only in the lack of the astrose microscleres. Three species previously described may be recognized as belonging here: Papyrula candidata $\mathrm{O}$. Schmidt, 1868, from the Mediterranean; $P$. hilgendorf Thiele, 1898, from Japan; and $P$. sphaera Lendenfeld, 1907, from south of the Cape of Good Hope. Add P. saccharis and one has four species whose descriptions permit of no sharp contrasts. I do not believe them synonymous, however; rather I should hazard a guess that all four are juveniles of other species, probably belonging to Penares, and in this case Papyrula Schmidt, 1868, would fall as

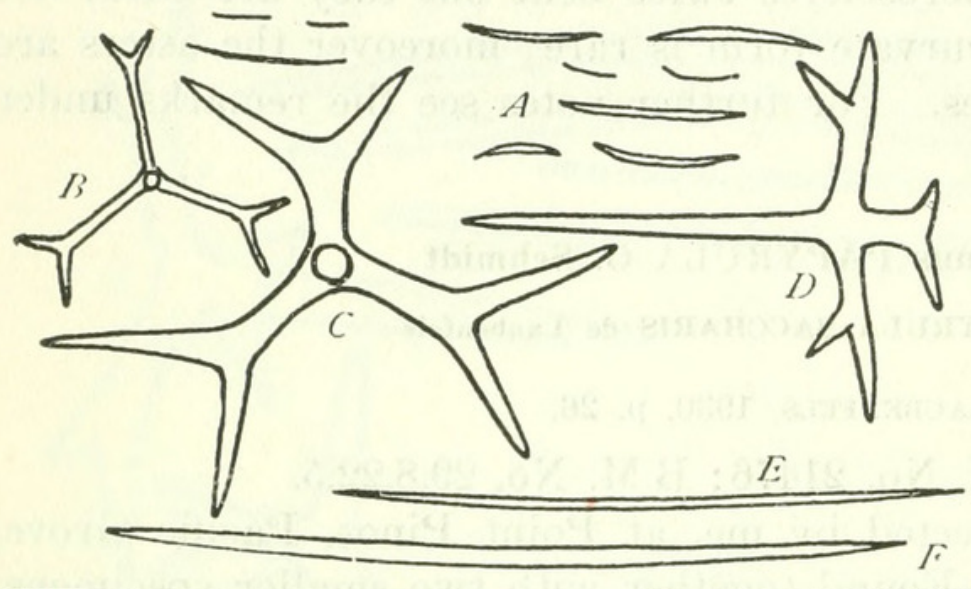

Figure 16.-Papyrula saccharis de Laubenfels, $\times 80$. Microscleres (microxeas) clustered about $A ; B-D$, dichotriaenes ; $E-G$, oxeas synonym of Penares Gray, 1867. For the present I hold with Wilson (1925,p.286) in retaining Papymula provisionally. As for the possibility (which I wish to stress) that saccharis may prove to be a synonym of Penares cortius, I shall make the following comparisons: They differ greatly in color; noticeably but probably not fundamentally, in surface structure; and further in spiculation. $P$. saccharis lacks the asters, has only rare tetraxon spicules, lacks the twice-bent modification of the microdiactine, and has it oxeote rather than strongylote. On the other hand, in view of the closeness in geographical location, one must stress the great similarity of the megascleres of the two species, the general agreement in cortical structure, and the known fact that certain microscleres may be missing at times although quite characteristic of a species.

\section{Genus DERCITUS J. E. Gray}

\section{DERCITUS SYRMATITUS de Laubenfels}

Dercitus syrmatitus DE LAUBENFELs, 1930, p. 26.

Holotype.-U.S.N.M. No. 21438; B.M. No. 29.8.22.20.

Type locality.-Laguna Beach, Calif., March 26, 1929, intertidal. Collected by me, one specimen or group of specimens. Habitat is given more in detail under description of endosomal structure.

Description.-Shape, amorphous. Size, see notes below. Consistency, mediocre. Color in life and when preserved, drab. Oscules and pores, not evident. Surface, superficially smooth. 
Ectosomal specialization (?). Endosomal structures: What was collected was a mass of sand held together by some slimy material having an odor like that of a keratose sponge, the only reason for suspecting sponge nature. Microscopic study indicates there really may be keratose sponge present, but not in condition to be described. Here and there in between the masses of sand grains are little areas, about 0.2 to $2 \mathrm{~mm}$ in greatest diameter, and very amorphous in outline, that are packed with calthrops and myriads of discasterlike microscleres. No further details can be made out.

Principal spicules, calthrops (fig. $17, B, C, D$ ); size of rays, $3 \mu$ by $25 \mu$ to $10 \mu$ by $80 \mu$; one ray may be missing, leaving triods. The rays are commonly $8 \mu$ by $65 \mu$, but one or two are commonly longer than the others. Microscleres, very abundant, discasters (?) or sani-

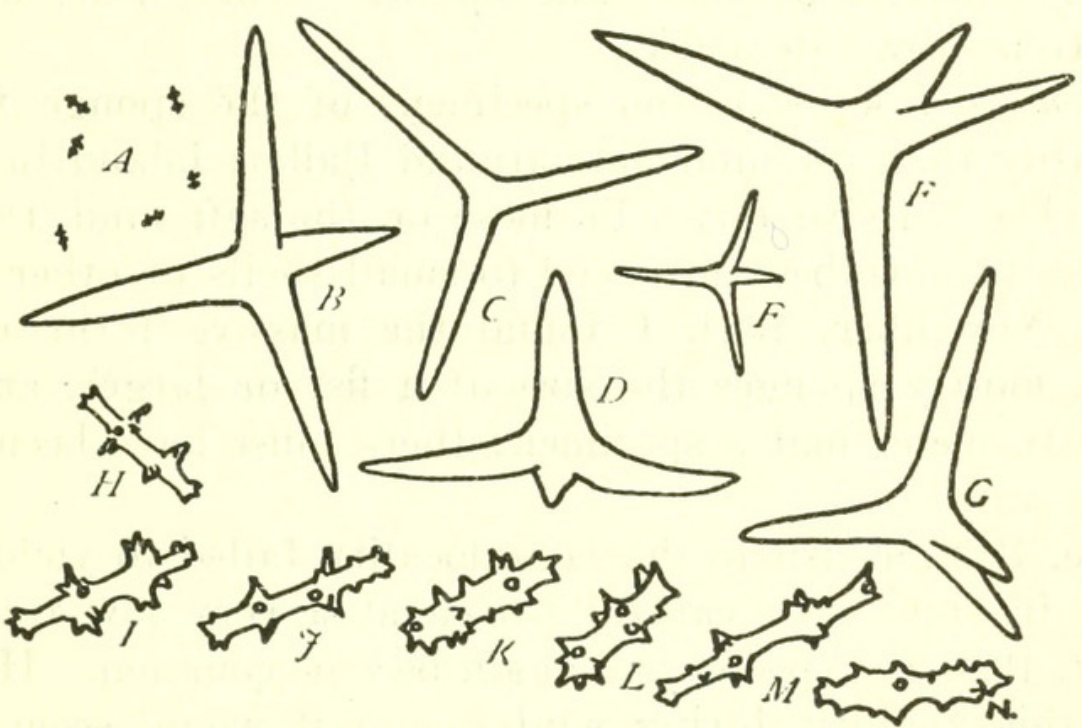

FigURe 17.-Dercitus syrmatitus de Laubenfels: $A-G, \times 300$; $H, \times 1,333 ; I-N, \times 1,500$

dasters (fig. $17, H-N$ ) ; length, $8 \mu$ to $12 \mu$. Some are so irregularly spiny as to resemble acanthomicrostrongyles, but most have two decided nodes, and many resemble the spicule type termed by Dendy (1921, p. 121) as discorhabd.

Remarks.-The previously described species of Dercitus are often regarded as all synonymous with the genotype, Dercitus bucklandi McAndrew-Bowerbank, 1861 (about p. 235). ${ }^{2}$ Its microscleres are about three times as long as those of syrmatitus and lack the nodal arrangement that makes those of the latter become discasters. Its megascleres include oxeas, and its calthrops have ray dimensions nearly four times those of syrmatitus, so that their mass must be 50 times as great. In fact, the California species seems to show close

2 The name bucklandi, first used (loc. cit.) as Halina bucklandi, may there be a nomen nudem, in which case the name should date from its use by Bowerbank, 1866, p. 226, as Hymeniacidon bucklandi. Dercitus was erected for it by Gray, 1867, p. 542. For the synonymization referred to, see Topsent, 1894 . 
relationship to the Homosclerophora. Toxas were found in bucklandi, and I can report a few in syrmatitus, but I consider them in both cases foreign inclusions, as were certainly three chelas of two different sorts, five sigmas, and some broken tylostyles that were in syrmatitus.

\section{Family TETILLIDAE Sollas}

\section{Genus TETILLA O. Schmidt}

TETILLA MUTABILIS de Laubenfels

Tetilla mutabilis de LAUbenfels, 1930, p. 26.

Holotype.-U.S.N.M. No. 21498; B.M. No. 29.8.22.33.

Type locality.-Newport Harbor, near San Pedro, Calif., November, 1924, collected by me. The species occurs near, often just below, extreme low-tide mark.

Occurrence.-I know of no specimens of the sponge from any other locality than the mud flats around Balboa Island in Newport Harbor. The massive forms lie loose on the soft mud, the clavate forms seem to have been attached to small shells or other solid objects. In November, 1924, I found the massive form amazingly abundant, mostly sponges the size of a fist or larger, and nearly every square meter had a specimen; there must have been literally bushels in sight.

In June, 1926, a visit to the same locality failed to yield a single specimen, in spite of a careful search at a very low tide, but in November, 1926, the species had again become common. Hard rains occur in this vicinity during winter, and it would seem probable that the great influx of fresh water, which then, but only then, runs into this harbor, would greatly lower the salt content over these flats. A rain at low tide would drench the sponges then exposed.

Description.-Shape, peduneulate-clavate to irregularly massive. Size, up to $8 \mathrm{~cm}$ high and $15 \mathrm{~cm}$ in diameter. Consistency, moderately spongy to cartilaginous. Color in life, dull red with greenish glints (due to algae ?) ; dry, gray; in alcohol, dull red. Oscules, oval, flush, about $2 \mathrm{~mm}$ in diameter; usually several centimeters apart. Pores, well under $100 \mu$ in diameter, very difficult to find. Surface, superficially hirsute with repent, exceedingly thin spicules matted or felted together.

Ectosomal specialization, not evident, other than that mentioned above. Endosomal structure :

I. Structure of clavate form. My largest specimen of this form was $22 \mathrm{~mm}$ high and $12 \mathrm{~mm}$ in diameter. Those of this form are typically much smaller than that. There is a central axis about $500 \mu$ thick, through stem and body, consisting of densely packed 
spicules with little protoplasm. In the body this is surrounded by gross chambers 1 to $2 \mathrm{~mm}$ in cross section diameter, and much longer in the direction of the axis of the sponge. In one specimen at least there are just four of these, very symmetrically arranged. The outer wall around the above described structure is about $1 \mathrm{~mm}$ thick, and like the partitions is packed with felted, interlaced spicules in confusion. The surface, as mentioned above, is thickly studded with protriaenes, clads outward, arranged to a certain extent in brushes but not erect. One may presume the inhalent openings lie between these tufts. The oscule is often apical in this form. Several sponges of this form were collected by the University of Southern California on November 28, 1914 (U.S.N.M. No. 21389) and by myself (the specimens unfortunately were lost) in the autumn of 1923. On both these occasions the massive form was present in greater abundance than the clavate.

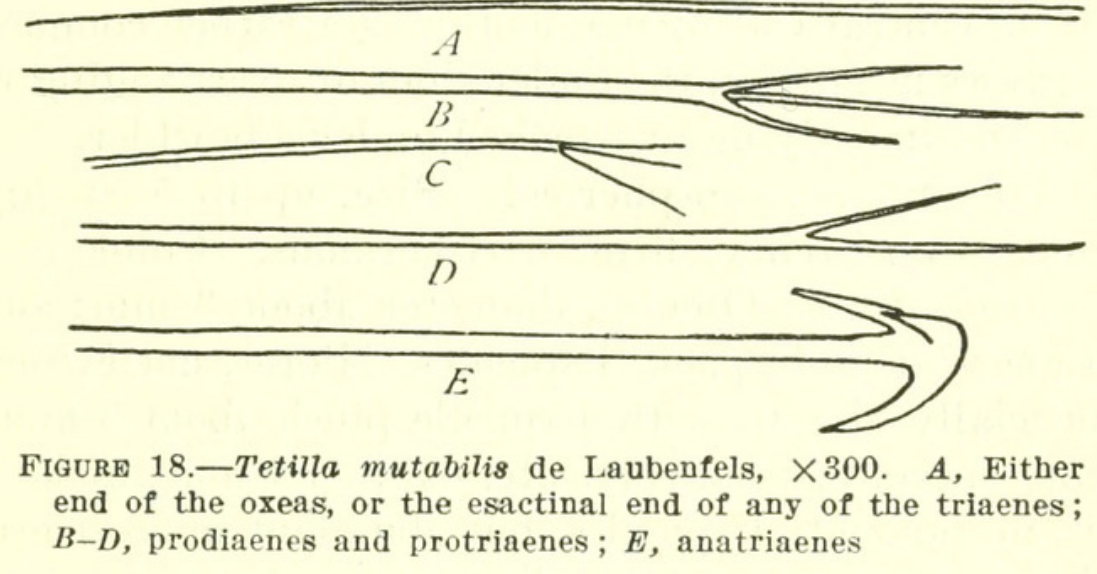

II. Structure of the massive form: Unlike most Tetillas there is no central or radiate skeleton, instead the spicules are matted together in sheets or walls around gross chambers. The surface, as mentioned above, is crowded with brushes of spicules, usually lying almost flat and practically never erect.

Ectosomal spicules, prodiaenes and protriaenes (fig. 18, $B, C, D$ ); rhabd diameter, $1 \mu$ to $6 \mu$; clad length, $30 \mu$ to $90 \mu$; chords, $20 \mu$ to $40 \mu$. Endosomal spicules, filiform oxeas (fig. $18, A$ ); size $2 \mu$ by (?) $\mu$ to $9 \mu$ by $2,000 \mu$. Auxiliary spicules, anatriaenes (fig. 18, $E$ ); rhabd diameter, $3 \mu$ to $7 \mu$; clad length, $20 \mu$ to $30 \mu$; chords, $30 \mu$ to $40 \mu$; rare and location in sponge not certain.

For all the above spicules, it will be noted there are few data as to total lengths. This follows from the fact that in spite of utmost care, it seems impossible to mount total spicules for this species. They are not only exceedingly thin, long, and brittle, but also are so interlaced that in disengaging any they are inevitably broken. I should estimate that they were frequently over a centimeter long and perhaps 2 or $3 \mathrm{~cm}$. 
Remarks.-The lack of spicules thicker than $9 \mu$ is one of the most distinctive features about mutabilis, the great rarity of the anatriaenes perhaps even more so. The most of the species of this genus have strongly radiate architecture, sigmoid microscleres, and papillate surface.

Although it is found concurrently with the massive form, I incline to believe the clavate form the juvenile of the massive. It is strongly suggestive of Tetilla radiata Selenka (1879, p. 467), from Rio de Janeiro, which also lacked microscleres, and is probably its closest relative.

\section{TETILLA ARB de Laubenfels}

Tetilla arb DE LAUBENFELS, 1930 , p. 36.

Holotype-U.S.N.M. No. 21496 ; B.M. No. 29.8.22.44.

Type locality.-Pescadero Point near Carmel, Calif., July, 1925, intertidal, collected by the author. Numerous specimens were examined, all from central California, as this is a rather common species there. It grows usually on the under sides of overhanging rocks, but I found one specimen lying unattached under a bowlder.

Description.-Shape, subspherical. Size, up to $5 \mathrm{~cm}$ high, $8 \mathrm{~cm}$ in diameter. Consistency, firm, cartilaginous. Color in life and when preserved, drab. Oscules, diameter about $3 \mathrm{~mm}$; surrounded by a palisade of densely packed spicules. Pores, not evident. Surface, superficially hirsute, with a spicule plush about $3 \mathrm{~mm}$ high.

Ectosomal specialization, corticate, 0.5 to $1.4 \mathrm{~mm}$ thick. I see no fibers in it, no tangential spicules, but abundant microscleres. Most of the spicules that project beyond it seem to be protriaenes. They might be considered as chiefly cortical. The outer portions of the cortex contain many cells with conspicuous dark granules. Endosomal structure, cartilaginous, crowded with radially arranged spicules. The axial region is almost solid spicule. Histological details: As is common, the cells proper are well under $15 \mu$ in size. There are present, scattered in the flesh of at least one of the specimens of Tetilla arb, large bodies about $60 \mu$ by $100 \mu$ in cross section, resembling cells. These may be large ova or small embryos.

First spicules, filiform oxeas (fig. $19, B, C$ ); size $9 \mu$ to $50 \mu$ in diameter; length certainly several millimeters, probably 2 or $3 \mathrm{~cm}$. Second spicules, anatriaenes (fig. $19, D, E$ ) ; chords, $50 \mu$ to $90 \mu$; rhabds, usually but $6 \mu$ to $12 \mu$ in diameter; length, probably more than $10 \mathrm{~mm}$. Their cladomes usually lie just below the surface. Third spicules, protriaenes (fig. $19, F, G, H, I$ ) ; chords, $8 \mu$ to $30 \mu$ rhabd diameter, $2 \mu$ to $12 \mu$; length up to at least $32.4 \mathrm{~mm}$ as based on one of which I was able to make accurate measurement. In the sponge they are so densely packed it is difficult to say where one begins and another ends; disengaged they are usually broken. 
Maximum lengths are probably more than $5 \mathrm{~cm}$. Many of the spicules seem to reach from the center of the sponge to a point several millimeters past the surface of the sponge, from which circumstance one is led to conclude that they may continue growth as the sponge enlarges, and that this increment must be added only at the deeply embedded end. Microscleres, spiny sigmas (fig. 19, A, $J-O)$; length, $7 \mu$ to $9 \mu$, located throughout the sponge. Only with oil immersion can they be seen to be microspined. One end is often slightly tylote; sometimes both ends are. This spicule need only have somewhat large spines to become a spiraster.

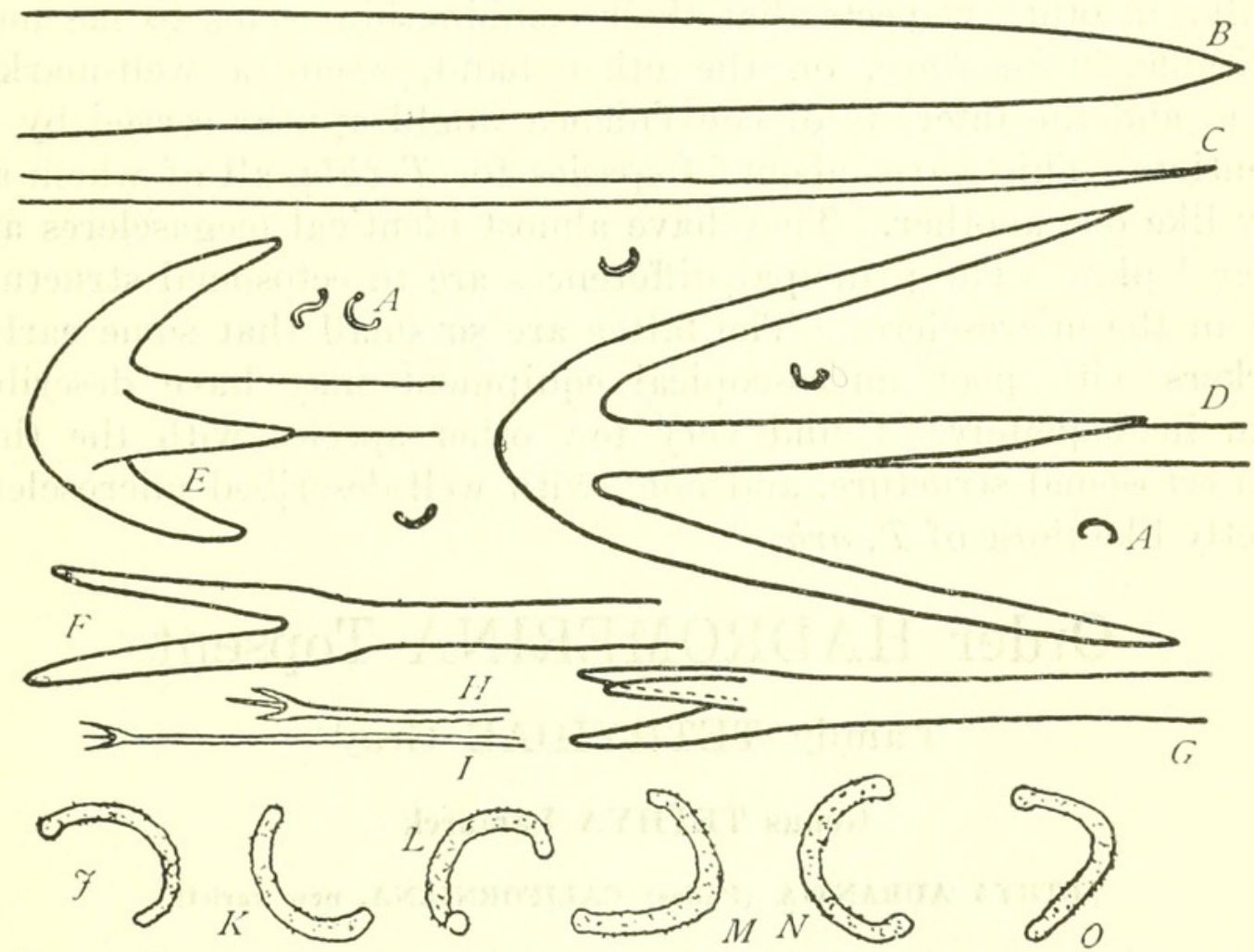

Figure 19.-Tetilla arb de Laubenfels: $A-I, \times 300$; others, $\times 1,333 . C$, termination of the more slender sort of oxea, and of the esactinal ends of the triaenes

Remarks.-Lambe (1893, pp. 34, 35), records two Tetillas from the vicinity of Vancouver Island, but neither seems at all close to the California species. Both the Canadian forms had the special dermal oxea for which certain recent authorities (see George and Wilson, 1921) would retain Craniella; their placement and size of spicules are also consistently different. For example, T. spinosa, the one of more southerly distribution of the two, has its megascleres in a whorled or spiral placement, and microscleres half again as long as in T. arb. For both of Lambe's species he mentions no spines on the microscleres, nor the tylote endings, but his figure for $T$. spinosa seems to show such. Both his species have conspicuously villous or conulose surfaces, strikingly absent in the California forms.

I agree with all recent writers in merging Tethyopsilla with Tetilla, from which it differed only in lack of microscleres. It is 
very evident that microscleres are easily lost. I also merge $C$ raniella, because of the difficulty of being sure whether one has a special type of oxea in the ectosome. Lambe seems confident his species are so supplied. There may be such in the California forms, but in such small numbers that they are overlooked; further, rather smaller oxeas do occur in the interior of the sponge most certainly; and still further, all the Tetilla megascleres are so easily broken that the whole problem of identification of special categories is most difficult. From many published descriptions one can not be sure that each Tetilla is not perhaps a Craniella. The two groups are so similar in other respects that their combination seems to me most advisable. Cinachyra, on the other hand, seems a well-marked genus, and the interests of convenience would appear served by its retention. This leaves about 71 species for Tetilla, all of which are very like one another. They have almost identical megascleres and general plan. The principal differences are in ectosomal structure, and in the microscleres. The latter are so small that some earlier workers with poor microscopical equipment may have described them inadequately. I find very few other species with the thin, even ectosomal structure, and none with well-described microscleres exactly like those of $T$. arb.

\title{
Order HADROMERINA Topsent
}

\author{
Family TETHYIDAE Gray
}

\section{Genus TETHYA Lamarck}

\section{TETHYA AURANTIA (Pallas) CALIFORNIANA, new variety}

\section{Holotype.-U.S.N.M. No. 21495; B.M. No. 29.8.22.15.}

Type locality.-Pescadero Point, near Carmel, Calif., July 25, 1926 , intertidal, collected by the author. Numerous other specimens were examined, especially in the collections dredged by the University of Southern California (U.S.N.M. Nos. 21390, 21411, and 21415), from shallow water in southern California. There is frequently a dense coating of diatoms and green algae over the surface of this variety.

Description.-Shape, hemispherical to ovate-stipitate. Size, up to $5 \mathrm{~cm}$ high, $3 \mathrm{~cm}$ in diameter. Consistency, moderately spongy. Color in life, yellow; preserved, it is drab. Oscules, not evident. Pores, not evident. Surface, superficially warty with mushroomshaped elevations about $2 \mathrm{~mm}$ high, crowded over the upper portion.

Ectosomal specialization, cortical, about $1 \mathrm{~mm}$ thick. Endosomal structure, fleshy, permeated by radiate fascicular tracts. Principal, or ascending, tracts $250 \mu$ to $800 \mu$ in diameter, packed with spicules, the more pointed end usually toward the surface. 
Principal spicules, fusiform strongyles (fig. 20, A) ; size, $6 \mu$ by $500 \mu$ to $40 \mu$ by $3,000 \mu$. Secondary spicules, tylostrongyles (not figured); size, about $30 \mu$ by $1,300 \mu$. First microscleres, spherasters (fig. $20, B, D, E, F$ ) ; diameter, up to at least $66 \mu$. Second microscleres, tylasters (fig. $20, C, H, I, J)$; diameter, up to at least $27 \mu$. Third microscleres, much smaller asters (fig. 20, $G$ ) ; size, diameter about $8 \mu$; these may be juvenile stages of either of the two preceding sorts.

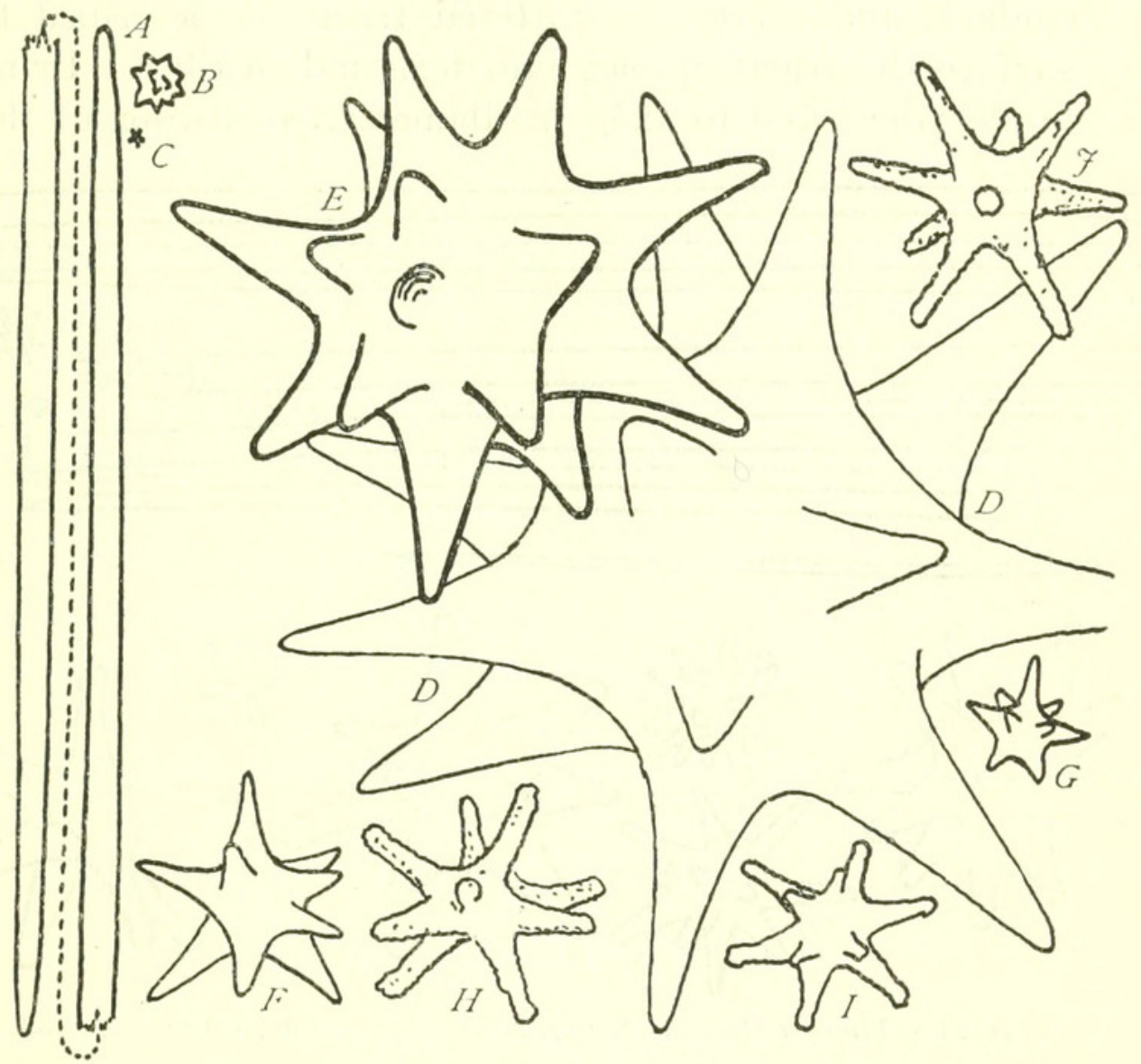

Figure 20.-Tethya aurantia (Pallas) caliorniana, new variety; $A-C$, $\times 80$; others, $\times 1,333$

Remarks.-This form is very close to the type variety, which is European (first described after 1758 as Alcyonium aurantium by Pallas, 1766), from which it differs in larger average spicule size and preponderance of the strongyle instead of style among the megascleres.

\section{Family TIMEIDAE Topsent}

Genus TIMEA J. E. Gray

TIMEA AUTHIA de Laubenfels

Timea authia DE LAUBENFELS, 1930, p. 26.

Holotype.-U.S.N.M. No. 21499; B.M. No. 29.8.22.22.

Type locality.-Laguna Beach, Calif., March 14, 1926, intertidal, only one specimen, collected by me. 
Description.-Shape, amorphous, massive, encrusting. Size, 2.5 $\mathrm{mm}$ thick, 3 or $4 \mathrm{~cm}$ in diameter. Consistency, mediocre, spongy, fragile. Color in life, orange; preserved, drab. Oscules, not evident. Pores, not evident. Surface, superficially between smooth and minutely tuberculate.

Ectosomal specialization, a dermal membrane about $80 \mu$ thick, not detachable, containing characteristic dark cells. Endosomal structure, fleshy; the canals are few and inconspicuous, asters are very abundant, and there are scattered tracts as described below. At the surface the tracts spread into terminal brushes. Principal, or ascending, tracts 100 to $125 \mu$ in diameter, consisting of densely

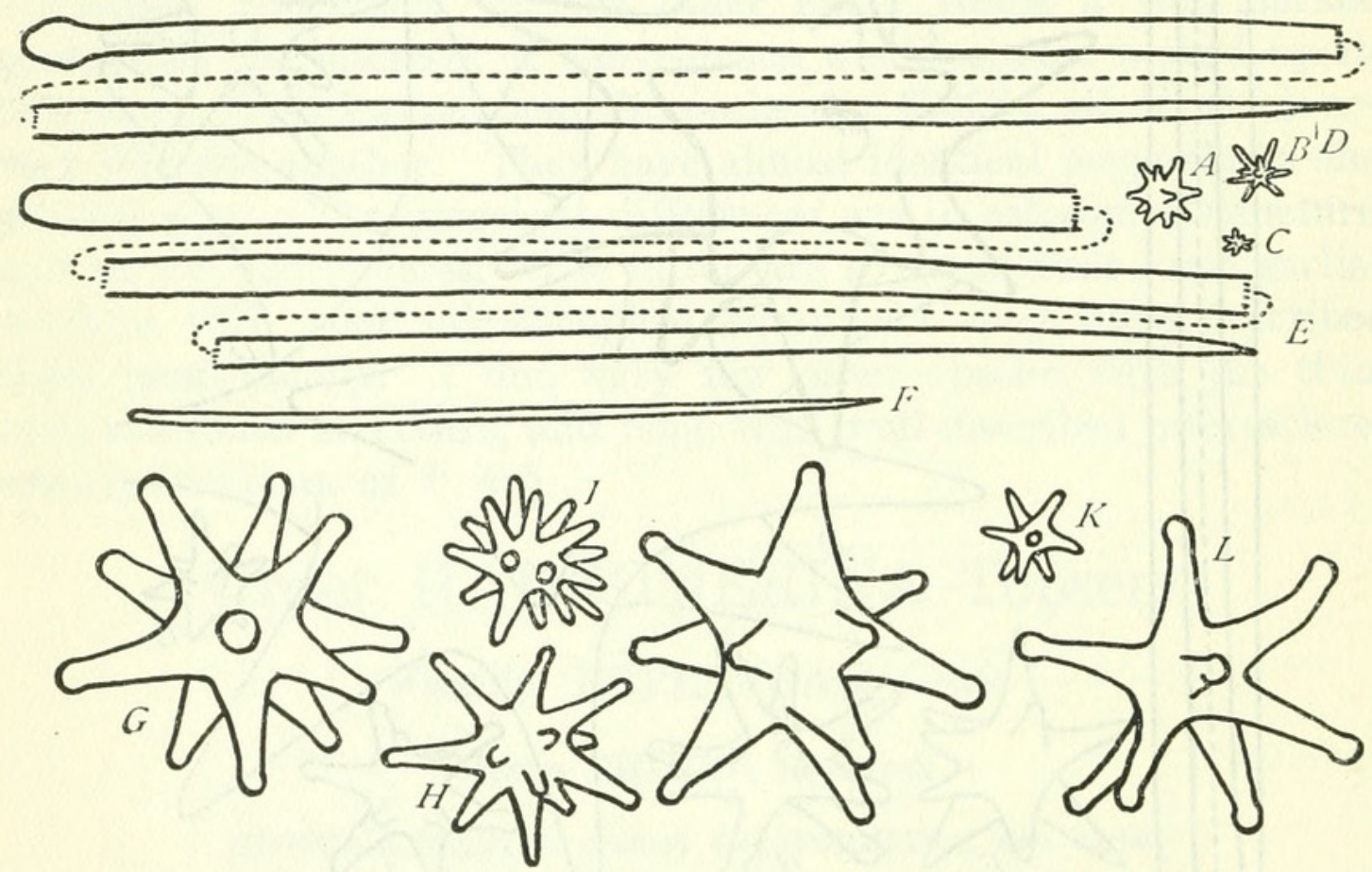

Figure 21.-Timea authia de Laubenfels: $A-F, \times 300$; others, $\times 1,333$

packed monaxons, points upward. These tracts ascend to the surface at an angle. They are about $600 \mu$ apart.

Principal spicules tylostyles (fig. $21, D$ ); size, about $10 \mu$ by $770 \mu$. Secondary spicules, styles (fig. $21, E, F$ ) ; size, $4 \mu$ by $200 \mu$ to $11 \mu$ by $840 \mu$. Microscleres, tylasters (figs. $21, A, B, C, G-L$ ); diameter, $6 \mu$ to $23 \mu$, located throughout the sponge. These spicules vary from smooth to minutely roughened. Some have 20 to 30 rays, others 10 or less. Some are so enlarged at the base that the appearance is of spherasters, others clearly have no centrum. The tylote termination seems consistently present.

Remarks.-Timea Gray (1867, p. 544), type T. stellata, receives as synonym Columnitis Schmidt (1870, p. 25), type $C$. squamata, and both are often merged in further synonymy with Tethya. After a study of the California specimens of each, I feel it most accurate to retain Timea and Tethya separate. Local conditions are so very 
favorable to the encrusting form that almost every sponge here is encrusting, yet our Tethyas are at least massive and hemispherical. The sponges properly referable to Timea seem to be merely encrusting in whatever part of the world they occur. The typical spicule in Tethya is a fusiform strongyle, which varies toward being a tylostrongyle or style, but is very large, usually around $25 \mu$ by $2,000 \mu$. The principal Timea spicule is a sharp-pointed, largeheaded tylostyle, about $10 \mu$ by $500 \mu$ to $800 \mu$. The principal microsclere of Tethya is a very large spheraster, usually about $75 \mu$ in diameter. The asters of Timea are characteristically well under $25 ;$ in diameter.

Timea as here understood comprises beside T. authia at least the following:

Hymedesmia stellata Bowerbank (1866, p. 150), from Great Britain, with tylostyles about $10 \mu$ by $500 \mu$ and strongylasters all about $13 \mu$ in diameter.

Columnitis squamata Schmidt (1870, p. 25), from the West Indies, with tylostyles and with tylasters, oxyasters, and roughened strongylasters. Schmidt gives no spicule measurements but from his figure one can deduce the megascleres are well under a millimeter long.

Donatia parasitica Higgin (1877, p. 5), from the West Indies, with tylostyles $7 \mu$ by $500 \mu$, rough tylasters $12 \mu$, and spherasters (?) $25 \mu$.

Timea tetractis Hentschel (1912, p. 322), from the south Pacific with tylostyles up to $7 \mu$ by $520 \mu$, strongylasters up to $12 \mu$, and roughened oxyasters with very few rays, $15 \mu$ to $31 \mu$.

\section{Family CLIONIDAE Gray}

\section{Genus CLIONA Grant}

\section{CLIONA CELATA Grant CALIFORNIANA, new variety}

Holotype.-U.S.N.M. No. 21437 ; B.M. No. 29.8.22.52.

Type locality.-Pacific Grove, Calif., February 7, 1929, intertidal, boring in the shells of dead barnacles.

Additional material examined.-The species is moderately common in the shells of Haliotis rufescens that are collected near Monterey at depths of 1 to 20 meters.

Description.-Shape, amorphous, boring, making tunnels about $1 \mathrm{~mm}$ in diameter, and proliferating out of them in masses. Size, the masses are well over $10 \mathrm{~mm}$ in diameter. Consistency, mediocre. Color in life, yellow; preserved, drab. Oscules, minute; on papillate projections in the boring form. Pores, minute; on papillate projections in the boring form. Surface, superficially smooth, but not even, very irregular. 
Ectosomal specialization, insignificant. Endosomal structure, fleshy, with spicules in confusion.

Principal spicules, tylostyles (fig. 22 ); size $2 \mu$ by $200 \mu$ to $9 \mu$ by $270 \mu$.

Remarks.-The nearest relative of this form seems to be the type species, which is European. The variety californiana differs in having spicules that average about one-fourth smaller than those of the European form, and in lacking the spicules (often found in the type variety) in which the head is so reduced that they are merely styles, not tylostyles. Furthermore, I can not record the small oxeas

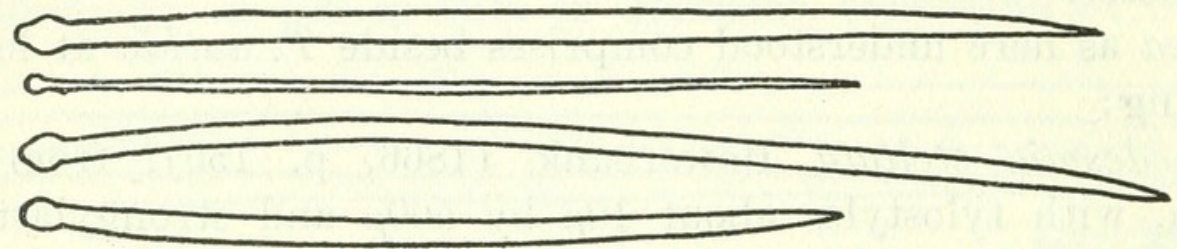

Figure 22.-Cliona celata Grant, $\times 300$

and spirasters of the type variety, but this has no significance taxonomically, because they often can not be found even in European specimens, being normally scarce and easily overlooked.

\section{Genus SPHECIOSPONGIA Marshall}

\section{SPHECIOSPONGIA CONFOEDERATA de Laubenfels}

Spheciospongia confederata DE LAUBenfels, 1930, p. 26.

Holotype-U.S.N.M. No. 21487; B. M. No. 29.8.22.50.

Type locality-As noted below, there was a large mass of this sponge at Point Pinos near Pacific Grove, Calif.; the holotype was taken from it.

Description.-Shape, massive. Size: The largest specimen is only about $12 \mathrm{~cm}$ in diameter, but the mass in the field was $14 \mathrm{~cm}$ thick and $70 \mathrm{~cm}$ in diameter, with a central hollow where lay two large sea urchins (Stongylocentrodus franciscanus); it would seem that the sponge grew around them. This was among granite bowlders, exposed to violent wave action, and out of water only at very low tides. This or a similar mass had been there four years that I know of, and longer according to Prof. W. K. Fisher. It had become appreciably larger throughout the years, but the exact rate of growth can not be given. Consistency, firm, slightly compressible. Color in life: Under water, creamy gray; out of water, dull, purplish leaden gray; in an aquarium the pore areas became lavender, the rest of the surface yellow. On subsequent days the appearance of the pore area was frequently rich brown, on account of coatings of diatoms apparently fil- 
tered out of the running sea water. These coatings were washed off by a stronger current directed across them. The second day in the aquarium, areas adjacent to the cuts made in detaching the specimen turned dull brown, as did bits plunged in formalin. On this day the areas formerly lavender were clear blue. On the third day in the aquarium the yellow areas were more ochraceous than before. The oscules still opened and closed vigorously. On the sixth day the latter evidence of vitality was still in evidence, but on the seventh the oscules were closed and remained closed. On the twelfth day there was still no odor of putrefaction, but a funguslike growth, or filamentous bacteria, attacked the cut areas. On the thirteenth day the entire specimen was a dull drab and was dead or nearly so. The dried specimen became dull yellow, the alcohol specimen, dull brown. Oscules, largely grouped on the summit, and when fully open nearly $10 \mathrm{~mm}$ in diameter. They are very readily closed by sphinctrate tissue about them. Into many of them hung fleshy, membranous sleeves, of very perplexing function. Why they did not act as valves and close the oscule is a mystery. Perhaps in life, with a strong current, they project as oscular chimneys; if so, they would protrude 2 or $3 \mathrm{~cm}$. The aquarium specimen showed no strong oscular current, but much evidence of strong inhalent current. This is probably because the exhalent current had much larger exit at the cut surface than at the oscules. There were amoeboid cells and a few spicules scattered in the otherwise homogeneous structure of these membranous sleeves. Pores, in pore areas several centimeters square. The pore canal is typically 1.5 to $3 \mathrm{~mm}$. in diameter. It is closed on the surface by a sieve with 3 to 6 round openings about $300 \mu$ in diameter. In the area between the pores and the oscules were a few scattered round openings about $1 \mathrm{~mm}$ in diameter. I could not determine whether they were inhalent or exhalent. Surface, superficially smooth.

Ectosomal specialization, the surface for a depth of about $2 \mathrm{~mm}$ is densely packed with spicules, the outer ones arranged points outward as in Suberites, but they are not smaller than the endosomal spicules. Endosomal structure, resembling nonboring examples of Cliona, with some very large cloacal canals nearly $1 \mathrm{~cm}$ in diameter, and with woody tracts of spicules about $2 \mathrm{~mm}$ in diameter making a vague reticulation.

Spicules, tylostyles (fig. 23 ) ; size, $14 \mu$ by $300 \mu$ to $13 \mu$ by $310 \mu$. A very few are much thinner and somewhat shorter, these are evidently developmental stages. The uniformity in size of the spicules in general is very remarkable.

$107704-32-4$ 
Remarks.-Lamarck (1815, p. 78) described Alcyonium vesparium. I have examined his specimens at the Paris Museum and unhesitatingly identify them with a common West Indian species with which I have had much field experience. His type specimen was of dubious locality, but his other two were clearly labeled as West Indian. This species can be readily recognized by the peculiar structure of its pores.

I found specimens clearly of this species labeled Suberites in the Berlin Museum. I heard of French specimens labeled Hardwickia. It is probably the species referred to by Duchassaing and Michelotti (1864, p. 85) as Thalysias vespara. Bowerbank $(1872$, p. 126) described it as Hymeniacidon pulvinatus. I have seen his specimens in the British Museum, and they are clearly vespara. Schmidt (1870, p. 48), described it as Papillina cribrosa. I have studied his type at Strasbourg and there is no question about it. Carter $(1879$, p. 348)

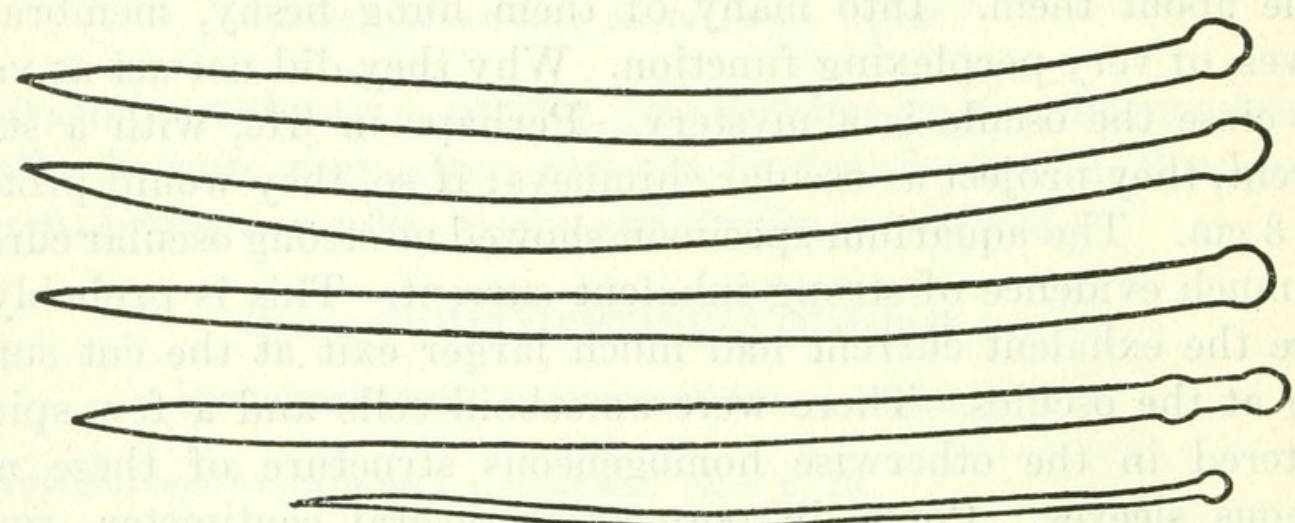

Figure 23.- Spheciospongia confoederata de Laubenfels, $\times 300$

referred to this species (from Bowerbank's specimen) as Spongia dysoni. Marshall (1892, p. 32) made it the type of a genus Spheciospongia for its peculiar pore structure, basing his work on Lamarck's specimens. Verrill $(1907$, p. 342) made it the type of a genus Heterocliona, using Schmidt's description. George and Wilson (1921, p. 135) described it as Spirastrella andrewsi, and later (p. 139) as Poterion atlantica. I have studied the specimens in the United States National Museum and am positive of the identification. (All the specimens are labeled Spirastrella andrewsi.) There is so much resemblance to Bowerbank's genus Raphyrus that one is tempted to call this Cliona, except for the lack of evidence, even in the smallest youngest specimens, of any boring ability or tendency, and for the peculiar pore structures. Two genera that are probably not valid, but that might have been used here, are Osculina and Rhaphiophora; nevertheless, the list of generic designations is rather complete, at least 10 or 11 having been employed. 
This species is of peculiar interest because it is the largest sponge in the world. I have frequently found examples nearly a meter in diameter and they are on definite record as of nearly 3 meters in diameter.

The Californian representative of this remarkable genus (Spheciospongia confoederata) resembles vespara in many ways. It is significant that it is one of our largest local sponges. The species vespara has the same most remarkable kaleidoscopic color changes, and the same architecture, but differs in having a few dermal spirasters in some specimens and in having (at least in mature specimens) much coarser pore structure.

Many species described as Spirastrella are probably rather closely related here. Other relatives are incorrectly described as Suberites, which is properly a genus of compact, nonfibrous sponges with a special dermal armor of outwardly pointing tylostyles smaller than those of the endosome.

\section{Family POLYMASTIIDAE Vosmaer}

\section{Genus POLYMASTIA Bowerbank}

POLYMASTIA PACHYMASTIA, new species

Holotype.-U.S.N.M. No. 22062; B.M. No. 30.10.8.5.

Type locality.-The holotype was collected by me at Point Lobos, south of Carmel, Calif., intertidal, July 12, 1930. A second specimen, presented to Prof. Harold Heath, of Stanford University, was trawled near Point Sur by a fisherman, August 20, 1929, depth not known.

Description.-Shape, massive with digitate protrusions 7 to 10 by $170 \mathrm{~mm}$. The holotype was about $2.5 \mathrm{~cm}$ in diameter, with 3 fistules; the second specimen was about 3 by 6 by $6 \mathrm{~cm}$, with 14 fistules. Consistency, woody. Color in life, bright yellow. No oscules were in evidence, and the pores were closed. The surface of the fistules was smooth, but that of the main mass was coarsely hispid.

Ectosomal specialization, in the form of a cortexlike rind, $1.5 \mathrm{~mm}$ thick and densely packed with spicules both perpendicular and parallel to the surface. It contains the extremities of the fascicular columns, and there are smaller tylostyles in their terminal brushes, points outward. Over the main mass of the sponge a spicule fur 
projects about $1 \mathrm{~mm}$ beyond the surface. Endosome, a fleshy basis permeated by radially arranged fascicular columns of spicules, the entire column being approximately $200 \mu$ in diameter.

The spicules are chiefly tylostyles, of all sizes up to $7 \mu$ in diameter by $2,000 \mu$ or more in length. Some are merely styles, and in others the globular swelling is not quite at the head of the spicule. These tylote swellings may be multiple, two or more to the spicule.

Remarks.-The present species is remarkable for the very short, large fistules. Within the genus Polymastia they are much longer and thinner as a rule than in pachymastia, and they often have an oscule at the distal extremity. It is probable that these projections are in all cases to be regarded as sieves protecting the exhalent apertures from invaders. In the walls of the fistules the tracts crisscross to make gratings, in some cases in very regular patterns. $P$. pachymastia is also marked off from most members of the genus by the very great length of its spicules and by the relative scarcity in its ectosome of shorter tylostyles.

\section{Family SUBERITIDAE Gray}

\section{Genus FICULINA J. E. Gray}

\section{FICULINA SUBEREA (Johnston) LATA (Lambe)}

Suberites latus LAMBE, 1892, p. 71.

Suberites suberea LAMBE, 1894, p. 126.

Holotype.-In the Museum of the Geological Survey, Ottawa, Canada.

Type locality.-The west coast of Canada.

Material examined.-One specimen (U.S.N.M. No. 21443; B.M. No. 29.8.22.51) was found in the wrack at Asilomar, near Pacific Grove, Calif., July, 1925; another was dredged by the University of Southern California, September 24, 1924, from 36 meters, south of the breakwater at San Pedro (U.S.N.M. No. 21396).

Description.--Shape, massive, subhemispherical. Size, $3 \mathrm{~cm}$ in diameter. Consistency, firm, slightly compressible. Color in life, bright orange; preserved, pale drab. Oscules, not evident. Pores, not evident. Surface, superficially smooth.

Ectosomal specialization: Smaller spicules that are otherwise like the endosomal ones are packed together-points outward and in a (curved) plane, heads not so even because of variations in spicule length. Endosomal structure, fleshy, with spicules in confusion. There is a high ratio of solid matter as compared to cavity.

Principal spicules, tylostyles (fig. 25 ), size, $5 \mu$ by $70 \mu$ to $12 \mu$ by $590 \mu$.

Remarks.-The nearest relative of this form seems to be the type variety, which is British and which differs in having spicules that 
average smaller and in being normally red or white rather than golden.

Lambe, 1892 (p. 71), described Suberites latus from the west coast of Canada. In 1894 (p. 127), he redescribed his specimens, identifying them as Suberites suberea Johnston. Since our Californian specimens agree with his in having consistently larger average size of spicules than the British form, it seems wise to retain Lambe's original designation as subspecific. Topsent in 1900 referred Lambe's species to Ficulina.

Suberites dates from Nardo (1833, p. 523), and was based on domunculus of Olivi, a well-known Mediterranean form. Ficulina dates from Gray (1867, p. 523), and was based on ficus, a well-known British form. The name ficus was employed by Pallas (1766, about p. 356), but his description and locality reference show clearly

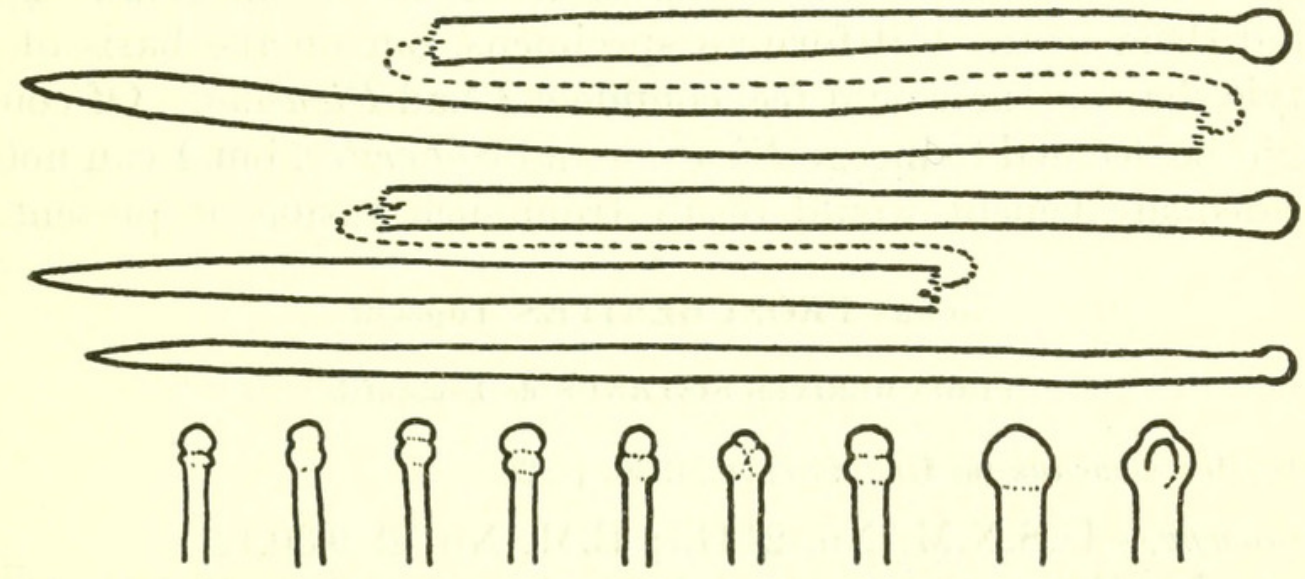

Figurf 25.-Fioulina suberea (Johnston) lata (Lambe), $\times 300$. Three complete typical spicules, and the heads of nine others to illustrate variations, are shown

that he referred by the name both to domunculus and the British form. See also Linnaeus, 1767 (p. 1295). The first species name that I find clearly applicable to the British sponge is suberea Montagu, 1818. The literature separates Ficulina from Suberites chiefly by the peculiar microscleres (centrotylote microstrongyles) of Ficulina, but these are so very frequently not in evidence that I made a careful study based on fresh material at Plymouth (of suberea) and at Naples (of domunculus) to obtain as much data as possible on their distinction in the absence of microscleres. I will tabulate some such distinctions:

1. Consistency.-All 16 of my specimens, undoubtedly suberea, shrunk notably on drying; none of my four domunculus did. Consistencies in life and in spirits were otherwise very similar between the two species.

2. Color.-My observations and the literature show the ordinary color range of domunculus to be from white to vermilion, with 
orange most common; grays and blues occur. Similar data show the normal range for suberea white to crimson, with grays and rosy pinks predominating.

3. Oscular closing.-In all four of my specimens, undoubtedly domunculus, the numerous oscules closed to a line, not to a point. It is odd that this is not mentioned in the literature; can it be that all four were unusual? This seems unlikely, and I presume this may be a valuable indication when one has fresh material.

4. Spicules.-Those of suberea are large-headed tylostyles, with the double-headed modification very common. Those of domunoulus are small-headed, so that they approach styles in appearance, and double-headed modifications are uncommon. The species suberea often has microscleres; domunculus, never. I consider the megasclere shape very important.

Lambe found the Ficulina miscroscleres in his material. I did not find them in the Californian specimens, but on the basis of the tylostyle shape alone would feel confident I had Ficulina. Of course, it might be decided to merge Ficulina and Suberites, but I can not see that adequate benefit would result from such fusion at present.

\section{Genus PROSUBERITES Topsent}

\section{PROSUBERITES SISYRNUS de Laubenfels}

Prosuberites sisyrnus de LaUbenfeis, 1930, p. 26.

Holotype.-U.S.N.M. No. 21413; B.M. No. 29.9.30.12.

Type locality.-South of the breakwater, San Pedro, Calif., dredged by the University of Southern California at 45 meters, April 5, 1924.

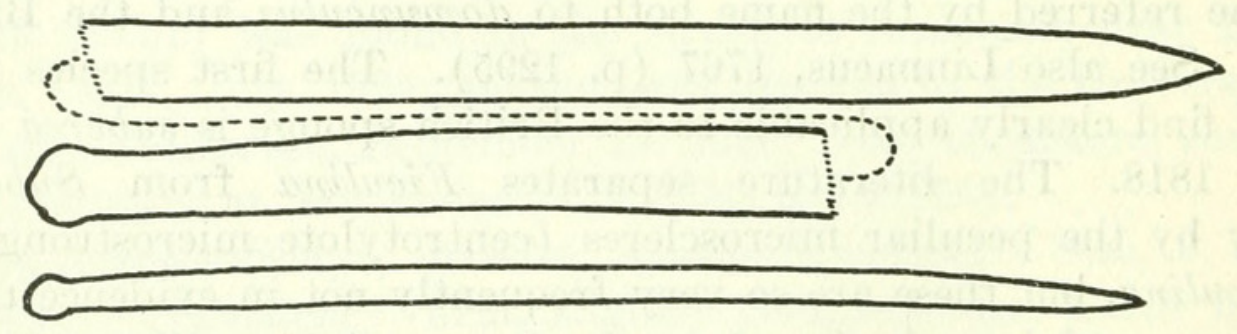

Figure 26.-Prosuberites sisyrnus de Laubenfels, $\times 300$

Additional material examined.-The University of Southern California also collected a specimen on March 31, 1915, near Catalina Island, and possesses a third without data. On the same date and at the same locality as for the type, but at 54 meters, the University of Southern California collected another specimen, which is so very poorly preserved that it is but a mass of fragments, but from the spiculation it seems probably conspecific.

Description.--Shape, encrusting. Size, actually probably only 1 or $2 \mathrm{~mm}$ thick, but so copiously surrounding small worm-tubes, 
algae, and similar substrates that considerable masses result. Consistency, mediocre. Color in alcohol, drab. Oscules, not evident. Pores, not evident. Surface, superficially velvety, with hispidation about $300 \mu$ high.

Ectosomal specialization, erect tylostyles, points upward. These are not conspicuously of a smaller size range than the deeper-placed spicules. Endosomal structure, very scanty, in places wanting; where present, of confused nature.

Principal spicules, tylostyles (fig. 26 ) ; size $8 \mu$ by $275 \mu$ to $20 \mu$ by $480 \mu$.

Remarks.-Prosuberites sisyrnus has spicules very much shorter than those of $P$. longispinus and rugosus and very much thicker than those of P. epiphytum. The genus Prosuberites Topsent, 1893, tends to merge into Laxosuberites Topsent, 1896, and into Suberites Nardo, 1833 , all being in a group that much needs revision.

\section{Genus SUBERITES Nardo}

\section{SUBERITES GADUS de Laubenfels}

Suberites gadus DE LAUBENFELs, 1926, p. 571.

Holotype.-U.S.N.M. No. 21489; B.M. No. 28.11.6.3.

Type locality.-Near Pacific Grove, Calif., taken from a depth of about 30 meters. A fisherman brought up the single specimen entangled in his line.

Description.-Shape, a branched cylindrical stem with enlarged clavate terminations. Size of specimen, about $30 \mathrm{~cm}$ high, lobes about $2 \mathrm{~cm}$ in diameter and $10 \mathrm{~cm}$ long; the stem is about $6 \mathrm{~mm}$ in diameter. Consistency, mediocre. Color in alcohol, nearly white. Oscules, with rims; diameter, 1.5 to $2 \mathrm{~mm}$; very irregularly scattered, but about 4 or 5 to the lobe. Pores, at least $150 \mu$ in diameter. Surface, superficially smooth.

Ectosomal structure, 1.5 to $2 \mathrm{~mm}$ thick; cartilaginous; bluish white in contrast to yellowish white of the endosome. The ectosome is densely packed with spicules perpendicular to the surface, points outward and all at about a level, so that the longer spicules run deeper down into the sponge. There is some tendency for the dermal spicules to be arranged in brushes. Endosomal structure: The stem consists of a dark-brown central axis of densely packed longitudinally placed spicules intermingled with dark granules not certainly, but probably, cellular. Around this extends the ectosome just as over the lobes. As the lobe proper is reached one finds the appearance of choanosome (between the stem and ectosome), which widens until it is about $6 \mathrm{~mm}$ thick. The prolongation of the stalk in the lobe neither increases nor diminishes in size, but becomes paler and paler, with more and more choanosome and fewer and fewer spicules. One 
can not say exactly where it ends. I find no tendency for it to spread out fanlike. In the choanosome are relatively large and rather few spicules. Histological details: The flagellate chambers are round; diplodal, $40 \mu$ to $50 \mu$ diameter.

Principal spicules, dull-pointed tylostyles (fig. 27 ); size $10 \mu$ by $200 \mu$ to $50 \mu$ by $1320 \mu$.

Remarks.-One finds a tendency to pedunculate form very common in Ficulina suberea. It is therefore to be expected in Suberites. A species having very similar shape to that of gadus is described by

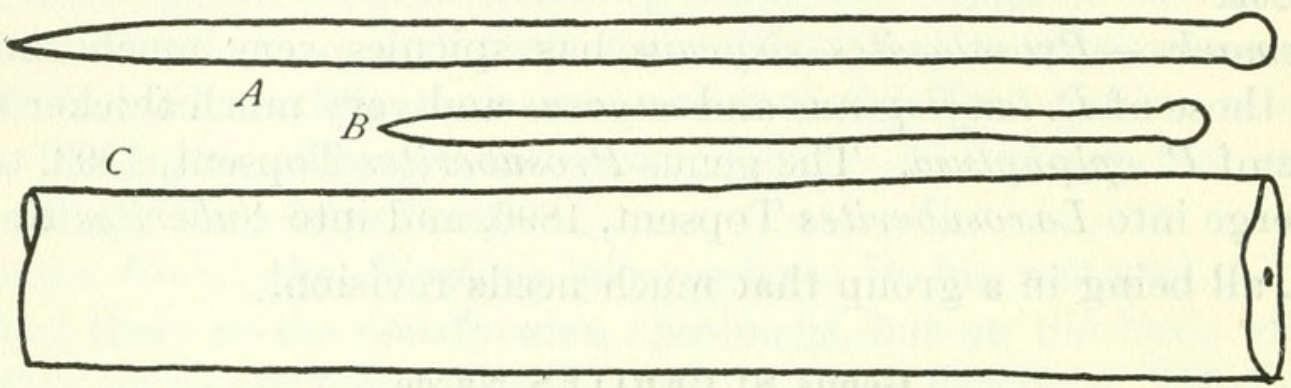

Figure 27.-Suberites gadus de Laubenfels, $\times 300$. $A$ and $B$ show size for the smaller spicules, and shape for all; $C$, portion of the shaft of one of the larger spicules, illustrating its proportionate size to the smaller ones

Wilson (1925, p. 352) as Rhizaxinella nuda, from the Philippines. It was more brownish than gadus, had spicules about half again as large as those of gadus and with sharper points, and its stem lacked the ectosomal crust. The two are doubtless closely related.

\section{Order HALICHONDRINA Vosmaer}

\section{Family AXINELLIDAE Ridley and Dendy}

\section{Genus HALICHONDRIA Fleming}

\section{HALICHONDRIA PANICEA (Pallas)}

Spongia panicea PaLlas, 1766, p. 388.

Halichondria panicea JoHnston, 1842, p. 114.

Holotype.-Location unknown.

Type locality.-Europe.

Material examined.-Specimens were collected at Point Pinos, $\mathrm{Pa}$ cific Grove, Calif., intertidal, on January 24, 1929, by J. E. Lynch, who reported it then plentiful. During the summer months it has been very rare or lacking, though on July 14, 1929, I found a small specimen at the same locality as that given by Mr. Lynch. In European waters this sponge is very abundant intertidally, and the same or a very similar species is reported from nearly every part of the world's coastal regions that have been well studied.

Description (U.S.N.M. No. 21447; B.M. No. 29.8.22.9).-Shape, amorphous, encrusting. Size, up to $6 \mathrm{~mm}$ thick, $3 \mathrm{~cm}$ in diameter. 
Consistency, fragile. Color in life, orange to green; preserved, nearly white. Oscules, raised; diameter, about $1 \mathrm{~mm}$. Pores, minute. Surface, superficially smooth to tuberculate.

Ectosomal specialization strongly marked, consisting of a dermal crust, about $200 \mu$ thick, of tangentially strewn spicules, not differing, however, from those of the endosome. This is underlaid by such extensive subdermal cavities as to be rather readily separable. Endosomal structure, "crumb-of-bread," most of the spicules strewn without order in the flesh, but there may be spicule tracts in a groundwork that is not reticulate. Histological details: I find spherical flagellate chambers $30 \mu$ to $40 \mu$ in diameter. Principal, or ascending, tracts about $45 \mu$ in diameter.

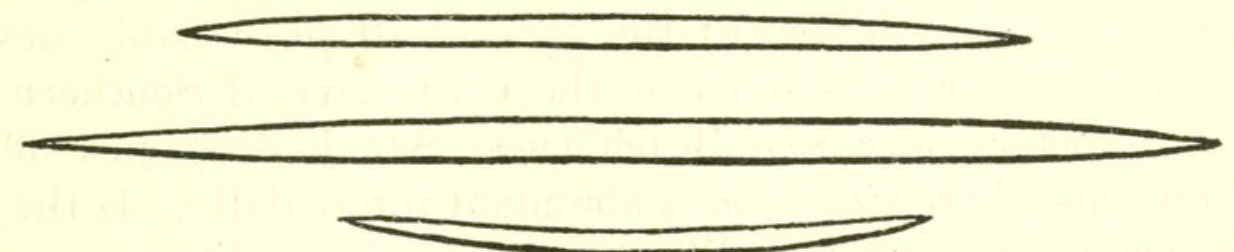

Figure 28.-Halichondria panicea (Pallas), $\times 300$

Principal spicules, oxeas (fig. 28) ; size up to $11 \mu$ by $300 \mu$. As is characteristic of the species and genus, there is no definite size range of spicules at all, but all sizes-from the largest down-are found intermingled in confusion.

Remarks.-In species so lacking in positive characters as this, it is difficult to be certain whether the similar specimens from various parts of the world are conspecific.

\section{Genus HYMENIACIDON Bowerbank HYMENIACIDON SINAPIUM de Laubenfels}

Hymeniacidon sinapium de LAUBENFELs, 1930, p. 26.

Holotype-U.S.N.M. No. 21456 ; B.M. No. 29.8.22.21.

Type locality.-Newport Bay (near San Pedro), Calif.; intertidal.

Occurrence.-This species is abundant along the rocky, surf-beaten portions of the coast of southern California at nearly every point I have visited. It is the most abundant sponge on the oyster beds in Newport Bay, where the water often becomes quiet and very warm. It is found in various places up the stream that enters the bay, where it must be in brackish water at low tide during rainy weather. It grows even where the water is almost opaque with suspended mud, where at low tide it is exposed to the very ardent rays of the southern California sun, and where it is always chilled by the very cool waters of the open ocean. I have vainly sought any difference in spicules, form, color, or any other quality that varied as a factor of any of these environments. 
In the vicinity of Monterey $H$. sinapium occurs very rarely, if at all, though similar ecological situations are found. E. F. Ricketts collected a specimen, July 24, 1926, in a tide pool near Hopkins Marine Station, which was like the southern California specimens in all ways save one; it has spicules up to $14 \mu$ by $380 \mu$. Having but the one specimen I hesitate to denominate this a new variety, though in no southern California specimen do I find spicules so large. The condition of the specimen is such that any identification of it must be provisional.

U.S.N.M. No. 21395 represents the only sponge from lower than intertidal zone that I can refer to sinapium. It deserves special mention, as its spicules are notably smaller, namely, but $6 \mu$ by $205 \mu$ at the largest, $5 \mu$ by $195 \mu$ for an average of apparently mature styles, but with only a few of the very small presumably developmental forms. It was dredged by the University of Southern California in 5 meters near Seal Beach (near San Pedro), just offshore from locations where sinapium is abundant intertidally. Is the small spicule size an ecological modification, or is this a different species? Its resemblance to my Plymouth specimens of $H$. caruncula merits comment. Having but the one specimen, no positive decision can be made, but my opinion is that it is an aberrant individual of a species normally intertidal, perhaps modified by the environment. This species is found associated with oysters more than any other one large organism. Numerous other specimens were examined.

Description.-Shape, amorphous to massive to encrusting, often with digitate processes. Size, up to about $10 \mathrm{~cm}$ high, $20 \mathrm{~cm}$ in diameter. Consistency, very soft. Color in life, bright yellow, sometimes with orange tints; preserved, drab. Oscules, often on raised processes; diameter, about $2 \mathrm{~mm}$. Pores, minute, very contractile. Surface, superficially smooth, with scattered low conules less than $1 \mathrm{~mm}$ high.

Ectosomal specialization in the form of a thin, transparent, fleshy dermis. It contains but few spicules. Endosomal structure, "crumbof-bread," with spicules mostly in confusion, but here and there organized into tracts, mostly directed vertically, points of the styles up. These tracts expand distally into subdermal brushes in a manner that may be described as axinellid, but is also found in most Mycales and some Biemnas, and may indicate axinellid relationships for those genera.

Principal spicules, styles (fig. 29 ); size up to $9 \mu$ by $340 \mu$, with moderately numerous smaller forms.

Remarks.-It is doubtful whether this is a new form, but as it seemed impossible to be absolutely positive of identifying it with any of the known species I applied a distinctive name to it so that 
it might be referred to recognizably in future revision. This action may be better understood after noting the following considerations:

In 1827, Grant described Spongia sanguinea, a thin, blood-red sponge. It was probabiy not just one species but several having similar color and styles as megascleres. Grant lacked microscopic equipment adequate for the discovery of microscleres. In 1828, Fleming (p. 521) referred this to his genus Halichondria. In 1842 (p. 134), Johnston so identified specimens he had that were preserved in the British $\mathrm{Mu}$ seum. $\mathrm{He}$ also gave figures and a fairly good description. Practically the only differencebetween his sanguinea and sinapium is in color. H. sanguinea was from British waters.

In 1859 , Lieberkühn described Halichondria luxurians; this was redescribed in 1862 (p. 76) by Oscar Schmidt as Reniera luxurians. Schmidt says that this is Reniera variabilis of Nardo, an utterly un-

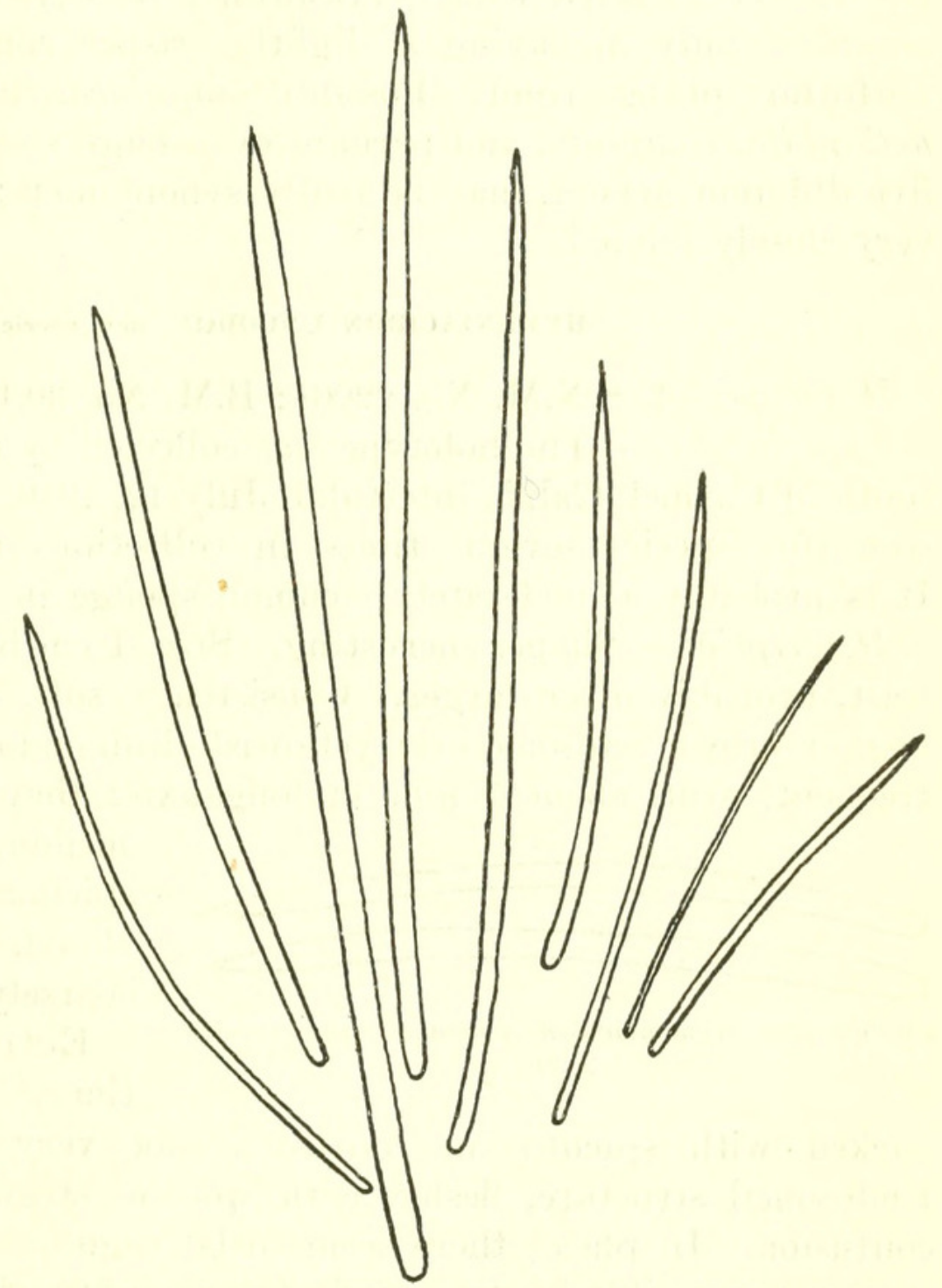

Figure 29.-Hymeniacidon sinapium de Laubenfels, $\times 300$ recognizable species, so devoid of description as to be properly a nomen nudem. I mention luxurians because, so far as Lieberkühn's and Schmidt's descriptions go, this may be the same as sinapium; but we do not know the spicule size, nor is the structure well described. R. Tuxurians is a Mediterranean species.

In 1862 (p. 1111), Bowerbank described Hymeniacidon caruncula, the type of this genus. It differs from sinapium only in having much smaller spicules. Bowerbank described them as $218 \mu$, and the specimens I collected at Plymouth had then only about 120 to 
$140 \mu$. Some authors synonymize caruncula with sanguinea, but there seem to be no British intergrades between the blood-red, longspiculed form and the yellow or orange short-spiculed form; our Californian sponge might be considered such an intergrade, or rather a distinct species, since we have here none just like either caruncula or sanguinea. H. caruncula was from British waters.

In 1911 (page 13), Wilson described Stylotella heliophila from the Eastern United States (Beaufort, N. C.). This differs from sinapium only in having a slightly crisper consistency and more uniformly orange color. Possibly sanguinea, luxurians, caruncula, heliophila, sinapium, and perhaps even more species, put in at least five different genera, may be really synonymous; they are certainly very closely related.

\section{HYMENIACIDON UNGODON, new species}

\section{Holotype.-U.S.N.M. No. 22061; B.M. No. 30.10.8.4.}

Type locality.-The holotype was collected by me at Point Lobos, south of Carmel, Calif., intertidal, July 12, 1930. Otherwise I have seen this species several times in collections made by students. It is probably a moderately common sponge in central California.

Description.-Shape, encrusting. Size, $1 \mathrm{~cm}$ by $3 \mathrm{~cm}$ by $4 \mathrm{~cm}$ at least, probably often larger. Consistency, soft. Color in life, mahogany-brown ectosome over yellowish-drab endosome. Oscules, infrequent, oval, about $1 \mathrm{~mm}$ in long axis; they are closable by a

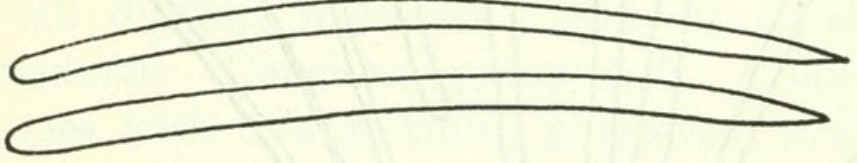

Figure 30.-Hymeniacidon ungodon, new species, $\times 300$ membrane. Pores, inconspicuous, usually found closed. The surface is coarsely rugose.

Ectosomal specializations, fleshy, densely packed with spicules in confusion, not very easily detachable. Endosomal structure, fleshy, with spicules strewn mainly in utter confusion. In places there seem to be vague ascending tracts, but these may possibly be due merely to proximity of canals from which the spicules are excluded. This results in concentrations of spicules in the regions between the canals.

Spicules, styles $4 \mu$ by $180 \mu$ to $8 \mu$ by $200 \mu$, with a few very much thinner that were probably immature forms (fig. 30).

Remarks.-Quite a few species of the genus Hymeniacidon have ectosome differently colored from the endosome, but the particular color scheme of ungodon seems characteristic and unique in the genus. The method of closure of oscules by a membrane stretching across instead of sphinctrate contraction is worthy of note. In at least some portions of the endosome of the present species were 
numerous annulate filaments, the annulations being due to swellings caused by spheroidal optically refringent granules. These structures were about $3 \mu$ in diameter and of indefinite length. They may have been elongate archaeocytes, but the most probable assumption seems to be that they were (symbiont?) algae.

\section{Genus PRIANOS J. E. Gray}

\section{PRIANOS PROBLEMATICUS de Laubenfels}

Prianos problematicus de Laubenfels, 1930, p. 26.

Holotype.-U.S.N.M. No. 21484; B.M. No. 29.8.22.16.

Type locality.-Two specimens were trawled on March 30, 1929, by Prof. T. Skogsberg, at a depth of 15 meters, south end of Monterey Bay, Calif.

Description.-Shape, massive to lobate. Size, $1 \mathrm{~cm}$ high, $2 \mathrm{~cm}$ in diameter. Consistency, stiff, slightly compressible. Color in life and when preserved, pale drab. Oscules, round, flush; diameter, about $2 \mathrm{~mm}$. Pores, $200 \mu$ to $450 \mu$ in diameter. Surface, superficially smooth.

Ectosomal specialization, a dermal membrane; this is not readily detachable, is fleshy, and contains spicules strewn irregularly. Endosomal structure, "crumb-of-bread," with spicules in confusion.

Principal spicules, strongyles (fig. 31, $A, B)$; size, $6 \mu$ by $135 \mu$ to $10 \mu$ by $140 \mu$. Secondary spicules, oxeas (fig. $31 \mathrm{D}$, $E)$; size, $2 \mu$ by $80 \mu$ to $2 \mu$ by $100 \mu$; these might be regarded as microscleres.

Remarks.-The systematic position of those sponges having spicules principally strongyles needs some explanation.

The first assignment of such was by

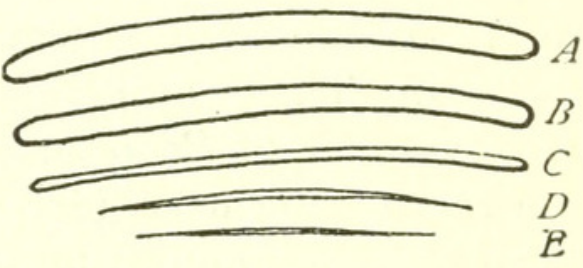

Figure 31.-Prianos problematicus de Laubenfels: Typical spicules, $\times 300 ; C$ probably an immature $A$

O. Schmidt to his genus Reniera (1862,

page 72), type species $R$. aquaeductus. Simultaneously he established $R$. cratera, which has a spiculation of strongyles only. Vosmaer in 1885 referred to this as genotype of Reniera, but this can not be, as Schmidt plainly stated in his original description that aquaeductus is the type. Among other Renieras with strongyles may be mentioned $R$. amorpha Schmidt (1864, p. 38), R. hebes Schmidt (1870, p. 40), and $R$. crassa Carter (1876, p. 312), which may be a Strongylophora (see below).

The first genus created for sponges characterized by strongyle spiculation was Prianos Gray (1867, p. 520) for Schmidt's Reniera amorpha (see above). This genus was regarded by Vosmaer (1885, p. 234) as not separable from Reniera, and it has therefore been subsequently ignored and forgotten. Prianos amorphus is not 
renierid, however, but contains spicules in confusion; Reniera (Haliclona) is for sponges with oxeas in isodictyal reticulation. As a matter of fact there is a British sponge that answers rather closely to Schmidt's description of amorpha. Bowerbank (1874, p. 243) called it Desmacidon columella, and subsequent authors, led by Hanitsch (1894, p. 180) have called it Stylotella columella. Stylotella Lendenfeld (1888, p. 185), type species as fixed by Hallmann (1914, p. 348), S. digitata (which is Ridley's Hymeniacidon agminata), is suberitid. It must be said that the specimen of columella that I collected at Plymouth, in September, 1928, agreed even more closely with Schmidt's description of amorpha than did Bowerbank's original description. The species columella and amorpha may or may not be specifically identical, but they are clearly congeneric and not properly Reniera, Desmacidon, or Stylotella. Prianos may quite fitly be employed for them.

Other genera with strongyles as principal spicules include the following without microscleres:

Joyeuxia Topsent (1892, p. 93), type species J. viridis. In this the spicules are almost all dermal, the endosome being nearly devoid of skeleton. Some of the spicules are oxeas. See the genus Phloedictyon for comparisons.

Batzella Topsent (1893, p. xxxiv), type species $B$. inops, like the above has very few spicules at all. It had mycalid embryos. Some of its spicules were styles. See Inflatella for comparisons.

Liosina Thiele (1899, p. 16), type species L. paradoxa. This may be a synonym of Prianos.

Petrosia Vosmaer (1885, p. 338), type species $P$. dura, is stony hard. It is interesting to compare consistencies here, as both Prianos amorphus and $P$. columellus are very soft, while $P$. problematicus is intermediate, just moderately stiff and firm.

Protoschmidtia Czerniavsky (1879, p. 380), type species $P$. simplex. This genus is inadequately known; is referred to as halichondroid with hispid dermis, "surface set over with tubes," spicules strongyles.

The following genera with microscleres have strongyles as principal spicules. In view of the well-known fact that microscleres may be lacking for unknown reasons, all species without them may be but derivatives by reduction, but often it is impossible to ascertain the source. Prianos may therefore really be congeneric with some one of the following:

Barbozia Dendy (1922, p. 131), type species B. primitiva. The microscleres are anisochelas and discorhabds; the sponge is papillate.

Phlyctaenopora Topsent (1904, p. 198), type species P. bitorquis. The microscleres are anisochelas and sigmas; this also is papillate. 
Guitarra Carter (1874, p. 210), type species G. fimbriata. The microscleres are very peculiar and distinctive, and therefore one can hardly believe that this is closely related to the others here mentioned. This is very provocative of thought in view of the impossibility of sharply separating it were it to lose its microscleres as individuals probably do.

Dyscliona Kirkpatrick (1900, p. 352), type species D. davidi, a boring sponge with very peculiar microscleres; this is another reason for doubting that similarity of megascleres indicates close relationship in absence of other bonds of unity.

Strongylacidon von Lendenfeld (1897, p. 110), type species $S$. sansibarense. This has anisochelas as microscleres.

Strongylamma Hallmann (1917, p. 643), type species S. carteri. This had two sizes of spiny microrhabds and contained much sand.

Strongylophora Dendy (1905, p. 141), type species S. durissima. This had smooth microrhabds, often bent, and was stony hard.

Although far from certain, it is quite possible that one of or all these last three are congeneric with Prianos. The structures are such that all may be considered much more closely related to Prianos than that genus or any of them is to Reniera. The same should be said of Petrosia and Liosina. It should be kept in mind that, of all these, Prianos (1867) has the priority.

\title{
Order POECILOSCLERINA Topsent
}

\section{Family DESMACIDONIDAE Gray}

\author{
Genus BIEMNA J. E. Gray \\ BIEMNA RHADIA de Laubenfels
}

Biemna rhadia De Laubenfels, 1930, p. 26.

Holotype.-U.S.N.M. No. 21507; B.M. No. 29.9.30.17.

Type locality.-The one specimen was collected by E. F. Ricketts in 1925 from Monterey Bay, Calif., depth 700 meters; it was lodged in a recess of a macerated dictyonine hexactinellid sponge skeleton.

Description.-Shape, amorphous. Size, $7 \mathrm{~mm}$ high, $12 \mathrm{~mm}$ in diameter. Consistency, stiffly fragile. Color dry, drab. Oscules and pores, not evident, because of cavernous structure. Surface, superficially very cavernous.

Ectosomal specialization, a dermal membrane about $15 \mu$ thick; detachable, fleshy, containing microscleres but not megascleres. Endosomal structure, "crumb-of-bread," with stiff, ascending, branching tracts. Principal, or ascending, tracts about $400 \mu$ in diameter, cored by densely packed styles. There seems to be little or no spongin present. 
Principal spicules, styles (fig. $32, A$ ) ; size, about $20 \mu$ by $1,300 \mu$. First microscleres, sigmas (fig. $32, B$ ) ; size, about $13 \mu$ by $300 \mu$. Second microscleres, sigmas (fig. $32, C$ ); size, about $4 \mu$ by $90 \mu$. Third microscleres, sigmas (fig. $32, D$ ); size, about $1 \mu$ by $25 \mu$. Fourth microscleres, smooth raphides (not figured) ; size, $1 \mu$ by $120 \mu$ to $2 \mu$ by $210 \mu$; these are usually packed in short fascicular tracts about $50 \mu$ in diameter.

Remarks. - The nearest relative of this form seems to be $B$. (Desmacella) fortis Topsent, 1897, from the East Indies and Red Sea, which differs in not having the larger size range of sigmas. Biemna megalosigma Hentschel, 1912, has the large size range of sigmas as well as the medium and smaller, but has peculiar siliceous spheres

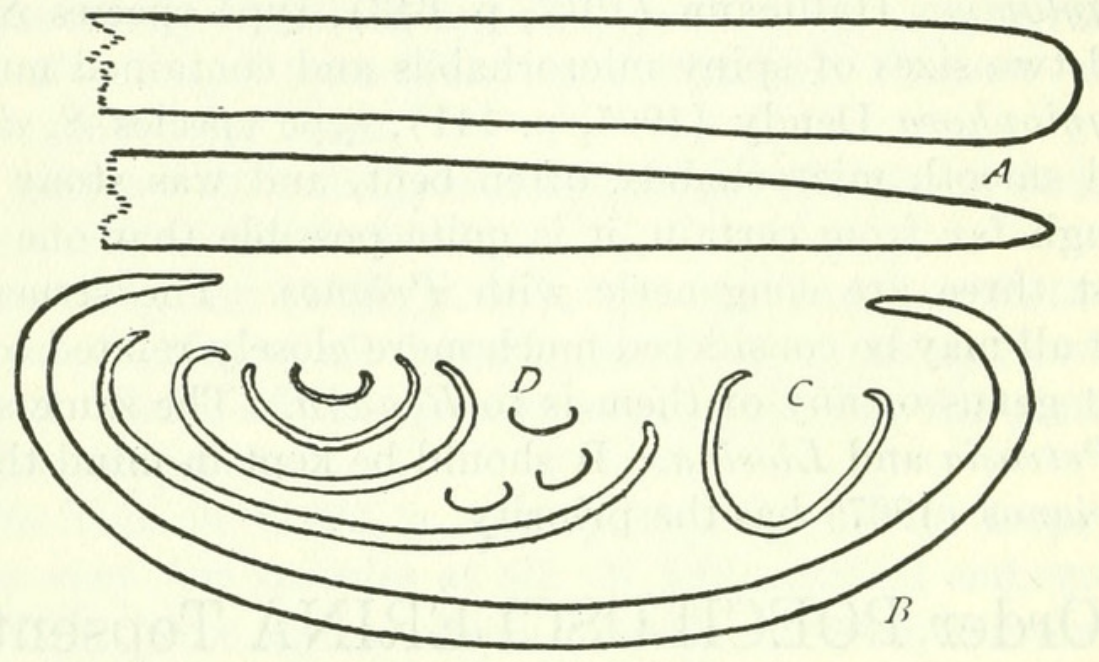

Figure 32.-Biemna rhadia de Laubenfels, $\times 300$. A, terminations of the styles, showing their thickness but not their length ; $B-D$, range in size and shape of the sigmas

not in the California species, has megascleres but two-thirds as large, and raphides also much smaller. It may well be that upon making thorough revision of the genus one would find these and numerous other species of Biemna worthy of reduction to synonymy, but this step does not seem called for at present.

Similar species of this genus are reported from practically all parts of the world.

\section{Genus DESMACELLA Schmidt \\ DESMACELla VAgABUNDA Schmidt}

Desmacella vagabunda O. Sснмірт, 1870, p. 53.

Holotype.-Location unknown; described from the West Indies.

Material examined.-One of several specimens (U.S.N.M. No. 21508; B.M. No. 29.8.22.61) growing in the interstices of a macerated dictyonine hexactinellid sponge skeleton collected by E. F. Ricketts, May 9, 1929, in Monterey Bay, depth 700 meters. 
Description.-Shape, amorphous. Size, undeterminable, because of concealment in hexactinellid skeleton. Consistency, fragile. Color in life and when dry, drab. Oscules, flush with the cloacal surface of the hexactinellid, each almost filling the cavity left by one of the hexact's oscules. Pores, not evident. Surface, superficially smooth.

Ectosomal specialization, a very thin, detachable, fleshy dermis. It contains a few scattered microscleres. Endosomal structure, short plumose eolumns or simple brushes of tylostyles, points toward the surface, accompanied by a surprisingly small quantity of protoplasmic material.

Principal spicules, tylostyles (fig. $33, A, B$ ) ; size, about $15 \mu$ by $600 \mu$. Microscleres, sigmas (fig. $33, D$ ) ; length, about $60 \mu$.

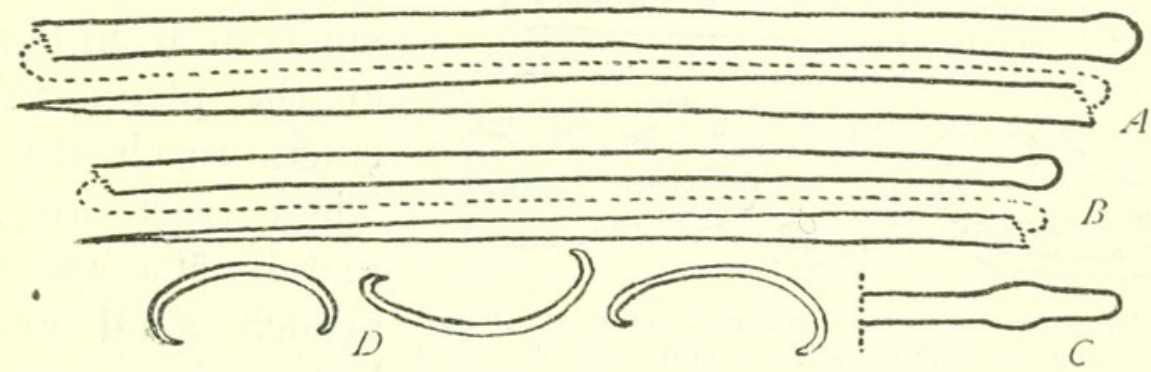

Figure 33.-Desmacella vagabunda Schmidt, $\times 300 . \quad C$, an unusual modification of the head of the megasclere

Remarks.-Schmidt's Desmacella vagabunda was very briefly described. The sponge now under discussion offers so little material for examination that it can only be said to be imperfectly known. It seems better to identify it with vagabunda than to establish a new species for it, because all that we know of it agrees sufficiently well with what we know of vagabunda to make it probable that they are conspecific.

\section{ZYGHERPE, new genus}

This genus is of the family Desmacidonidae and is close to Desmacella, from which it differs chiefly by the addition of the diancistra to the other skeletal elements. Genotype: Zygherpe hyaloderma, new species.

ZYGHERPE HYALODERMA, new species

Holotype.-U.S.N.M. No. 22060 ; B.M. No. 30.10.8.3.

Type locality.-The holotype was collected by me on July 13, 1930, at Point Lobos, intertidal, south of Carmel, Calif. The encrustation carpeted a rock on the floor of a grotto, which was inaccessible except at very low tide.

$107704-32-5$ 
Description.-Shape, encrusting. Size, 1 to $3 \mathrm{~mm}$ thick, spreading laterally indefinitely. Consistency, soft, fleshy. Color in life, pale ochraceous-yellow. Surface, lipostomous and smooth. A conspicuous feature of the living and preserved sponge is the very evident system of comparatively coarse canals meandering about beneath the transparent dermis, branching and reuniting. It is to be presumed that contractile minute exhalent apertures riddled the covering to these canals during life, and that similar inhalent openings were dispersed over the rest of the surface.

Ectosomal specialization, fleshy, abundantly packed with microscleres. Endosomal structure, basically fleshy with abundant microscleres and scattered ascending plumose tracts of tylostyles,

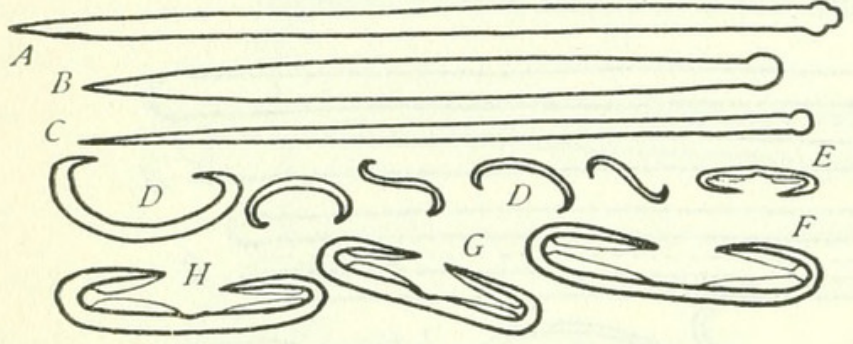

FIGURE 34.-Zygherpe hyaloderma, new species: $A-E, \times 300 ; F-H, \times 600$ points upward and outward. These make inconspicuous terminal brushes at the places where the tracts reach the surface. These tracts are approximately $50 \mu$ apart; the y branch and anastomose but rarely.

Megascleres, tylostyles about $5 \mu$ by $150 \mu$. First microscleres, sigmas $25 \mu$ to $50 \mu$ in length of chord. Second microscleres, diancistras, the points nearly meeting.

Remarks. - The diancistra is a very curious and characteristic spicule. Possession thereof can hardly be used, however, as an indication of close phylogenetic relationship, for the three previously described genera having this microsclere differ fully as much from each other as from Zygherpe. In addition to the diancistra, each possesses other spicules as follows: Hamacantha, styles to oxea and toxas with rhaphides; Vomerula, styles and toxas with chelas; Pozziella, exotyles, peculiar styles and very peculiar sigmas. As mentioned above, Zygherpe seems much more closely related to Desmacella than to any other genus.

\section{Genus MYCALE J. E. Gray}

\section{MYCALE BELLABELLENSIS (Lambe)}

Esperella bellabellensis LAMBE, 1905, p. 14.

Esperella fisheri DE LAUbenfels 1926, p. 570.

Holotype.-In the Museum of the Geological Survey, Ottawa, Canada.

Type locality.-The west coast of Canada.

Material examined.-There is a magnificent specimen of this sponge at Hopkins Marine Station (Pacific Grove) a good 4 feet 
in diameter; it was taken at a depth of about 50 meters, date not recorded, in Monterey Bay, entangled on a fisherman's line. It is represented by U.S.N.M. No. 21440 and B.M. No. 28.11.6.4. E. F. Ricketts also collected a specimen from Monterey Bay, depth 800 meters, date not recorded. It is represented by U.S.N.M. No. 21470 and B.M. No. 29.8.22.12.

Description.-Shape, stipitate, older specimens funnel-shaped. Size, up to at least $100 \mathrm{~cm}$ high, $122 \mathrm{~cm}$ in diameter. Consistency, between spongy and fragile. Color in life and when preserved, drab. Oscules, irregular in size and shape, not definitely delineated, especially in the larger specimens. Pores, represented by even more irregular openings. Surface, superficially very rough with depressions sometimes $5 \mathrm{~cm}$ deep.

Ectosomal specialization, a dermal membrane. It is fleshy, very thin, and contains microscleres and a very few megascleres. Endo-

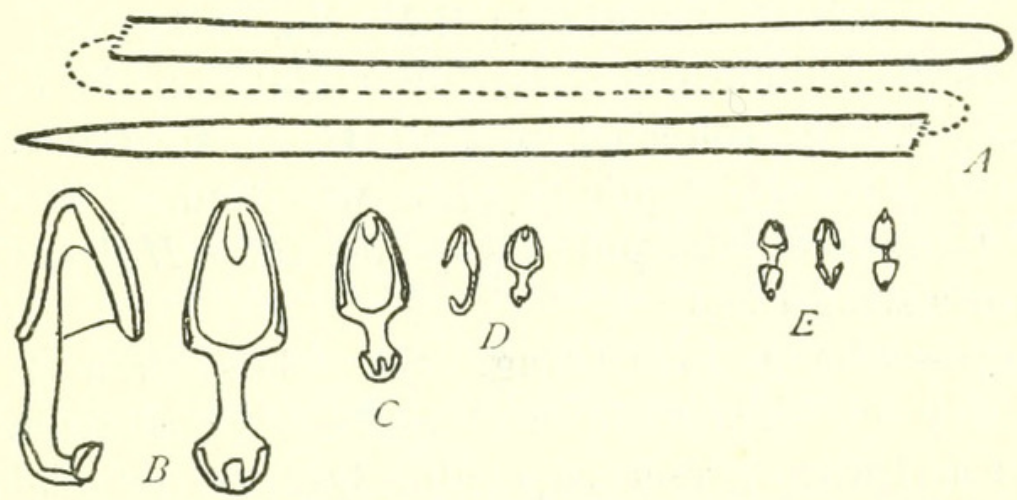

Figure 35.-Mycale bellabellensis (Lambe), $\times 300$. Spicules of Californian specimen (U.S.N.M. No. 21470 and B.M. No. 29.8.22.12). Microscleres $B, D$, and $E$ in front and side views

somal structure cavernous, traversed by spicular tracts which branch but rarely anastomose. Principal, or ascending, fibers up to $1 \mathrm{~mm}$ in diameter, cored by abundant styles.

Principal spicules, styles (fig. $35, A$ ) ; size, $12 \mu$ by $432 \mu$ to $13 \mu$ by $491 \mu$. First microscleres, palmate anisochelas (fig. $35, B$ ) ; length, $70 \mu$ to $90 \mu$, often in rosettes. Second microscleres, palmate anisochelas (fig. $35, C$ ) ; length, $32 \mu$ to $36 \mu$. Third microscleres, palmate anisochelas (fig. 35, D) ; length, $22 \mu$ to $27 \mu$. Fourth microscleres, palmate isochelas (fig. $35, E$ ) ; length, about $22 \mu$.

Remarks.-The large funnel-shaped Californian specimen (U. S. N. M. No. 21440 and B. M. No. 28.11.6.4) agrees with Lambe's rather closely; but Lambe recorded small sigmas $(19 \mu$ to $30 \mu)$; whereas long search has so far yielded only one doubtfully proper sigma in the California specimen, and Lambe's was much smaller. I have also another specimen still smaller, possibly a juvenile, collected at a depth of about 800 meters in Monterey Bay by E. F. Ricketts. It is 
only $10 \mathrm{~cm}$ high and $6 \mathrm{~cm}$ in diameter and is stipitate but not funnelshaped, being instead rather lobate. It agrees with the funnelshaped specimens except that it seems to have no sigmas at all, but instead a few toxas about $4 \mu$ by $400 \mu$. It has also numerous palmate isochelas about $22 \mu$ long, which may be foreign, yet several species of Mycale are recorded with such microscleres in addition to the typical amoschelas. That they and the toxas may not be proper is indicated by the finding of a few such obviously foreign spicules as some plesiasters, tylotes, and short renierid oxeas, but the isochelas are quite numerous. The surface of this specimen is also notably different, in having a distinct oscule $4 \mathrm{~mm}$ in diameter and definite contractile dermal pores, one to three to each square millimeter of surface.

\section{MYCALE MACGINITIEI ${ }^{8}$ de Laubenfels}

Mycale macginitiei DE LAUBENFELS, 1930, p. 26.

Holotype.-U.S.N.M. No. 21471; B.M. No. 29.8.22.3.

Type locality-Elkhorn Slough (intertidal) on the east shore of Monterey Bay, Calif., collected by Prof. G. E. MacGinitie, March 1, 1929. Several years ago a pile of rocks was dumped at one place in this area of tidal mud flats, and this sponge and a Hatisarca have now appeared encrusting them.

Description.-Shape, encrusting. Size, less than $1 \mathrm{~cm}$ thick. Patches mostly less than $6 \mathrm{~cm}$ in diameter. Consistency, mediocre. Color in life and when preserved, drab. Oscules, not evident. Pores, about $30 \mu$ in diameter and about $70 \mu$ from center to center. Surface, superficially smooth.

Ectosomal specialization, a dermal membrane; very thin, detachable, fleshy, contains spicules in confusion. Endosomal structure, "crumb-of-bread," with fibers; little or no reticulation is present. Principal, or ascending, fibers $70 \mu$ to $100 \mu$ in diameter, cored by many spicules, but with little spongin. Below the surface they expand in brushes, the most divergent spicules being actually within the dermis.

Principal spicules, subtylostyles (fig. $36, A$ ); size, $9 \mu$ by $250 \mu$ to $10 \mu$ by $280 \mu$. First microscleres, palmate anisochelas (fig. 36, B); length, $30 \mu$ to $36 \mu$, often in rosettes. Second microscleres, palmate anisochelas (fig. $36, C$ ) ; length, about $13 \mu$. Third microscleres, toxas (fig. 36, D) ; length, $45 \mu$ to $75 \mu$. Fourth microscleres, sigmas (fig. $36, E)$; length, $60 \mu$ to $75 \mu$. The microscleres are distributed generally throughout the flesh. The toxas are very rare.

Remarks.-The nearest relatives of this species seem to be the Mycale macitenta Bowerbank, 1866, from Great Britain (recorded by Hentschel in 1912 from Australia), and Mycale aegagropila Bower-

${ }^{s}$ Named for Prof. G. E. MacGinitie, of Stanford University, who discovered this sponge. 
bank, 1866, from Great Britain. M. macilenta differs in having enormous toxas. $M$. aegagropita differs in that its megascleres, sigmas, and toxas are 15 to 50 per cent larger than in macginitiei. Were one to synonymize those two, macginitie $i$ would fall as a third synonym. As long as the two mentioned are retained as separate species, macginitiei should also stand. Bowerbank put macilenta in Hymeniacidon, aegagropila in Desmacidon; and Gray, 1867, made a genus Aegagrophila for the latter. Some recent authors, especially Wilson, 1925, synonymize macilenta with aegagropila. On the other hand, Hentschel, 1913, gives data that seem to me adequate demonstration of sufficient difference to warrant retaining most of the present species

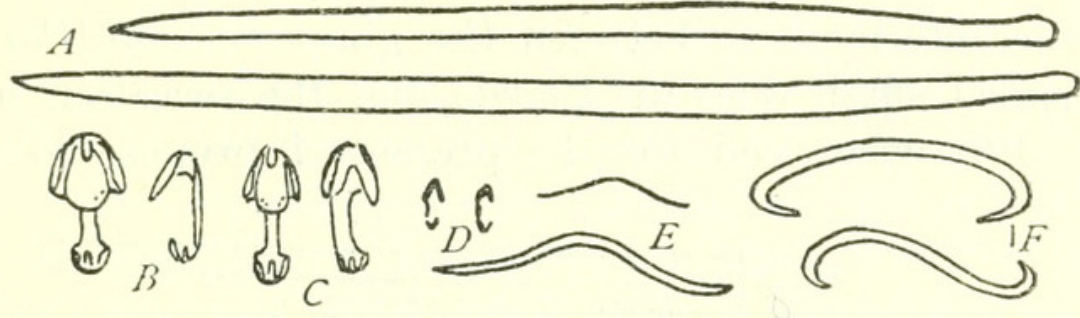

Figure 36.-Mycale macginitiei de Laubenfels, $\times 300$

of Mycale for our convenience in discussing them, if for no other reason. The differences between these others and macginitiei, though not great, when taken in conjunction with the geographical locations, make it seem advisable to retain it and them as distinct species.

\section{Genus PARESPERELLA Dendy}

PARESPERELla PSILA de Laubenfels

Paresperella psila de Laubenfels, 1930, p. 26.

Holotype.-U.S.N.M. No. 21478; B. M. No. 29.8.22.38.

Type locality.-Monterey Bay, Calif., trawled by Prof. T. Skogsberg, on March 30,1929, depth 15 meters. I found one other specimen, beachworn and macerated, in the wrack at Hopkins Marine Station, March 20, 1929. That the species may be moderately common is indicated by the frequency with which one notes the distinctive serrated sigmas in sponges having obviously foreign spicules. There is this much evidence to indicate its occurrence also in southern California.

Description.-Shape, amorphous to massive. Size, $3 \mathrm{~cm}$ high, $5 \mathrm{~cm}$ in diameter. Consistency, between spongy and fragile. Color in life and when preserved, pale drab. Oscules, not evident. Pores, $50 \mu$ to $200 \mu$ in diameter; abundant. Surface, superficially smooth.

Ectosomal specialization, a dermal membrane, about $20 \mu$ thick. It is fleshy, detachable, and contains abundant tangentially placed spicules of all the sorts characteristic of the species. Endosomal structure, "crumb-of-bread," with very evident threadlike fibers. 
Very few of the large sigmas are found in the endosome. Ascending fibers, $100 \mu$ to $300 \mu$ in diameter, cored by the styles.

Principal spicules, subtylostyles (fig. $37, A$ ); size, about $10 \mu$ by $410 \mu$. First microscleres, giant serrated sigmas (fig. $37, B$ ); length, about $210 \mu$ to $265 \mu$. Second microscleres, sigmas (fig. $37, C$ ) ; length, about $40 \mu$ to $45 \mu$. Third microscleres, palmate anisochelas (fig. 37, $D)$; often in rosettes; length, $32 \mu$ to $38 \mu$. Fourth microscleres, palmate anisochelas (fig. $37, E$ ) ; length, $16 \mu$ to $17 \mu$.

Remarks.-Hentschel (1913) in his summary of the genus Mycale includes Paresperella (Dendy, 1905, p. 162, type species P. serratohamata), but I hesitate to drop Dendy's genus without further study. The size of the sigmas can not be used, it is true, for all grades occur intermediate between the giant ones of Paresperella and the typical small ones of Mycale, but the serration may be a distinctive difference; and for the present, I propose to use it as

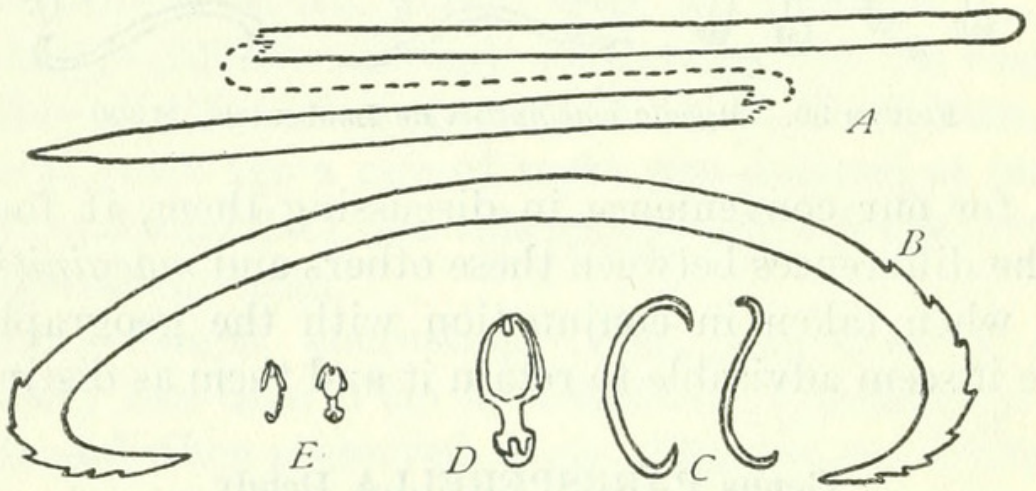

Figure 37.-Paresperella psila de Laubenfels, $\times 300$

distinctive of Paresperella, retaining this genus. The only sponge having spicule measurements at all close to those of psila is Mycale fascifibula Topsent, 1904, from the Azores, but its megascleres are polytylote, it has raphides, and its large sigmas not serrated. Lambe (1894, p. 130) records a sponge from Vancouver Island, British Columbia, as Esperella serratohamata Carter, but it is quite distinct from psila and is not certainly correctly identified with Carter's species. As compared to psila, it has much smaller $(335 \mu)$ megascleres, smaller $(157 \mu)$ macrosigmas, lacks the smaller anisochelas, and has toxas, which psila lacks.

\section{Genus ESPERIOPSIS Carter}

ESPERIOPSIS ORIGINALIS de Laubenfels

Esperiopsis originalis de LAUBenfels, 1930, p. 27.

Holotype.-U.S.N.M. No. 21441; B.M. No. 29.8.22.54.

Type locality.-Pacific Grove, Calif., July 2, 1926, intertidal, collected by me. The species is common in this vicinity. At first I 
confused it with Ophlitaspongia pennata (which see); but in addition to the differences between the sponges there is also a difference in the habitat, the two overlapping little if any. As noted elsewhere, pennata occurs nearer high-tide mark than any other sponge of which I know, usually on the sides of bowlders beneath pendant seaweed. E. originalis occurs very near low-tide mark and also below it, usually underneath stones. It also grows loose and unattached or on coralline algae. It is moderately common in central California, and on March 14, 1926, I found several small patches of this species encrusting rocks intertidally at Laguna Beach.

Description.-Shape, massive. Size, 2 by 3 by $7 \mathrm{~cm}$. Consistency, stiff, slightly compressible. Color in life, light brownish red; preserved, pale drab. Oscules, round, not raised; diameter, up to $2 \mathrm{~cm}$. The oscules are largest and most frequent where the sponge is thickest. One small, undamaged specimen brought into the laboratory, July 2, 1926, exhibited strong oscular currents, tall transparent protoplasmic "chimneys" being thrown up above the surface by the force of the stream. They were contractile, at times reducing the size of the actual opening to far less than that of the canal or cloaca below, without shortening much if at all. In this sponge the cloacal tubes were about $300 \mu$ in diameter, and the chimneys raised also about $300 \mu$ above the surface. Pores, not evident; clearly they must be exceedingly minute. Surface, superficially very smooth.

Ectosomal specialization, a dermal membrane only $2 \mu$ to $5 \mu$ thick; detachable, fleshy, contains probably but one cell layer and seemingly no spicules. Endosomal structure, a very regular reticulation of strong fibers perpendicular to the surface, containing a little spongin and many rows of styles, points almost always toward the surface. The connectives are merely single spicules, however, but placed almost as symmetrically as the rungs of a ladder. Histological details: The subspherical flagellate chambers are about $30 \mu$ in diameter. Ascending fibers, $25 \mu$ to $35 \mu$ in diameter and about $150 \mu$ apart. Accessory, or transverse, fibers, single spicules only.

Principal spicules, subtylostyles (fig. $38, A, B$ ); size, $12 \mu$ by $150 \mu$ to $13 \mu$ by $155 \mu$. Microscleres, palmate isochelas (fig. $38, C, D$ ); length, $13 \mu$ to $16 \mu$.

Remarks.-Comparison between this species and Ophlitaspongia pennata is interesting. Neither is typical of the genus in which it is now placed, and either could be shifted over to the other genus without violence. The two species are easily separated when the microscleres are to be found, however, as the one has only chelas where the other has toxas. E. originatis has also much smaller magascleres. The colors are not quite the same, originalis having a rather brownish tinge where pennata is clear bright red. 
This differs from typical Esperiopsis in lacking sigmas. The very symmetrical ladder structure is a bit unusual, though isodictyal structure and fibrous structure are common in this genus. The dermis is typical. The closest relative seems to be Esperiopsis glaber Brøndsted (1924, p. 141) from New Zealand, which has exactly the same architecture, but longer styles (up to $10 \mu$ by $370 \mu$ ), and has three sizes of sigmas.

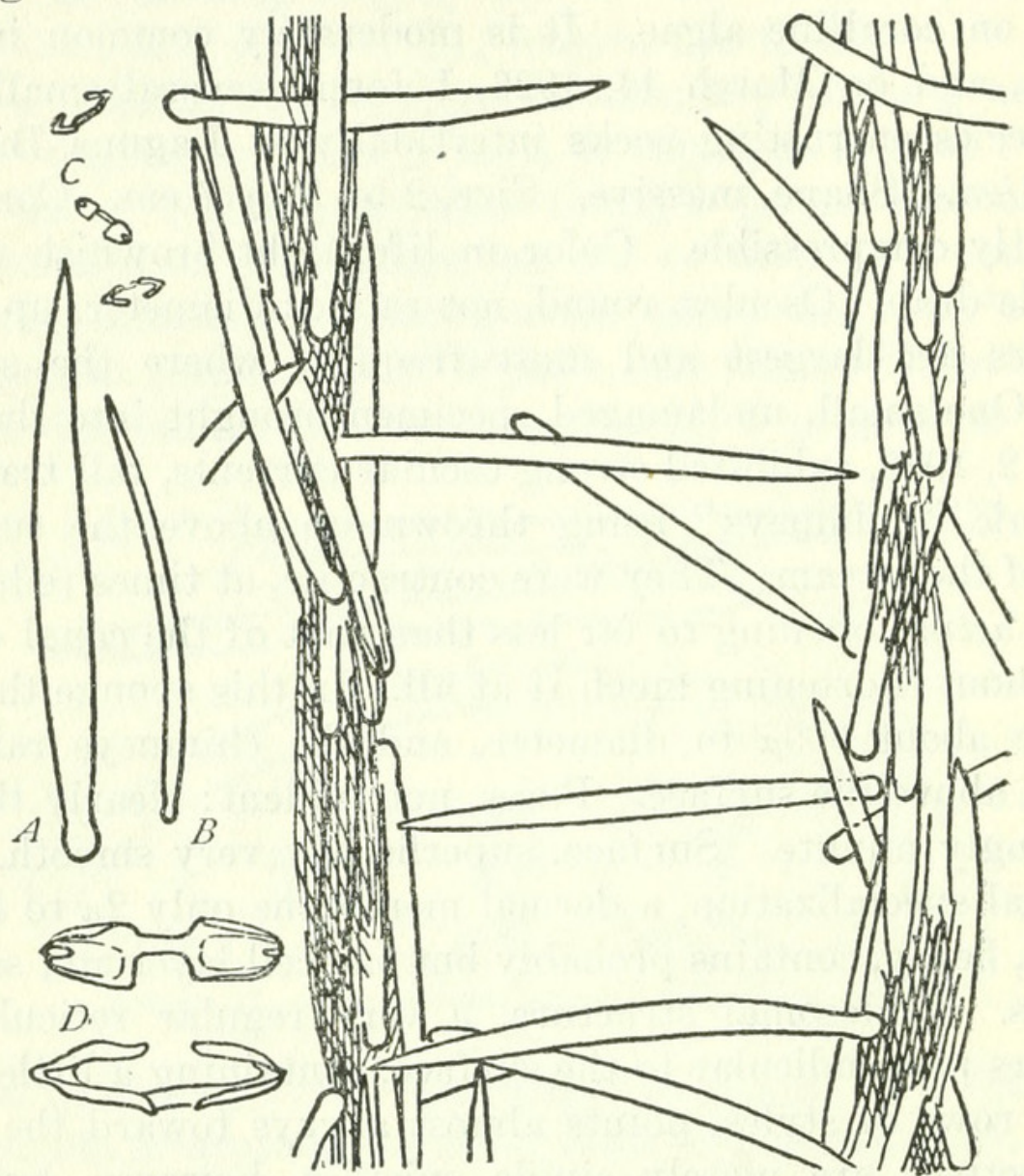

Figure 38.-Esperiopsis originalis de Laubenfels: Portion of the skeleton. $A$, Maximum size of the megasclere; $B$, small size of the megasclere, probably immature; $C, D$, microscleres. $D, \times 1,333$; others, $\times 300$

\section{Genus WILSA ${ }^{4}$ de Laubenfels}

Wilsa may be defined as of the subfamily Mycalinae, for sponges with smooth monaxon megascleres, palmate isochelas and forceps, typically with macrosigmas as well as sigmas of the more usual size. Genotype: Wilsa hymena.

WILSA HYMENA de Laubenfels

Wilsa hymena de LAUBenfels, 1930, p. 27.

Holotype.-U.S.N.M. No. 21515; B.M. No. 29.8.22.62.

Type locality.-Monterey Bay, Calif., May 9, 1929, depth 700 meters, collected by E. F. Ricketts. The one specimen was on the 
macerated skeleton of a dictyonine hexactinellid sponge, and was in intimate contact along one edge with Lissodendoryx kyma (which see).

Description.-Shape, encrusting. Size, 5 by $18 \mathrm{~mm}$ in area; the depth can not be measured, as the sponge penetrated into the macerated dictyonine skeleton on which it was growing. Consistency, fragile. Color in life and when dry, pale drab. Oscules and pores, not evident. Surface, superficially smooth.

Ectosomal specialization, a dermal membrane; fleshy, detachable, about $30 \mu$ to $70 \mu$ thick, containing abundant macrosigmas. Endosomal structure, the endosome is so blended with the hexactinellid skeleton that its proper structure can not be ascertained.

Principal spicules, smooth styles (fig. $39, A$ ); size, $10 \mu$ by $330 \mu$ to $15 \mu$ by $600 \mu$. First microscleres, palmate isochelas (fig. 39, D); length, $17 \mu$ to $20 \mu$. Second microscleres, giant sigmas or macrosigmas

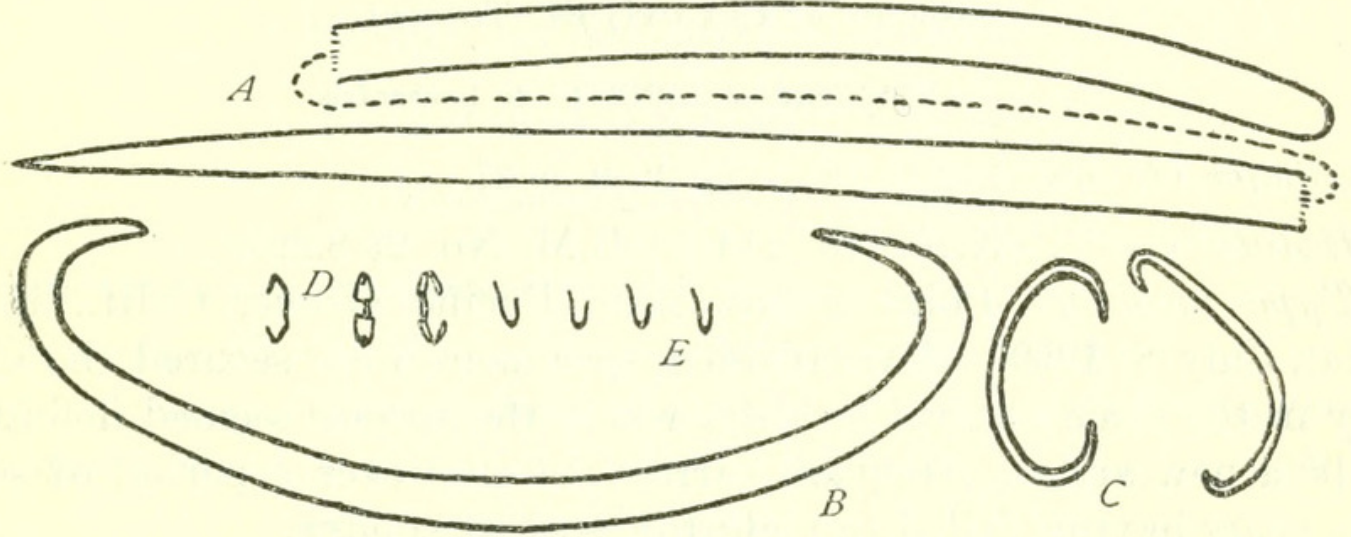

Figure 39.-Wilsa hymena de Laubenfels, $\times 300$

(fig. 39, $B$ ) ; length, about $250 \mu$. Third microscleres, sigmas (fig. 39, $C$ ); length, $55 \mu$ to $75 \mu$. Fourth microscleres, forceps (fig. 39, E); length, $10 \mu$ to $12 \mu$.

Remarks.-Practically all that can be obtained for this interesting sponge is of the nature of ectosome. It contains some tornotes and a very few arcuate chelas, obviously from its neighbor L. kyma. It is packed with the macrosigmas, has but few of the microsigmas, moderate quantities of the palmate isochelas, and rather numerous forceps. These latter appear smooth with less resolving power than 0.95 numerical aperture, and even with the utmost care only the very faintest traces of spination can be discovered, but very small spines are certainly present. The deeper portions contain a few scattered styles as mentioned, but no scheme of their arrangement could be discovered.

The closest relative of hymena is clearly Lundbeck's Esperiopsis forcipula $(1905$, p. 17), which should also be placed in the genus Witsa. Its styles are $540 \mu$ to $680 \mu$; its macrosigmas only $83 \mu$; its 
microsigmas only $30 \mu$; its chelas are much larger $(38 \mu$ to $50 \mu)$ and more nearly arcuate than those of hymena; its forceps are larger $(17 \mu)$ and much more clearly spined.

Some authors (see Topsent, 1928) would regard the presence of forceps as of little taxonomic value. Such conclusions as this are probably correct, but until an extensive revision of the phylum is carried out, consistently eliminating the very numerous genera founded on such bases, it is only consistent to continue using such criteria. Topsent himself continues to found many new genera based upon peculiarities of microscleres. I think he is quite justified in this on the grounds of expediency, and I follow this action of his rather than his suggestion that would lead to making Esperiopsis a genus of a size so large as to be unwieldy.

\section{Family COELOSPHAERIDAE Hentschel}

\section{Genus ASTYLINIFER Topsent}

\section{ASTYLINIFER ARNDTI ${ }^{5}$ de Laubenfels}

Astylinifer (?) arndti de Laubenfels, 1930, p. 27.

\section{Holotype.-U.S.N.M. No. 21435; B.M. No. 29.8.22.4.}

Type locality.-Point Pinos, near Pacific Grove, Calif., intertidal, July 8, 1929. Several other specimens were secured the same day in the same general locality, where the species seemed definitely to be a new arrival, frequent earlier searches over a period of some five years having failed to yield this sort of sponge.

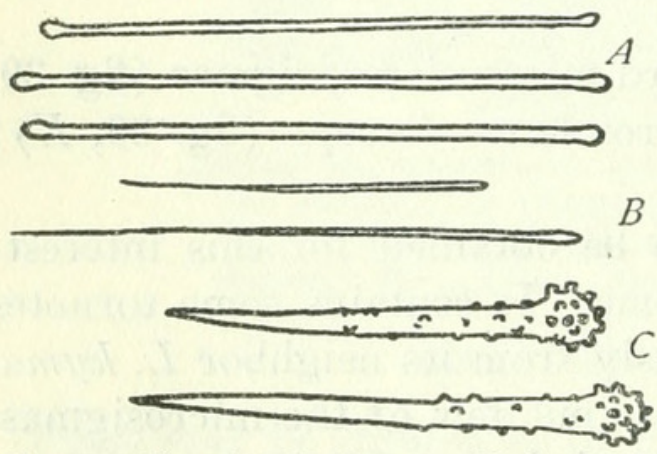

Figure 40.-Astylinifer arndti de Laubenfels, $\times 300$

Description.-Shape, encrusting. Size, 0.4 to $1.3 \mathrm{~mm}$ thick; several centimeters in diameter. Consistency, mediocre. Cólor in life, some specimens ocher-yellow, others with purple areas, and some halfway between the two colors present and appearing brown. Preserved specimens are drab. Oscules and pures, not evident. Surface, superficially smooth.

Ectosomal specialization not discernible. Endosomal structure, predominantly protoplasmic with scattered fascicular bundles of tylotes, often, but not always perpendicular to the surface. At the very base are a few acanthotylostyles perpendicular to the substratum.

Principal spicules, tylotes (fig. $40, A$ ), $3 \mu$ by $140 \mu$ to $4 \mu$ by $145 \mu$. Echinating spicules, acanthotylostyles (fig. $40, C$ ), $8 \mu$ by $110 \mu$ to $9 \mu$

' Named for Prof. Walther Arndt, of the University of Berlin. 
by $130 \mu$. Microscleres, rhaphides (fig. $40, B$ ) ; size $1 / 2 \mu$ by $95 \mu$ to $1 \mu$ by $140 \mu$.

Remarks.-The other member of this genus, A. planus Topsent (1927, p. 9), has tylotes of double the measurements of those of arndti and a few toxas in addition to diactinal rhaphides. As a matter of fact arndti is very close to the genus Hymedesmia from which it may be derived. It is interesting to compare it to Hymenamphiastra cyanocrypta from the same general locality. A. arndti has much smaller acanthotylostyles, which further play a very insignificant part in the sponge as a whole, the bulk of it having only tylotes. In cyanocrypta the tylotes are more distinctively just dermal spicules, and, of course, there are the very peculiar microscleres. A further noteworthy difference is in the shape of the ends of the tylotes, which in arndti are ball-like, nearly spherical; in cyanocrypta they are elongate-oval with hastate terminations.

\section{Family MYXILLIDAE Topsent}

\section{Genus LISSODENDORYX Topsent}

\section{LISSODENDORYX KYMA de Laubenfels}

Lissodendory $x$ kyma DE LAUBenfels, 1930, p. 27.

Holotype.-U.S.N.M. No. 21511; B.M. No. 29.8.22.60.

Type locality.-The one specimen was growing on the macerated dictyonine skeleton collected by E. F. Ricketts, on May 9, 1929, in Monterey Bay, Calif., depth 700 meters.

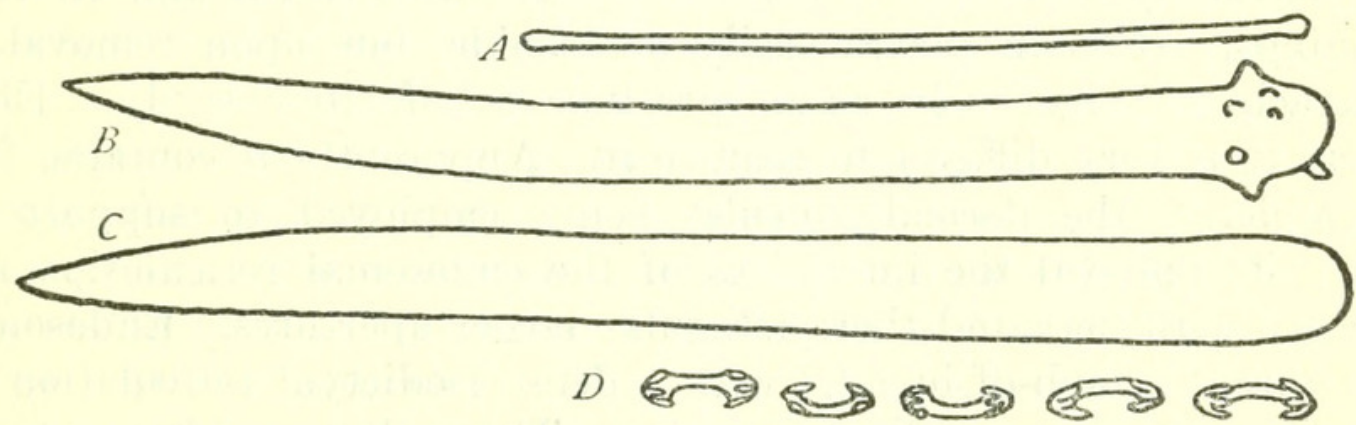

Figure 41.-Lissodendory $x$ kyma de Laubenfels, $\times 300$

Description.-Shape, encrusting. Size, $5 \mathrm{~mm}$ thick, $28 \mathrm{~mm}$ in diameter. Consistency, fragile and friable. Color in life and when dry, pale drab. Oscules and pores, not evident. Surface, superficially wavy, with the troughs about $2 \mathrm{~mm}$ deep.

Ectosomal specialization, an indefinite sort of dermal membrane, not detachable; it is packed with tangentially placed tornotes. Endosomal structure, "crumb-of-bread," with large styles in confusion. 
Principal spicules, smooth styles (fig. $41, C$ ); size, $25 \mu$ by $350 \mu$. Secondary spicules, styles with spiny heads (fig. $41, B$ ) ; size, $20 \mu$ by $340 \mu$. Ectosomal spicules, tornotes (fig. $41, A$ ); size, $5 \mu$ by $205 \mu$. Microscleres, arcuate chelas (fig. $41, D$ ) ; length, $25 \mu$ to $30 \mu$.

Remarks.-This species is peculiar for having only the one sort of microsclere, and the disproportion between the ectosomal and endosomal spicules is not common.

Similar species of this genus are reported from all parts of the world.

LISSODENDORYX NOXIOSA de Laubenfels

Lissodendoryx noxiosa DE LAUBENFELS, 1930, p. 27.

Holotype.-U.S.N.M. No. 21467; B. M. No. 29.8.22.14.

Type locality.-Pacific Grove, Calif., intertidal, July, 1925, collected by me. This species is very abundant in the Monterey region, growing in a variety of situations in the intertidal zone, but most frequently in crevices or under rocks.

Description.-Shape, amorphous. Size, at least $10 \mathrm{~cm}$ high and $15 \mathrm{~cm}$ in diameter. Consistency, spongy. Color in life, yellow; preserved much paler, nearly colorless. Oscules, there may or may not be present surface openings or depressions of very irregular size and shape, which may or may not be oscules or pores or neither or both. Pores, see remarks above. Surface, primarily smooth but with more or less abundant irregularities in the form of both lumps and pits.

Ectosomal specialization, a dermal membrane, about $30 \mu$ thick; so contractile that it is difficult to study the afferent and efferent openings. It is in places easily detachable, but upon removal it contracts so vigorously as to preclude satisfactory study. Elsewhere it is very difficult to remove it. Apparently it contains few megascleres, the dermal spicules being employed to support it. After its removal the interstices of the endosomal reticulation are exposed with here and there irregular larger apertures. Endosomal structure, "crumb-of-bread," with a dense isodictyal reticulation of the styles; meshes usually triangular. The styles are often side by side, so placed as to outline chambers with walls having some resemblance to those of old-fashioned log cabins.e

Principal spicules, styles (fig. $42, B, C$ ) ; size, $10 \mu$ by $180 \mu$ to $12 \mu$ by $200 \mu$. These styles almost always have about two to four rather large spines; occasionally they have as many as six or eight, and also a few are entirely smooth. The spines are rather more often to be noted on the heads than on the shafts. Very thin forms of both sorts of megascleres are met with, probably immature stages (fig. $41, D$ ). Ectosomal spicules, tylotes (fig. $42, A$ ) ; size, $4 \mu$ by $180 \mu$ 
to $5 \mu$ by $200 \mu$. First microscleres, arcuate chelas (fig. 42, F); length, $28 \mu$ to $33 \mu$. Second microscleres, contort sigmas (fig. 42, E) ; length, $32 \mu$ to $40 \mu$.

Remarks.-Many species of Lissodendoryx have been described as of Myxilla, and many differ from one another but slightly. Two Myxillas, properly to be transferred to Lissodendoryx, described by Lambe from the west coast of Canada, particularly merit comparison to noxiosa. The first is lacunosa (1892, p. 70), which differs from noxiosa in having hastate dermal spicules twice the thickness of those in the California species; it has styles very similar but with practically no spination, somewhat larger chelas, and smaller sigmas. The second is firma (1894, p. 122), which has dermal spicules shaped like those of noxiosa, but twice as thick, and styles about twice as large (up to $19 \mu$ by $366 \mu$ ), and with no spines at all. Its chelas and sigmas are each much larger than in noxiosa, but quite noteworthy for their similarity in shape.

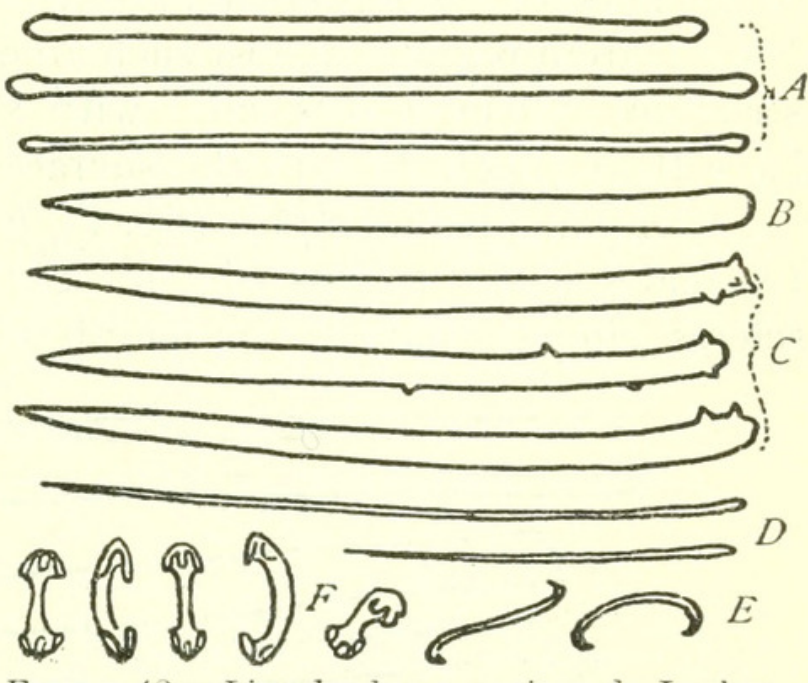

Figure 42.-Lissodendoryx noxiosa de Laubenfels, $\times 300 . F$, row of chelas, one at right nearly in end view

The styles of noxiosa are peculiar in having a few large spines, there being usually either smooth styles, or styles with many small spines, or many large ones. The most striking characteristic, however, is the strong, offensive odor of noxiosa. I am familiar with one other Lissodendoryx in the living condition (a West Indian form); that has a pungent odor, seemingly the same. In view of the supposed close relationship of Lissodendoryx with Myxilla, it is interesting to note that none of the Myxillas I have known in the living state had this odor. The odor may not be proper, however, as in $1929 \mathrm{I}$ found two specimens of this species that lacked it.

\section{LISSODENDORYX REX de Laubenfels}

Lissodendoryx rex DE LAUBENFELs, 1930, p. 27.

\section{Holotype.-U.S.N.M. No. 21512; B.M. No. 29.8.22.63.}

Type locality.-This sponge was growing on the macerated skeleton of a dictyonine sponge collected in Monterey Bay, Calif., depth 700 meters, by E. F. Ricketts, on May 9, 1929.

Description.-Shape, massive. Size, $2 \mathrm{~cm}$ high, $3 \mathrm{~cm}$ in diameter. Consistency, fragile. Color in life and when dry, drab. Oscules, not evident. The exhalent openings presumably were toward the 
concavity of the macerated hexactinellid on which this species grew, and therefore impossible to study. The bulk of the sponge was on the outer (convex) part of the hexact, but it ramified extensively into the dictyonine framework. Pores, not evident. Surface, superficially smooth.

Ectosomal specialization, a dermal membrane; very thin, detachable, fleshy. The dermis contains many of the sigmas, and a few scattered tangential tornotes, and is held up and away from the endosome by numerous fascicular bundles of the tornotes, perpendicular to the surface. The Lissodendoryx with which I am familiar in the West Indian region has just such an ectosomal structure. Endosomal structure, "crumb-of-bread," with scattered styles, most of which have their points toward the surface.

Principal spicules, styles (fig. $43, B$ ) ; size, about $16 \mu$ by $570 \mu$. Ectosomal spicules, tylotes (fig. $43, A$ ) ; size, about $7 \mu$ by $280 \mu$. Microscleres, sigmas (fig. $43, C$ ) ; length, $50 \mu$ to $55 \mu$.

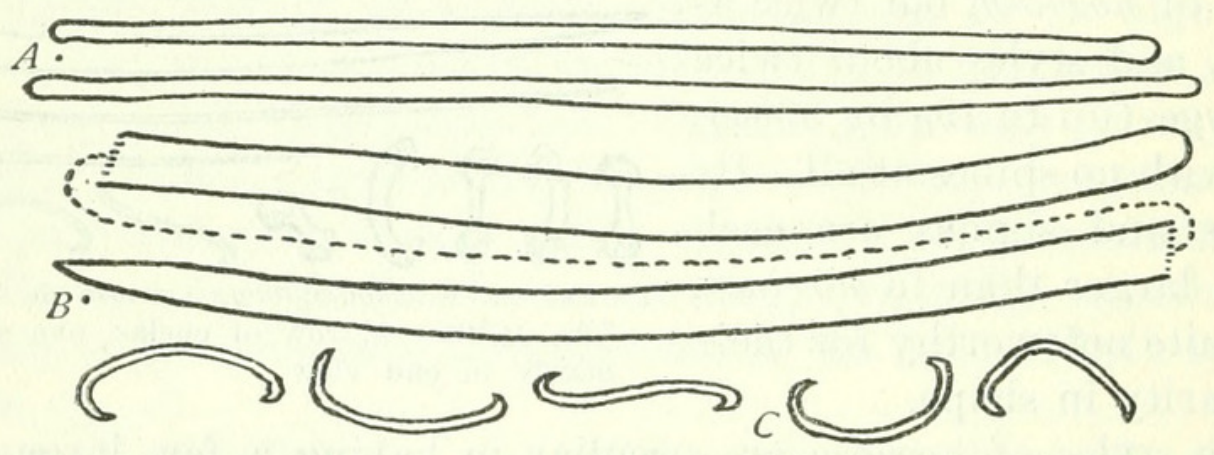

FIGURE 43.-Lissodendoryx rex de Laubenfels, $\times 300$

Remarks.-Generic allocation of this sponge is very difficult, even for a sponge. The ectosome is typically Lissodendory $x$ and so are the sigmas, but the complete absence of chelas makes one doubt that this genus is the proper one to use. Smooth styles in the endosome are also characteristic of Lissodendoryx, but not styles so much larger than the ectosomal spicules, and the structure is radically different. Lissodendoryx should have monaxons in compact and nearly isodictyal reticulation; this sponge has the mycalid structure of many Biemnas. Biemna has similar spiculation, moreover, except for the special dermal spicules, so this could be described as a Biemna with the ectosome of a Lissodendoryx. One might erect a new genus, but in view of the scarcity of specimens on hand I regard such action as not at present called for.

Lundbeck (1905) would make the distinction between Myxilla and Lissodendoryx that the former has anchorate chelas, the latter arcuate or palmate. Where the chelas occur this is doubtless the best line of demarcation. In this aberrant form lacking the chelas, however, Lissodendoryx is chosen because, as Lundbeck notes, it usually has 
smooth principal spicules as against Myxilla's usually spiny principal spicules. Topsent separated Lissodendoryx originally on just this difference.

\section{Genus MYXILLA O. Schmidt}

MYXILLA AGENNES de Laubenfels

Myxilla agennes de LaUbenfels, 1930, p. 27.

Holotype.-U.S.N.M. No. 21415 ; B.M. No. 29.9.30.14.

Type locality.-The one specimen was collected February 16, 1924, by the University of Southern California at Point Fermin near San Pedro, Calif., intertidal.

Description.-Shape, amorphous. Size, $25 \mathrm{~mm}$ high, $30 \mathrm{~mm}$ in diameter. Consistency, mediocre. Color in alcohol, drab. Oscules and pores, not evident. Surface, superficially very lumpy.

Ectosomal specialization, a dermal membrane; this is $20 \mu$ to $60 \mu$ thick, not readily detachable, fleshy, and contains almost no spicules at all, but those present are tornotes. Endosomal structure, "crumbof-bread," with very numerous spicules, often in confusion, but occasionally in vague isodictyal reticulation, and again sometimes in ascending plumose columns ending in surface protuberances.

Principal spicules, styles usually curved or bent and usually quite smooth, but now and then with a few spines. Size, $7 \mu$ by $155 \mu$ to $10 \mu$ by $175 \mu$. There are a very few about twice this size that may be

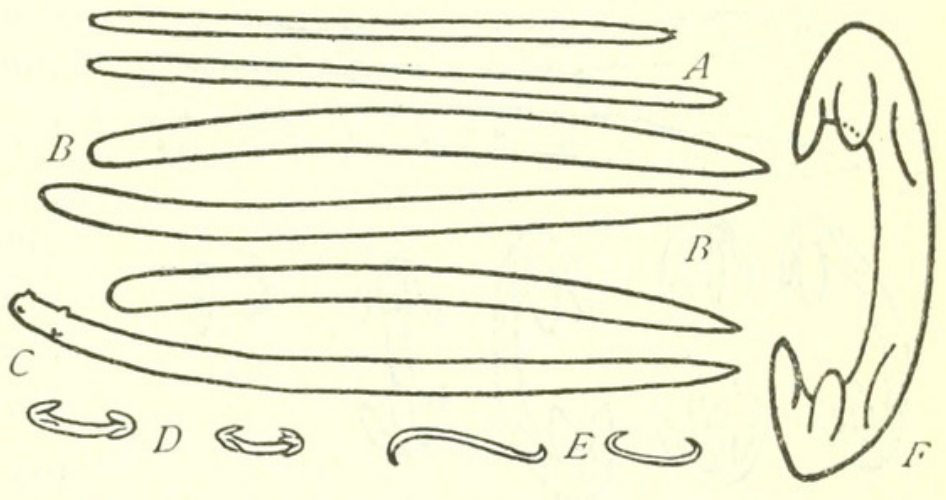

Figure 44.-Myxilla agennes de Laubenfels: $F$, side view of an anchorate chela, $\times 1,333$; others, $\times 300$

foreign. There are also many forms barely $1 \mu$ or $2 \mu$ thick, which seem to be developmental stages of those mentioned above (fig. 44, $B, C)$; size, $7 \mu$ by $155 \mu$ to $10 \mu$ by $175 \mu$. Ectosomal spicules, tornotes with ends microspined (fig. $44, A$ ) ; size, $4 \mu$ by $145 \mu$ to $4 \mu$ by $155 \mu$, rare. First miscroscleres, anchorate chelas (fig. 44, D, F) ; length, about $27 \mu$, rare. Second microscleres, sigmas (fig. $44, E$ ) ; length, $30 \mu$ to $36 \mu$, rare.

Remarks.-This species is remarkable for the almost total loss of all but the styles, and on them of the almost total loss of the characteristic spination. The typical Myxilla structure is also almost lost. On the other hand, all the items are there, though in reduced quantity; a few characteristic dermal tornotes properly placed, a few spines in the endospicules, a few characteristic anchorate chelas, a few 
sigmas, and bits of the isodictyal reticulation. A little further reduction and one would have a Hymeniacidon, which like most every simple sponge genus is probably polyphyletic.

\section{MYXILLA PARASITICA Lambe}

My xilla parasitica LAMBE, 1893, p. 31.

Holotype.-In the Museum of the Geological Survey, Ottawa, Canada.

Type locality.-The west coast of Canada.

Material examined.-One specimen was collected January 11, 1925, in the south end of Monterey Bay, Calif. The University of Southern California collected three: One on April 19, 1929, at Point Fermin, near San Pedro; one without locality data other than depth 30 meters; and one without locality data other than depth 60 meters.

Description (U.S.N.M. No. 21473; B.M. No. 29.9.30.15).-Shape, amorphous. Size, up to $15 \mathrm{~mm}$ high, $5 \mathrm{~cm}$ in diameter. Consistency, firm. Color in life and when preserved, drab. Oscules, indistinct, liable to confusion with the

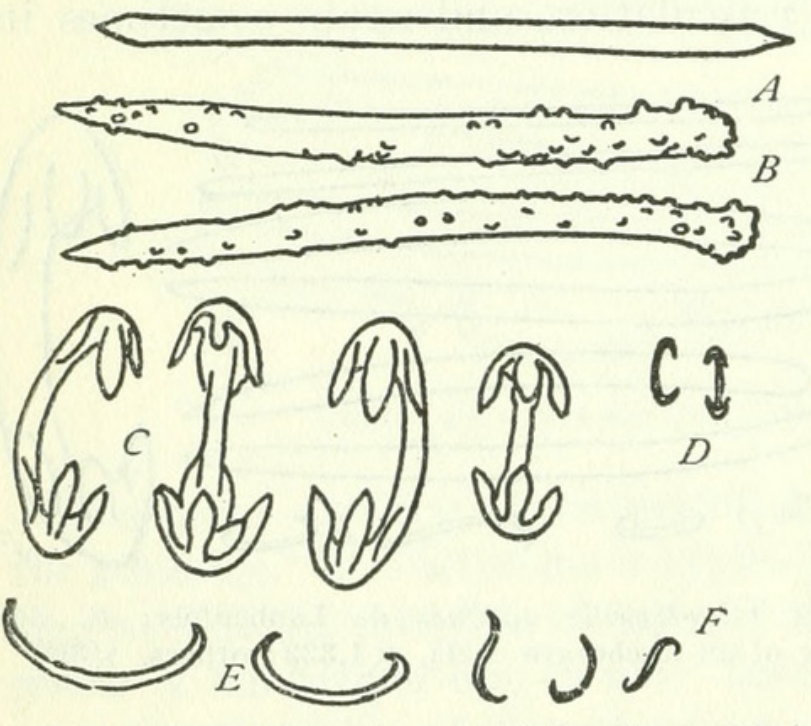

Figure 45.-Myxilla parasitica Lambe, $\times 300$ pores. Pores, at least $200 \mu$ in diameter when open. Surface, superficially very irregular; there are smooth places, also even more numerous lumps and depressions.

Ectosomal specialization obscure, doubtful. Endosomal structure, a typical myxilloid isodictyal reticulation. Histological details: The flagellate chambers are subspherical, about $25 \mu$ in diameter.

Principal spicules, acanthostyles (fig. $45, B$ ) ; size, $10 \mu$ by $170 \mu$ to: $15 \mu$ by $200 \mu$. Ectosomal spicules, hastate tornotes (fig. $45, A$ ) ; size, $7 \mu$ by $170 \mu$ to $11 \mu$ by $210 \mu$. First microscleres, anchorate chelas (fig. $45, C$ ) ; length, $48 \mu$ to $68 \mu$. Second microscleres, anchorate chelas (fig. $45, D$ ) ; length, $14 \mu$ to $18 \mu$. Third microscleres, sigmas (fig. $45, E, F)$; length, $22 \mu$ to $52 \mu$.

Remarks.-The specimen collected by the University of Southern California differs from the Monterey specimens in the shape of the larger chela, its median tooth being very much smaller than the corresponding one in the sponge from central California. This variation within the species is surprising, but the agreement in other ways is so striking that there need be little hesitation in identifying 
the two. The resemblance to Lambe's sponge is not complete, but it is still so great that I hesitate to create a new species when the geographical location is so close. The principal spicules of the Canadian sponge range somewhat larger, and it has a distinct category of very short acanthostyles that I do not find in the California specimens. Lambe's description mentions no sigmas more than $26 \mu$. Aside from these items the agreement is very close. This species is rather close to Myxilla rosacea Lieberkühn, which is the type species of the genus, a Mediterranean form.

On May 11, 1929, I collected a sponge near Pacific Grove, Calif., that had the megascleres and all the characteristics of $M$. parasitica, but no microscleres. The literature contains very few references to myxillalike sponges without microscleres (see notes under Myxilla versicolor), so this occurrence is most remarkable. As $M$. parasitica is probably common in the vicinity, I hesitate to create a new species for this form, but hazard a guess that it was an aberrant growth of $M$. parasitica. It was crowded with embryos, ovoid in shape, about $200 \mu$ in diameter.

\section{MYXILLA VERSICOLOR Topsent CALIFORNIANA, new variety}

Holotype.-U.S.N.M. No. 21474; B.M. No. 29.8.22.20.

Type locality.-Laguna Beach, Calif., intertidal, March 14, 1926, collected by me.

Description.-Shape, amorphous. Size, $15 \mathrm{~mm}$ thick, $5 \mathrm{~cm}$ in diameter. Consistency, fragile. Color in life and when preserved, pale drab. Oscules, not evident. Pores, not evident. Surface, superficially tuberculate.

Ectosomal specialization, a dermal membrane; very easily detachable, fleshy, containing abundant tangent tylostrongyles. Endosomal structure, collenchymatous, with spicules in tracts and others in confusion. Histological details: About $90 \mu$ below the surface was a layer of very dark cells, which may have been algae. Principal, or ascending, fibers about $40 \mu$ in diameter, cored by abundant styles.

Principal spicules, smooth tylostyles (fig. $46, B$ ) ; size, $8 \mu$ by $265 \mu$ to $12 \mu$ by $250 \mu$. There are also a few acanthostyles about $7 \mu$ by $150 \mu$ (fig. 46, A). Ectosomal spicules, tylostrongyles (fig. 46, D, E); size, $4 \mu$ by $240 \mu$ to $8 \mu$ by $235 \mu$. Interstitial spicules, tylostrongyles, just like the dermal, are found also scattered through the flesh.

Remarks.-The nearest relative of this form seems to be Myxilla versicolor Topsent (1893, p. xli), from Banyuls, France (on the Mediterranean coast), which differs in having much larger $(400 \mu)$ endosomal tylostyles, more so and more usually spined, and in showing a variety of colors not yet found in the Californian form.

107704-32-6 
Similar species of this genus are reported from nowhere else, the complete absence of microscleres being noteworthy.

As noted under Myxilla parasitica, I collected another myxillid sponge in California with no microscleres, rather clearly an aberrant form of a common local species. Myxilla versicolor seems the only member of the group definitely attended with such a deficiency, and equally well marked by the peculiar dermal spicule.

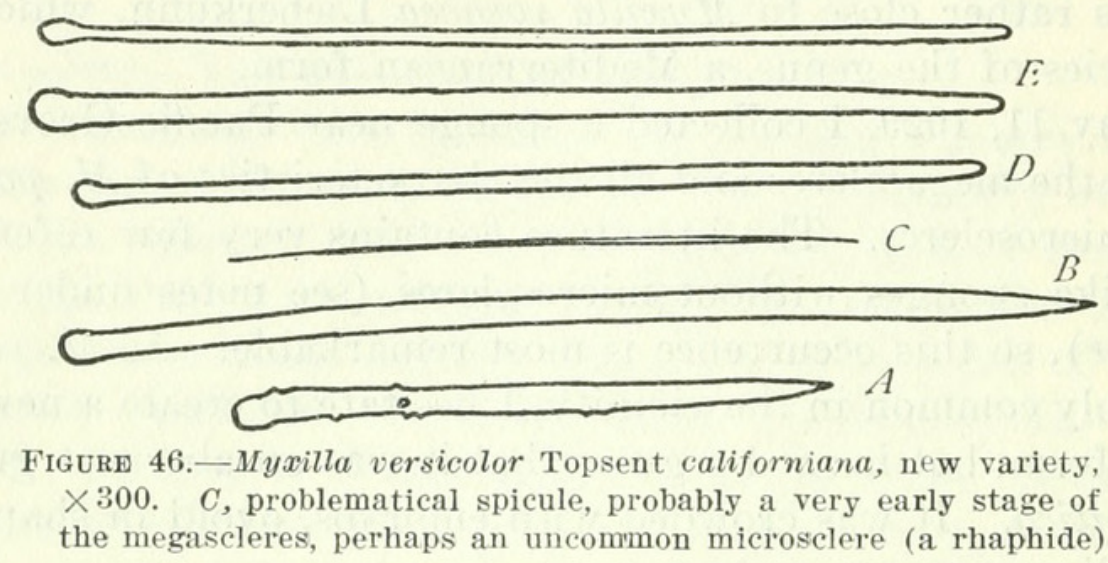

In $M$. versicolor californiana the dermal spicules are also numerous in the endosome, and the typical Myxilla reticulation is lacking. 'This latter may or may not be true for the Mediterranean form, all of Topsent's specimens having been very thin incrustations.

\section{Genus IOPHON J. E. Gray}

\section{IOPHON CHELIFER Ridley and Dendy CALIFORNIANA, new variety}

Holotype.-U.S.N.M. No. 21401; B.M. No. 29.9.30.7.

Type locality.-A handful of fragments of this sponge was dredged by the University of Southern California on December 27, 1916, south of San Pedro, Calif., depth 48 meters.

Description.-Shape, amorphous. Size, the largest fragment is about $2 \mathrm{~cm}$ in diameter; the size of the complete sponge (colony) can not be ascertained. Consistency, fragile. Color in alcohol, very dark brown. Oscules, very irregular; diameter, about $1 \mathrm{~mm}$. Pores, minute. Surface, superficially very lumpy and irregular.

Ectosomal specialization, a dermal membrane; it is fleshy, not easily detachable, and contains few spicules. The tylotes are bunched irregularly at or near the surface. Endosomal structure, "crumb-of-bread," with a dense myxilloid isodictyal reticulation of acanthostyles, cemented together by a small quantity of spongin at the nodes.

Principal spicules, acanthostyles (fig. $47, A$ ) ; size, $12 \mu$ by $265 \mu$ to $13 \mu$ by $290 \mu$. Ectosomal spicules, tylotes with heads microspined (fig. $47, C$ ) ; size, $6 \mu$ by $250 \mu$ to $8 \mu$ by $240 \mu$. Interstitial spicules, smooth styles (fig. $47, B$ ) ; about $3 \mu$ in diameter; they are probably 
developmental stages of the principal spicules. First microscleres, palmate anisochelas (fig. $47, G$ ) ; length, $15 \mu$ to $33 \mu$. Second microsclere, bipocillates (fig. $47, E$ ) ; length always very close to $15 \mu$, the shorter illustrations in the figure being end views.

Remarks.-This form differs from the typical species in having all its spicules, except the palmate anisochelas, somewhat smaller.

Lambe (1893, p. 30) describes sponges from the Pacific coast of Canada as Iophon chelifer, which should be regarded as synonymous with the new variety. Wilson $(1904$, p. 143) records sponges from
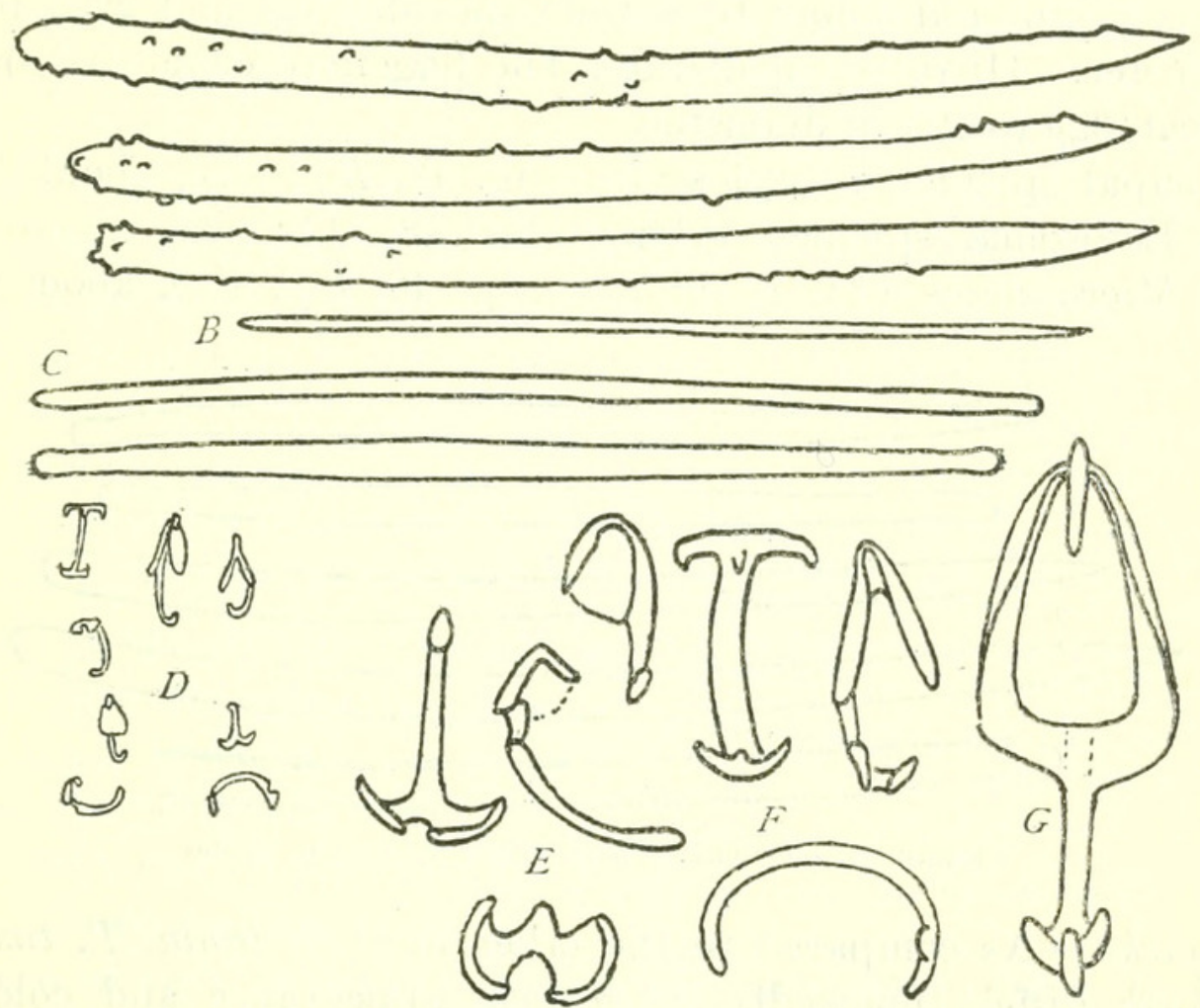

FigURe 47.-Iophon chelifer Ridley and Dendy californiana, new variety: $E-G, \times 1,333$; others, $\times 300 . F$, above and below, spicules more suggestive of anchorate chelas than of bipocillates. Such series as this, very easily noted in microscopical preparations of Iophon, point to the pathogenic distortions of chelas

the eastern tropical Pacific (Albatross Station 3384) as chelifer, variety ostia-magna. This seems not so close to the Californian form as Lambe's. The type of the species is from subantarctic waters (Ridley and Dendy, 1886, p. 349).

\section{Genus TEDANIA J. E. Gray}

\section{TEDANIA TOPSENTI ${ }^{B}$ de Laubenfels}

Tedania topsenti DE LAUBENFELs, 1930, p. 27.

\section{Holotype.-U.S.N.M. No. 21490; B.M. No. 29.8.22.2.}

Type locality.-Just below low-tide mark at Pescadero Point, near Carmel, Calif., July, 1926; the holotype and several other specimens were all collected by me. 
Description.-Shape, massive to encrusting. Size, up to $3 \mathrm{~cm}$ thick and more than $3 \mathrm{~cm}$ in diameter. Consistency, spongy. Color in life, reddish orange; preserved, very pale drab. Oscules, diameter 0.8 to $1.1 \mathrm{~mm}$. Pores, not evident. Surface, superficially smooth with numerous tubercles less than $1 \mathrm{~mm}$ high.

Ectosomal specialization, a dermal membrane; it is exceedingly thin and difficult to detach intact, and it contains tangentially placed tornotes. Endosomal structure, "crumb-of-bread," with spicules in confusion. When collected the numerous embryos were conspicuous by their bright red color; they were subspherical and $220 \mu$ to $270 \mu$ in diameter. Histological details: The flagellate chambers are subspherical, $32 \mu$ to $40 \mu$ in diameter.

Principal spicules, subtylostyles (fig. $48, B$ ); size, about $11 \mu$ by $250 \mu$. Ectosomal spicules, tylotes (fig. $48, A$ ) ; size, about $8 \mu$ to $200 \mu$. Microscleres (?), rhaphides (fig. $48, C$ ); size, about $2 \mu$ by $180 \mu$.

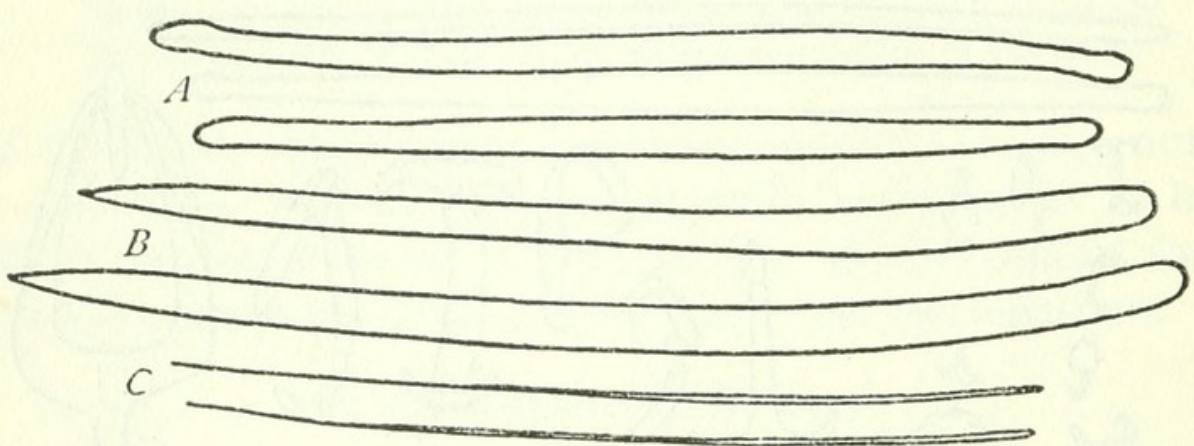

Figure 48.-Tedania topsenti de Laubenfels, $\times 300$

Remarks.-As compared to the other local Tedania, T. toxicalis, this form differs markedly in general appearance and color. It has fewer and thicker rhaphides; its endosomal subtylostyles are half again as thick; and the shape of the dermal tornotes of topsenti is quite peculiar. They are notable for the swollen shape of the central part of the shaft. The spicules here called rhaphides are not at all the rhaphides typical of the genus Tedania, but instead are possibly merely very young forms of the two sorts of megascleres. The general structure, however, and the spiculation of dermal tornotes over smooth styles are by definition Tedania. One isochela was found in a boiled-out spicule preparation, but several other similar preparations were made and they and several sections of the sponge itself were studied very carefully without the discovery of any more; it was doubtless foreign, but its occurrence should be recorded in view of the faint suggestion of resemblance to Lissodendoryx. One might use Kirkpatrickia but for the very distinctive architecture of the one species ( $K$. variolosa) of that genus. 
TEDANIA TOXICALIS de Laubenfels

Tedania toxicalis de LaUbenfels, 1930, p. 27.

Holotype.-U.S.N.M. No. 21492; B.M. No. 29.8.22.24.

Type locality.-Point Pinos, Pacific Grove, Calif., intertidal, July, 1925, collected by me. In 1925 this species was abundant in one place and about a dozen specimens were collected, all within a range of a few square meters. In 1926, only a few specimens were observed at the same place, and at no time have I found any in any other locality.

This species was found associated with Phyllospadix, growing around the bases of the stems of this seaweed.

Description.-Shape, massive; a compound of smoothly rounded parts resembling masses of foam or froth. Size, $3 \mathrm{~cm}$ high, $5 \mathrm{~cm}$ in diameter. Consistency, softly fragile. Color in life, brownish red; preserved, very pale drab. Oscules, not readily made out, as the surface has numerous pits, from 1.5 to $3 \mathrm{~mm}$ in diameter; some of these may be due to seaweed that grew through the sponge, others but "blind" depressions, others oscules, and some of the smaller may be large inhalent a pertures. Pores, not evident. Surface, superficially smooth with numerous cavities as noted above.

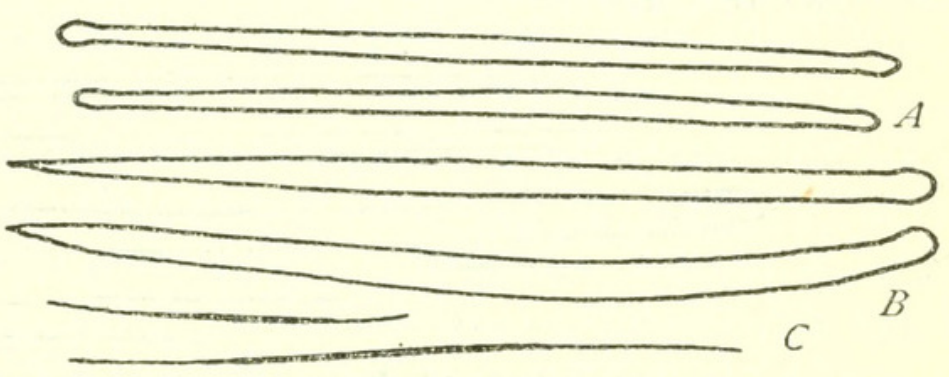

Figure 49.-Tedania toxicalis de Laubenfels, $\times 300$

Ectosomal specialization, a dermal membrane; this is fleshy, detachable, about $20 \mu$ thick, and contains tangentially placed tylotes. Endosomal structure, "crumb-of-bread," with numerous cavities about $1 \mathrm{~mm}$ in diameter surrounded by spicules tangent to their periphery, and in places vague tracts of spicules. Principal tracts about $30 \mu$ in diameter.

Principal spicules, subtylostyles (fig. $49, B$ ); size, $2 \mu$ by $100 \mu$ to $7 \mu$ by $200 \mu$. Ectosomal spicules, tylotes (fig. $49, A$ ) ; size, $8 \mu$ by $200 \mu$ to $14 \mu$ by $200 \mu$. Microscleres, smooth rhaphides (fig. $49, C$ ); size, about $2 / 3 \mu$ by $150 \mu$.

Remarks.-This is sharply marked off from most species of the genus by the tylote nature of its parenchymal monaxons. It has another striking character, its evident toxic nature, which may or may not be present in other species, as most lack descriptions of their characteristics when freshly collected. If a specimen of it be placed in a bucket with other living sea animals, as for example, fish, crabs, mollusks, and worms, in an hour or less they are observed to die, while in controls lacking the sponge they survive. 
This is interesting enough to warrant much further investigation, but since 1926 I have been unable to locate any more examples of this species.

\section{Genus TEDANIONE Wilson}

TEDANIONE OBSCURATA de Laubenfels

Tedanione obscurata DE LAUBENFELs, 1930, p. 27.

Holotype.-U.S.N.M. No. 21494; B.M. No. 29.8.22.25.

Type locality.-The one specimen is from my personal collection, taken at Point Pinos, Pacific Grove, Calif., July, 1925, intertidal. It was completely covered by a thin growth of a compound ascidian of the family Diademnidae.

Description.-Shape, amorphous. Size, $25 \mathrm{~mm}$ high, $5 \mathrm{~cm}$ in diameter. Consistency, mediocre. Color in life and when preserved, drab. Oscules, slightly less than $1 \mathrm{~mm}$ in diameter. Pores, not evident because of the overlying ascidian. Some of the openings resembling oscules may really be inhalent. Surface, covered as described above.

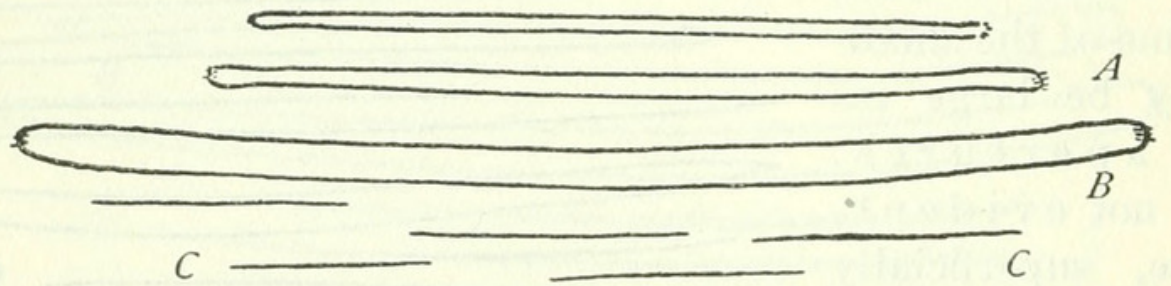

Figure 50.-Tedanione obscurata de Laubenfels, $\times 300$

Ectosomal specialization, none. Endosomal structure, "crumbof-bread," with abundant scattered spicules in confusion.

Principal spicules, tylotes to strongyles with heads microspined (fig. $50, A, B$ ) ; size, $6 \mu$ by $200 \mu$ to $12 \mu$ by $300 \mu$. Microscleres, rhaphides (fig. $50, C$ ) ; size, about $2 \mu$ by $80 \mu$.

Remarks.-In boiled-out spicule mounts one finds a few smooth styles, not shown in the figure. As these are very uncommon and do not show up in the sections of the sponge itself, they are probably foreign, yet they deserve mention. If they are proper, this would be a Tedania, having almost the entire sponge given over to ectosomal skeleton. Since this specimen had the ectosome proper replaced by the ascidian above mentioned, this is all quite puzzling.

The nearest relative of this form seems to be $T$. wilsoni Dendy, 1922, from the Indian Ocean, which differs in having all its spicules about half as thin as the California form; it also had distinct tracts and in general a more orderly structure. It, of course, was not combined with an ascidian, but was a thin crust on a hexactinellid sponge. 


\section{Family HYMEDESMIIDAE Topsent}

\section{Genus HYMENAMPHIASTRA de Laubenfels}

Hymenamphiastra may be defined as differing from Hymetrochota in having unsymmetrical desmalike amphiasters instead of symmetrical birotulates. Genotype and only species: Hymenamphiastra cyanocrypta.

HYMENAMPHIASTRA CYANOCRYPTA de Laubenfels

Hymenamphiastra cyanocrypta DE LAUBenfels, 1930, p. 27.

Holotype.-U.S.N.M. No. 21455; B.M. No. 29.8.22.18.

Type locality.-Point Pinos, Pacific Grove, Calif., July, 1925, collected by me. In July, 1929, I searched for this species, but did not find it. Several other investigators, however, discovered it, and according to their description it was in the same locality as in 1925 , one sufficiently difficult to locate that I had missed it. Judged from their remarks, the colony had more than doubled in size during the four years' elapsing. This species has an unusual habitat. There are numerous rounded granite bowlders piled one above the other, the top layer exposed only at very low tides. This top layer bears abundant life, but if one lifts many stones it is observed that the deeper ones are bare of life; they are, of course, in the dark. It was while investigating to see if any life at all occurred in these depths that this species was discovered. Though in 1925 it was found only about $60 \mathrm{~cm}$ below low-tide mark, in 1929, by enlarging its area, it had come up within $20 \mathrm{~cm}$ of that point.

Description.-Shape, encrusting. Size, less than $1 \mathrm{~mm}$ thick but spreading laterally from stone to stone so that probably more than a square meter was covered. Consistency, mediocre. Color in life, rich dark cobalt blue, growing gradually paler and paler in alcohol; after four years much blue remains. Oscules, not evident. Pores, at least $10 \mu$ in diameter; perhaps larger when expanded. Surface, superficially velvety.

Ectosomal specialization, a dermal membrane only some $7 \mu$ thick, not easily detachable, fleshy, containing very few spicules. There are extensive subdermal spaces of great variation in size, some more than $100 \mu$ deep. Endosomal structure, at the base of the sponge, where it is in contact with the substratum, there is a thin layer of spongin, at least $10 \mu$ thick, perhaps much more. Many of the acanthostyles have their heads embedded in this, very nearly perfectly perpendicular to the substratum. Above this is a zone where some of the acanthostyles are strewn in confusion. Above this, near 
the surface, is a zone where there are few acanthostyles, instead tornotes (subtylotes with hastate ends) in bundles and in confusion. Histological details: Some at least of the fiagellate chambers are about $18 \mu$ in diameter. Throughout the sponge, but especially in the ectosomal regions, there are abundant dark blue spiral microbes, $4 \mu$ or $5 \mu$ long and about $1 / 2 \mu$ thick, very probably symbionts, and certainly responsible for the blue color of the sponge. Bowerbank's Hymeniacidon gelatinosa (1866, p. 222, probably a Laxosuberites) and a sponge, perhaps identical, which Carter (1882, p. 355) identified as Terpios coerula, have very similar color and symbionts. Carter called these microbes Hypheotrix coerula. Topsent (1900, p. 199) says that he submitted them to M. Lignier, professor of botany at the University of Caen, who identified them as Beggiatoa alba var.
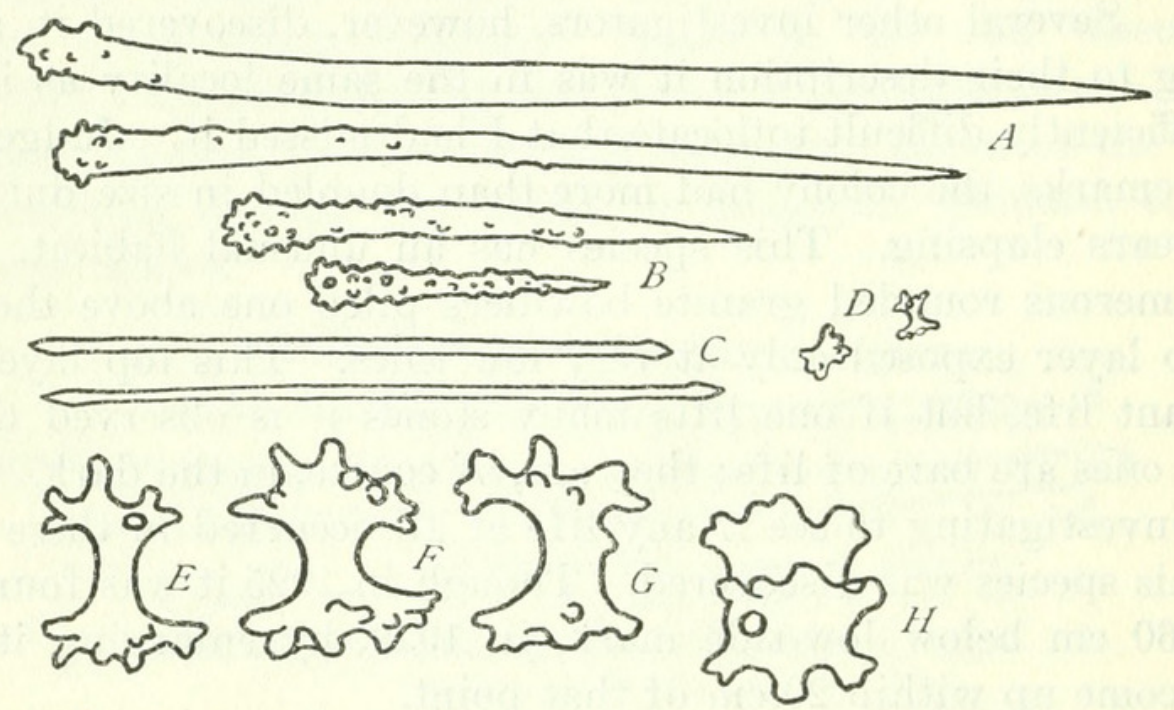

Figúre 51.--Hymenamphiastra cyanocrypta de Laubenfels: $A-D$, $\times 300$; others, $\times 1,333$. $H$, one of the peculiar microscleres in end view

marina Cohn. Recent taxonomic botany does not admit any colored forms to the genus Beggiatoa.

Principal spicules, acanthostyles (fig. $51, A, B$ ); size, $10 \mu$ by $75 \mu$ to $13 \mu$ by $280 \mu$. Ectosomal spicules, tornotes (fig. $51, C$ ); size, $3 \mu$ by $160 \mu$ to $3 \mu$ by $170 \mu$. Microscleres, amphiasters (fig. $51, D-H$ ); length, $10 \mu$ to $11 \mu$.

Remarks.-The amphiasters are located abundantly throughout the sponge and might be regarded as greatly modified birotulates, but oftenest they closely resemble desmas. In one place in this sponge were found some anchorate isochelas $26 \mu$ long, some others $36 \mu$ long, and some sigmas about $16 \mu$ long. From their exceedingly local distribution, these would seem branded as foreign inclusions, but they are worthy of mention in view of the indicated relationships.

This form is obviously most clearly related to Hymetrochota rotula Topsent (1904, p. 168), type species of and only species in the 
genus. If separate genera, such as Lissodendoryx and Myxilla are to be established upon a distinction of chela form, the Californian form with its contort desmalike obscure birotulates deserves a separate genus from Hymetrochota. H. rotula has megascleres much larger than those in Hymenamphiastra, and has neat symmetrical birotulates of the Iotrochota type. Reference to the anchorate chelas and the sigmas found in one place in $H$. cyanocrypta is interesting, because that portion exactly answers to the description of Bowerbank's Hymedesmia. Hymenamphiastra, Hymetrochota, Hymedesmia, and Hymesigma are clearly very closely related.

\section{Genus ANAATA de Laubenfels, new name}

Aata de Laubenfels, 1930, p. 27 (preoccupied).

The genus Anata may be characterized as of the family Hymedesmiidae, with smooth monaxons in the ectosome, spiny monaxons in the endosome, and isochelas as microscleres. Genotype: Anaata spongigartina.

\section{ANAATA SPONGIGARTINA de Laubenfels}

Aata spongigartina DE LAUBENFELS, 1930, p. 27.

Holotype.-U.S.N.M. No. 21428; B.M. No. 29.8.22.13.

Type locality.-Pescadero Point, near Carmel, Calif., May 11, 1929 , intertidal, collected by me. At this locality is a spot, readily recognized from year to year, where there has been a growth of this sponge since 1925 . It must either persist or recur regularly with brief absences; the former theory appearing much the more plausible. I know of only this one colony of this species in central California. On July 18, 1914, the University of Southern California collected this species on the wood pilings of the "Long Wharf," which was at Santa Monica, in southern California. Their specimen resembles the type to the most minute details that I could observe.

Description.-Shape, encrusting. Size, $5 \mathrm{~mm}$ thick and about 4 by $10 \mathrm{~cm}$ in area as growing. The specimens removed were but portions of this. Consistency, spongy. Color in life, rich brown, slightly reddish; preserved, very pale drab. Oscules-pores-craterlike openings over the entire surface, about one to each four square millimeters. Only the one sort of opening could be observed, and no decision is given as to whether all are exhalent or some inhalent. Each crater is externally a subspherical pit about $200 \mu$ in diameter surrounded by sphinctrate contractile tissue. This does not operate so as to obliterate the pit by contraction, but as follows: At the rim of the crater is a palisade of very straight subtylostyles, points outward, about $100 \mu$ of each extending beyond the protoplas- 
mic structures. With contraction of the sphincter these spicules are tilted inward till their points almost or quite meet at an apex, creating a conical shield or cap over the aperture. At the base of the chamber there is typically a constriction, so that the opening from it to the ramifying canals of the endosome is only about $100 \mu$ in diameter. I have never observed the complete closure of the cap above referred to, at the least an opening of $100 \mu$ being left, but it may be assumed that upon appropriate stimulation, as perhaps by attempted entrance of some enemy, complete closure would be possible.

Surface, superficially smooth, with projections as described above.

Ectosomal specialization, spiculous; about $100 \mu$ to $200 \mu$ thick of spicules (principally the straight smooth subtylostyles) felted together exceedingly densely so there is room for but a minimum of

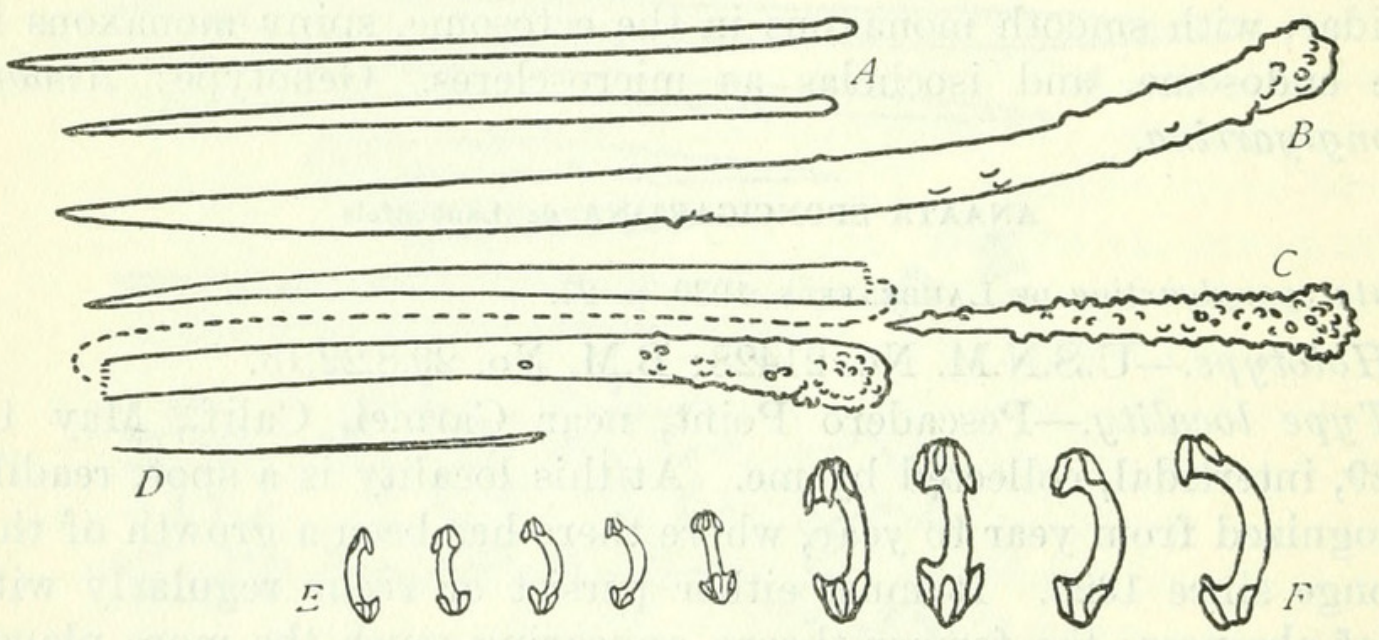

Figure 52.-Anaata spongigartina de Laubenfels, $\times 300$

protoplasm. This makes an almost solid siliceous armor. From the difficulty in tearing or cutting this layer, one may guess the presence of spongin, but no evidence of it could be noted in sections. Endosome, a rather dense protoplasmic structure, with moderately numerous acanthotylostyles, typically perpendicular to the substratum, points upward. Histological details: There are flagellate chambers up to nearly $50 \mu$ in diameter.

Ectosomal spicules, subtylostyles (fig. $52, A$ ) ; size, $6 \mu$ by $190 \mu$ to $5 \mu$ by $210 \mu$. Endosomal spicules, acanthotylostyles (fig. $52, B, C$ ); size, $13 \mu$ by $115 \mu$ to $13 \mu$ by $390 \mu$. First microscleres, arcuate isochelas (fig. $52, F$ ) ; length, $42 \mu$ to $50 \mu$. Second microscleres, arcuate isochelas (fig. $52, E$ ) ; length, $23 \mu$ to $25 \mu$.

Remarks.-The nearest relative of this species would seem to be Leptosiopsis Topsent (1927, p. 13), type species L. inaequalis. This has anisochelas of the anchorate type and is much subject to deformation, thus separating that genus from Anaata decidedly. L. inaequalis has its ectospicules often polytylote and its endospicules 
almost twice as large as those of spongigartina. The peculiar nature of the orifices of spongigartina is most noteworthy.

Another genus worthy of mention here is Leptosastra Topsent (1904, p. 194), type species L. constellata, which has astrose microscleres instead of the chelas. If these asters be derived from such deformed chelas as are found in Leptosiopsis, and the chelas of Leptosiopsis be regarded as deformities of the symmetrical ones of Anaata, then these three genera might be regarded as a linear series. This is, of course, mere speculation.

\section{ANAATA BREPHA de Laubenfels}

Aala brepha DE LAubenfels, 1930, p. 27.

Holotype-U.S.N.M. No. 21427; B.M. Nos. 29.8.22.36, 29.8.22.57.

Type locality.-Pescadero Point, near Carmel, Calif., intertidal, May 11, 1929, collected by me. It was growing over the shell of a Hinnites (a large sessile bivalve mollusk). The locality was about 5 meters from that of the holotype of Anaata spongigartina. Description.-Shape, encrusting. Size, well under $1 \mathrm{~mm}$ thick, and covering a shell about $7 \mathrm{~cm}$ in diameter. Consistency, mediocre. Color in life, salmon red; dry, brownish red; in alcohol, pale flesh color. The Hinnites was full of minute ova and was extruding these at the time of collection. The sponge was exactly the same color as these eggs. Oscules, not evident. Surface, superficially smooth but following the very rough contours of the shell of the scallop.

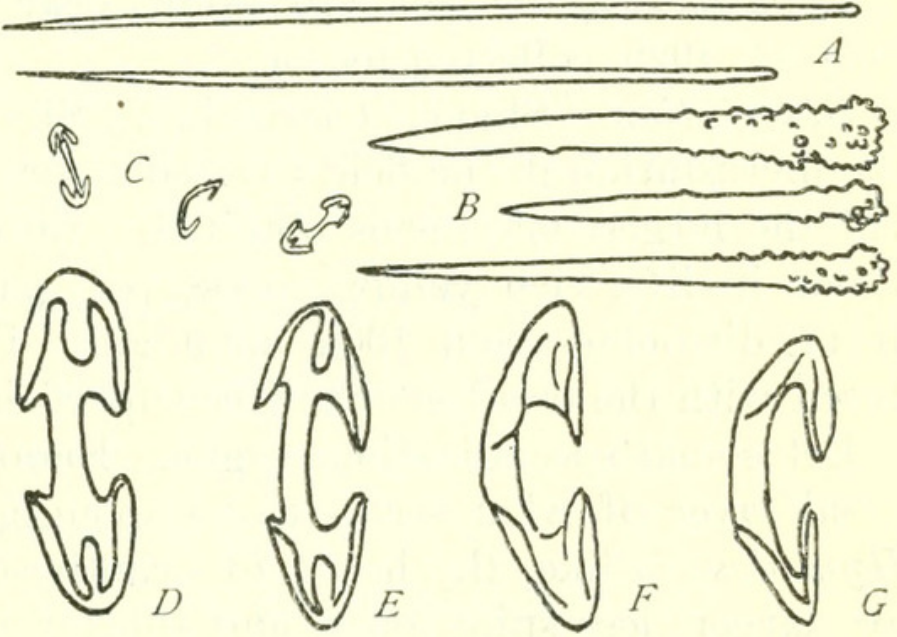

Figure 53.-Anata brepha de Laubenfels : $A-C$, $\times 300$; others, $\times 1,333$

Ectosomal specialization, not discernible because of the extreme thinness of the sponge. The styles were very definitely dermal, however. Endosomal structure, no order discernible (note above), because of the thinness of the incrustation and the great irregularity of the substrate.

Ectosomal spicules, styles (fig. $53, A$ ) ; size, $3 \mu$ by $190 \mu$ to $3 \mu$ by $210 \mu$. Endosomal spicules, acanthotylostyles (fig. 53, $B$ ) ; size, $8 \mu$ by $95 \mu$ to $8 \mu$ by $130 \mu$. Microscleres, arcuate isochelas (fig. 53, $C-$ $G$ ) ; length, $17 \mu$ to $21 \mu$. 
Remarks.-The nearest relative of this form seems to be Anaata spongigartina from the same locality, which differs in having a second (larger) size range of chelas, and much larger megascleres. A. brepha also fails to show the very peculiar apertures of spongigartina, perhaps because of its exceedingly thin size. Various conjectures naturally arise. Is this but an immature form of spongigartina? Monaxon sponges are not known to show pronounced increase in spicule size with age. Are the differences due to some such ecological item as food, for example? We absolutely do not know, and consequently, in view of the very distinct differences, I make a new species for this, particularly because of the distinct difference in chela shape between the two forms, a difference seldom seen within a species.

\section{Family EURYPONIDAE Topsent}

Genus EURYPON J. E. Gray

EURYPON ASODES de Laubenfels

Eurypon asodes de Laubenfels, 1930, p. 27.

\section{Holotype.-U.S.N.M. No. 21442 ; B.M. 29.8.22.29.}

Type locality.-Pescadero Point, near Carmel, Calif., intertidal, May 11, 1929, collected by me.

Description.-Shape, encrusting. Size, 0.2 to $0.5 \mathrm{~mm}$ thick; the incrustation in the field covered a space about the size of a hand, but the largest specimens obtainable were about $1 \mathrm{~cm}$ in diameter. Color in life, rich yellow; preserved, pale drab. Oscules, punctiform, diameter about $100 \mu$, abundant. Pores, not evident, or confused with the oscules. Surface superficially smooth, slimy.

Ectosomal specialization, vague. Endosomal structure, there is a basal layer of what seems to be spongin, in which are embedded, Hymedesmia-like, the heads of acanthostyles of two sorts. There are larger, less spiny ones, and shorter more spiny ones. Free in among the protoplasmic structures are very numerous long straight smooth tylostyles and abundant microscleres.

Principal spicules, acanthostyles (fig. $54, B$ ); size, $8 \mu$ by $100 \mu$ to $13 \mu$ by $345 \mu$. Interstitial spicules, tylostyles (fig. $54, \mathrm{~A}$ ) ; size, $3 \mu$ by $180 \mu$ to $4 \mu$ by $250 \mu$. Microscleres, palmate isochelas (fig. $54, C-E$ ); length, $3 \mu$ to $13 \mu$.

Remarks.-The nearest relatives of asodes seem to be Eurypon microchela Stephens (1916, p. 240), where stress is laid upon the chelas being as small as $8 \mu$. E. microchela is from about 1,000 meters depth off the coast of Ireland. Its megascleres are more than twice the size of those of asodes, in addition to the difference in microscleres. Another species worthy of mention here is Thiele's Micro- 
ciona discreta (Thiele, 1905 , p. 447) from the coast of Chile. It has toxas as well as chelas, which latter we note are remarkably small $(8 \mu)$, and its spicules, other than the dermal, are much thicker than those in asodes. It also differs in having plumose ascending columns of spicules. Topsent $(1914$, p. 618) made this the type of his genus Dictyciona. That this genus is synonymous with Eurypon may well be argued.

The smallness of the chelas of asodes is phenomenal. Very accurate measurement showed many as small as $0.0035 \mathrm{~mm}$ in total length. Whitelegge (1906, p. 471), describing Esperiopsis canaliculata, lists chelas $0.0014 \mathrm{~mm}$ long, but does not speak in his text as if

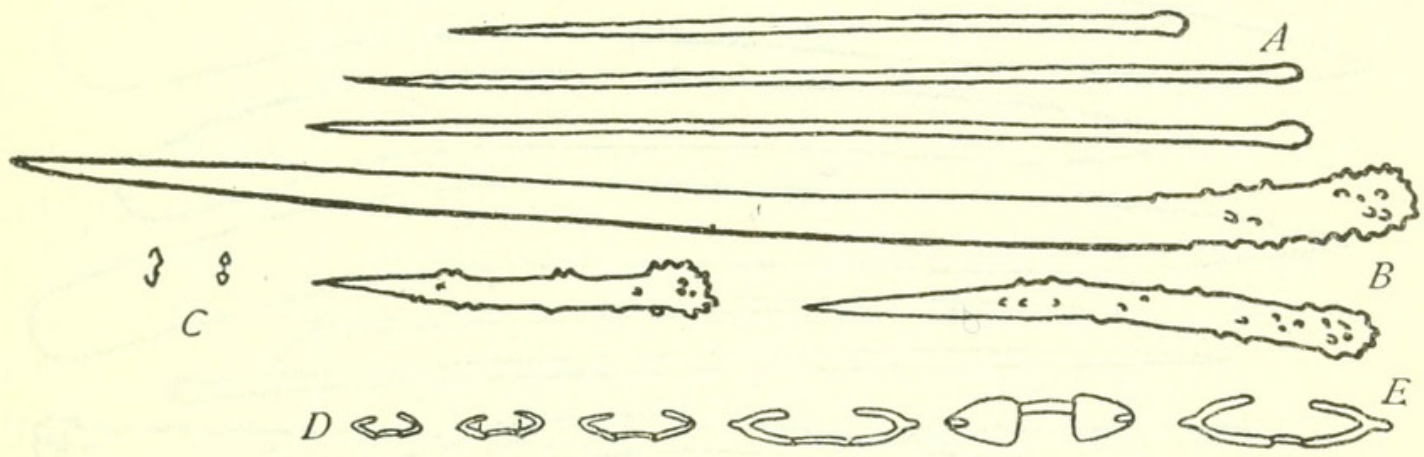

Figure 54.-Eurypon asodes de Laubenfels: $A-C, \times 300$; others, $\times 1,333$

they were at all marvelous; one is very much inclined to believe it a misprint for $0.014 \mathrm{~mm}$; if not, that is the only instance I can find of smaller microscleres than these remarkable ones of Eurypon asodes.

\section{Family MICROCIONIDAE ${ }^{6}$ \\ Genus MICROCIONA Bowerbank \\ MICROCIONA MICROJOANNA de Laubenfels}

Mierociona microjoanna De LAUBenfeLs, 1930, p. 27.

Holotype.-U.S.N.M. No. 21468; B.M. No. 29.8.22.28.

Type locality.-Pescadero Point, near Carmel, Calif., May 11, 1929 , collected by me. The species is moderately common in central California, and there was a specimen in the collection of the Un versity of Southern California. This latter was taken near Point Vincente, July 5, 1924, depth 18 meters, and is U.S.N.M. No. 21406.

Description.-Shape, encrusting. Size, up to $2 \mathrm{~cm}$ thick, $7 \mathrm{~cm}$ in diameter. Consistency, firm, slightly spongy. Color of holotype in life, brilliant scarlet; that collected from the same locality in 1926 was a beautiful rich pink. That collected by the University of Southern California bore no notation of color in life. All fade to drab in preservatives. Oscules, round, scattered, with sphinctrate membrane; diameter $1.5 \mathrm{~mm}$; they are found only where the sponge

' For Clathriidae Hentschel, because Microciona supplants Clathria. 
is thicker than $15 \mathrm{~mm}$. Pores, $60 \mu$ to $75 \mu$ in diameter; abundant over the entire surface. Surface, superficially pilose, with spicules.

Ectosomal specialization, vague. There seem to be no special ectosomal spicules, unless those rated as interstitial may be so regarded; their location is definitely down amidst the endosomal structures, however. Endosomal structure, predominantly protoplasmic, with ascending plumose columns of smooth styles, sparsely echinated by small acanthostyles. Numerous slender subtylostyles are scattered in the flesh and protrude from the surface. Histological details: The abundant flagellate chambers are about $30 \mu$ in

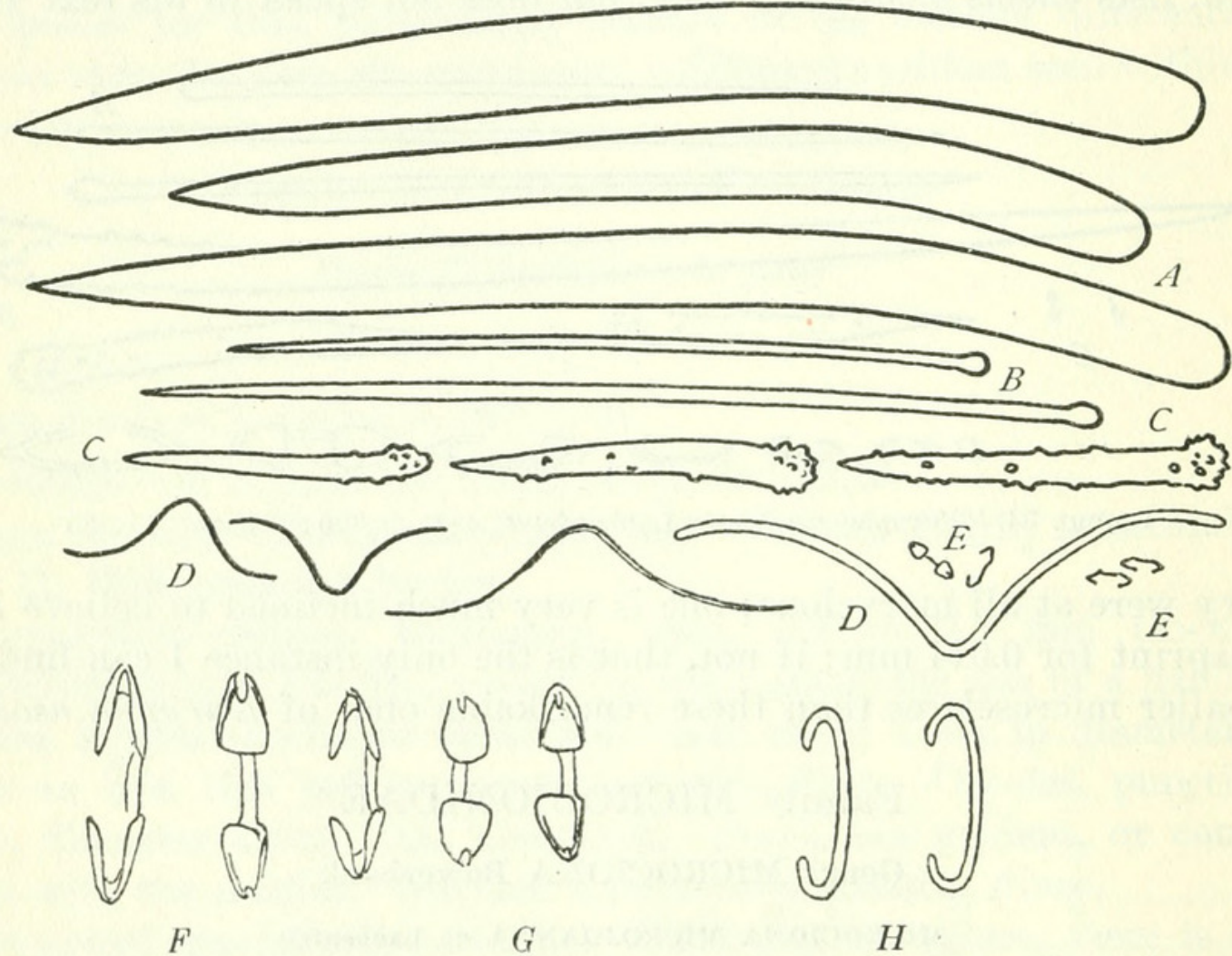

Figure 55.-Microciona microjoanna de Laubenfels: $A-E, \times 300$; others, $\times 1,333$

diameter. Ascending fibers, about $300 \mu$ in diameter, containing little spongin.

Interstitial spicules, subtylostyles (fig. $55, B$ ) ; size, $3 \mu$ by $205 \mu$ to $4 \mu$ by $260 \mu$. Coring spicules, smooth styles (fig. $55, A$ ); size, $20 \mu$ by $280 \mu$ to $27 \mu$ by $330 \mu$. Echinating spicules, acanthostyles (fig. $\left.55, C^{\prime}\right)$; size, $5 \mu$ by $85 \mu$ to $10 \mu$ by $100 \mu$. First microscleres, palmate isochelas (fig. $55, E-G$ ) ; length, $12 \mu$ to $16 \mu$. Second microscleres, toxas (fig. $55, D$ ); length $60 \mu$ by $140 \mu$. Third microscleres, peculiar sigmoid siliceous bodies present in small numbers in boiled-out samples of the specimen collected in 1926 (fig. $55, H$ ); they may not be proper and may have some connection with the chelas, but satisfactory explanation of them is not now at hand.

Remarks.-There is a group of sponges, characterized, among other features, by fibers cored with smooth monaxones and echinated by 
spiny monaxons, usually with toxas and palmate isochelas for microscleres; the generic name Clathria has usually been employed for this group. Clathria was erected by Schmidt (1862, p. 57), and the genotype fixed by Vosmaer (1885, p. 356) as C. coralloides Schmidt. Schmidt's description says quite plainly that his sponge had only smooth spicules. Topsent (1925, p. 645) described a sponge that he assumed to be the coralloides of Schmidt and that had smooth monaxons, toxas, and palmate isochelas. Topsent's identification may be correct, but one can not be certain; Schmidt mentions no microscleres in his species at all, for example. Both Schmidt's and Topsent's species, however, are clearly congeneric with the group usually called Ophlitaspongia, and not with that called Clathria.

Shall we drop Ophtitaspongia in favor of Clathria? Both were published in 1862, Clathria in the latter part of the year. Unless definite evidence is forthcoming to show that Ophlitaspongia was published yet later, I propose to retain it.

Microciona Bowerbank (1862, p. 1109), genotype M. astrosanguinea Bowerbank, differs from so-called Clathria only in external form, being encrusting instead of with branching and anastomosing projections. It will be noted, however, that juvenile specimens of the so-called Clathria are often encrusting, that the encrusting form is very often the result of environmental factors such as strong currents, and that some species well established as Microciona, for example, $M$. prolifera Verrill, with old age assume the clathrous shape. I see no reason for maintaining separate genera for such insignificant differences, and propose that the whole group be termed Microciona.

The most distinctive items about $M$. microjoanna are the very large size of the coring spicules and the fact that they are stylote, instead of subtylostylote.

\section{MiCROCIONA PARTHENA de Laubenfels}

Microciona parthena de LAUBENFels, 1930, p. 27.

\section{Holotype.-U.S.N.M. No. 21383; B.M. No. 29.9.30.6.}

Type locality.-Point Vincente (near San Pedro), Calif., depth 26 meters, November 15, 1924, dredged by the University of Southern California. A second specimen (U.S.N.M. No. 21397) was taken the same day and at the same locality, but at 32 meters. A third was dredged south of San Pedro, depth 45 meters, other data lacking.

Description.-Shape, amorphous to encrusting. Size, up to $2 \mathrm{~cm}$ thick, $4 \mathrm{~cm}$ in diameter. Consistency, mediocre. Color in life, red; in alcohol, drab. Oscules and pores, not evident. Surface, superficially tuberculate, the tubercles hispid.

Ectosomal specialization, vague or wanting. Endosomal structure, a mass of plumose ascending columns, scarcely connected with 
one another except at the base. Principal, or ascending, fibers about $200 \mu$ in diameter.

Interstitial spicules, subtylostyles (fig. $56, B$ ) ; size, $3 \mu$ by $260 \mu$ to $5 \mu$ by $300 \mu$. Coring spicules, smooth styles (fig. $56, A$ ); size, $27 \mu$ by $350 \mu$ to $33 \mu$ by $430 \mu$ to $30 \mu$ by $475 \mu$. Echinating spicules, acanthostyles (fig. $56, C$ ) ; size, $5 \mu$ by $100 \mu$ to $8 \mu$ by $108 \mu$. First microscleres, palmate isochelas (fig. $56, D$ ) ; length, $24 \mu$ to $28 \mu$. Second microscleres, large toxas (fig. $56, F$ ) ; size, $3 \mu$ by $40 \mu$ to $7 \mu$ by $72 \mu$. Third microscleres, small toxas (fig. $56, E$ ) ; length, $14 \mu$ to $22 \mu$.

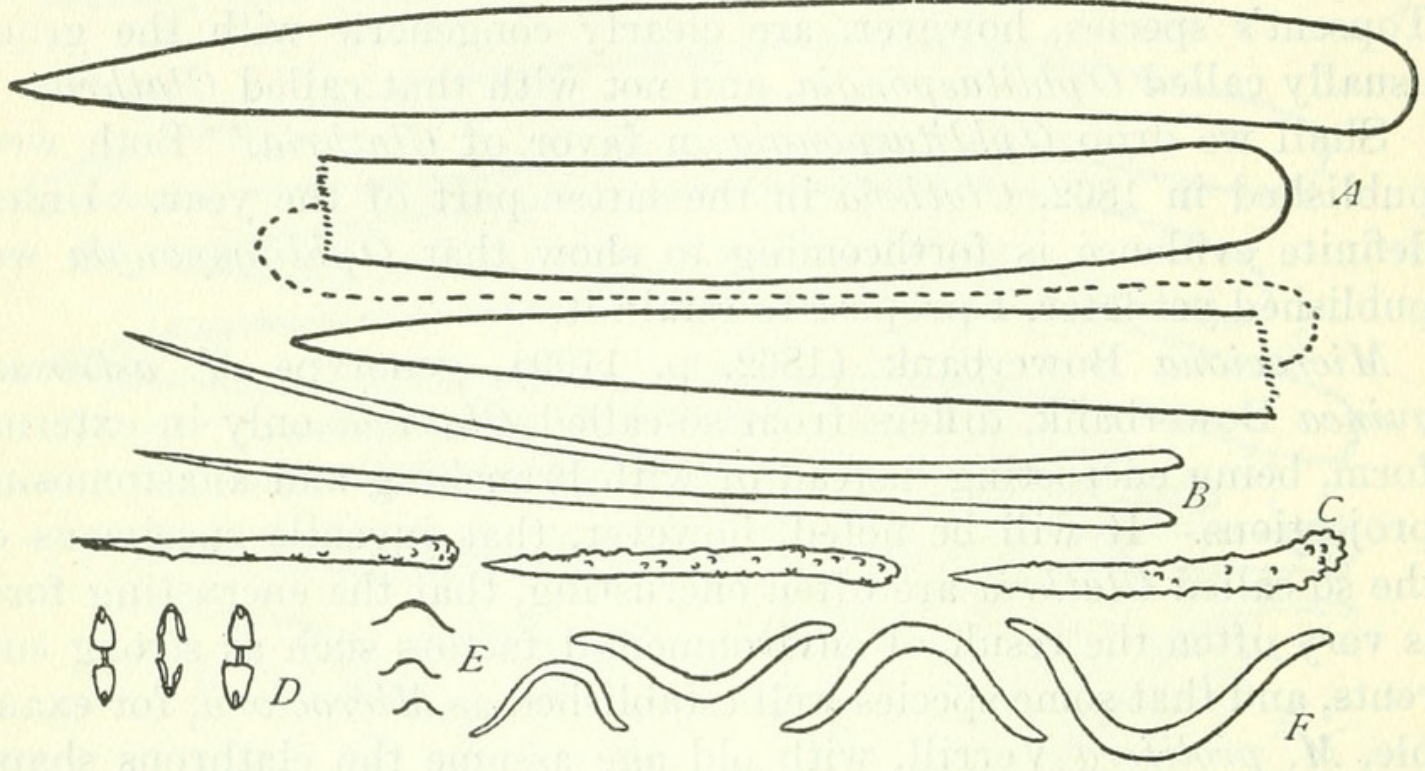

Figure 56.-Microciona parthena de Laubenfels, $\times 300$

Remarks.-The nearest relative of this form seems to be Microciona microjoanna from central and southern California, which differs in having chelas of very different shape, toxas of only one size range, a quite different shape, and coring styles very much smaller.

\section{Genus CLATHRIOPSAMMA Lendenfeld}

\section{CLATHRIOPSAMMA PSEUDONAPYA de Laubenfels}

Clathriopsamma pseudonapya DE LAUBENFels, 1930, p. 28.

Holotype.-U.S.N.M. No. 21436; B.M. No. 29.8.22.19.

Type locality.-The one specimen is from Pacific Grove, Calif., intertidal, June 30, 1926.

Description.-Shape, encrusting. Size, up to $1 \mathrm{~cm}$ thick, $4 \mathrm{~cm}$ in diameter. Consistency, spongy to fragile. Color in life, yellow; preserved, pale drab. Oscules and pores, not evident. Surface, superficially smooth, with irregularly scattered conules about $1 \mathrm{~mm}$ high.

Ectosomal specialization, a dermal membrane, about $50 \mu$ thick; it is fleshy, detachable, and contains some tangent spicules of the sorts 
found in the endosome. Endosomal structure, mostly sand. For further details, see notes given below concerning spicule locations.

Interstitial spicules, tylostyles (fig. $57, A$ ) ; size, $8 \mu$ by $330 \mu$ to $8 \mu$ by $355 \mu$, heads microspined. These occur in sparsely scattered fascicular bundles or tracts in the endosome, points toward the surface, also scattered without order in the ground substance, and most abundantly scattered tangentially in the ectosome. Echinating spicules, acanthostyles (fig. $57, C$ ) ; size, $5 \mu$ by $60^{\prime} \mu$ to $7 \mu$ by $70 \mu$. First microscleres, toxas (fig. $57, D$ ) ; length, $40 \mu$ to $72 \mu$. Second microscleres, microxeas (fig. $57, E$ ) ; size, $1 / 5 \mu$ by $52 \mu$ to $4 / 5 \mu$ by $65 \mu$.

Remarks.-This species is assigned to Clathriopsamma with much hesitation, that genus being poorly known. It was created by von Lendenfeld in 1888 (p. 227), type species $C$. reticulata, according to Hallmann (1920, p. 771). Lendenfeld's description is, of course,

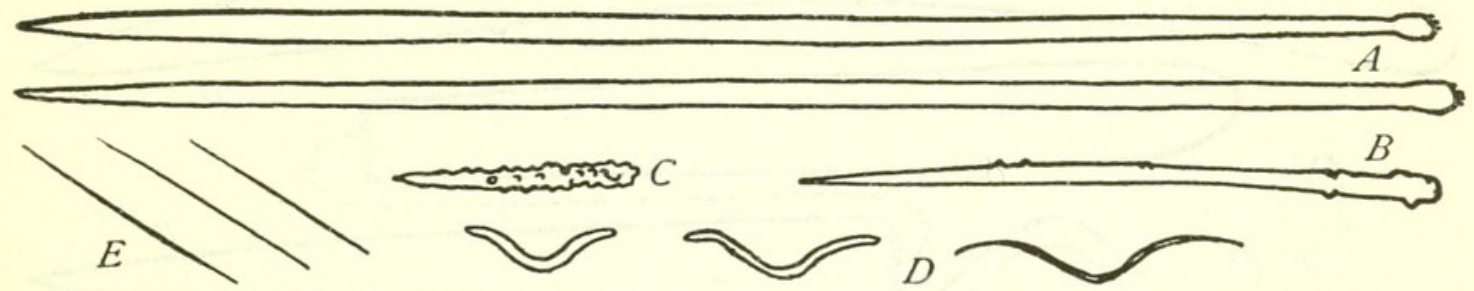

Figure 57.-Clathriopsamma pseudonapya de Laubenfels, $\times 300 . \quad B$, an uncommon spicule intermediate between the other two megascleres

worthless. Hallmann's redescription is as good as possible in view of the damaged condition of the specimen.

C. pseudonapya has too elaborate a dermis to be a Microciona, and because its dermal spicules are tangent instead of perpendicular and as large as, instead of smaller than, the endosomal it can not be Eurypon. Fusifer is of great interest here, as it has also the sand inclusions. Its megascleres are all very small, however, and it has distinctive shuttle-shaped microxeas instead of the exceedingly thin ones of pseudonapya.

\section{Genus JIA de Laubenfels}

This genus may be characterized by peculiar microscleres shaped like the letter $\mathrm{J}$, one end blunt and the other of ultimate fineness. The known species has also chelas and toxas. The megascleres are monaxons (partly acanthose) in confusion. Genotype and only species: Jia j̈a.

JIA JIA de Laubenfels

Jia jia de LAUBenfels, 1930, p. 28.

Holotype.-U.S.N.M. No. 21510; B.M. Nos. 29.8.22.30.

Type locality.-The one specimen is from Monterey Bay, Calif., depth 700 meters, collected May 9, 1929, by E. F. Ricketts. The $107704-32-7$ 
sponge was growing on a macerated dictyonine hexactinellid skeleton.

Description.-Shape, encrusting. Size, $8 \mathrm{~mm}$ thick, 3 by $6 \mathrm{~cm}$ in area. Consistency, very fragile. Color in life, drab with a distinct tinge of orange; dry, dull, drab. Oscules and pores, not evident. Surface, superficially wavy, the ridges about $2 \mathrm{~mm}$ high and 3 to $4 \mathrm{~mm}$ from crest to crest.

Ectosomal specialization vague, but probably to be characterized as a dermal membrane. Endosomal structure, "crumb-of-bread," with the spicules in complete confusion.

Principal spicules, styles, usually smooth, but occasionally with a few large spines (fig. $58, B$ ) ; size, $18 \mu$ by $340 \mu$ to $33 \mu$ by $415 \mu$. In-

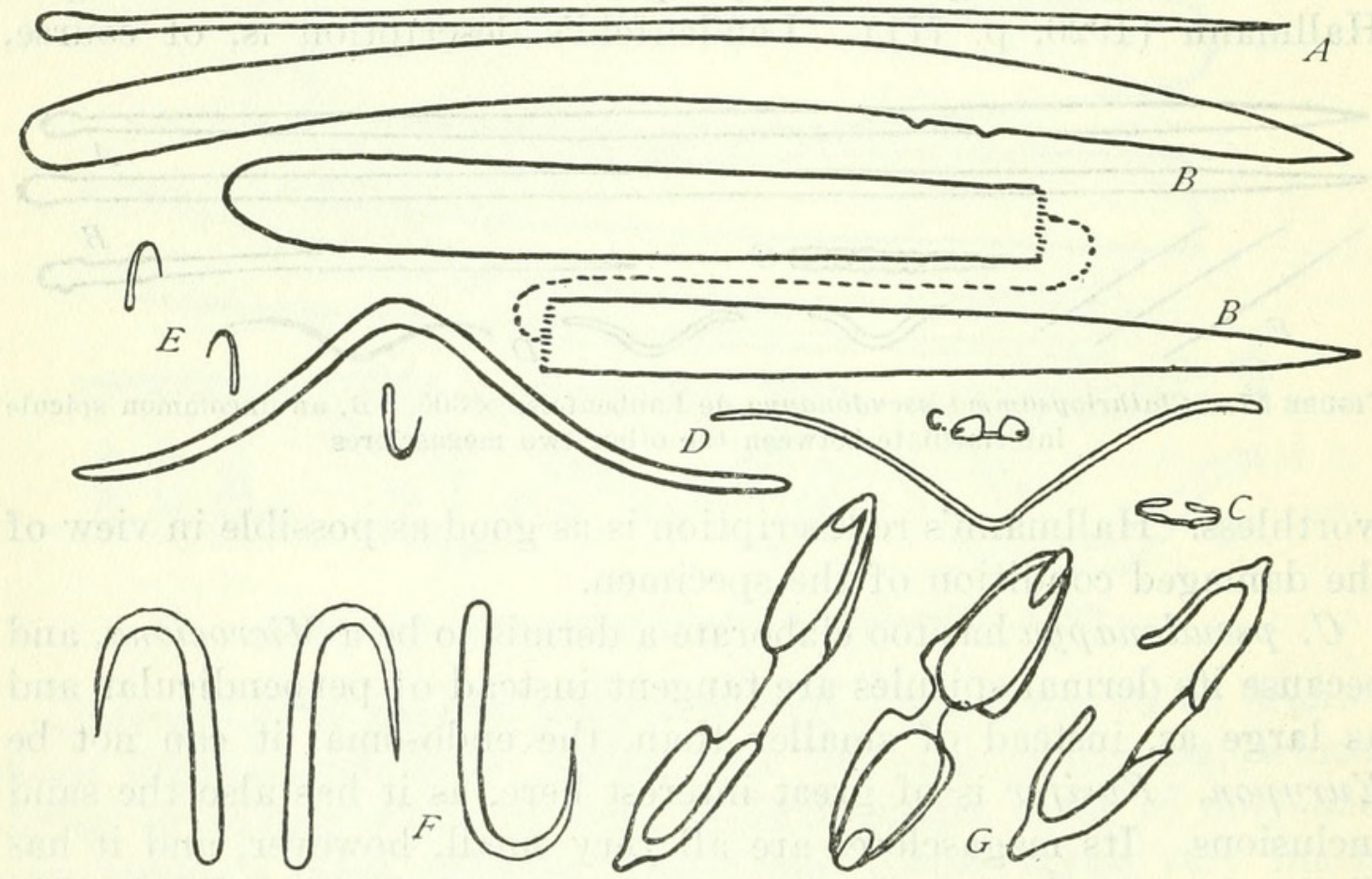

Figure 58.- Jia jia de Laubenfels: $F, G, \times 1,333$; others, $\times 300$

terstitial spicules, tylostyles (fig. $58, A$ ); size, about $5 \mu$ by $330 \mu$. First microscleres, palmate isochelas (fig. 58, $C, G$ ) ; length, $24 \mu$ to $29 \mu$; they are quite markedly contorted. Second microscleres, toxas (fig. $58, D$ ) ; length, $145 \mu$ to $190 \mu$. Third microscleres, J-shaped (fig. $58, E, F)$; the length from the large end to the bend is between $16 \mu$ and $17 \mu$, with very little variation. The entire microsclere if straightened out would probably be $30 \mu$ to $35 \mu$ long. At the thicker, longer branch they reach a diameter of about $0.0015 \mathrm{~mm}$ and terminate in a rounded shape like a microstyle. Throughout their length they grow progressively finer, so that even with oil immersion it is impossible to see exactly where they end, the slender branch growing finer and finer down to the limit of vision. This is most extraordinary. They are very nearly in one plane, not contort. 
Remarks.-The nearest approach to the peculiar microsclere of this genus seems to be the sigmas of the sponge described as Dendoryx luciensis Topsent (1889, p. xxxvii).

The closest genus to this one seems to be Amphilectus. This has been used as such a "catch-all," however, that one awaits a revision of it before using it with confidence. The most remarkable microscleres afford ample ground for a new genus here, and the other structures are rather peculiar, too. The lack of order and plan, plus spicules partly smooth, partly acanthose yet not showing indications of echinate architecture, together with the palmate chelas and toxas, are all novel.

\section{Genus ISOCIONA Hallmann}

\section{ISOCIONA LITHOPHOENIX (de Laubenfels)}

Plocamia lithophoenix de Laubenfels, 1927, p. 263.

\section{Holotype.-U.S.N.M. No. 21460; B.M. No. 29.8.22.42.}

Type locality.-Pacific Grove, Calif., intertidal, July, 1925, collected by me. The species is abundant in central California, and the University of Southern California had three specimens from the southern part of the State, all without depth record and possibly intertidal. They were taken as follows: Santa Catalina Island, March 21, 1915, and April 1, 1915; and Whites Point (near San Pedro), August 1, 1925.

Description.-Shape, massive to encrusting. Size, up to $3 \mathrm{~cm}$ thick, $10 \mathrm{~cm}$ in diameter. Consistency, firm, slightly compressible. Color in life, brilliant vermilion red; preserved, very pale drab. Oscules, rare; diameter, about $0.5 \mathrm{~mm}$. Pores, not evident. Surface, superficially tuberculate, tubercles 1 to $2 \mathrm{~mm}$ high, crowded all over the surface.

Ectosomal specialization, vague or lacking, except for the dense stand of erect spicules. Endosomal structure, a dense isodictyal reticulation exactly of the Myxilla type, meshes often triangular, cells walled in with ranks of very spiny spicules. If one searches, one finds here and there a few smooth styles, points toward the surface. These may be regarded theoretically as vestiges of coring spicules of vanished ascending tracts, the echinating spicules of which have proliferated into ascendency. Our typical Myxillas may have similarly developed from fibroreticulate ancestors. Along the canals leading to the openings mentioned as probably oscular are regions packed with long smooth straight tylostyles. These same spicules stand upright about the apertures and are densely felted all over the surface, together with a few obviously foreign spicules. There is often a layer of the chelas between the tylostyle felt and 
the acanthostyle reticulation. Some chelas and smooth tylostyles are mixed in with the spiny spicules of the parenchyma. Toxas occur in both places.

Principal spicules, acanthostyles to acanthostrongyles (fig. $59, C)$; size, $12 \mu$ by $120 \mu$ to $12 \mu$ by $140 \mu$. These were interpreted in my earlier paper on this species as acanthotylotes, but further study shows the supposed tylote enlargement of the ends to be merely the somewhat greater spination at these points; actually this spicule is basically a style, and its pseudotylote shape is derived, I believe, from its attachment at both ends in connection with the very distinctive type of reticulation present. A few that project freely into canals are larger (up to $180 \mu$ ) and obviously stylote. Ectoso-

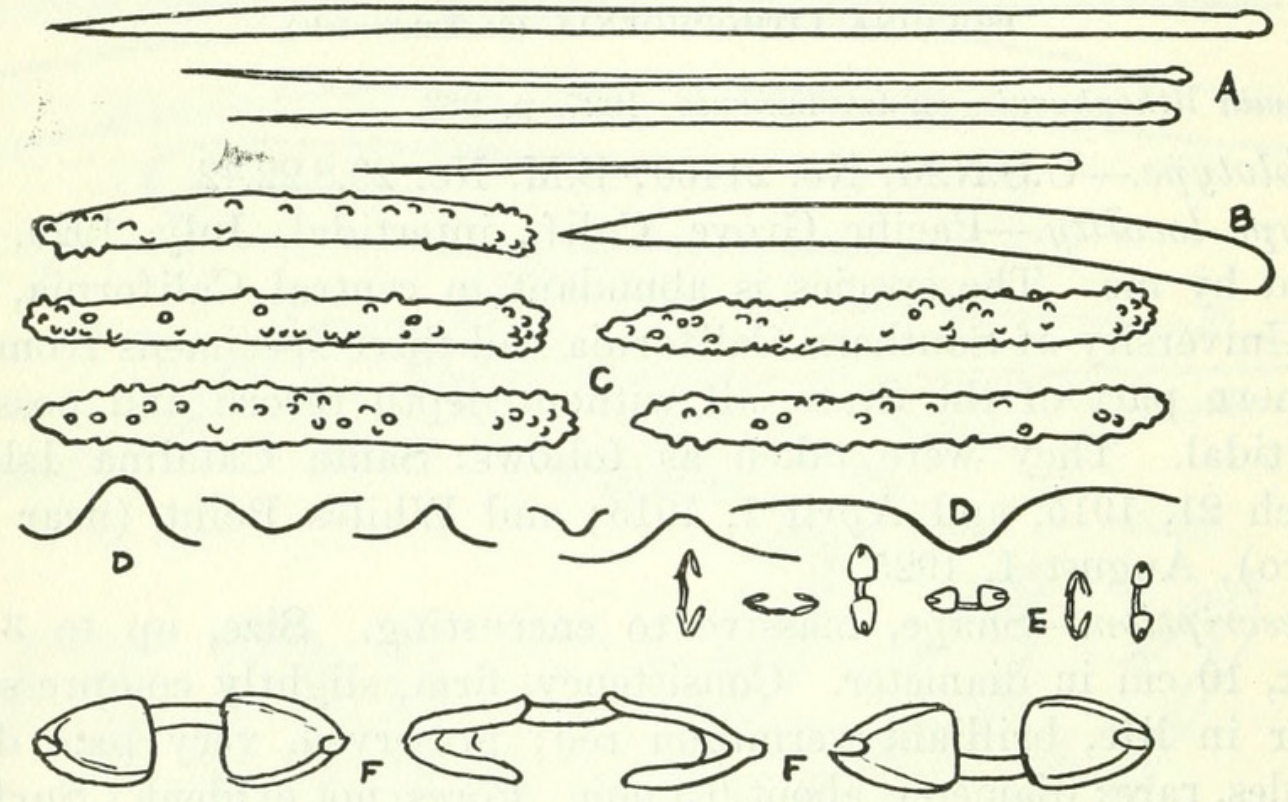

Figure 59.-Isociona lithophoenix (de Laubenfels): $E, F, \times 1,333$; others; $\times 300$

mal spicules, tylostyles (fig. $59, A$ ) ; size, $3 \mu$ by $180 \mu$ to $4 \mu$ by $305 \mu$. Third type of spicules, acanthostyles (not figured) ; size, about $12 \mu$ by $180 \mu$. Fourth type of spicules, smooth styles (fig. $59, B$ ); size, $9 \mu$ by $200 \mu$ to $14 \mu$ by $180 \mu$, rare. First microscleres, palmate isochelas (fig. $59, E, F$ ) ; length, $19 \mu$ to $24 \mu$. Second microscleres, toxas (fig. $59, D)$; length, $23 \mu$ to $110 \mu$.

Remarks.-The only other described species of Isociona is tuberosa Hentschel (1911, p. 326), which lacks the toxas and the rare smooth endosomal styles and has small $(4 \mu$ by $90 \mu)$ endosomal spicules, less spiny than in lithophoenix. This West Australian sponge was dredged from 3 meters. Hentschel described it as Lissodendoryx with much hesitation, commenting that a new genus might be needed. In 1920 (p. 768), Hallmann discussed it further and erected Isociona for it. I agree heartily with Hallmann. 


\section{Family PLOCAMIIDAE Topsent}

\section{Genus PlOCAMIA O. Schmidt \\ PLOCAMIA KARYKINA de Laubenfels}

Plocamia karykinos de Laubenfels 1927, p. 262.

Holotype.-U.S.N.M. No. 21480; B.M. No. 29.8.22.35.

Type locality.-Pacific Grove, Calif., intertidal, July, 1925. The species is very abundant in central California but seems lacking in the southern part of the State.

Description.-Shape, encrusting. Size, up to $4 \mathrm{~cm}$ thick, spreading laterally indefinitely. The thickness is usually well under $1 \mathrm{~cm}$. Consistency, firm, woody. Color in life, brilliant scarlet; preserved, drab. Oscules, sometimes with slightly raised collars; diameter 1 to $2 \mathrm{~mm}$; about one to the square centimeter. Pores about $180 \mu$ in diameter when fully open; about one to the square millimeter. Surface, superficially hispid; level.

Ectosomal specialization, vague or lacking. The tylostyles classed as interstitial are also found rather frequently at the surface. Endosomal structure, plumose ascending columns with ladderlike connectives. Ascending fibers, $50 \mu$ to $100 \mu$ in diameter, cored by

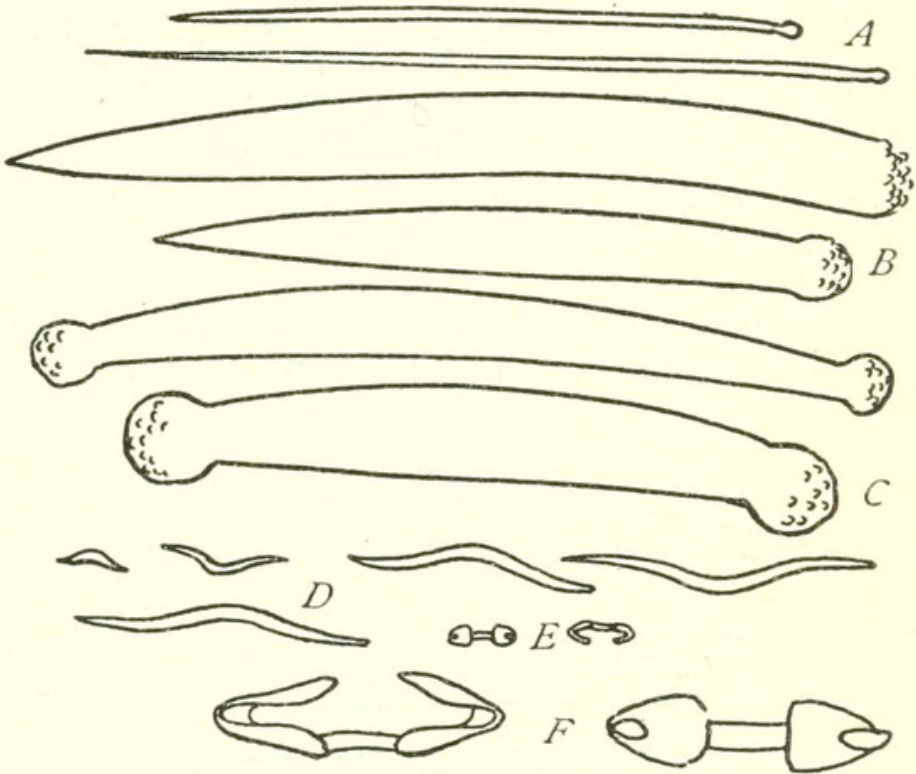

Figure 60.-Plocamia karykina de Laubenfels: Two spicules $(F), \times 1,333$; others, $\times 300$ subtylostyles. Accessory or transverse fibers consisting of single spicules only, the tylotes.

Principal spicules, subtylostyles with microspined heads (fig. $60, B)$; size, $18 \mu$ by $175 \mu$ to $22 \mu$ by $220 \mu$. Secondary spicules, tylotes with microspined heads (fig. $60, C$ ) ; size, $16 \mu$ by $210 \mu$ to $22 \mu$ by $175 \mu$. Interstitial spicules, tylostyles (fig. $60, A$ ) ; size, $2 \mu$ by $200 \mu$ to $3 \mu$ by $160 \mu$; besides occurring interstitially these are almost common enough at the surface to be considered also as ectosomal. First microscleres, palmate isochelas (fig. $60, E, F$ ) ; length, $10 \mu$ to $17 \mu$. Second microscleres, toxas (fig. $60, D$ ) ; length, $18 \mu$ to $80 \mu$.

Remarks.-This species has a characteristic useful in field determination-upon injury, it emits copious quantities of a colorless slime not conspicuous before the injury. 
As for the relationships of this species, I may quote my 1927 article (p. 263), as follows:

Its closest relatives are $P$. manaarensis Carter, 1880 , from India, and $P$. noviselanica Ridley 1881, from New Zealand. Both of these, however, are Gorgonialike in architecture, the former has an isodictyal structure, the latter has its tylotes entirely spined and both have very large smooth styles quite unlike any in our local form.

There is in the United States National Museum a small iragment of a sponge with no more definite locality record than from "The Coast of California," which Mr. L. M. Lambe identified as P. manaarensis. It certainly is not the Indian sponge, but there is not enough of it to be sure if it is P. karykinos or some other Plocamia.

Plocamia IGZo, new species

Holotype.-U.S.N.M. No. 22058; B.M. 30.10.8.1.

Type locality.-Collected by me at Point Pinos, Calif., intertidal, July 11, 1930.

Description.-Shape, encrusting. Size, $9 \mathrm{~mm}$ thick. Consistency, stiff to fragile. Color in life, carmine-red. Oscules, not evident. Pores, very evident; $20 \mu$ to $25 \mu$ in diameter and only about $70 \mu$ to $75 \mu$ apart, center to center. The surface was minutely hispid, very lumpy.

Ectosomal specialization, a very intangible protoplasmic dermis, not separable; it contains abundant microscleres. Endosomal struc-

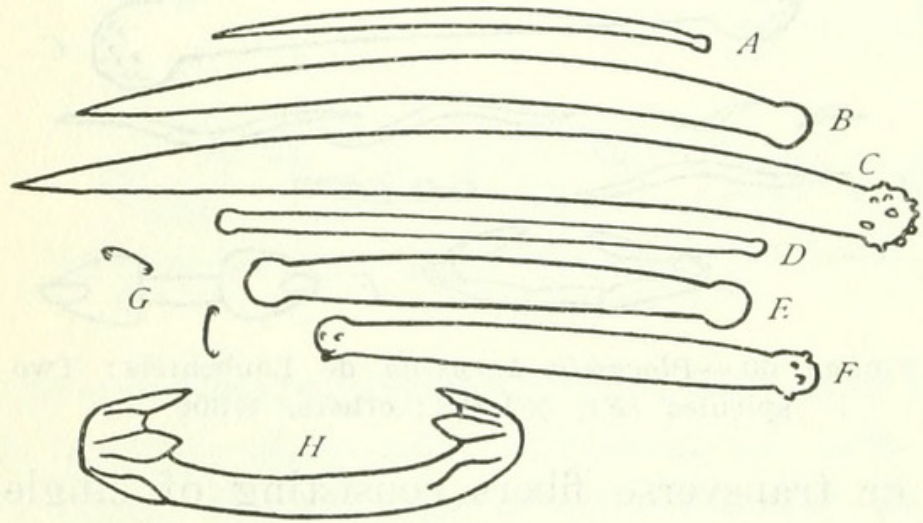

Figure 61.-Plocamia igzo, new species, $\times 300$, except $H, \times 2,400$

ture: There are rather meandering but in general ascending plumose tracts, containing perhaps a little spongin. The total diameter of each is a bout $200 \mu$, and each is profusely echinated by smooth monaxons.

There are regions where the flesh contains practically no spicules except the microscleres. Principal spicules, tylostyles with heads often but apparently not always spined, the spines varying from coarse to exceedingly fine (fig. $61, A-C$ ) ; the common range is from $11 \mu$ by $190 \mu$ to $35 \mu$ by $240 \mu$. Some very thin ones are probably immature or undeveloped examples of this spicule sort. These spicules make up the bulk of the megascleres; namely, the plumose columns. Secondary spicules, tylotes, with heads varying from rather coarsely spined to very finely so, or not at all (fig. $61, D-F$ ); the size range is commonly about $13 \mu$ by $130 \mu$, but there are much thinner ones, pre- 
sumably immature. These tylotes are chiefly interstitial but occur here and there in the plumose tracts. The microscleres are arcuate isochelas $14 \mu$ long (fig. $61, G, H$ ).

Remarks.-The probability must be considered that this is a variation of Plocamia karykina, from the same locality, which has very similar megascleres and architecture. P. karykina shows no signs, however, of varying toward the characteristics of $i g z o$ in the respects wherein the latter differs from it. P. igzo is darker red than karykina, its chelas are very different in shape, approaching those for which Topsent $(1927$, p. 17) separated denticulata from Plocamia into his new genus Plocamiancora. P. karykina has few chelas and many toxas. It seems advisable, therefore, to regard $i g z o$, at least provisionally, as a separate species.

The closest description to that of Plocamia igro is that of Plocamia plena Sollas (1879, p. 44), which, however, differed in having small entirely acanthose styles in addition to the spicule sorts of igzo. It had toxas and isochelas that seem to have been either anchorate or arcuate (it can not be ascertained which from the figures or description). It was collected from deep water off the west coast of Africa.

\section{Family ? (MICROCIONIDAE or DESMACIDONIDAE)}

\section{Genus OPHLITASPONGIA Bowerbank}

\section{OPHLITASPONGIA PENNATA (Lambe) CALIFORNIANA, new variety}

Holotype.-U.S.N.M. No. 21475; B. M. No. 29.8.22.37.

Type locality-Pacific Grove, Calif., intertidal, July, 1925. This variety is very abundant in central California, where I have found it nearer high-tide mark than any other sponge; it seems always to be so placed as to avoid direct sunlight, however, shaded usually by seaweed.

Description.-Shape, encrusting. Size, up to $2.5 \mathrm{~mm}$ thick, spreading laterally indefinitely. Consistency, firm, slightly spongy. Color in life, scarlet; preserved, drab. Oscules, not peculiar as seen in life, but on drying or taking out of water each is seen to be in the center of a stellate figure of radiating grooves that is locally very distinctive; the size is about $0.6 \mathrm{~mm}$ in diameter. Pores, minute, abundant. Surface, superficially velvety.

Ectosomal specialization, vague or lacking. Endosomal structure, permeated by plumose tracts cored and echinated by smooth subtylostyles. At the surface these make extensive brushes or tufts. The echinating spicules often make a picture strongly suggestive of Esperiopsis originalis (which see, for further comparisons). Ascending fibers, $60 \mu$ to $90 \mu$ in diameter. 
Principal spicules, subtylostyles (fig. $62, A$ ) ; size, $17 \mu$ by $215 \mu$ to $22 \mu$ by $261 \mu$. Microscleres, toxas (fig. $62, C$ ) ; length, $45 \mu$ to $55 \mu$. There are also rhaphides or very slender tylostyles (fig. $62, B$ ); size, about $2 \mu$ by $140 \mu$, which may be regarded as microscleres or as interstitial megascleres.

Remarks.-The original name for this species was Desmacella pennata Lambe (1894, p. 129), from Vancouver Island, about latitude $48^{\circ} 20^{\prime} \mathrm{N}$., longitude $123^{\circ} 40^{\prime}$ W. (holotype, now U.S.N.M. No. 7488). It had styles with microspined heads, total size from

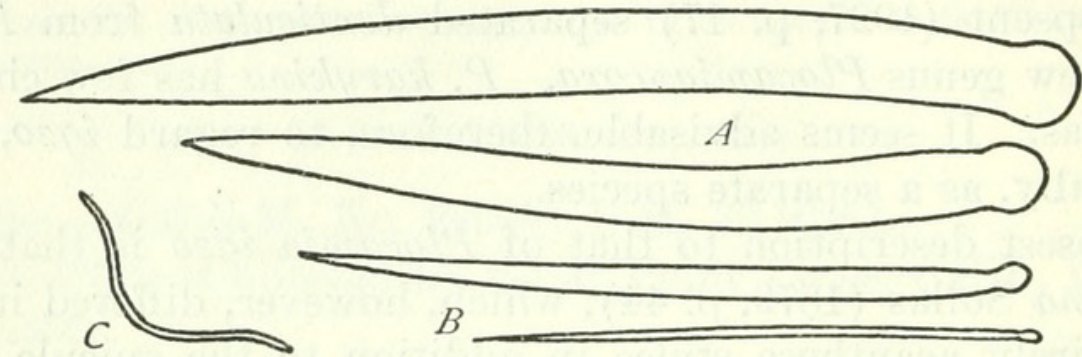

FIgURE 62.-Ophlitaspongia pennata (Lambe) californiana, new variety, $\times 300$

$16 \mu$ by $170 \mu$ to $19 \mu$ by $379 \mu$, and toxas both more numerous and much larger $(72 \mu$ to $255 \mu)$ than in the Californian form, which is therefore described here as a new variety.

\title{
Family ACARNIDAE Topsent
}

\author{
Genus ACARNUS J. E. Gray
}

\section{ACARNUS ERITHACUS de Laubenfels}

Acarnus erithacus de LAUBenfels 1927, p. 258.

Holotype.-U.S.N.M. No. 21430; B.M. No. 29.8.22.32.

Type locality.-Near Pacific Grove, Calif., intertidal.

Material examined.-Nine specimens, as follows:

1. Collected about 1850 from "California." Zoological Museum, Berlin.

2. No date nor data, except southern California. Univ. Southern California coll.

3. January 28, 1924, Santa Catalina Island, 36 meters, bottom temperature $15^{\circ}$. Univ. Southern California coll., U.S.N.M. No. 21416.

4. July, 1925, Pacific Grove; intertidal (holotype).

5. August 1, 1925, Whites Point (near San Pedro) (southern California); intertidal. Univ. Southern California coll., U.S.N.M. No. 21420.

6. July 25, 1926, Pescadero Point (central California) ; intertidal. U.S.N.M. No. 21431.

7. January 24, 1929, Carmel, Calif., intertidal.

8. March 30, 1929, Monterey Bay, 15 meters; trawled by Professor Skogsberg.

9. May 9, 1929, Monterey Bay, 700 meters; trawled by E. F. Ricketts. U.S.N.M. No. 21506.

Description.-Shape, encrusting to massive. Size, up to $5 \mathrm{~cm}$ thick, $10 \mathrm{~mm}$ in diameter. Consistency, firm, slightly compressible. 
Color in life, brilliant scarlet; preserved, drab. Oscules, round, often with elevated, craterlike rims; diameter about $4 \mathrm{~mm}$; distance apart 2 to $5 \mathrm{~cm}$. Pores, abundant, minute, represented by the spaces between the distal ends of the ascending columns. Surface, superficially hispid.

Ectosomal specialization: There is an occasional patch of a very thin dermal membrane covering the larger spaces between the summits of the columns. Endosomal structure, characterized by conspicuous ascending tracts. Histological details: The flagellate chambers are subspherical and about $30 \mu$ to $40 \mu$ in diameter. Ascending fibers, $200 \mu$ to $350 \mu$ in diameter, nearly $1 \mathrm{~mm}$ apart.

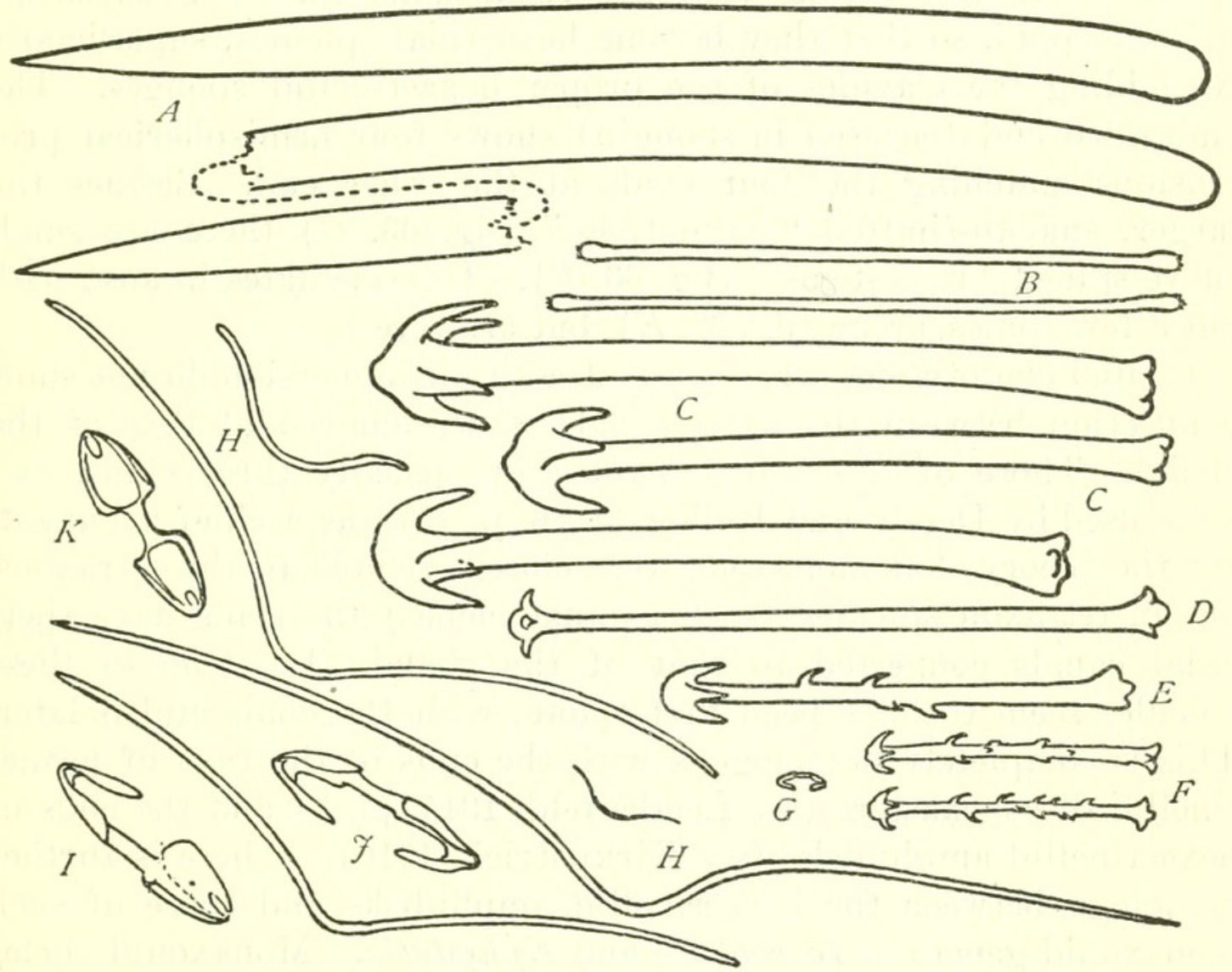

Figure 63.-Acarnus erithacus de Laubenfels: $I-K, \times 1,333$; others, $\times 300$. $E, D$, uncommon intermediates between $C$ and $F$

Ectosomal spicules, tylotes with heads microspined (fig. 63, $B$ ); size, $3 \mu$ by $185 \mu$ to $4 \mu$ by $175 \mu$. Interstitial spicules, cladotylotes (fig. $63, C$ ) ; size, $11 \mu$ by $230 \mu$, chords $35 \mu$. Coring spicules, styles (fig. $63, A$ ) ; size, $18 \mu$ by $345 \mu$ to $17 \mu$ by $425 \mu$; these are the most conspicuous spicular element. Echinating spicules, acanthocladotylotes (fig. $63, F$ ) ; size, $3 \mu$ by $80 \mu$, chords $11 \mu$ and larger. First microscleres, palmate isochelas (fig. $63, G, I-K$ ) ; length, $14 \mu$ to $16 \mu$. Second microscleres, toxas (fig. $63, H$ ) ; length, $40 \mu$ to $340 \mu$.

Remarks.-The most conspicuous spicules are the smooth styles, which are grouped, points toward the surface, in ascending plumose tracts held together by a small quantity of nearly invisible spongin. 
The chelas are quite commonplace, of the Microciona sort, and very abundant. The toxas are also often abundant and exhibit a most amazing variation in size, at least $40 \mu$ to $340 \mu$, with all sizes in between of approximately equal abundance.

The so-termed dermal tylotes are more properly secondary or tangential connections between the ascending columns near the surface of the sponge. Their terminal spines, often just four in number, are nearly $2 \mu$ long but so very fine that they can not be clearly seen without oil immersion. Deeper in the sponge their place seems to be taken by the cladotylotes, which are only fastened at one end, so that they are also quite properly to be termed echinating spicules. In this species they are remarkable for their tetrasymmetrical plan, so that they become hexactinal spicules, superficially resembling the clavules of the proper hexactinellid sponges. The embedded end (encased in spongin) shows four hemispherical protrusions matching the four clads at the other end. Besides the larger, smooth-shafted "palm trees" (fig. 63, $C$ ) there are small curve-spined "rose stems" (fig. 63, F). Intermediates in size, with but a few spines, occur (fig. $63, E$ ), but are rare.

Heated cladotylotes when studied with oil immersion do not show connection between the axial canals of the clads and that of the rhabd. Those of Acarnus ternatus have usually three clads, and were used by Dendy and Ridley $(1886$, p. 157) as a chief argument for the theory that monaxons were closely related to the tetraxons, but in tetraxon spicules (such as anatriaenes) the clads have their axial canals connected to that of the rhabd. In Acarnus these spicules seem to have been first tylote, with the clads added later. This is completely homologous with the ends of the rays of hexactinellid discohexasters (see Lendenfeld, 1915, pl. 9) and the ends of hexactinellid amphidisks (see Kirkpatrick, 1910). There is further homology between the hexactinellid amphidisks and those of such monaxonid genera as Iotrochota and Ephydatia. Monaxonid chelas are merely amphidisks with the central shaft displaced laterally until it has coalesced with teeth with which it has made contact. Spicules very strongly suggestive of hexactinellid relationship are to be found in such diverse monaxonid genera as Acarnus, Axos, Cliothoosa, Dolichantha, Endectyon, Proteleia, Hymeraphia, and Raspailia. Undoubtedly many seemingly monaxonid sponges, such as the epipolasids, are really reduced tetraxonids, but the majority are rather closer to the hexactinellids. Separate orders are indicated from monaxons and triaxons, but Dendy's Astrotetraxonida and Sigmatotetraxonida imply relationships not borne out by the evidence. 
Acarnus erithacus shows a variability that will be discussed with reference to the list given above of the nine specimens studied. These display the following range of variation:

All were brilliant scarlet in life, as far as known, except No. 9, from very deep water. It was drab in life.

All had very similar consistency except No. 3. This consisted of several handfuls of separate sponges, all rather soft and compressible.

No. 7 was crowded with brilliant-red embryos about $150 \mu$ to $350 \mu$ in diameter. The tissue around them was somewhat paler thar normal so that they showed distinctly.

Nos. 1, 7, and 8 lack the "palm tree" sort of spicule entirely. This is of great importance as to possible bearing upon value of spiculation in taxonomy, and this species will bear careful study in the years to come. It may be noted that Nos. 4, 5, 6, and 9 were known to be collected during summer months, and all had the "palm trees." Nos. 3, 7, and 8 were known to be collected during winter months, and of them only No. 3 had this sort of spicule, and it came from a water temperature that is decidedly high for the coast of California ; furthermore it very definitely is not in breeding condition, and No. 7 certainly was, and No. 8 possibly so. Can it be that the "palm trees" are lost in connection with the breeding season and that the temperature has some connection with the time of reproduction? Pending much further investigation this is but surmise.

The great similarity between No. 9, from the very considerable depth of 700 meters, and the other specimens, from intertidal or very shallow water, is quite interesting. Linearly, the point of collection was but about 10 kilometers from the localities for Nos. 4 and 8.

\section{Family RASPAILIIDAE Hentschel}

\section{Genus HEMECTYON Topsent}

HEMECTYON HYLE de Laubenfels

Hemectyon hyle De Laubenfels, 1930, p. 28.

Holotype-U.S.N.M. No. 21418; B.M. No. 29.9.30.4.

Type locality.-The one specimen was collected by the University of Southern California on February 16, 1924, at Point Fermin, near San Pedro, Calif.

Description.-Shape, frondose. Size, $28 \mathrm{~mm}$ high, $20 \mathrm{~mm}$ in diameter. Consistency, between spongy and cartilaginous. Color in alcohol, pale drab. Oscules and pores, not evident. Surface, superficially smooth.

Ectosomal specialization, a dermal membrane about $75 \mu$ thick; it contains scattered dark cells or foreign bodies. Endosomal structure, divided sharply in two portions, an axial region and a peripheral 
zone. The axial region consists of much protoplasmic structure with smooth styles in confusion, showing perhaps a trace of reticulation; they are held together by small quantities of spongin. The peripheral zone is about $400 \mu$ thick and is a dense forest of peculiar acanthostyles, points out. These, as characteristic of this genus, have the basal third curved and smooth, the spines very large and recurved. Since most of the lamellate fronds are less than $2 \mathrm{~mm}$ in thickness, the axial portion averages only about $700 \mu$ thick.

Ectosomal or echinating spicules, acanthostyles (fig. 64, $A, B$ ); size, $12 \mu$ by $180 \mu$ to $20 \mu$ by $320 \mu$. Interstitial spicules, smooth, ends so regularly broken that it is not certain what sort they were (fig. 64, $E)$; size, $10 \mu$ by at least $800 \mu$, rare, probably several millimeters long

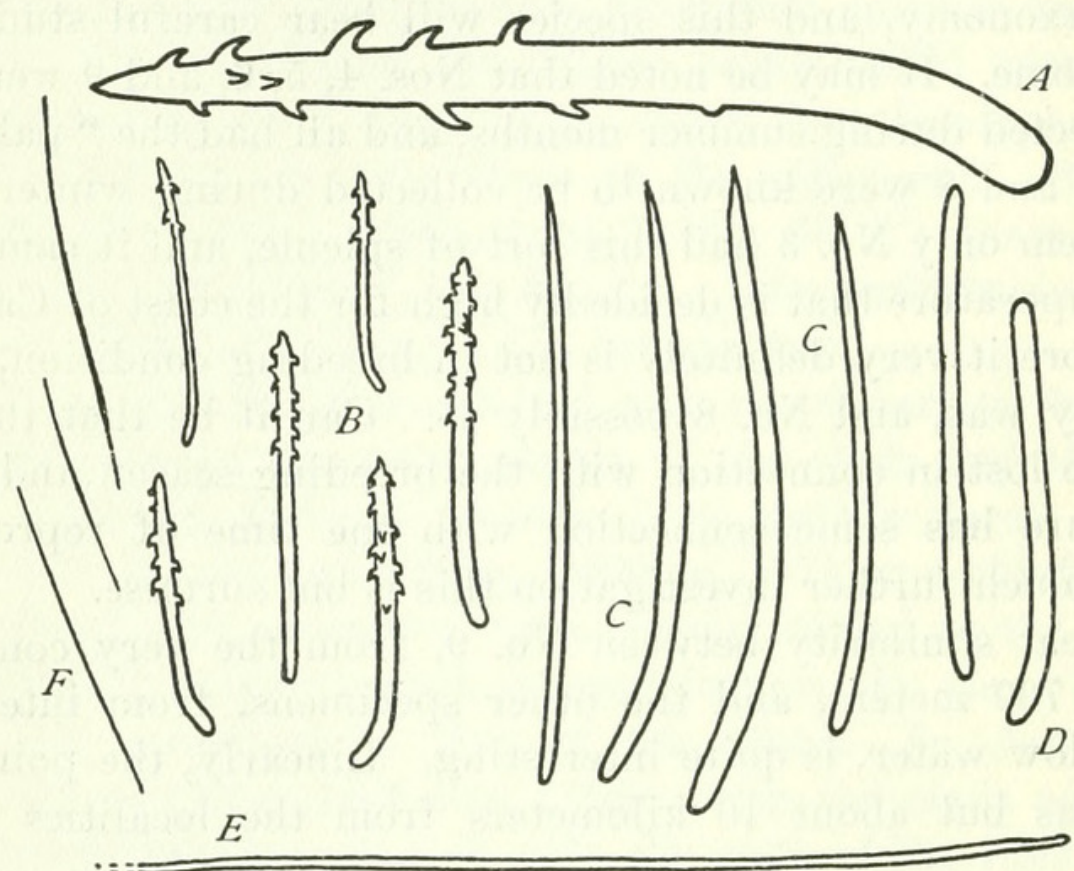

Figure 64.-Hemectyon hyle de Laubenfels: $A, \times 300$; others, $\times 100$. $E$, fraction of total length of spicule shown

when intact. Coring spicules, smooth styles (fig. $64, C$ ); size, $15 \mu$ by $430 \mu$ to $20 \mu$ by $550 \mu$; also smooth strongyles (fig. $64, D$ ); size, $16 \mu$ by $350 \mu$ to $19 \mu$ by $370 \mu$. Microscleres, oxeote rhaphides (fig. $64, F$ ); size, $2 \mu$ by $200 \mu$ to $2 \mu$ by $330 \mu$.

Remarks.-The nearest relative of this form is Hemectyon hamata Schmidt (1870, p. 62) from the West Indies. This, the only other member of the genus, was inaccurately described by Schmidt and put in the genus Raspailia. It is correctly redescribed by Topsent (1920, p. 26), who erected the genus Hemectyon for it. The species hyle clearly belongs in this genus, but it has many features of specific difference; hamata has a strongly reticulate axial region with much spongin. Its smooth styles are smaller, only $300 \mu$ to $350 \mu$ long. Its interstitial spicules are shorter than those of hyle, being only up to about $600 \mu$. Its peripheral region had definite radiating fibers echinated by the acanthostyles; such fibers are lacking in hyle. Its 
rhaphides were stylote, not oxeote as in hyle. The similarities are even more remarkable, however, especially the distinctive form of the acanthostyles and their peripheral localization, and the unusual axial core of styles in spongin.

\section{Family ? (RASPAILIIDAE or EURYPONIDAE)}

\section{Genus CYAMON J. E. Gray}

CYAMON NEON de Laubenfels

Cyamon neon DE LAUBENFELs, 1930, p. 28.

Holotype.-U.S.N.M. No. 21412 ; B. M. No. 29.9.30.5.

Type locality.-Between Point Dume and Newport (near San Pedro, Calif.), depth and date not stated.

Additional material examined.-Two specimens, like the holotype, collected by the University of Southern California, one (U.S.N.M. No. 21384) from south of San Pedro, depth 36 meters, September 24, 1924; the other from Point Fermin, near San Pedro, February $16,1924$.

Description.-Shape, massive. Size of largest specimen, $2 \mathrm{~cm}$ thick, $7 \mathrm{~cm}$ in diameter; the other two are much smaller. Consistency, spongy. Color in alcohol, dark brown. Oscules, not evident (see below under "Surface"). Pores, not evident. Surface, superficially a dermal membrane; this is fleshy, detachable, about $15 \mu$ thick and contains very abundant cells about $15 \mu$ diameter, having conspicuous very dark granules. There are no pores visible in it, it probably having contracted, thus obliterating them. Very few spicules are in it, and some of those, as for instance a few short $(100 \mu)$ oxeas, are probably foreign. Endosomal structure, densely protoplasmic. In places there are spicules in confusion; again there are definite ascending fibers of spongin containing spicules as described below. Much rather coarse sand occurs throughout. Ascending fibers are $40 \mu$ to $50 \mu$ in diameter and about $150 \mu$ apart.

Interstitial spicules, styles (fig. $65, D$ ) ; size, about $15 \mu$ by more than $1,700 \mu$; these occur scattered in the flesh, usually with points perpendicular to the surface, and they project scatteringly from the surface of the sponge. Coring spicules (?), styles (fig. 65, $C$ ); size, about $35 \mu$ by $630 \mu$; these are to be regarded as coring spicules only upon surmise, as they are quite rare, and I am not sure of their exact location in the sponge, but it seems they are in the very center of the spicule bundles of the fibers. Echinating spicules, triacts or tetracts (fig. $65, A, B$ ) ; size of rays, about $15 \mu$ by $60 \mu$ to $20 \mu$ by $120 \mu$. These are usually triacts, with two rays smooth and lying lengthways in the fiber, the third ray distally microspined and projecting from the fiber to echinate it. The ends are sometimes 
strongylote and sometimes oxeote. Tetracts show in boiled-out preparations but are not readily found in sections.

Remarks.-Cyamon and Trikentrion are in a little group by themselves, very distinct from other sponges. Practically all the species of Cyamon hitherto described have had their distinctive (polyactine) spicules entirely and finely spined, the other spicules styles. In contrast, Trikentrion has its polyactine spicules usually triacts and with only one ray spined, but that coarsely so and with diactines as accompanying spicules. $C$. neon is a very distinct type, answering the definition of Cyamon but being very different from any of the genus. On paper it reads a bit like Trikentrion flabelliformis Hentschel (1912, p. 377), from the East Indies, but the illustrations

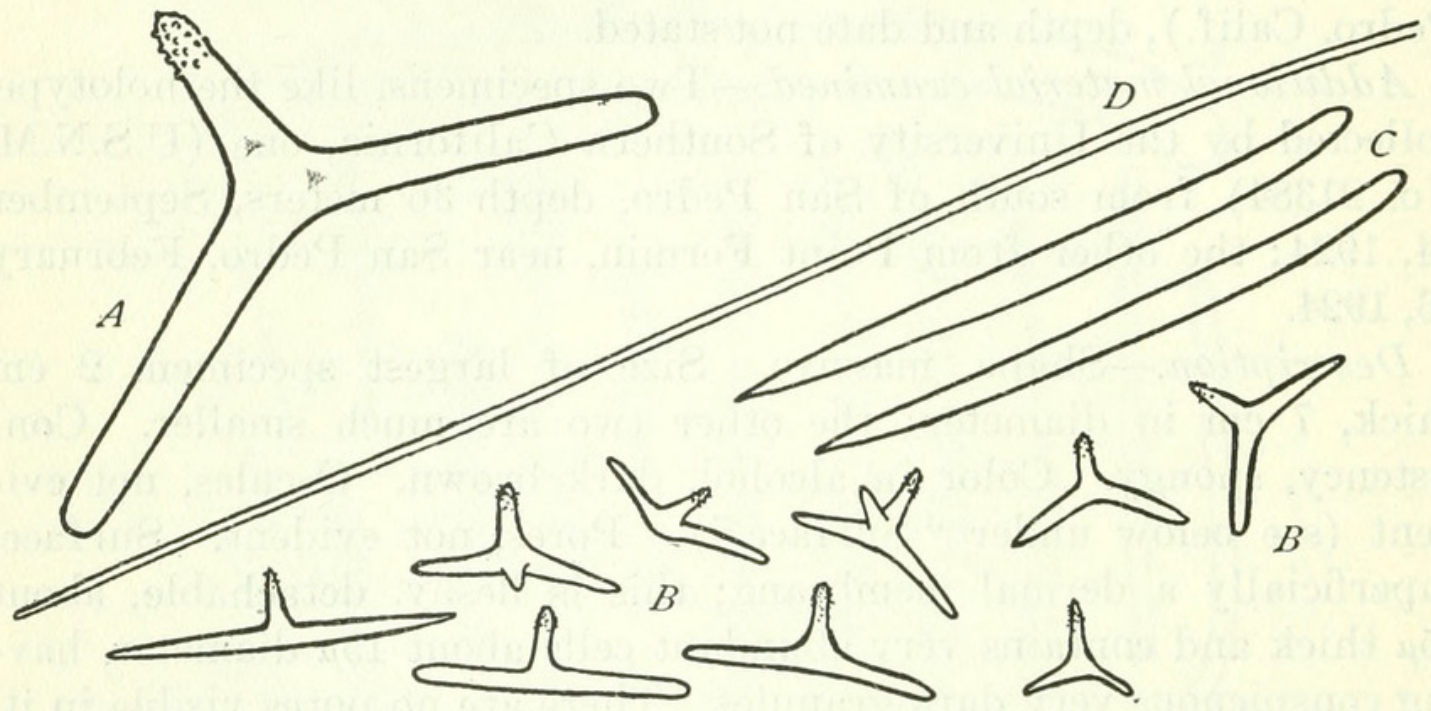

Frgure 65.-Cyamon noon de Laubenfels: $A, \times 300$; others, $\times 80$. $D$, fraction of total length of spicule shown

show great differences. The comparison is mentioned only because flabelliformis shows us a species with both monacts and diacts, with the polyactines mostly triacts and only one ray spined; these are coarse spines, however, and there are numerous differences in spicule size, and general architecture of the sponge.

\section{Order HAPLOSCLERINA Topsent}

\section{Family SPONGILLIDAE Gray}

\section{Genus SPONGILLA Lamarck}

SPONGILLA LACUSTRIS (Linnaeus)

Spongia lacustris Linnaeus, 1759, p. 1348.

Spongilla lacustris LamarcK, 1815.

Material examined.-U.S.N.M. No. 21516; B.M. Nos. 29.10.31.1, 29.9.30.3. These bright green digitate fresh-water sponges were collected by Prof. W. K. Fisher, of Stanford University, at Lake Tahoe, elevation 2,040 meters, August, 1925. 
Description.-No gemmules could be found in this material, but the smooth oxeote principal spicules, about $11 \mu$ by $330 \mu$, and spiny microxeas, about $6 \mu$ by $65 \mu$, as well as all other characteristics, are those of the cosmopolitan and abundant Spongilla lacustris.

Remarks.-Gemmules are absolutely necessary for certain identification of most fresh-water sponges, but the probabilities are very great that this is lacustris.

\section{Genus EPHYDATIA Lamouroux}

EPHYDATIA ROBUSTA (Potts)

Meyenia robusta Potтs, 1887, p. 225.

Ephydatia robusta WeLtNer, 1895, p. 127.

Occurrence.-Potts (1887) recorded this species from Honey Lake Valley near Susanville, Calif., in northeastern California, at an elevation of about 1,400 meters. Annandale (1907, p. 24), recorded it from Bhim Tal, Kumaon, northern India, at an elevation of 1,350 meters. These seem to be the only records for this species.

\section{Genus CARTERIUS Petr \\ CARTERIUS TUbisperma (Potts)}

Carterella tubisperma Poтts, 1881, p. 150.

Carterius tubisperma Sмгтн, 1921, p. 15.

Occurrence.-Smith (1921, p. 15), recorded a specimen of this species as being in the United States National Museum with locality listed as Fresno, Calif. It was collected by Gustav Eisen and determined by Potts (U.S.N.M. No. 5979). This species is probably cosmopolitan, there being numerous records from localities scattered over the Eastern United States and Europe. It was originally described without name by Mills (1880, p. 132).

\section{Family HALICLONIDAE ${ }^{7}$}

\section{Genus GELLIUS J. E. Gray \\ GELLIUS EDAPHUS de Laubenfels}

Gellius edaphus de Laubenfels, 1930, p. 28.

\section{Holotype.-U.S.N.M. No. 21444; B.M. No. 29.8.22.17.}

Type locality.-Pescadero Point, near Carmel, July, 1926; all my specimens have been removed from a mass at this point, readily identified as to location from year to year. There is every indication that it is the same sponge that remains there. Its placement is ecologically most interesting; it grows in a cavern at low tide, where sponges are extraordinarily abundant as covering the walls and ceilings; but it is the only one growing on the floor. It is just below low tide, hence never out of water. It is very unusual to find sponges

\footnotetext{
"For Haploscleridae Topsent. There is no sponge genus "Haplosclera."
} 
growing on a rocky coast where they could be stepped on without turning a rock.

Additional material examined.-A sponge in the collection of the University of Southern California, from Point Fermin, near San Pedro, Calif., intertidal, April 19, 1924.

Description.-Shape, massive. Size: The mass in the field was about $20 \mathrm{~cm}$ thick and 30 or $40 \mathrm{~cm}$ in diameter. Consistency, friable, almost stony hard. Color in life and when preserved, almost white. Oscules, round; diameter, about $1 \mathrm{~mm}$; distance apart, about $8 \mathrm{~mm}$. Pores, abundant, about $150 \mu$ in diameter. Surface, superficially smooth.

Ectosomal specialization, a dermal membrane; it is about $10 \mu$ thick, fleshy, not detachable, and contains some tangent spicules, but the special ectosomal reticulation so characteristic of this genus is not in evidence. Endosomal structure, densely packed with spicules in considerable confusion, with just an indication of basic isodictyal plan.

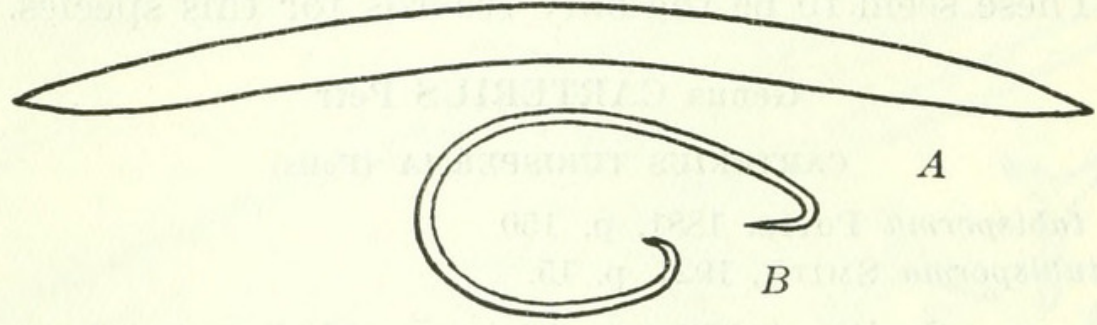

Figure 66.-Gellius edaphus de Laubenfels, $\times 300$

Principal spicules, oxeas (fig. $66, A$ ) ; size, $13 \mu$ by $260 \mu$ to $15 \mu$ by $270 \mu$. Microscleres, sigmas (fig. $66, B$ ) ; length, $30 \mu$ to $100 \mu$.

Remarks. - The nearest relative of this form seems to be Gellius centrangulatus I. Sollas, 1902, from the East Indies, which differs in having very renierid structure and even smaller spicules. Most species of Gellius have much larger spicules than edaphus. G. imperiatis Dendy, 1924, has spicules about the size of those of edaphus but has a very furrowed surface and structure with conspicuous tracts. Most species of Gellius, however, are separated by very narrow margins, and a reviewer with abundant material might be able to carry out extensive synonymy. This might even be regarded in common with perhaps a score of others as being within the range of variation of Gellius flagellifer.

\section{GELLIUS TEXTAPATINA de Laubenfels}

Gellius textapatina DE LAUBENFELs, 1926, p. 567.

Holotype.-U.S.N.M. No. 21446; B.M. No. 28.11.6.5.

Type locality.-The one specimen was in the small collection of Stanford University, date of collection unknown, locality Monterey Bay, Calif.; estimated depth, 720 meters. 
Description.-Shape, concavo-convex lamellate. Size, $1 \mathrm{~cm}$ thick, about $12 \mathrm{~cm}$ in diameter. Consistency, fragile. Color in alcohol, very pale drab. Oscules (on the concave side only), diameter 0.7 to $1.2 \mathrm{~mm}$; distance apart, about $6 \mathrm{~mm}$. There is a very thin $(10 \mu$ ? ) transparent membrane over the entire oscular surface, except for the openings of the oscules themselves, and it even closes them partially, in a sphinctrate manner. Pores, apparently only on the convex side. The above-mentioned dermis also covers the porous surface. The meshes of the skeleton are 0.7 to $1.1 \mathrm{~mm}$ in diameter, but the round apertures in the dermis, which may be considered the real pores, are but $100 \mu$ to $200 \mu$. Surface, superficially smooth.

Ectosomal specialization, an optically evident reticulation of large spicules; the polygonal meshes are 0.5 to $0.8 \mathrm{~mm}$ in diameter. This dermal skeleton is about $0.2 \mathrm{~mm}$ thick. Endosomal structure, in places a typical renierid isodictyal reticulation with spongin nodes, elsewhere confused and vague. Most of the microscleres are endo-

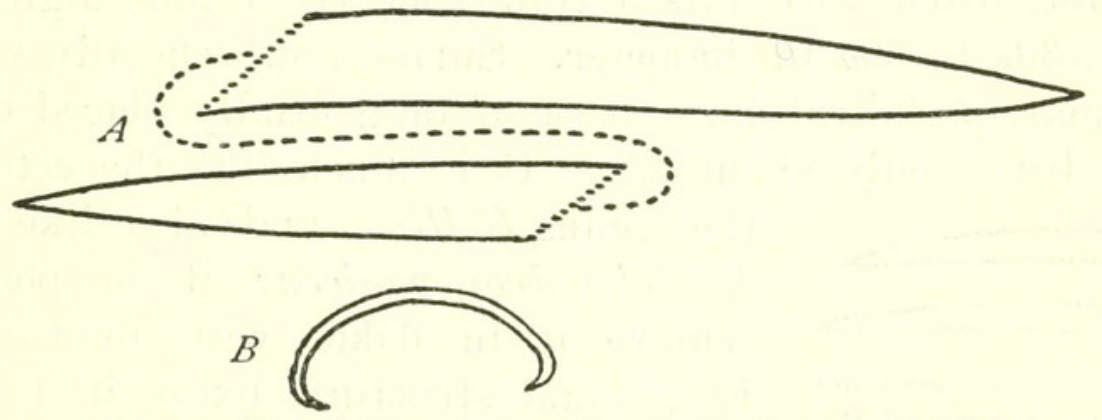

Figure 67.-Gellius textapatina de Laubenfels, $\times 300$

somal. Histological details: There are spherical flagellate chambers of very great variation in size, namely, from about $30 \mu$ to $60 \mu$ in diameter. There are also fairly numerous embryos, about $350 \mu$ in diameter, grouped principally about the canals in the deeper portions of the endosome. A few of them have fairly numerous full-sized sigmas and minute straight rhabds in their peripheral region.

Principal spicules, oxeas (fig. $67, A$ ) ; size, $20 \mu$ by $340 \mu$ to $22 \mu$ by $460 \mu$. Microscleres, sigmas (fig. $67, B$ ) ; length, $50 \mu$ to $80 \mu$.

Remarks.-The almost complete lack of microscleres in the ectosome is remarkable. Both megascleres and microscleres are large as compared to most species in the genus.

\section{HALICHOCLONA, new genus}

The genus may be briefly characterized by comparison. It has the endosome of Haliclona (isodictyal reticulation of oxeas) plus the ectosome of Halichondria (detachable, with a definite dermal skeleton of tangential spicules). It may also be described as Gellius without the sigmas. Genotype, Hatichoclona gellindra, new species. 
Holotype.-U.S.N.M. No. 22063; B.M. No. 30.10.8.6.

Type locality.- The holotype was collected by me at Carmel, Calif., intertidal, on July 27, 1930.

Additional material studied.-At Laguna Beach, on March 14, 1926, I took a somewhat similar specimen with larger spicules, but in very poor condition for study, as it was growing over the macerated remains of a textraxonid sponge of radiate structure. This specimen was designated Gellius (?) epocheomaius in de Laubenfels (1930, p. 28). It was so difficult to allocate, even generically, that it could scarcely be regarded as a synonym of $H$. gellindra, but it is not worth treating as a separate species because of its similarity to gellindra.

Description.-Shape, encrusting. Size, 2 to $4 \mathrm{~mm}$ thick, somewhat more than $4 \mathrm{~cm}^{2}$ in area. Consistency, fragile. Color in life, pale lavender. Oscules, few and irregular in shape, about $1 \mathrm{~mm}$ in diameter, often with raised collars nearly $1 \mathrm{~mm}$ high. Pores, abundant, $30 \mu$ to $50 \mu$ in diameter. Surface, superficially smooth.

Ectosomal specialization, a crust of tangentially placed oxeas, its thickness being only about $20 \mu$. It is much like the ectosome of

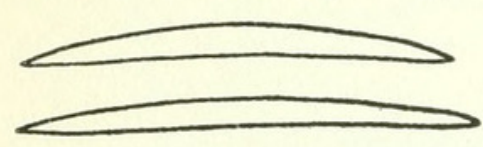

Figure 68.-Halichoclona gellindra, new species, $\times 300$ the genus Gellius, and also like that of Hatichondria panicea; it is possible to remove it in flakes with moderate ease. Endosomal structure, oxeas in very regular isodictyal reticulation, $\mathrm{u}$ it ed (by spongin?) at their apices only. This is much like Gellius and Haliclona.

Principal spicules, oxeas (fig. 68) ; size, $3 \mu$ by $110 \mu$ to $4 \mu$ by $120 \mu$, but the vast majority are very near to the latter size. The specimen from Laguna Beach had spicules $8 \mu$ by $150 \mu$ to $10 \mu$ by $170 \mu$.

Remarks.-Haticlona is characterized by spicules of rather uniform size and by its reticulate endosome without trace of special tangential dermal skeleton.

Halichondria is characterized by its spiculation of most varied lengths and by its confused endosomal structure with very distinct tangential dermal skeleton.

Gellius has the same sort of isodictyal endosome as that of Haticlona, with the special ectosome resembling Halichondria, but has microscleres, namely, sigmas.

Halichoclona is compared to these three genera, but of the three, the most closely related in my judgment is Gellius. When I found the Laguna Beach specimen aforementioned, I considered it a Gellius that had lost its microscleres, it being in rather poor condition if not actually dead, before collection. It also might have been 
altered by its growth within the surface of the macerated tetraxon sponge. The specimen from central California was alive and in excellent condition, however. All our local Gellius species have spicules very much larger than either of the specimens above referred to the new genus Halichoclona.

We may eventually merge all genera that are alike except for differences in microscleres, though there are practical reasons for depreciating such amalgamation. For the present there seems good reason for retaining this as distinct from Gellius.

\section{XESTOSPONGIA, new genus}

This genus is characterized by having only oxeas as spicules and these so abundant that any reticulate arrangement is obscured; there is no special dermal skeleton. Genotype, Xestospongia diprosopia.

\section{XESTOSPONGIA DIPROSOPIA (de Laubenfels)}

Haliclona diprosopia DE LAUBEnfFls, 1930, p. 28.

Holotype.-U.S.N.M. No. 21509; B.M. No. 29.8.22.59.

Type locality.-The one specimen was collected in Monterey Bay, Calif., depth about 500 meters, by E. F. Ricketts.

Description.-Shape, lamellate. Size, 1 to $4 \mathrm{~cm}$ thick, 6 by $12 \mathrm{~cm}$ in area. Consistency, friable. Color dry, very pale drab. Oscules, on one side only; diameter, $3 \mathrm{~mm}$; distance apart, $15 \mathrm{~mm}$; over very shallow cloacas that branch almost at once into about a dozen diverticules. Pores, at least $100 \mu$ in diameter; principally on the nonoscular face. Sur-

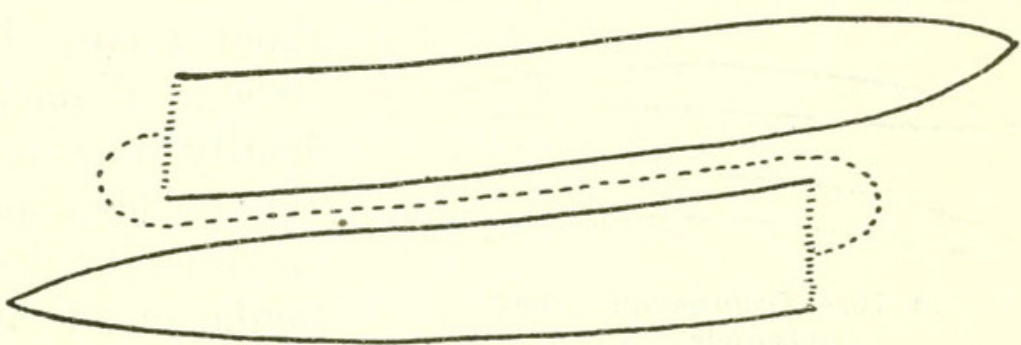

Figure 69.-Xestospongia diprosopia (de Laubenfels), $\times 300$

face, superficially smooth, with low rounded protuberances 5 to 15 $\mathrm{mm}$ high on the oscular surface.

Ectosomal specialization, lacking, although there is a false appearance as of a special ectosomal reticulation, because of the fact that the endosomal reticulation is finer above and coarser below. Endosomal structure, reticulate, with polygonal meshes about 0.5 to $0.7 \mathrm{~mm}$ in diameter, bounded by fascicular bundles of spicules. The spicule size is notably uniform.

Principal spicules, oxeas (fig. 69) ; size, about $30 \mu$ by $400 \mu$.

Remarks.-This specimen was collected from the same general locality as Gellius textapatina and Poecillastia rickettsi and is note- 
worthy for external simulation of these two sponges. We must conclude that the remarkable structure is in a large part an ecological adaptation. This should not be interpreted that this is some common shallow-water sponge that has lightly assumed such shape because of its surroundings, but that this species has by selection or some other determiner come to have this structure. It is remarkable further in that it is the slightly convex side that is oscular; usually in concavo-convex sponges the reverse is true. This very unusual circumstance is also reported for Xestospongia (Petrosia) coralloides Dendy (1924, p. 325). It may be a generic tendency. $X$. diprosopia is remarkable for this character, which it shares with coralloides, and for the large size of its spicules, by which it may be distinguished from that species and most others.

\section{XESTOSPONGIA VANILLA (de Laubenfels)}

Haliclona vanilla DE LAUBENFELs, 1930, p. 28.

Holotype.-U.S.N.M. No. 21452 ; B.M. No. 29.8.22.45.

Type locality.-Pacific Grove, Calif., July, 1925, collected by me. This is one of the most abundant sponges in central California, occurring usually on the under side of bowlders in the lower half of the intertidal zone.

Description.-Shape, encrusting. Size, up to $1 \mathrm{~cm}$ thick, spreading laterally indefinitely. Consistency, stony hard. Color in life and when preserved, white or very pale yellowish drab. Oscules, round, often with raised rim, diameter 1 to $1.5 \mathrm{~mm}$, distance apart about $1 \mathrm{~cm}$. Pores, approximately
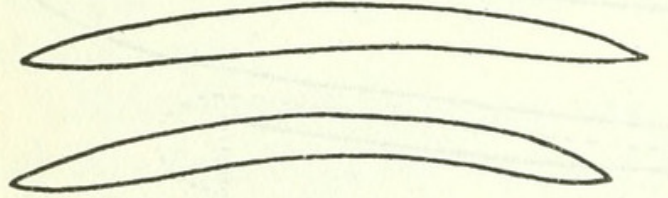

F'IguRe 70.-Xestospongia vanilla (de Laubenfels), $\times 300$ $100 \mu$ in diameter. Surface, superficially smooth.

Ectosomal specialization, vague or lacking. Endosomal structure, a reticulation of canals in a ground substance in which the spicules are so

densely packed that no pattern can be discerned in their arrangement. The canals, however, are usually either perpendicular or parallel to the surface and often meet at right angles, so that they make a symmetrical pattern.

Principal spicules, oxeas (fig. 70 ) ; size, $11 \mu$ by $150 \mu$ to $12 \mu$ by $160 \mu$.

Remarks.-Petrosia was erected by Vosmaer (1885, p. 338) for Reniera dura of Schmidt (1862, p. 76), to replace Schmidtia of Balsamo Crivelli; that name being preempted. He lists various forms and specifies stony consistency, spicules crowded together, oxeas, strongyles, and rarely styles. Ridley and Dendy (1887, p. 9), define Petrosia thus:

Sponge usually hard or even stony; generally with numerous, well-defined large oscula. Skeleton more or less confused; spicules oxeote to strongylote, 
usually short and thick, packed close together in tracts. The most obvious feature of this genus is its hard, often stony texture.

It would seem that two distinct generic types are included in the sponges assigned to the above diagnosis. One group typically has large thick strongyles, plus large thick oxeas plus very small spicules apparently representing a distinct category, because they are found of considerable diameter although short. The spicules that seem clearly to be immature are nearly as long as, though much thinner than, the type they are approaching by their growth. The ectosome seems unknown for the genotype, but most of the species having the above characteristics, as for example Petrosia lignosa Wilson (1925, p. 403), have special dermal tangential skeletons. A second group lacks this ectosmal specialization and therefore may be taken as worthy of generic separation; a further parallelism seems to be that this group has only oxeote spicules. I would suggest that the group exemplified by Petrosia lignosa and probably by the genotype, P. dura, is most closely related to Gellius and Strongylophora (and possibly even to Hatichondria ?), while the second group is most closely related to Haticlona. The second group comprises several sponges described by Dendy, for example Petrosia densissima (1905, p. 145) and coralloides (1924, p. 324), and perhaps several other species, such as $P$. variabilis Ridley $(1884$, p. 415), $P$. similis Ridley and Dendy (1886, p. 327), and P. fistulata Kirkpatrick (1907, p. 290). Most of the earlier authors and some of the later ones fail to give adequate data concerning surface structure. The new generic name Xestospongia is proposed for this latter group.

\section{Genus HALICLONA Grant}

\section{IALICLONA ECBASIS de Laubenfels}

Haliclona ecbasis DE LAUBENFELs, 1930, p 28.

Holotype.-U.S.N.M. No. 21449 ; paratype, B.M. No. 29.8.22.48.

Type locality.-From the floating dock of the Yacht Club in San Diego Bay, Calif., collected by Prof. C. M. Child.

Additional material examined.-I have found the same species growing abundantly on the floating dock of the Yacht Club at Wilmington (near San Pedro). On March 4, 1926, I found small bits of an encrusting sponge, intertidal, at Laguna Beach, which may be of the same species.

Description.-Shape, ramose or digitate, often with an axial hollow about one-third the diameter of the branch. Size, up to $10 \mathrm{~cm}$ high, about $1 \mathrm{~cm}$ in diameter. Consistency, spongy. Color in life: Prof. C. M. Child, writing of his specimen, collected during the summer, says: "The color in life is purple, apparently becoming brown later 
in the season." My specimens doubtfully referred to this species (collected intertidally in March), were bluish lavender. My specimens clearly of this species, collected from a similar situation to that of the holotype but in April, were drab.

Oscules, few, apical, diameter 2 to $5 \mathrm{~mm}$. Pores: There are openings over the entire surface very irregular in size and shape, varying at least from $60 \mu$ to $200 \mu$ in diameter. Surface, superficially hirsute, on account of projecting fiber ends nearly $1 \mathrm{~mm}$ high.

Ectosomal specialization, vague or lacking. Endosomal structure, a fibrous reticulation with polygonal meshes about $75 \mu$ in diameter. There is a groundwork of spicules in confusion amid the protoplasmic structures. Ascending fibers $10 \mu$ to $20 \mu$ in diameter, cored by 4 to 7 rows of spicules. Accessory or transverse fibers $10 \mu$ to $20 \mu$ in diameter, cored by 4 to 7 rows of spicules.

Principal spicules, oxeas (fig. 71) ; size, usually about $5 \mu$ by $100 \mu$; a few much thinner ones are probably developmental stages.

Remarks.-Linnaeus (1759) lists a Spongia oculata that may well be the same species as that which Bowerbank in 1862 (p. 1126) made the type of his genus Chatina, namely $C$. ocu-

Figure 71.-H a liclon a ecbasis de Laubenfels, $\times 300$

lata. This is a very common British sponge.

Oddly enough Bowerbank accredited the genus to Grant, though I can find no mention of the name in Grant's writings. In 1841 (p. 5), however, Grant erected a genus Haliclona for a species that he called occulata, obviously a misspelling of oculata. His figure is an excellent representation of the common oculata. This seems to be the first generie name other than Linnaeus's all-inclusive Spongia to be applied to this species, and it appears to have been mere oversight on the part of the early spongologists that it has not been in use ever since. Grant's Halina, a nomen nudem, has little or no bearing here.

Against employment of Haliclona it may be argued that the original description could have included Acervochalina limbata, or even Isodictya palmata. It must be admitted that Grant would probably have diagnosed either of these as Haticlona. There is no doubt, however, that the well-known oculata was included, and there is grave question whether Grant had any specimens of the rarer species resembling it. Grant's genus Cliona, as he described it, might well have included Thoosa, yet we should hardly drop it for that reason. It seems quite as logical to employ Haliclona as to use Cliona.

As compared to the type of oculata, ecbasis averages more spicules to the fiber, and fiber less kinky. As compared to the type of limbata (made type species of the genus Acervochalina Ridley, 1884), ecbasis averages finer mesh, has less visible spongin, yet seems 
tougher. Conditions of preservation may be the cause of this difference. As compared to the type of simulans (made type species of the genus Adocia Gray, 1867, p. 522), the fibers of ecbasis stand out more conspicuously from the other tissues, and it has smaller spicules. No comparison can be made to Pachychalina Schmidt $(1868$, p. 8$)$, which is little more than a name; its type species, $P$. mustica, is represented by no specimens, and from its very brief description it may have belonged to any of many different genera.

As for the matter of few as contrasted to many rows of spicules in the fiber, while some species of Haliclona have definite tendencies one way or the other, the type species regularly exhibits, within a single specimen, portions that have the isodictyal reticulation characteristic of so-called Reniera, and portions of fiber having the many rows of spicules, which supposedly determine the group Pachychatina.

\section{HALICLONA ENAMELA de Laubenfels}

Haliclona enamela de LAubenfels, 1930, p. 28.

Holotype.-U.S.N.M. No. 21450; B.M. No. 29.8.22.8.

Type locality.-Laguna Beach, intertidal, collected by me. On numerous other occasions $I$ have seen sponges in the field that $I$ feel confident were of this species, but in most cases I have been unable to detach specimens without injuring them excessively. The species is very thin, grows on hard rocks of great irregularity of surface, and is so firmly attached that utmost care is required to obtain fragments large enough to work with.

Description.-Shape, encrusting. Size, 1 to $2 \mathrm{~mm}$ thick, spreading laterally indefinitely. Consistency, spongy. Color in life and when preserved, drab. Oscules, with raised collars, diameter 1 to $1.5 \mathrm{~mm}$, distance apart about $1 \mathrm{~cm}$. Pores, very minute. Surface, superficially smooth to verrucose.

Ectosomal specialization, vague or lacking. Endosomal structure, a fibrous reticulation, meshes rectangular and $75 \mu$ to $125 \mu$

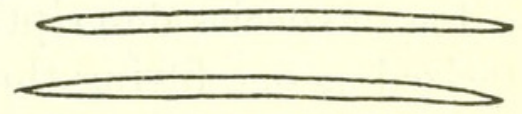

Figure 72.-Haliclona enamela de Laubenfels, $\times 300$ in diameter; the plan is very symmetrical, though numerous spicules not in the fibers but strewn in confusion among them tend somewhat to obscure the regularity of arrangement. Ascending fibers, $15 \mu$ to $25 \mu$ in diameter, cored by 6 to 8 rows of spicules; the spongin is very pale. Accessory or transverse fibers, $5 \mu$ to $10 \mu$ in diameter, cored by 1 to 2 rows of spicules.

Principal spicules, oxeas (fig. 72 ) ; size, about $4 \mu$ by $120 \mu$

Remarks.-Were one to use the diagnoses affixed to the names Reniera, Chatina, and Pachychalina, placing this sponge would be difficult. Thin crusting was supposedly characteristic of Reniera, 
while the architecture of enamela is microscopically that of Pachychatina and Chatina, which were supposed to be usually ramose forms. Although moderately close to every one of the numerous species of Haticlona, I find no one species to single out as closest to enamela.

\section{HALICLONA LUNISIMILIS de Laubenfels}

Haliclona lunisimilis de LAUbenfels, 1930, p. 28.

Holotype.-U.S.N.M. No. 21451; B.M. No. 29.8.22.34.

Type locality.-Pacific Grove, Calif., intertidal, July, 1925, collected by me.

Additional material examined.-Two specimens taken at Laguna Beach, October, 1925. The species is moderately common in central California. So far, all the specimens I have found were growing on and around coralline algae near low tide.

Description.-Shape, massive, subspherical, attached only to coralline algae. Size, up to 2 by 3 by $5 \mathrm{~cm}$. Consistency, toughly spongy, yet easily damaged. Color in life and when preserved, very pale drab. Oscules, craterlike, with raised rims; diameter about $4 \mathrm{~mm}$;

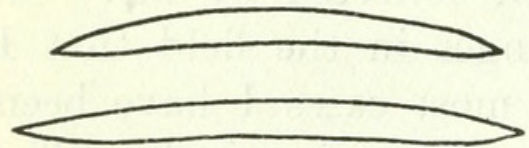

Figure 73.-Haliclona lunisim-

ilis de Laubenfels, $\times 300$ distance apart, more than $1 \mathrm{~cm}$. Pores, $20 \mu$ to $60 \mu$ in diameter. Surface, superficially smooth.

Ectosomal specialization, vague or lacking. Endosomal structure; there is a groundwork that is a very fragile, typically renierid isodictyal reticulation. Throughout this there is a course reticulation of tough spongin fibers about $75 \mu$ in diameter, crowded with many rows of spicules in typical pachychaline fashion. This species admirably shows the impossibility of separating genera upon these characteristics, which are, however, of supplementary value in species descriptions. This particular species may be characterized as one fitting the diagnoses of the old genus Reniera and the so-called Pachychatina.

Ascending fibers $70 \mu$ to $100 \mu$ in diameter, cored by many rows of spicules. Accessory or transverse fibers $70 \mu$ to $100 \mu$ in diameter, cored by many rows of spicules.

Principal spicules, oxeas (fig. 73 ) ; size, $8 \mu$ by $110 \mu$ to $10 \mu$ by $125 \mu$.

Remarks.-This seems a well-marked species, though numerous sponges described as Reniera and as Pachychatina resemble it more or less. See notes given above in the description of the endosome.

\section{HALICLONA CINEREA (Grant)}

Spongia cinerea Grant, 1827, p. 204.

Halichondria cinerea Fleming, 1828, p. 521.

Isodiotya oinerea BowERBANK, 1866, p. 274.

Reniera cinerea SснміDт, 1870, p. 77. 
Holotype.-Probably in the British Museum of Natural History. Type locality.-Europe.

Material examined.-This species is at times abundant intertidally in central California; at other times rare. In the summer of 1925 it was most conspicuous, a year later it was rare, in the winter of 1929 a few specimens were seen, late in the spring none could be found. In southern California, at Laguna Beach, on March 14, 1926, I found a few little nubbins of a sponge agreeing in spiculation and structure with cinerea and probably of the same species, but brownish instead of the lavender color usually so regular on this coast.

Description (U.S.N.M. No. 21448; B.M. Nos. 28.11.6.1; 28.11.6.2).Shape, encrusting. Size, up to $3 \mathrm{~cm}$ thick, $6 \mathrm{~cm}$ in diameter. Consistency, softly fragile. Color in life, lavender; occasional drab specimens are probably pathological. Preserved, drab. Oscules, conspicuous, with raised, craterlike rims; diameter, 2 to $5 \mathrm{~mm}$; distance apart,

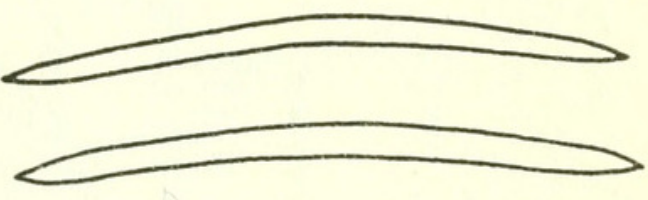

Figure 74.-Haliclona cinera (Grant), $\times 300$ usually a little more than $1 \mathrm{~cm}$;

see notes under "Surface." Surface, superficially very porous, crowded with depressions about $200 \mu$ in diameter; all or many of these probably represent actual pores.

Ectosomal specialization, inconspicuous; there are traces of a diaphanous, fleshy, nondetachable dermal membrane. Endosomal structure, a pronounced isodictyal reticulation with a few vagne spicular tracts.

Principal spicules, oxeas (fig. 74 ); size, $6 \mu$ by $150 \mu$ to $8 \mu$ by $150 \mu$.

Remarks.-In almost all parts of the world where sponges have been studied are found species that lack characteristics that would separate them from cinerea, so this is said to be a cosmopolitan species.

\title{
Order DICTYOCERATINA Minchin
}

\author{
Family SPONGIIDAE Gray
}

Genus SPONGIA？? ?

SPONGIA IDIA, new species

Holotype.-U.S.N.M. No. 22059 ; B.M. 30.10.8.2.

Type locality.-The specimen was collected by me intertidally at Point Lobos, south of Carmel, Calif., July 12, 1930. It was growing in a cave that was uncovered only at very low tide, and that was abundantly lined with sponges. 
Description.-Shape, massive. Size, 4 by 7 by $12 \mathrm{~cm}$. Consistency, spongy. Color in life, slaty ectosome over drab ectosome. As collected the sponge appeared lipstomous on account of the closure of apertures, and even in the aquarium the sphincters did not relax. It would seem that both pores and oscules must be less than $100 \mu$ when open. Surface, profusely conulose, the conules less than $1 \mathrm{~mm}$

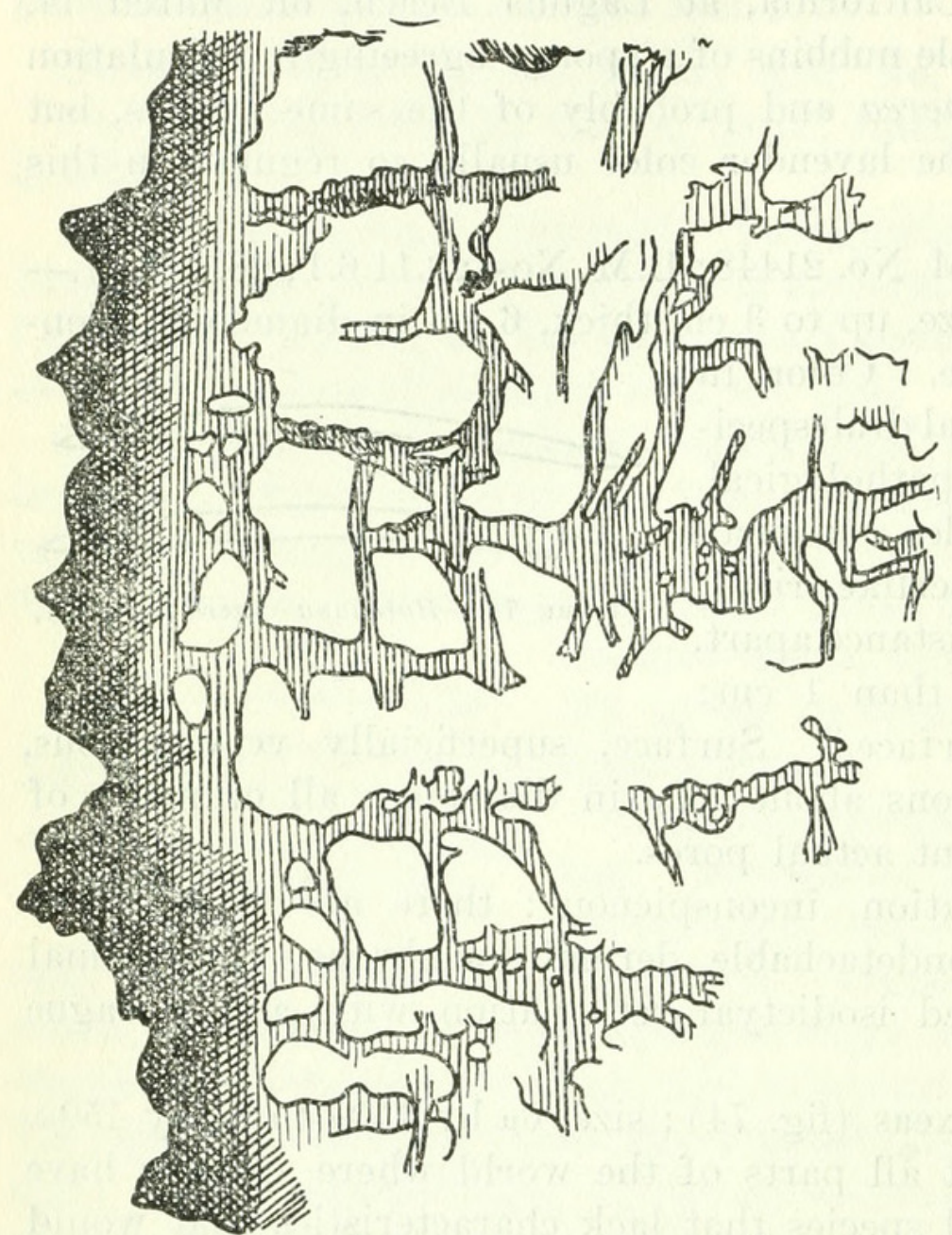

Figure 75.-Spongia idia, new species, $\times 18$, drawn from a section taken perpendicular to the surface. Only the fiber and dermis are drawn, the flesh and foreign intrusions being omitted because their inclusion would obscure the structures to be illustrated

high and about $1 \mathrm{~mm}$ apart, apex to apex.

Ectosomal specialization, an organic dermis not readily detachable, opaque and melanistic; this f r o m $300 \mu$ to $700 \mu$ th i ck. Endosomal structure, a flesh packed with spheroidal flagellate chambers about $25 \mu$ to $30 \mu$ in diameter, and also containing rather numerous evenly distributed foreign spicules and fragments of spicules, a little sand, and other débris. The skeleton is a reticulation chiefly of solid secondary fibers $60 \mu$ to $200 \mu$ in d i a meter. The spongin is $\mathrm{r}$ ather granular-surfaced and medium dark brown, very like that in the commercial sponges. The fibers are often contorted, but the meshes are usually rectangular, about $200 \mu$ to $500 \mu$ in diameter. Here and there through the reticulation are principal fibers ascending perpendicularly to the surface. These are recognizable by having slight, scattered content of coring spicule fragments, but more so by somewhat fasciculated or fenestrated architecture.

Remarks.-With some hesitation this species is here described in the genus Spongia, from typical members of which it differs sharply by having semifasciculated principal fibers. It agrees closely with Spongia in most or all other points, and this genus may well be employed pending revision of the horny sponges. 


\section{Family DYSIDEIDAE ${ }^{8}$}

\section{Genus DYSIDEA Johnston}

DYSIDEA AMBLIA de Laubenfels

Duseideia amblia de LAUBEnfELs, 1930, p. 28.

Holotype.-U.S.N.M. No. 21424; B.M. No. 29.9.30.8.

Type locality._- "Long Wharf," Santa Monica, collected by the University of Southern California, July 18, 1914.

Additional material examined--On February 25, 1926, following a severe storm, I found enormous quantities of this species cast up at Venice, southern California. This is only about 8 or 10 kilometers from the type locality. On the following day immense quantities of it were reported, with specimens brought me for identification, from near Ventura, about 90 kilometers from the type locality. I found no other species of sponge in the wrack with this one, but it must have been tremendously abundant, as bushels could have been col!ected. In all the dredging and other collecting of the University of Southern California, however, they seem to have taken but one fresh specimen. In July, 1930, I collected a massive specimen, intertidally, at $\mathrm{P}$ oint Lobos, south of Carmel, Calif. It is certainly a Dysidea and probably conspecific with the southern specimens, though differing in shape and having all its fibers more load ed with coarse sand grains.

Description.-Shape, digitate, somewhat ramose. Size, up to 20 or $30 \mathrm{~cm}$ in height, about

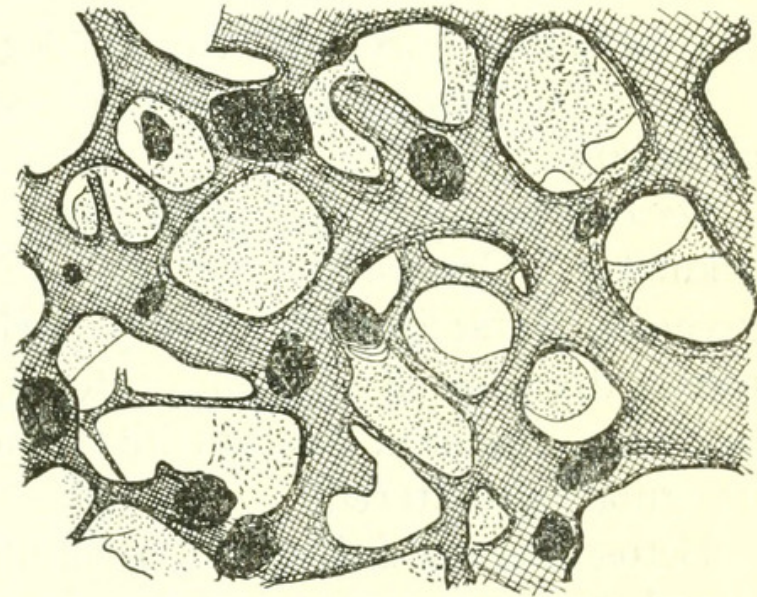

FigURE 76.-Dysidea amblia de Laubenfels, $\times 40$, a characteristic bit of the structure of this species

$1 \mathrm{~cm}$ in diameter. Consistency, spongy. Color in alcohol, drab. Oscules, inconspicuous, barely $100 \mu$ in diameter. Pores, not evident. Surface, superficially conulose with conules usually less than $1 \mathrm{~mm}$ high and less than $1 \mathrm{~mm}$ apart.

Ectosomal specialization, a very thin dermis, not detachable. Endosomal structure, a fibrous reticulation with meshes about $250 \mu$ in diameter. Principal, or ascending, fibers $100 \mu$ to $200 \mu$ in diameter, cored, sometimes superabundantly, by scattered sand grains often more than $100 \mu$ in diameter. Accessory or transverse fibers $10 \mu$ to $25 \mu$ in diameter, often uncommon, usually free from inclusions. The flagellate chambers are conspicuous, crowded together, and about $45 \mu$ to $55 \mu$ in diameter.

${ }^{8}$ For Spongeliidae Lendenfeld, because Dysidea supplants Spongelia. 
Remarks.-This genus has often been called Spongelia, but Spongetia of Nardo, 1834, is a nomen nuden. It is first described by Johnston (1842, p. 185) as Duseideia or (preferably) Dysidea. The genus falls rather sharply into two divisions, fine-surfaced grays and coarse-surfaced purples. The first includes the genotype, $D$. fragilis Montagu. The second includes pallescens Schmidt, the genotype of Spongelia according to Vosmaer (1885, p. 363), and this might be retained as a separate genus, though the affinities are so close this seems to me inadvisable. Our Californian form is very close to fragitis, but differs in rather smaller fiber, which is also more sparsely cored, and by the frequency with which the principal fibers are horizontal as well as vertical.

\section{Family VERONGIIDAE ${ }^{9}$}

\section{Genus VERONGIA Bowerbank}

VERONGIA THIONA de Laubenfels

Verongia thiona DE LAUbenfels, 1930, p. 28.

Holotype.-U.S.N.M. No. 21500; B.M. No. 29.8.22.31.

Type locality.-Laguna Beach, Calif., intertidal, March 14, 1926, abundant.

Description.-Shape, encrusting. Size, up to $4 \mathrm{~cm}$ thick, $12 \mathrm{~cm}$ in diameter. Consistency, spongy. Color in life, lemon yellow with greenish tints; in alcohol very dark purple. Oscules, few and scattered; diameter 2 to $7 \mathrm{~mm}$. Pores, not evident, evidently very contractile. Surface, superficially smooth with conules $0.5 \mathrm{~mm}$ high, irregularly scattered.

Ectosomal specialization, a cellular dermis about $7 \mu$ thick. Endosomal structure, as typical for this genus, of the general consistency of a rather stiff jelly, permeated by meandering canals (about $1 \mathrm{~mm}$ in diameter) and by rather scattered fibers in reticulation. These fibers are clear yellow, with a core often apparently empty, again filled with opaque substance. In this species the thickness of the peripheral portion seems much more constant than the size of the pith, which is larger in the larger fibers, smaller in the smaller. The mesh is so very irregular in outline that it is very difficult to assign it measurements, but one is safe in saying that the mesh size averages more than $1 \mathrm{~mm}$.

Histological details: The flagellate chambers are spheroidal, $25 \mu$ in diameter. Principal fibers $80 \mu$ to $150 \mu$ in diameter, cored by the usual pith as found in this genus. Pith of the fibers, $50 \mu$ to $110 \mu$ in diameter. (Fig. 77.)

\footnotetext{
${ }^{\circ}$ For Aplysinidae Schulze, because Verongia supplants Aplysina
} 
Remarks.-All or nearly all the species of Verongia are very near the genotype, $V$. fistularis Lamarck, 1815, and can only be separated by little differences that may well be insignificant. If the accepted criteria be used, however, this form approaches in size of mesh, size of fiber, and size of pith only one other species of this genus, that described as Aplysina procumbens Lendenfeld (1889, p. 416), from New Zealand. That is also an encrusting form, but it is described with black fibers, a very g reat difference. Incidentally, it is very briefly and inadequately described.

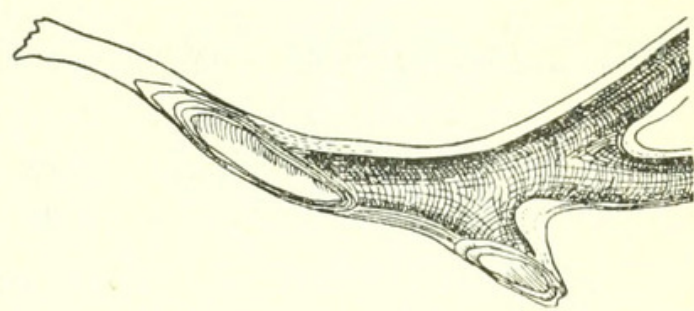

Figure 77.-Verongia thiona de Laubenfels, $\times 40$; typical fiber cut obliquely at one point to show the lamellate, pithed structure

Verongia thiona is moderately common, at times at least, in the intertidal areas of southern California. I know of no other local form from which it may not easily be distinguished by its tendency (very common in this genus) to change from yellow to very dark blue or purple upon drying.

\title{
Order DENDROCERATINA Minchin
}

\section{Family DARWINELLIDAE Merejkowsky}

\author{
Genus APLYSILLA F. E. Schulze
}

\section{APLYSILla GLACIALIS (Dybowski)}

Simplicella glacialis DYBowsKi, 1880, p. 65.

Aplysilla glacialis Lendenfeld, 1889, p. 706.

Holotype.-Location unknown.

Type locality.-Arctic (White Sea).

Material examined.-Numerous specimens, all collected intertidally at Pacific Grove, Calif., in which vicinity the species is rather common. It occurs on granite bowlders fairly high up in the intertidal zone, seeming to be a very hardy sponge.

Description (U.S.N.M. No. 21432; B.M. No. 29.8.22.23).-Shape, encrusting. Size, 1 to $2 \mathrm{~mm}$ thick, 5 to $6 \mathrm{~cm}$ in diameter. Consistency, weakly spongy. Color in life, colorless to rosy red; in alcohol, drab. Oscules, round and scattered; about $1 \mathrm{~mm}$ in diameter. Pores, not evident. Surface, superficially glabrous, with conules about 1 to $2 \mathrm{~mm}$ high and 2 to $3 \mathrm{~mm}$ apart.

Ectosomal specialization, a dermis about $8 \mu$ thick, fleshy, and rather slimy. Endosomal structure, a rather dense mass of flagellate chambers and other protoplasmic structures permeated by canals and dendritic fibers. Histological details: The flagellate chambers 
are eurypyllous, often polygonal in section, and typically about $30 \mu$ by $50 \mu$ by $70 \mu$ in size. Principal fibers, $80 \mu$ to $255 \mu$ in diameter, obviously of concentric layers. A pith

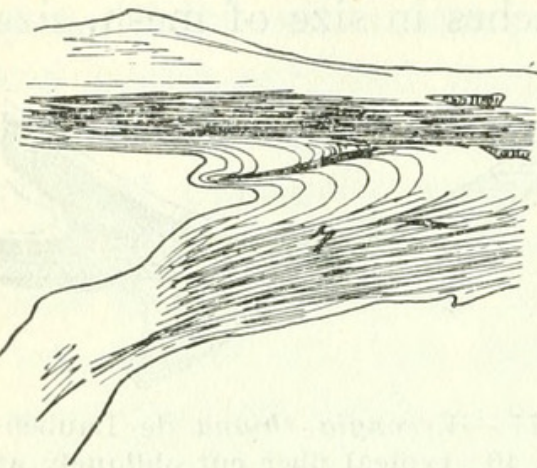

Eigure 78. - Aplysilla glacialis (Dybowksi) : Fiber, $\times 40$ often occupies as much as 80 per cent of the total, especially near the base of the sponge. These fibers arise from a basal plate (very thin) and branch a few times, but I find no anastomoses. The distal ends of the fibers cause the conules. (Fig. 78.)

Remarks.-It is quite remarkable that the Californian specimens agree so closely with the original specimen from north of Europe, and with Lendenfeld's description of what he records as the same species from Australia.

\section{APLySilla POLYRAPHIS de Laubenfels}

Aplysilla polyraphis de LaUbenfels, 1930, p. 29.

Holotype.-U.S.N.M. No. 21434; B.M. No. 29.8.22.41.

Type locality.-The one specimen, or group of specimens, is from my personal collection, taken at Pacific Grove, Calif., July, 1925.

Description.-Shape, encrusting. Size, $5 \mathrm{~mm}$ thick, $3 \mathrm{~cm}$ in diameter. Consistency, spongy. Color in life and when preserved, purple. In collecting this sponge, it was necessary to detach its rather thin encrustation from the rock under water. Upon doing this, such copious quantities of deep purple coloring material were emitted that the entire tide pool, about a meter in diameter, was rendered purple. The sponge was put in a bucket of sea water to be taken to the laboratory, and this was also colored purple. The first jar of alcohol in which it was placed was colored so deeply as to become opaque, but the alcohol was changed twice, and the third filling remains uncolored, though the sponge appears as dark as ever.

Oscules, not evident as distinct from the pores (which see). Pores, skeletal, $120 \mu$ to $300 \mu$; protoplasmic, probably up to $200 \mu$ when fully open, but closed or nearly closed in my specimen. Surface, superficially smooth, with scattered conules $1 \mathrm{~mm}$ high.

Ectosomal specialization, a fibrous reticulation in one plane, with meshes having openings $120 \mu$ to $300 \mu$ in diameter. The fibers are about $80 \mu$ to $180 \mu$ in diameter and are densely packed with foreign spicules; these are presumably united by spongin, but remain united during only very slight maceration, more vigorous maceration separating them easily. Endosomal structure, a minimum of protoplasm with relatively enormous quantities of foreign spicules, the 
mass permeated by dendritic fibers, and all set on a tough basal plate of spongin. Ascending fibers, $80 \mu$ to $200 \mu$ in diameter, without foreign inclusions, with lamellate structure, and terminating above in the conules. (Fig. 79.)

Remarks.-Because of the enormous quantities of siliceous matter present (mostly foreign spicules) and because of the extreme opacity of the cells (they are packed with purple granules that are almost black), the difficulties in studying this sponge were excessively great. Recourse was had to hydrofluoric acid as a solvent for the siliceous matter, but the resulting material was badly shriveled and distorted, so that the method helped very little. By dint of making many sections some data can be given, however. There is a basal plate of spongin from which dendritic processes rise. These are typically about $130 \mu$ in diameter near the base, and about 0.8 to $2.7 \mathrm{~mm}$ high, with occasional branching but no anastomosing. The spongin is now dark, perhaps stained by coloring matter dissolved into the alcohol from the cells. Near the base these fibers are rather obviously cored with pith, but their structure is in general that of several concentrically placed cones, a hollow within the inner, smallest ones. This organization of fiber is quite typical of the genus Aplysilla.

All through the flesh are enormous quantities of spicules. It would seem that every species in the vicinity was represented. There is but cramped space left for the protoplasmic structure. As the spicules are placed to avoid closing the

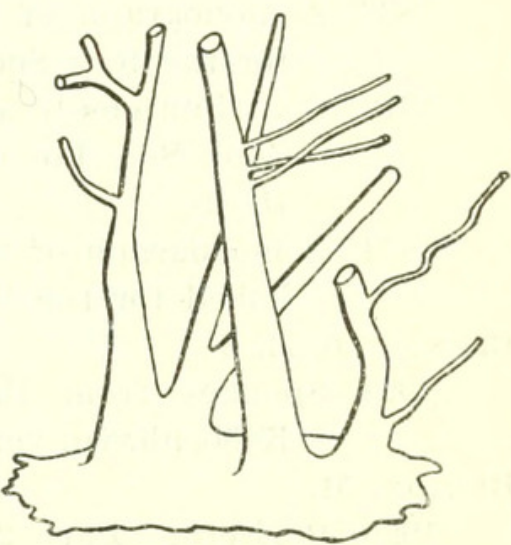

Figure 79.-Aplysilla polyraphis de Laubenfels, $\times 50$; section of macerated skeleton; free-hand drawing dermal pores there is at the surface that which resembles a reticulation of foreign spicules, densely packed. From the ease with which these are macerated apart, I judge they are not held together by spongin. I find no foreign inclusions in the fibers themselves.

Very careful search was made for the flagellate chambers. I believe that in this sponge, on account of the small size of the interstices between spicules, the flagellate cells are poorly organized into chambers. I find a few that seem to be eurypyllous, about $30 \mu$ wide by $100 \mu$ long. Others in this section are round, and about $30 \mu$ in diameter. These may be cross sections of the eurypyllous ones.

On all counts, the closest species to polyraphis is violacea Lenden feld (1883, p. 237), from Australia. It had sand grains in its basal plate of spongin, which I think is probably true of polyraphis. From it and all others of the genus, however, the California sponge is very widely separated by its profusion of foreign spicules. 


\section{BIBLIOGRAPHY}

Annandale, N.

1907. Notes on the freshwater fauna of India. No. 9. Descriptions of new freshwater sponges from Calcutta, with a record of two known species from the Himalayas and a list of the Indian forms. Journ. Proc. Asiat. Soc. Bengal, vol. 3, pp. 15-26, 7 figs.

Bowerbank, J. S.

1860. List of British sponges, in McAndrew's List of the British Marine Invertebrate Fauna. Rep. 30th Meeting British Assoc., pp. 235, 236.

1862. On the anatomy and physiology of the Spongiadae. Phil. Trans. Roy. Soc. London, vol. 152, pp. 747-829, 1087-1135, pls. 27-35, 72-74.

1863. A monograph of the Spongillidae. Proc. Zool. Soc. London, pp. 440 472 , pl. 38.

1864. A monograph of the British Spongiadae, vol. 1, 290 pp., 37 pls. Published for the Ray Society, London.

1866. A monograph of the British Spongiadae, vol. 2, 388 pp. Published for the Ray Society, London.

1872. Contributions to a general history of the Spongiadae, pts. 1-3. Proc. Zool. Soc. London, pp. 115-129, 196-202, 626-635, pls. 5, 6, 10, 11, 16-19.

1874. A monograph of the British Spongiadae, vol. 3, 263 pp., 92 pls. Published for the Ray Society, London.

BRøNdSTEd, H. V.

1924. Sponges from the Auckland and Campbell Islands. Vid. Medd. Kjöbenhavn, vol. 75, pp. 117-167, 36 figs.

Burton, M.

1929. Porifera. Part 2. Antarctic sponges. British Antarctic ("Terra Nova ”) Expedition, Zoology, 1910, vol. 6, no. 4, pp. 393-458, pls. 1-5.

Carter, H. J.

1874. Descriptions and figures of deep-sea sponges and their spicules from the Atlantic Ocean, dredged up on board H. M. S. "Porcupine," chiefly in 1869 ; with figures and descriptions of some remarkable spicules from the Agulhas Shoal and Colon, Panama. Ann. Mag. Nat. Hist., ser. 4, vol. 14, pp. 207-221, 245-257, pls. 13-15.

1876. Descriptions and figures of deep-sea sponges and their spicules, from the Atlantic Ocean, dredged up on board H. M. S. "Porcupine," chiefly in 1869. Ann. Mag. Nat. Hist., ser. 4, vol. 18, pp. 226-240, $307-324$, 388-410, $458-479$, pls. $12-16$.

1878. Parasites of the Spongida. Ann. Mag. Nat. Hist., ser. 5, vol. 2, pp. 157-172.

1879. Contributions to our knowledge of the Spongida. Ann. Mag. Nat. Hist., ser. 5, vol. 3, pp. 284-304, 343-360, pls. 25-29.

1882. Some sponges from the West Indies and Acapulco in the Liverpool Free Museum described, with general and classificatory remarks. Ann. Mag. Nat. Hist., ser. 5, vol. 9, pp. 266-301, 346-348, pls. 11, 12. Czerniavsky, V.

1879. The littoral sponges of the Black and Caspian Seas. Preliminary report. Bull. Soc. Nat. Moscow, vol. 53, pt. 2, Ann. 1878, pp. 375379 , pls. $5-8$. 
Dendy, A.

1891. A monograph of the Victorian sponges. Part 1, The organisation and classification of the Calcarea Homocoela, with descriptions of the Victorian species. Trans. Roy. Soc. Victoria, vol. 3, pp. 1-81, pls. $1-11$.

1893. On a new species of Leucosolenia from the neighbourhood of Port Phillip Heads. Proc. Roy. Soc. Victoria, new ser., vol. 5, pp. 178-180.

1905. Report on the sponges collected by Professor Herdman, at Ceylon, in 1902, in Herdman, Rep. Pearl Oyster Fisheries, suppl. 18, pp. 57-246, pls. $1-16$.

1921. The tetraxonid sponge-spicule: A study in evolution. Acta Zool. Stockholm, 1921, vol. 2, pp. 95-152.

1922. Report on the Sigmatotetraxonida collected by H. M. S. "Sealark" in the Indian Ocean. Trans. Linn. Soc. London, vol. 18, pp. 1-164, pls. 1-18.

1924. Porifera. Part 1, Non-Antarctic sponges. British Antarctic ("Terræ Nova ”) Expedition 1910, Zoology, vol. 6, no. 3, pp. 269-392, pls. $1-15$.

Dendy, A., and Ridley, S. O.

1886. On Proteleia Sollasi, a new genus and species of monaxonid sponges allied to Polymastia. Ann. Mag. Nat. Hist., ser. 5, vol. 18, pp. 152-159, pl. 5.

Dendy, A., and Row, R. W. H.

1913. The classification and phylogeny of the calcareous sponges; with a reference list of all the described species, systematically arranged. Proc. Zool. Soc. London, pp. 704-813.

Duchassaing de Fonbressin, P., and Michelotti, G.

1864. Spongiaires de la Mer Caraïbe. Nat. Verh. Mij. Haarlem, vol. 21, pp. 1-124, pls. 1-25.

Drвowski, W.

1880. Studien über die Spongien des russischen Reiches, mit besonderer Berücksichtigung der Spongien-Fauna des Baikal-Sees. Mém. Acad. St. Pétersbourg, ser. 7, vol. 27, 71 pp., 4 pls.

ELLIS, J.

1786. The natural history of many curious and uncommon zoophytes, collected from various parts of the globe. Systematically arranged and described by the late Daniel Solander, 206 pp., 63 pls. London.

Fleming, J.

1828. A history of British animals, exhibiting the descriptive characters and systematical arrangement of the genera and species of quadrupeds, birds, reptiles, fishes, Mollusca and Radiata of the United Kingdom, 565 pp. Edinburgh-London.

George, W. C., and Wilson, H. V.

1921. Sponges of Beaufort (N. C.) Harbor and vicinity. Bull. U. S. Bur. Fish., vol. 36, 1917-1918, pp. 133-179, pls. 56-61.

Grant, Robert E.

1827. Notice of two new species of British sponges. Edinburgh New Philos. Journ., vol. 2 (1826?), pp. 203, 204.

1833. On the classification of the organs of animals, and on the organs of support in animalcules and poripherous animals. The Lancet, 1833-34, vol. 1, pp. 193-200, figs. A-D, Nov. 2.

1841. Outlines of comparative anatomy. Porifera, pp. 5-9, 310-313, figs. 2-4. London.

$107704-32-9$ 
Gray, J. E.

1867. Notes on the arrangement of sponges, with the description of some new genera. Proc. Zool. Soc. London, pp. 492-558, pls. 27, 28.

HAECkel, E. (H. P. A.)

1872. Die Kalkschwämme. Eine Monographie in zwei Bänden Text und einem Atlas mit 60 Tafeln Abbildungen. Berlin.

Hallmann, E. F.

1914. A revision of the monaxonid species described as new in Lendenfeld's "Catalogue of the sponges in the Australian Museum." Proc. Linn. Soc. New South Wales, vol. 39, pp. 263-376, 397-446, pls. 15-24.

1917. A revision of the genera with microscleres included, or provisionally included, in the family Axinellidae; with descriptions of some Australian species. Proc. Linn. Soc. New South Wales, vol. 41, pp. $633-675$, pls. $29,33,38,39,41-44$.

1920. New genera of monaxonid sponges related to the genus Clathria. Proc. Linn. Soc. New South Wales, vol. 44, pp. 767-792, pls. 36-40, figs. 1-3.

Hanitsch, R.

1894. Revision of the generic nomenclature and classification in Bowerbank's “British Spongiadae.” Trans. Liverpool Biol. Soc., vol. 8, pp. 173-206.

Hentschel, E.

1911. Tetraxonida, Teil 2. In Michaelson and Hartmeyer's Fauna Südwest-Australiens, vol. 3, pp. 279-393, 54 figs.

1912. Kiesel- und Hornschwämme der Aru- und Kei-Inseln. Abh. Senck. Ges., vol. 34, pp. 295-448, pls. 13-21.

1913. Uber einen Fall von Orthogenese bei den Spongien. Zool. Anz., vol. 42 , pp. $255-267,1$ fig.

Higgin, T. H.

1877. Description of some sponges obtained during a cruise of the steamyacht "Argo" in the Caribbean and neighbouring seas. Ann. Mag. Nat. Hist., ser. 4, vol. 19, pp. 291-299, pl. 14.

Hozawa, S.

1929. Studies on the calcareous sponges of Japan. Journ. Faculty of Sci. Imp. Univ. Tokyo, sect. 4, Zoology, vol. 1, pt. 5, pp. 277-389, pls. $12-23$.

IJIMA, I.

1897. Revision of hexactinellids with discoctasters, with descriptions of five new species. Annot. Zool. Japon., vol. 1, pp. 43-59.

JoHnston, G.

1842. A history of British sponges and Lithophytes, 264 pp., 23 figs., 25 pls. Edinburgh, London, Dublin.

KinkPATRICK, R.

1900. Description of sponges from Funafuti. Ann. Mag. Nat. Hist., ser. 7, vol. 6, pp. 345-362, pls. 13-15.

1907. Porifera of Lambay. Irish Nat., vol. 16, pp. 86, 87. Dublin.

1907. Preliminary report on the Monaxonellida of the National Antarctic Expedition. Ann. Mag. Nat. Hist., ser. 7, vol. 20, pp. 271-291.

1910. On hexactinellid sponge spicules and their names. Part 2, Supplementary. Ann. Mag. Nat. Hist., ser. 8, vol. 5, pp. 347-350, 5 figs.

LAMARCK, J. B. P. A. De M.

1813-1814. Sur les polypiers empâtés. Ann. Mus., vol. 20, pp. 294-312, $370-386,432-458$. 
Lamarck, J. B. P. A. DE M.-Continued.

1815. Suite des polypiers empâtés (dont l'exposition commence au $20^{\circ}$ volume des Annales, p. 294). Mém. Mus., vol. 1, pp. 69-80, 162-168, $331-340$.

LAMBE, L. M.

1892. On some sponges from the Pacific coast of Canada and Behring Sea. Proc. and Trans. Roy. Soc. Canada, vol. 10, sect. 4, pp. 67-78, pls. 3-6.

1893. Sponges from the Pacific coast of Canada. Proc. and Trans. Roy. Soc. Canada, vol. 11 , sect. 4 , pp. $25-43$, pls. $2-4$.

1894. Sponges from the western coast of North America. Proc. and Trans. Roy. Soc. Canada, vol. 12, sect. 4, pp. 113-138, pls. 2-4.

1905. A new recent marine sponge (Esperella bellabellensis) from the Pacific coast of Canada. Ottawa Nat., vol. 19, pp. 14, 15, pl. 1.

LAUBenfels, M. W. DE

1926. New sponges from California. Ann. Mag. Nat. Hist., ser. 9, vol. 17, pp. 567-573, figs. 1-15.

1927. The red sponges of Monterey Peninsula, California. Ann. Mag. Nat. Hist., ser. 9, vol. 19, pp. 258-266.

1930. The sponges of California. Stanford Univ. Bull., ser. 5, vol. 5, no. 98 , pp. 24-29.

LENDENFELD, R. voN.

1883. Ueber Coelenteraten der Südsee. Neue Aplysinidae. Zeitschr. Wiss. Zool., vol. 38, pp. 234-313, pls. 10-13.

1888. Descriptive catalogue of the sponges in the Australian Museum, Sydney. (Pub. of the Australian Museum.) 260 pp., 12 pls. London.

1889. A monograph of the horny sponges, 936 pp., 50 pls. London.

1897. Spongien von Sansibar. Abh. Senck. Nat. Ges., vol. 21, pp. 93-133, pls. $9,10$.

1907. Die Tetraxonia. Wiss. Erg. "Valdivia," vol. 11, pp. 59-374, pls. $9-46$.

1910. Reports on the scientific results of the expedition to the eastern tropical Pacific, in charge of Alexander Agassiz, by the U. S. Fish Commission Steamer "Albatross," from October, 1904, to March, 1905, Lieut. Commander L. M. Garrett, U.S.N., Commanding, and of other expeditions of the "Albatross," 1888-1904. The Sponges. I. The Geodidae. Mem. Mus. Comp. Zoöl., vol. 41, no. 1, 259 pp., 48 pls.

1915. Reports on the scientific results of the expedition to the eastern tropical Pacific, in charge of Alexander Agassiz, by the U. S. Fish Commission Steamer "Albatross," from October, 1904, to March, 1905, Lieut. Commander L. M. Garrett, U.S.N., Commanding, and of other expeditions of the "Albatross," 1891-1899. The Sponges. 3. Hexactinellida. Mem. Mus. Comp. Zoöl., vol. 42, 396 pp., 109 pls.

LIEBERK ÜHN, N.

1859. Neue Beiträge zur Anatomie der Spongien. Arch. Anat. Phys., pp. 353-382, 515-529, pls. 9-11.

Linnaeus, C. von.

1759. Systema naturae, ed. 10, vol. 2, Vegetabilia.

1767. Systema naturae, ed. 12, vol. 1, pt. 2, Insecta, Vermes. Holmiae.

LUNDBECK, W.

1905. Porifera (part 2). Desmacidonidae (part). Danish Ingolf-Expedition, vol. 6, 219 pp., pls. 1-20. 
MCANDRew, R. (Bowerbank, J. S.).

1861. List of the British marine invertebrate fauna. Rep. 30th Meeting Brit. Assoc., pp. 235, 236.

MarshaLl, W.

1892. Spongiologische Beiträge. Festschrift 70. Wiederk. Geburtst. Leuckart, 36 pp., 8 pp. explanation, 8 pls.

\section{MinLs, H.}

1880. Fresh-water sponges. Amer. Journ. Micr., vol. 5, pp. 125-132.

Minchin, E. A.

1900. A treatise on zoology. Part 2, The Porifera and Coelentera, pp. 1-178, 97 woodcuts. (Edited by E. Ray Lankester.) London.

Montagu, G.

1818. An essay on sponges, with descriptions of all the species that have been discovered on the coast of Great Britain. Mem. Werner Soc., vol. 2 , pp. $67-122$, pls. $3-16$.

NARDO, G. D.

1833. Auszug aus einem neuen System der Spongiarien, wornach bereits

die Aufstellung in der Universitäts-Sammlung zu Padua gemacht ist. Isis von Oken, Coll. 515-524.

1834. De Spongiis. Isis von Oken, Coll. 714-716.

Pallas, P. S.

1766. Elenchus Zoophytorum. Hagae-comitum apud Petrum van Cleef.

PotTs, E.

1881. Some new genera of fresh-water sponges. Proc. Acad. Nat. Sci. Philadelphia, 1881, pp. 149, 150.

1887. Contributions toward a synopsis of the American forms of fresh water sponges with descriptions of those named by other authors and from all parts of the world. Proc. Acad. Nat. Sci. Philadelphia, 1887 , pp. $158-279$, pls. $5-12$.

RIDLEY, S. O.

1884. Spongiida. Report on the zoological collections made in the IndoPacific Ocean during the voyage of H. M. S. "Alert" 1881-82, pp. 366-482, 582-630, pls. 39-43, 53, 54. London.

RidLey, S. O., and Dendy, A.

1886. Preliminary report on the Monaxonida collected by H. M. S. “Challenger." Ann. Mag. Nat. Hist., ser. 5, vol. 18, pp. 325-351, $470-493$.

1887. Report on the Monaxonida collected by H. M. S. "Challenger" during the years 1873-76. Rep. Sci. Res. Challenger, Zoology, vol. 20, pt. 59, 275 pp., pls. 1-51, 1 map.

SchMidt, (E.) O.

1862. Die Spongien des adriatischen Meeres, 88 pp., 7 pls. Leipzig.

1864. Supplement der Spongien des adriatischen Meeres. Enthaltend die Histologie und systematische Ergänzungen, 48 pp., 4 pls. Leipzig.

1868. Die Spongien der Küste von Algier. Mit Nachträgen zu den Spongien des adriatischen Meeres. (Drittes Supplement.) 44 pp., 5 pls. Leipzig.

1870. Grundzüge einer Spongien-Fauna des atlantischen Gebietes, 88 pp., 6 pls. Leipzig.

SOHULze, F. E.

1887. Report on the Hexactinellida collected by H. M. S. "Challenger" during the years 1873-1876. Rep. Sci. Res. Challenger, Zoology, vol. 21, pt. 53, 514 pp., 104 pls., 1 map. 
Schulze, F. E.-Continued.

1899. Amerikanische Hexactinelliden nach dem Materiale der AlbatrossExpedition bearbeitet, 126 pp., 19 pls. Jena.

SELENKA, E.

1879. Ueber einen Kieselschwamm von achtstrahligem Bau, und über Entwicklung der Schwammknospen. Zeitschr. Wiss. Zool., vol. 33, pp. 467-476, pls. 27, 28.

Sмiтн, F.

1921. Distribution of the fresh-water sponges of North America. Bull. Nat. Hist. Surv. Illinois, vol. 14, art. 11, pp. 9-22.

Sollas, Igerna B. J.

1902. On the sponges collected during the "Skeat Expedition" to the Malay Peninsula, 1899-1900. Proc. Zool. Soc. London, vol. 2, pt. 1, pp. 220,221 , pls. 14,15 .

SoLLAs, W. J.

1879. On Plocamia plena, a new species of echinonematous sponge. Ann. Mag. Nat. Hist., ser. 5, vol. 4, pp. 44-53, 4 woodcuts.

1886. Preliminary account of the tetractinellid sponges dredged by H. M. S. “Challenger," 1872-1876. Pt. 1. The Choristida. Sci. Proc. Roy. Dublin Soc., vol. 5, pp. 177-199.

1888. Report on the Tetractinellida collected by H. M. S. "Challenger," during the years 1873-1876. Rep. Sci. Res. Challeuger, Zoology, vol. 25,458 pp., 44 pls., 1 map.

Stephens, J.

1916. Preliminary notice of some Irish sponges.-The Monaxonellida (suborder Sigmatomonaxonellida) obtained by the fisheries branch of the Department of Agriculture and Technical Instruction, Ireland. Ann. Mag. Nat. Hist., ser. 8, vol. 17, pp. 232-242.

THIELE, J.

1898. Studien über pazifische Spongien, I. Zoologica, Heft 24, pp. 1-72, pls. $1-8$.

1899. Studien über pazifische Spongien, II. Zoologica, Heft 24, pp. 1-33, pls. 1-5.

1905. Die Kiesel- und Hornschwämme der Sammlung Plate. Zool. Jahrb., Suppl. 6, pp. 407-496, pls. 27-33.

Topsent, E.

1889. Notes spongologiques. Arch. Zool. Exp., ser. 2, vol. 6, pp. xxxiiixliii.

1892. Contribution à l'étude des Spongiaires de l'Atlantique Nord. Résultats des campagnes scientifiques accomplies sur son yacht par Albert $\mathrm{I}^{\mathrm{er}}$ Prince Souverain de Monaco, fasc. 2, 165 pp., 11 pls.

1893. Nouvelle série de diagnoses d'éponges de Roscoff et de Banyuls. Arch. Zool. Exp., ser. 3, vol. 1, pp. xxxiii-xliii.

1894. Etude monographique des Spongiaires de France. I, Tetractinellida. Arch. Zool. Exp., ser. 3, vol. 2, pp. 259-400, pls. 11-16.

1896. Matériaux pour servir à l'étude de la faune des Spongiaires de France. Mém. Soc. Zool. France, vol. 9, pp. 113-133.

1897. Spongiaires de la Baie d'Amboine. Rev. Suisse Zool., vol. 4, pp. 421487 , pls. $18-21$.

1900. Etude monographique des Spongiaires de France, vol. 3, Monaxonida (Hadromerina). Arch. Zool. Exp., ser. 3, vol. 8, pp. 1-331, pls 1-8.

1904. Spongiaires des Açores. Résultats des campagnes scientifiques accomplies sur son yacht par Albert $\mathrm{I}^{\mathrm{er}}$ Prince Souverain de Monaco, fasc. 25 , pp. 1-280, pls. 1-18. 
'Topsent, E.-Continued.

1914. Spongiaires de l'expédition antarctique nationale écossaise. Trans. Roy. Soc. Edinburgh, vol. 49, pt. 3, no. 9, pp. 579-643, pls. 1-6.

1920. Spongiaires du musèe zoologique de Strasbourg. Monaxonides. Bull. Inst. Oceanogr. Monaco, no. 381, 36 pp., 5 figs.

1925. Etude de Spongiaires du Golfe de Naples. Arch. Zool. Exp., vol. 63, fasc. 5, pp. 623-725, pl. 8, figs. 1-27.

1927. Diagnoses d'éponges nouvelles recueillies par le Prince Albert $\mathrm{I}^{\mathrm{er}}$ de Monaco. Bull. Inst. Océanogr. Monaco No. 502, pp. 1-19.

1928. Spongiaires de l'Atlantique et de la Méditerranée, provenant des croisières du Prince Albert $\mathrm{I}^{\text {er }}$ de Monaco. Résultats des campagnes scientifiques accomplies sur son yacht par Albert $\mathrm{I}^{\mathrm{er}}$, Prince Souverain de Monaco, fasc. 74, pp. 1-376, pls. 1-11.

I:RBAN, F.

1902. Rhabdodermella nuttingi, nov. gen. et nov. spec. Zeitschr. Wiss. Zool., vol. 71 , pp. 268-275, pl. 14.

1905. Kalifornische Kalkschwämme. Arch. für Nat., vol. 72, pp. 33-76, pls. 6-9.

VERRILl, A. E.

1907. The Bermuda Islands. Porifera: Sponges. Trans. Connecticut Acad. Arts and Sci., vol. 12, pp. 330-344.

Vosmaer, G. C. J.

1882-1886. Porifera, in Bronn's Die Klassen und Ordnungen des Thierreichs, vol. 2, pp. 1-496, pls. 1-260. Leipzig. Most of the references to this work are to the part that appeared in 1885 , hence show that date.

1928. Bibliography of sponges, 1551-1913. Edited by G. P. Bidder and C. S. Vosmaer-Röell. 234 pp. Cambridge.

WeLtNeR, W.

1895. Spongillidenstudien, pt. 3, Katalog und Verbreitung der bekannten Süsswasserschwämme. Arch. für Nat., vol. 66, pp. 114-144.

Whitelegge, TH.

1906. Scientific results of the trawling expedition of H. M. C. S. "Thetis" off the coast of New South Wales in February and March, 1898. Part 9, Sponges. Australian Mus. Mem., vol. 4, pp. 453-484, pls. $43,44$.

WILson, H. V.

1904. The sponges. (No. 30 of Reports on an exploration off the west coasts of Mexico, Central and South America, and off the Galapagos Islands, in charge of Alexander Agassiz, by the U. S. Fish Commission Steamer "Albatross," during 1891, Lieut. Commander Z. L. Tanner, U. S. N., commanding.) Mem. Mus. Comp. Zoöl., vol. 30, no. 1, 164 pp., 26 pls.

1911. Development of sponges from dissociated tissue cells. Bull. U. S. Bur. Fish., vol. 30 (1910), pp. 1-30, pls. 1-5.

1925. Silicious and horny sponges collected by the U. S. Fisheries Steamer "Albatross" during the Philippine Expedition, 1907-10. U. S. Nat. Mus. Bull. 100, vol. 2, pt. 4, 532 pp., 52 pls. 


\section{N D E X}

(SYNONYMS ARE GIVEN IN ITALICS)

Aata, 89 .

brepha, 91.

spongigartina, 89.

Acanthascus, 18. platei, 18.

Acanthosaccus tenuis, 3.

Acarnidae, 104.

Acarnus, 104, 106.

erithacus, 4, 104.

ternatus, 106.

Acervochalina, 118.

limbata, 118.

aculeata, Farrea, 3 .

Adocia, 119.

simulans, 119.

Aegagrophila, 69.

aegagropila, Mycale, 68.

agassizii, Geodia, 4, 25.

agennes, Myxilla, 79.

agminata, Hymeniacidon, 62.

Alcyonium aurantium, 45.

vesparium, 50.

amblia, Duseideia, 123.

amblia, Dysidea, 123.

amorpha, Reniera, 61.

amorphus, Prianos, 61.

Amphilectus, 99.

Amphoriscidae, 15.

Anaata, 89.

brepha, 91 .

spongigartina, 89.

andrewsi, Spirastrella, 50.

angulata, Sidonops, 4, 23.

Aphorme, 17.

horrida, 17

Aphrocallistes, 21.

vastus, 21.

whiteavesianus, 21.

Aphrocallistidae, 21.

apicalis, Leucandra, 4, 11.

Aplysilla, 125.

glacialis, 125.

polyraphis, 126 .

violacea, 127.

Aplysina, 124. procumbens, 125.

Aplysinidae, 124.

aquaeductus, Reniera, 61 .

arb, Tetilla, 42.

arndti, Astylinifer, 74.

Ascilla convallaria, 3, 6 .

Ascute, 10.

uteoides, 10.

asodes, Eurypon, 92. asper, Rhabdocalyptus, 20.

astrosanguinea, Microciona, 95.

Astrotetraxonida, 106.

Astylinifer, 74.

arndti, 74 .

planus, 75.

atlantica, Poterion, 50.

aurantia californiana, Tethya, 44.

aurantium, Alcyonium, 45 .

authia, Timea, 45.

Axinellidae, 56.

Axos, 106.

Barbozia, 62.

primitiva, 62 .

Bathydorus daxsoni, 20.

Bathyxiphus subtilis, 3.

Batzella, 62.

inops, 62

bellabellensis, Esperella, 66.

bellabellensis, Mycale, 66 .

bicolor, Sidonops, 4, 23.

Biemna, 63, 78.

fortis, 64 .

megalosigma, 64 .

rhadia, 63 .

bitorquis, Phlyctaenopora, 62 .

brepha, Aaata, 91.

brepha, Anaata, 91.

breviana, Geodia, 4, 25.

bucklandi, Dercitus, 39, 40.

bucklandi, Halina, 39

Hymeniacidon, 39.

Calcarea, 5, 6.

californiana, Cliona celata, 47 .

Iophona chelifer, 82.

Myxilla versicolor, 81 .

Ophlitaspongia pennata, 103.

Tethya aurantia, 44.

calyx, Chonelasma, 21.

canaliculata, Esperiopsis, 93.

candidata, Papyrula, 38.

Carterella tubisperma, 111.

carteri, Strongylamma, 63.

Carterius, 111.

tubisperma, 111.

caruncula, Hymeniacidon, 58, 59.

celata californiana, Cliona, 47.

centrangulatus, Gellius, 112.

Chalina, 118, 119. oculata, 118.

chelifer californiana, Iophon, 82. chelifer ostia-magna, Iophon, 83. 
Chonelasma, 21. calyx, 21. tenerum, 21.

Choristida, 5, 23. ciliata, Grantia, 11.

Cinachyra, 44. cinerea, Halichondria, 120.

Isodictya, 1:0. Reniera, 120. Spongia, 120.

cinerea, Haliclona, 120. clarella, Stelletta, 29.

Clathria, 93, 95. coralloides, 95.

Clathriidae, 93.

Clathrina, 8, 9.

Clathriopsamma, 96. pseudonapya, 96.

Cliona, 47, 118. celata californiana, 47 .

Clionidae, 47.

Cliothoosa, 106.

coacta, Sycandra, 4, 10.

coactum, Sycon, 10.

Coelosphaeridae, 74.

coerula, Terpios, 88.

columella, Desmacidon, 62. Stylotella, 62.

columella, Prianos, 62.

Columnitis squamata, 46, 47.

compressa, Poecillastra, 33.

confoederata, Spheciospongia, 48.

constellata, Leptosastra, 91.

convallaria, Ascilla, 3, 6.

convallaria, Leucosolenia, 6 .

convolvulus, Farrea, 20.

coralloides, Clathria, 95.

Petrosia, 117.

coralloides, Xestospongia, 116.

coriacea, Leucosolenia, 7 .

coronata, Spongia, 11.

Sycandra, 3, 11.

coronatum, Sycon, 11.

cortius, Penares, 35.

Coscinoporidae, 21.

Craniella, 43, 44.

crassa, Reniera, 61.

cratera, Reniera, 61.

cribrosa, Papillina, 50.

Cyamon, 109. neon, 109.

cyanocrypta, Hymenamphiastra, 87.

Cydonium mülleri, 25.

Darwinellidae, 125.

davidi, Dyscliona, 63.

dawsoni, Bathydorus, 20.

dawsoni, Rhabdocalyptus, 20.

Dendoryx luciensis, 99.

Dendroceratina, 6, 125.

densissima, Petrosia, 117.

Dercitus, 38.

bucklandi, 39, 40.

syrmatitus, 38 .
Desmacella, 64. pennata, 4, 104. vagabunda, 64 .

Desmacidon columella, 62 .

Desmacidonidae, 63, 103.

Dictyciona, 93.

Dictyoceratina, 6, 121.

digitata, Stylotella, 62 .

diprosopia, Haticlona, 115.

diprosopia, Xestospongia, 115.

discreta, Microciona, 93.

Dolichantha, 106.

domunculus, Suberites, 53.

Donatia parasitica, 47.

dowlingi, Rhabdocalyptus, 18.

dowlingi, Staurocalyptus, 18.

dujardini, Halisarea, 22.

dura, Petrosia, 62, 117.

dura, Reniera, 116.

durissima, Strongylophora, 63.

Duseideia amblia, 123.

Dyscliona, 63. davidi, 63.

Dysidea, 123.

amblia, 123.

fragilis, 124 .

Dysideidae, 123.

dysoni, Spongia, 50.

ecbasis, Haliclona, 117.

edaphus, Gellius, 111.

eleanor, Leucosolenia, 3, 8 .

enamela, Haliclona, 119.

Endectyon, 106.

Ephydatia, 3, 106, 111. robusta, 111.

epiphytum, Prosuberites, 5.5.

epocheomaius, Gellius, 114

erithacus, Acarnus, 4, 104.

Esperella bellabellensis, 66. fisheri, 4, 66 .

Esperella serratohamata, 70 .

Esperiopsis, 70.

canaliculata, 93.

forcipula, 73 .

glaber, 72.

originalis, 70,103 .

estrella, Stelletta, 31.

Euretidae, 20.

Eurypon, 92.

asodes, 92.

microchela, 92 .

Euryponidae, 92, 109.

Euspongia hospes, 3.

Farrea, 20.

aculeata, 3.

convolvulus, 20 .

ocea, 3.

fasciculatus, Staurocalyptus, 19.

fascifibula, Mycale, 70 .

Ficulina, 52 .

ficus, 53.

suberea lata, 52 .

ficus, Ficulina, 53. 
fimbriata, Guitarra, 63.

firma, Myxilla, 77.

fisheri, Esperella, 4, 66.

fistularis, Verongia, 125.

fistulata, Petrosia, 117.

flabelliformis, Trikentrion, 110.

fiagellifer, Gellius, 112.

forcipula, Esperiopsis, 73.

fortis, Biemna, 64 .

fragilis, Dysidea, 124.

Fusifer, 97.

gadus, Suberites, 4, 55 .

gelatinosa, Hymeniacidon, 88 .

gellindra, Halichoclona, 114.

Gellius, 111, 114.

centrangulatus, 112.

edaphus, 111.

epocheomaius, 114.

flagellifer, 112.

imperialis, 112.

textapatina, 4, 112.

Geodia, 25.

agassizii, 4, 25.

breviana, 4, 25.

mesotriaena, 4, 25.

mesotriaenella, 4, 25.

ovis, 4, 25.

Geodiidae, 23.

Geodinella robusta, 4,28 . var. megasterra, 28.

glaber, Esperiopsis, 72.

glacialis, Aplysilla, 125.

glacialis, Simplicella, 125.

Grantia ciliata, 11.

Grantiidae, 11.

Guitarra, 63.

fimbriata, 63 .

Hadromerina, 5, 44.

Halichoclona, 113, 114. gellindra, 114.

Halichondria, 56, 114. cinerea, 120.

luxurians, 59 panicea, 56.

Halichondrina, 5, 56.

Haliclona, 62, 114, 117. cinerea, 120

diprosopia, 115.

ecbasis, 117.

enamela, 119

lunisimilis, 120.

occulata, 118.

oculata, 118.

vanilla, 116.

Haliclonidae, 111.

Halina bucklandi, 39.

Halisarca, 22.

dujardini, 22.

sacra, 22 .

Halisarcidae, 22

Hamacantha, 66.

hamata, Hemectyon, 108.

Haploscleridae, 111.
Haplosclerina, 5, 110.

Hardwickia, 50.

heathi, Leucandra, 4, 12.

heathi, Leuconia, 12.

hebes, Reniera, 61.

heliophila, Stylotella, 60 .

Hemectyon, 107.

hamata, 108.

hyle, 107.

Heterocliona, 50.

Hexactinellida, 5, 17.

hilgendorfi, Papyrula, 38.

horrida, Aphorme, 17.

hospes, Euspongia, 3 .

hyaloderma, Zygherpe, 65.

Hyalonema, 17. populiferum, 17.

Hyalonematidae, 17.

hyle, Hemectyon, 107.

Hymedesmia, 75, 89. stellata, 47.

Hymedesmiidae, 87.

hymena, Wilsa, 72 .

Hymenamphiastra, 87. cyanocrypta, 75, 87.

Hymeniacidon, 57. agminata, 62 . bucklandi, 39. caruncula, 58, 59. gelatinosa, 88 . pulvinatus, 50. sinapium, 57. ungodon, 60.

Hymeraphia, 106.

Hymesigma, 89.

Hymetrochota, 87, 89 . rotula, 88,89 .

idia, Spongia, 121.

igzo, Plocamia, 102.

imperialis, Gellius, 112.

inaequalis, Leptosiopsis, 90.

Inflatella, 62.

inops, Batzella, 62 .

Iophon, 82. chelifer californiana, 82 . chelifer ostia-magna, 83 .

Iotrochota, 89, 106.

Isociona, 4, 99. lithophoenix, 99. tuberosa, 100.

Isodictya cinerea, 120.

Isodictya palmata, 118.

japonica, Leucosolenia, 6 .

Jia, 97. jia, 97.

Joyeuxia, 62. viridis, 62 .

kagoshimensis, Leucosolenia, 6.

karykina, Plocamia, 4, 101.

karykinos, Plocamia, 101.

Kirkpatrickia, 84. variolosa, 84 .

kyma, Lissodendoryx, 73, 75. 
lacunosa, Myxilla, 77.

lacustris, Spongia, 110.

lacustris, Spongilla, 110.

laminaris, Poecillastra, 34 .

lata, Ficulina suberea, 52.

latus, Suberites, 52.

Laxosuberites, 55, 88.

lendenfeldi, Stelletta, 31 .

Leptosastra, 91. constellata, 91.

Leptosionsis, 90. inaequalis, 90.

Leucandra apicalis, 4, 11. heathi, 4, 11. sagittata, 11.

Leucandra solida, 15.

Leucascidae, 13.

Leucetta losangelensis, 13. sagittata, $3,11$.

Leucilla, 17. amphora, 17. nuttingi, 15.

Leuconia, 4, 11. heathi, 12. losangelensis, 13. sagittata, 11 .

Leucosolenia, 3,6 . convallaria, 6 . coriacea, 7 . eleanor, 3,8 . japonica, 6 . kagoshimensis, 6 . macleayi, 6 . nautilia, 9 . stipitata, 6.

Leucosoleniidae, 6 .

lignosa, Petrosia, 117.

limbata, Acervochalina, 118.

Liosina, 62. paradoxa, 62 .

Lissodendoryx, 75, 84, 100. kyma, 73,75 . noxiosa, 76 . rex, 77 .

lithophoenix, Isociona, 99. lithophoenix, Plocamia, 4. longispinus, Prosuberites, 55. losangelensis, Leucetta, 13. losangelensis, Leuconia, 13. luciensis, Dendoryx, 99. lunisimilis, Haliclona, 120. luxurians, Halichondria, 59.

macginitiei, Mycale, 68. macilenta, Mycale, 68. macleayi, Leucosolenia, 6. manaarensis, Plocamia, 3, 102. megalosigma, Biemna, 64 . megans, Sidonops angulata, 23. megasterra, Geodinella robusta, 28. mesotriaena, Geodia, 4, 25. mesotriaenella, Geodia, 4, 25. Meyenia robusta, 3, 111. microana, Sidonops angulata, 23. microchela, Eurypon, 92. Microciona, 93.
Microciona astrosanguinea, 95. discreta, 93. microjoanna, 93. parthena, 95. prolifera, 95.

Microcionidae, 93, 103. microjoanna, Microciona, 93. mülleri, Cydonium, 25. mutabilis, Tetilla, 40 Mycale, 66. aegagropila, 68 . bellabellensis, 66 . fascifibula, 70 . macginitiei, 68 . macilenta, 68 .

Mycalinae, 72.

Myxilla, 79.

agennes, 79 .

firma, 77 .

lacunosa, 77 .

parasitica, 80 .

rosacea, 81 .

versicolor californiana, 81

Myxillidae, 75.

Myxospongida, 5, 22.

nautilia, Leucosolenia, 9 . neon, Cyamon, 109.

nodulosus, Rhabdocalyptus, 20.

Normania tenuilaminaris, 35. noxiosa, Lissodendoryx, 76 . nuda, Rhyzaxinella, 56. nuttingi, Leucilla, 15.

nuttingi, Rhabdodermella, 3, 15.

obscurata, Tedanione, 86. occulata, Haliclona, 118.

ocea, Farrea, 3.

oculata, Chalina, 118.

Spongia, 117.

oculata, Haliclona, 118.

Ophlitaspongia, 4, 95, 103. pennata, 71

pennata californiana, 103

originalis, Esperiopsis, 70, 103. orthotriaena, Sidonops angulata, 23. Osculina, 50.

ostia-magna, Iophon chelifer, 83. ovis, Geodia, 4, 25.

Pachastrella, 35.

Pachychalina, 119, 120. rustica, 119.

pachymastia, Polymastia, 51. pallescens, Spongelia, 124. palmata, Isodictya, 118. panicea, Halichondria, 56. panicea, Spongia, 56.

Papillina cribrosa, 50.

Papyrula, 37. candidata, 38. hilgendorfi, 38 . saccharis, 37. sphaera, 38 .

paradoxa, Liosina, 62. parasitica, Donatia, 47. Myxilla, 80. 
Paresperella, 69.

psila, 69.

serratohamata, 70 .

parthena, Microciona, 95.

Penares, 35.

cortius, 35.

tyloaster, 37.

pennata californiana, Ophlitaspongia, 103.

pennata, Desmacella, 4, 104.

Petrosia, 62, 116.

coralloides, 117.

densissima, 117.

dura, 62, 117.

fistulata, 117.

lignosa, 117.

similis, 117.

variabilis, 117.

Phloedictyon, 62.

Phlyctaenopora, 62.

bitorquis, 62 .

planus, Astylinifer, 75.

platei, Acanthascus, 18.

plena, Plocamia, 103.

Plocamia, 101.

igzo, 102.

karykina, 4, 101.

karykinos, 101.

lithophoenix, 4, 99.

manaarensis, 3, 102.

plena, 103.

Plocamiancora, 103.

Plocamiidae, 101.

Poecillastra, 32.

compressa, 33.

laminaris, 34 .

rickettsi, 32 .

schultzei, 33.

tenuilaminaris, 35 .

Poecilosclerina, 5, 63.

Polymastia, 51.

pachymastia, 51.

Polymastiidae, 51.

Polynia, 17.

polyraphis, Aplysilla, 126.

populiferum, Hyalonema, 17.

Poterion atlantica, 50.

Pozziella, 66.

Prianos, 61.

amorphus, 61.

columella, 62 .

problematicus, 61.

primitiva, Barbozia, 62.

problematicus, Prianos, 61.

procumbens, Aplysina, 125.

prolifera, Microciona, 95.

Prosuberites, 54.

epiphytum, 55.

longispinus, 55 .

rugosus, 55.

sisyrnus, 54.

Proteleia, 106.

Protoschmidtia, 62.

simplex, 62.

pseudonapya, Clathriopsamma, 96.

psila, Paresperella, 69.

pulvinatus, Hymeniacidon, 50 . radiata, Tetilla, 42.

Raphyrus, 50.

Raspailia, 108.

Raspailiidae, 107, 109.

Reniera, 61, 119, 120.

amorpha, 61.

aquaeductus, 61 .

cinerea, 120.

crassa, 61.

cratera, 61.

dura, 116.

hebes, 61.

luxurians, 59 .

variabilis, 59.

rex, Lissodendoryx, 77.

rhadia, Biemna, 63.

Rhabdocalyptus, 20.

asper, 20.

dawsoni, 20.

dowlingi, 18.

nodulosus, 20.

tener, 20.

Rhabdodermella, 15.

nuttingi, 3, 15.

Rhaphiophora, 50.

Rhizaxinella nuda, 56.

rickettsi, Poecillastra, 32.

robusta, Ephydatia, 111.

Geodinella, 4, 28.

robusta, Meyenia, 3, 111.

rosacea, Myxilla, 81.

Rossellidae, 17.

rotula, Hymetrochota, 88, 89 .

rugosus, Prosuberites, 55.

rustica, Pachychalina, 119.

saccharis, Papyrula, 37.

sacra, Halisarca, 22.

sagittata, Leucetta, 3, 11.

Leucandra, 11.

sanguinea, Spongia, 59.

sansibarense, Strongylacidon, 63.

Schmidtia, 116.

schultzei, Poecillastra, 33.

serratohamata, Esperella, 70. Paresperella, 70.

Sidonops, 23.

angulata, 4, 23 .

angulata megana, 23.

angulata microana, 23.

angulata orthotriaena, 23.

bicolor, 4, 23.

Sigmatotetraxonida, 106.

similis, Petrosia, 117.

simplex, Protoschmidtia, 62.

Simplicella glacialis, 125.

simulans, Adocia, 119.

sinapium, Hymeniacidon, 57.

sisyrnus, Prosuberites, 54.

solida, Leucandra, 15.

solidus, Staurocalyptus, 18.

sphaera, Papyrula, 38.

Spheciospongia, 48 . confoederata, 48.

Sphinctrella, 34 .

spinosa, Tetilla, 43. 
Spirastrella, 51. andrewsi, 50.

Spongelia, 123, 124. pallescens, 124.

Spongeliidae, 123.

Spongia, 121.

cinerea, 120.

coronata, 11.

dysoni, 50.

idia, 121.

lacustris, 110.

oculata, 118.

panicea, 56.

sanguinea, 59.

spongigartina, Aaata, 89.

spongigartina, Anaata, 89.

Spongiidae, 121.

Spongilla, 110.

lacustris, 110.

Spongillidae, 110.

squamata, Columnitis, 46, 47.

Staurocalyptus, 18.

dowlingi, 18.

fasciculatus, 19.

solidus, 18.

stellata, Hymedesmia, 47.

Stelletta, 19.

clarella, 29.

estrella, 29.

lendenfeldi, 31 .

Stellettidae, 29.

stipitata, Leucosolenia, 6.

Strongylacidon, sansisbarense, 63.

Strongylamma, carteri, 63 .

Strongylophora, 61, 63 . durissima, 63.

Stylotella, 62 . columella, 62. digitata, 62. heliophila, 60 .

suberea lata, Ficulina, 52.

suberea, Suberites, 52.

Suberites, 50, 51, 53, 55 .

domunculus, 53.

gadus, 4,55 .

latus, 52 .

suberea, 52.

Suberitidae, 52.

subtilis, Bathyxiphus, 3.

Sycandra coacta, 4, 10. coronata, 3, 11.

Sycettidae, 10.

Sycon, 4, 10. coactum, 10. coronatum, 11.

Sylleibidae, 17.

syrmatitus, Dercitus, 38.

Tedania, 83 .

topsenti, 83.

toxicalis, 84,85 .

Tedanione, 86.

obscurata, 86 .

wilsoni, 86.

tener, Rhabdocalyptus, 20.

tenerum, Chonelasma, 21.

tenuilaminaris, Normania, $3 \check{.}$ tenuilaminaris, Poecillastra, 35.

tenuis, Acanthosaccus, 3.

ternatus, Acarnus, 106.

Terpios coerula, 88 .

Tethya, 44, 46, 47.

aurantia californiana, 44 .

Tethyidae, 44.

Tethyopsilla, 43.

Tetilla, 40.

arb, 42.

mutabilis, 40 .

radiata, 42 .

spinosa, 43.

Tetillidae, 40.

tetractis, Timea, 47.

textapatina, Gellius, 4, 112.

Thalysias vespara, 50 .

Theneidae, 32.

thiona, Verongia, 124.

Thoosa, 118.

Timea, 45. authia, 45 .

stellata, 46.

tetractis, 47.

Timeidae, 45.

topsenti, Tedania, 83.

toxicalis, Tedania, 85 .

Trikentrion, 110 .

flabelliformis, 110.

tuberosa, Isociona, 100.

tubisperma, Carterella, 111.

tubisperma, Carterius, 111.

tyloaster, Penares, 37.

ungodon, Hymeniacidon, 60 .

uteoides, Ascute, 10.

vagabunda, Desmacella, 64 .

vanilla, Haliclona, 116.

vanilla, Xestospongia, 116.

variabilis, Petrosia, 117. Reniera, 59.

variolosa, Kirkpatrickia, 84.

vastus, Aphrocallistes, 21.

Verongia, 124. fistularis, 125.

thiona, 124.

Verongiidae, 124.

versicolor californiana, Myxilla, 81 .

vespara, Thalysias, 50.

vesparium, Alcyonium, 50.

violacea, Aplysilla, 127.

viridis, Joyeuxia, 62.

Vomerula, 66.

Vosmaeria, 17.

whiteavesianus, Aphrocallistes, 21.

Wilsa, 72.

hymena, 72 .

wilsoni, Tedanione, 86 .

Xestospongia, 115. coralloides, 116.

diprosopia, 115.

vanilla, 116.

Zygherpe, 65.

hyaloderma, 65 . 


\section{$2 \mathrm{BHL}$ Biodiversity Heritage Library}

De Laubenfels, M. W. 1932. "The marine and fresh-water sponges of California." Proceedings of the United States National Museum 81(2927), 1-140. https://doi.org/10.5479/si.00963801.81-2927.1.

View This Item Online: https://www.biodiversitylibrary.org/item/32577

DOI: https://doi.org/10.5479/si.00963801.81-2927.1

Permalink: https://www.biodiversitylibrary.org/partpdf/10054

\section{Holding Institution}

Smithsonian Libraries

\section{Sponsored by}

Smithsonian

\section{Copyright \& Reuse}

Copyright Status: NOT_IN_COPYRIGHT

Rights: https://www.biodiversitylibrary.org/permissions/

This document was created from content at the Biodiversity Heritage Library, the world's largest open access digital library for biodiversity literature and archives. Visit BHL at https://www.biodiversitylibrary.org. 